JOINT HIGHWAY RESEARCH PROJECT

Final Report

FHWA/IN/JHRP-90/6

THE PHYSICAL DURABILITY AND

ELECTRICAL RESISTIVITY OF

INDIANA BOTTOM ASH

Te-Chin Ke 
FINAL REPORT

\section{THE PHYSICAL DURABILITY AND ELECTRICAL RESISTIVITY OF INDIANA BOTTOM ASH}

To: H. L. Michael, Director

$$
\text { Joint Highway Research Project }
$$

Apri1 26, 1990

From: C. W. Lovell and J. E. Lovell

Joint Highway Research Project

Project: $\mathrm{C}-36-50 \mathrm{~J}$

File: 6-19-10

Attached is the Final Report of the JHRP project entitled "The Physical Durability and Electrical Resistivity of Indiana Bottom Ash". The report was prepared by $\mathrm{Mr}$. Te-Chih Ke, Graduate Research Assistant, under our direction.

The results of the study will be useful in determining the durability and corrosiveness of bottom ashes used as a highway construction material. The suggested testing methods and evaluation criteria are included. A total of four Indiana bottom ashes were selected, sampled, and tested. To increase the data base for evaluation, additional tests were conducted on the other 7 ashes sampled earlier. The comparison of the test results and the established evaluation criteria shows that Indiana bottom ashes are durable but may be corrosive.

The report is submitted for review, comment and acceptance in fulfillment of the referenced study.

Respectfully submitted,

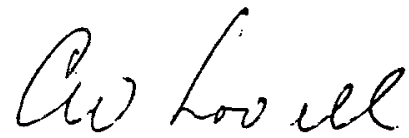

C. W. Lovell

Research Engineer

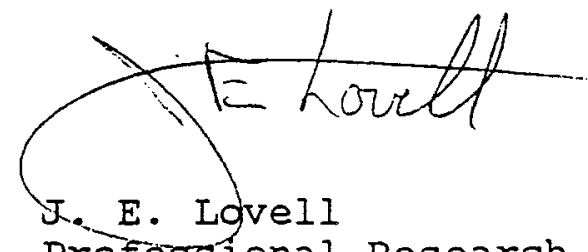

Professional Research Assistant

CC: A. G. Altschaeffl

J. M. Bell

M. E. Cantrall

W. F. Chen

W. L. Dolch

R. L. Eskew

J. D. Fricker

D. E. Hancher
R. A. Howden

M. K. Hunter

J. P. Isenbarger

J. F. McLaughiin

K. M. Mellinger

R. D. Miles

P. L. Owens
B. K. Partridge

G. T. Satterly

C. F. Scholar

K. C. Sinha

C. A. Venable

T. D. White

L. E. Wood 
FINAL REPORT

THE PHYSICAL DURABILITY AND ELECTRICAL RESISTIVITY

OF INDIANA BOTTOM ASH

by

Te-Chih Ke

Graduate Research Assistant

Joint Highway Research Project

Project No.: $\mathrm{C}-36-50 \mathrm{~J}$

File No.: 6-19-10

Prepared as part of an Investigation

Conducted by the

Joint Highway Research Project

Engineering Experiment Station

Purdue University

In cooperation with the

Indiana Department of Transportation

and the

U.S. Department of Transportation

Federal Highway Administration

The contents of this report reflect the views of the author who is responsible for the facts and accuracy of the data presented herein. The contents do not necessary reflect the official views or policies of the Federal Highway Administration. This report does not constitute a standard, specification, or regulations.

Purdue University

West Lafayette, Indiana 47907

April 26, 1990 
TECHNICAL REPORT STANDARD TITLE PACE

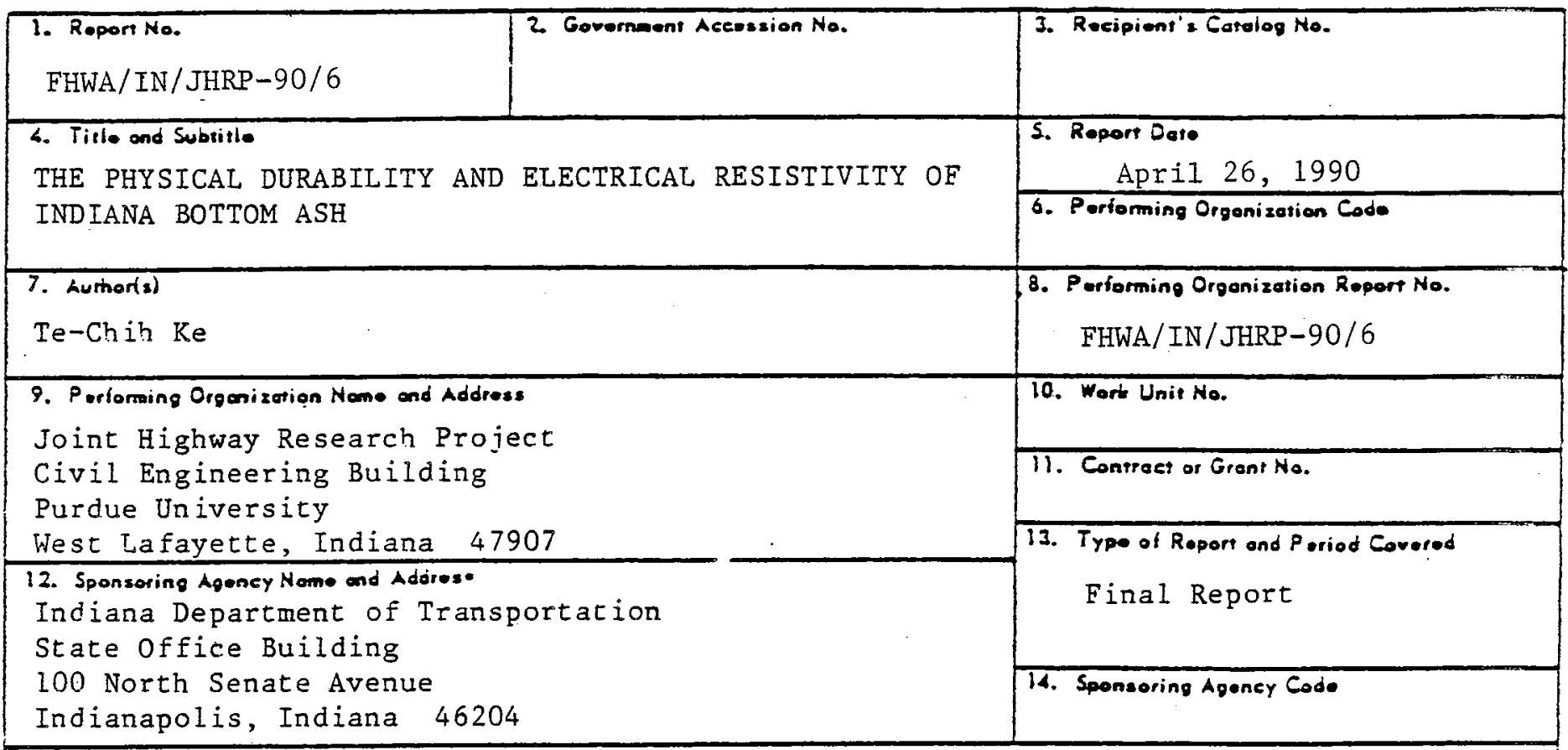

\section{Supplenentary Notes}

Prepared in cooperation with the U.S. Department of Transportation, Federal Highway Administration.

\section{Abstroet}

This research assessed the long-term performance (durability) and the environmental effect (corrosiveness to adjacent metal structures) of Indiana bottom ashes, based mainly on laboratory investigation. The 5-cycle sodium sulfate soundness tests and the 50-cycle freeze-thaw tests were conducted to examine the physical durability. Four electrochemical characteristics (electrical resistivity, pH, soluble chloride, and soluble sulfate) were used to estimate the corrosion potential of Indiana bottom ashes.

Evaluation criteria for durability and corrosiveness of bottom ash, based on appropriate specifications for aggregates and past experiences for soils, were developed. The comparison of test results and the above criteria shows that Indiana bottom ashes are durable but may be corrosive. The bottom ashes with a high corrosion potential should not be utilized in highway construction where metal structures are involved.

\begin{tabular}{|c|c|c|c|c|}
\hline \multicolumn{2}{|c|}{$\begin{array}{l}\text { 17. Key mords } \\
\text { bottom ash, durability, weighted loss, } \\
\text { corrosiveness, electrochemical } \\
\text { characteristics }\end{array}$} & \multicolumn{3}{|c|}{$\begin{array}{l}\text { 18. Distribution Statomont } \\
\text { No restrictions. This document is } \\
\text { available to the public through the } \\
\text { National Technical Information Service, } \\
\text { Springfield, Virginia } 22161 \text {. }\end{array}$} \\
\hline $\begin{array}{l}\text { 19. Socurity Clossif. (sl misis report) } \\
\text { Unclassified }\end{array}$ & \multicolumn{2}{|c|}{$\begin{array}{l}\text { - Socurlisy Closolf. (ol this pooo) } \\
\text { Unc lassified }\end{array}$} & $\begin{array}{l}\text { 21. No. of Pag0t } \\
335\end{array}$ & 22. Price \\
\hline
\end{tabular}




\section{ACKNOWLEDGMENTS}

The author would like to thank Professor C. W. Lovell for his supervision and guidance throughout the course of the research and Professors L. E. Wood and A. G. Altschaeffl for their participation on my graduate committee and for all constructive criticism pertaining to the final manuscript.

Financial support provided by Indiana Department of Transportation and the Federal Highway Administration through the Joint Highway Research Project of Purdue University which made this study possible is much appreciated.

The author is especially indebted to Ms. Janet Lovell for her technical advice and assistance in laboratory testing, as well as critical reading of the thesis. Thanks are also extended to the California Department of Transportation and the Reinforced Earth Company for providing testing methods and relevant specifications. Beneficial discussions with Messrs A. C. Headon, B. Rahn, W. H. Huang, and Chuck Levergood were much appreciated.

Finally, the author wishes to thank his family in Taiwan for their encouragement all over the period of this investigation. 
TABLE OF CONTENTS

Page

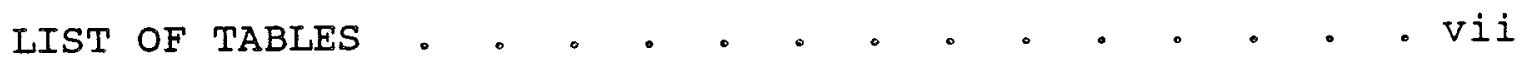

LIST OF FIGURES • • • • • • • • • • • • • • x

LIST OF ABBREVIATIONS AND SYMBOLS • • • • • • • • . xiii

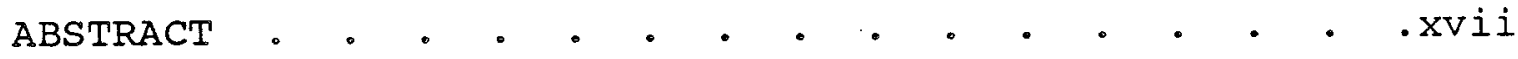

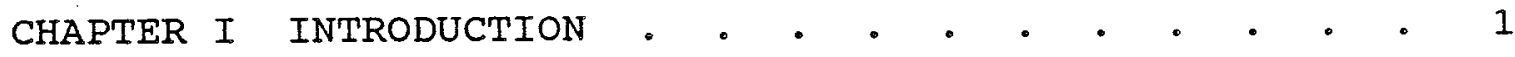

Background . • • . • • • • • • •

Deficiency of Natural Mineral Aggregates . . . . 1

Mass Production of Coal Ash . . . . . . . . 2

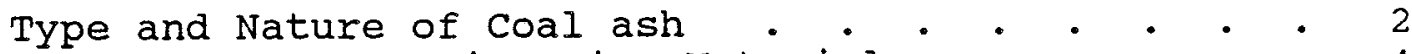

Bottom Ash: An Engineering Material . . . . . . 4

The Statement of the Problem . . . . . . . . . 5

Lack of Durability . . • . • . . • . . . 6

Corrosiveness to Adjacent Metal structures . . . 6

Research Objectives • • • • • • • • • • • • 7

Physical Durability • • • • • • • • • • • 7

Corrosiveness • • • • • • • • • •

Evaluation Criteria . . . . . . . . . . . 8

Research Approach • • • • • • • • • • •

CHAPTER II LITERATURE REVIEW • • • • • • • • • 11

Durability . • • • • • • • • • • • • • $~ 11$

Definition . . • • . . . • • • • • • • 12

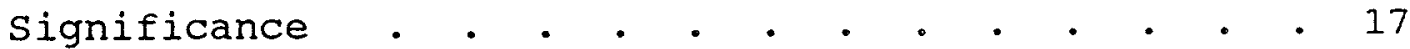

Elements of Durability . • . . . . . . . . 19

Material properties . . . . . . . . . . 19

Serviceability . . . . . . . . . . . . 23

Time and Life Expectancy . . . . . . . . . 24

Environmental Agents and Related Mechanisms . . 30

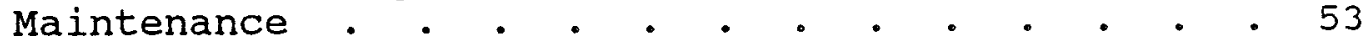

Meaningful Durability Test . . . . . . . . . 55

Test Methods to be Used . . . . . . . . . . 71

Summary • • • • • • • • • • • • • • •

Corrosiveness .

Definition of Corrosion and Corrosiveness . . . . 81

Significance . . . . . . . . . . . . . 86

Basic Corrosion Mechanism . . . . . . . . 90

Underground Corrosion . . . . . . . . . . 109 
Corrosion by Stray Current . . . . . . • . 111

Bacteria Attack • . . . . . . . • . . . 114

Corrosion in Undisturbed Soils . . . . . . . 119

Corrosion in Disturbed Soils . . . . . . . 121

A Review of Test Methods . . . . . . . . . 154

Burial Method . . . . . . . . . . . . 154

Electrochemical Techniques . . . . . . . . 159

Correlations with Soil Environmental Parameters . 165

Past Corrosion Studies on Bottom Ash . . . . . 170

Summary • • • • • • • • • • • • • • • 174

CHAPTER III TESTING MATERIALS • • • • • • • • 177

Selection of Ash Samples - . • . • . . • . 177

Sampling Procedure and Field Testing . . . . . . 182

Sampling Procedure . . . • . • • • . . . 182

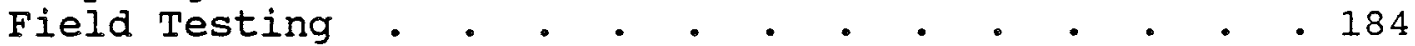

Sampling Description and

Known Properties of Candidate Ashes . . . . . . 188

Perry K Ash • • . • . . . . • . • . • . 192

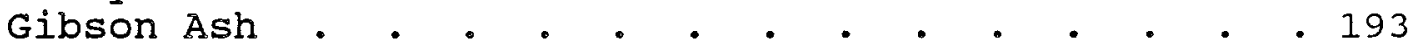

Schahfer Unit $14 \mathrm{Ash}$. . . . . . • . . . . 195

Schahfer Unit 17 Ash . . . . . . . . . . . 196

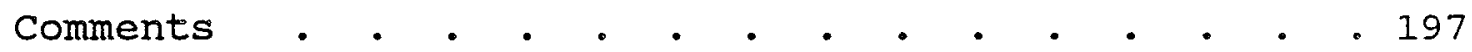

CHAPTER IV EXPERIMENTAL PROGRAM • • • • • • • . 199

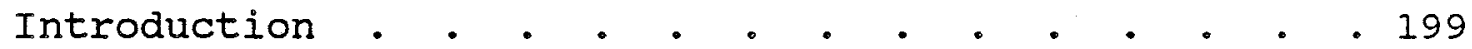

Durability Tests . . . . . . . . . . . . . 200

Sodium Sulfate Soundness Test. . . . . . . . 200

Freeze and Thaw Test. . . . . . . . . . . 201

Corrosiveness Tests . . . . . . . . . . . . 204

Chloride Content . . . . . . . . . . . . 204

Sulfate content . . . . . . . . . . . . 207

Resistivity . . . . . . • . . . . . . . 208

$\mathrm{pH} \cdot .+. \quad . \quad . \quad . \quad . \quad . \quad . \quad . \quad . \quad . \quad . \quad . \quad .215$

CHAPTER V PRESENTATION AND DISCUSSION OF RESULTS • . 218

Durability Tests . . . . . • . • . • . . . 218

Sodium Sulfate Soundness Test . . . . . . . 218

Freeze and Thaw Test... . . . . . . . . 224

Corrosiveness Tests . . . . . . . . . . . . 228

Soluble Salts . . . . . . . . . . . . . 230

Chloride Content . $\cdot$. . . . . . . . . 230

Sulfate Content . . . . • . . . . . . . 232

Time-Dependent Soluble Salts . . . . . . . 234

Resistivity . • . • . . . . . . • . . . 238

Minimum Resistivity . . . . . . . . . . 238 $\mathrm{pH}$

Size Effect on Minimum Resistivity . . . . . 240 
Page

Comparison of California Test and INDOT Method $\quad 242$

Size Effect on Ash pH... . . . . . . . . 244

Effect of Ash:Water ratio on Ash pH . . . . . 246

Effect of Stirring Time on Ash pH . . . . . . 246

Comparison with Soils . . . . • • . • • • 249

CHAPTER VI EVALUATION CRITERIA • . • • • • • 258

Durability Criteria . . . . . . • . • . . . 258

Sodium Sulfate Soundness Test . . . . . . . . 264

Freeze and Thaw Test. . . . . . . . . . . 269

Corrosiveness Criteria . . . . . . . . . . . 271

A set of Threshold values . . . . . . . . . 272

Service Life Equivalent to the Criteria . . . . 288

Service Life Equivalent to Determined Parameters . 293

CHAPTER VII EVALUATION RESULTS . • . . . • . . 306

Durability of Indiana Bottom Ashes . . . . . . . 306

Corrosiveness of Indiana Bottom Ashes . . . . . . 308

CHAPTER VIII SUMMARY AND CONCLUSIONS • • • • • • 313

CHAPTER IX RECOMMENDATIONS FOR FURTHER RESEARCH • • • 319

Meaningful Durability Tests . • • • • • • • 319

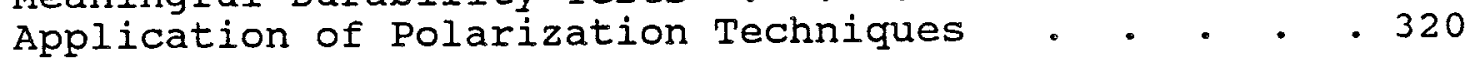

BIBLIOGRAPHY • • • • • • • • • • • • • • 325 


\section{LIST OF TABLES}

Table

Page

1. Classification of the Age or Service Life of Materials under Various Conditions . . . . . 16

2. Relative stabilities of Some Soil Mineral Structural Units . . . . . . . . . . . 22

3. List of Environmental Agents . • • • • • 33

4. Recommended Intervals of Selected Paintings and Coverings (in years) . . . . . . . . 56

5. List of Aging Indicators and Measures . . . . 65

6. Galvanic series in Seawater . . . . . . . 95

7. Electromotive Force Series . • • • • • • 96

8. Weight Loss of Metals by stray-Current Corrosion . . . . . . . . . . . . . . 117

9 Relationship of Soil Aggressivity to Resisivity and Redox Potential . . . . . . . . . 131

10. Relationship between Redox Potential and Soil Corrosivity . . . . . . . . . • . • . 133

11. Relationship between corrosion Type and Elements of Corrosion in Disturbed Soils . • . 152

12. Corrosion of Steels, Copper, Lead, Zinc in Soils . . . . . . . . . . . . . . 156

13. Conversion Factors of Current Density to Corrosion Rate . . . . . . . . . . . . 164

14. Statistic Results of Four Electrochemical Characteristics on Soils . . . . . . . . • 171

15. Statistic Results of Four Electrochemical Characteristics on Metal-Reinforced Soils . . . 172

16. Indiana Bottom Ash Sources . . . . . . . . 180 
17. Coal Source and Ash Type [5] • . . . . . . 181

18. Ash Storage Conditions . . . . . . . . . 183

19. Field Resistivity and $\mathrm{pH}$ of Candidate

Bottom Ashes . . . . . . . . . . • . . 189

20. Chemical Composition and Engineering Properties

of Candidate Bottom Ashes . . . . . . . . 191

21. Comparison of Sieve Analysis Results of Old

Sample and New Sample of Perry K Ash • • . • . 220

22. Comparison of Sieve Analysis Results of old and New Samples of Candidate Ashes except

Perry K Ash . . . . . . . . . . . . . 221

23. Results of Sodium Sulfate Soundness Tests . . . 223

24. Comparison of Results of Soundness Tests and

Freeze-Thaw Tests . . . . . . . . . . . 227

25. Results of Soundness Tests of Other 7 Ashes - 229

26. Chloride Contents of Candidate Bottom Ashes . . 231

27. Sulfate Contents of Candidate Bottom Ashes . . . 233

28. Time-Dependent Soluble Salts (dynamic) • . . . 236

29. Time-Dependent Soluble Salts (static) • • • . 237

30. Minimum Resistivity of Candidate Bottom Ashes . . 239

31. Size Effect on Minimum Resistivity . . • . . 241

32. $\mathrm{pH}$ Values of Candidate Bottom Ashes . . . . 243

33. Size Effect on Ash pH . • . • • . . . . . 245

34. Influence of Ash:Water Ratio on Ash pH . . . . 247

35. Influence of Stirring Time on Ash pH . . . . . 250

36. Summary of Four Electrochemical Characteristics

of Candidate Bottom Ashes . . . . . . . . 251

37. Minimum Resistivity and $\mathrm{pH}$ of Other 7 Ashes . 252

38. Conversion of salt content to salt
Concentration . . . . . . . . . . . 255 
Table

39. Statistic Results of Three Electrochemical Characteristics of Indiana Bottom Ashes . . . . 256

40. Statistic Results of Four Electrochemical Characteristics of Indiana Bottom Ashes . . . . 257

41. Suggested Seasons Length for the Six U.S. Climatic Regions. . . . . . . . . . 261

42. Design Lives of Common Aggregate Applications • 263

43. Evaluation Criteria on Ash Durability • • • . 268

44. Relationship between Soil Resistivity and Soil Corrosivity . . . . . . . . . . . . . 274

45. Characteristics of Soil Resistivity . • . . . 275

46. Steel Pipe Corrosion Classification . . . . . 276

47. Soil Corrosivity versus Resistivity • • • • • 277

48. Soil-Test Evaluation AWWA Rating • • • • • • 278

49. Soil Corrosive Description . . . . . . . . 280

50. Evaluation Criteria on Ash Corrosiveness . . . 286

51. Service Lives of Typical Reinforcing strips . . 292

52. Corrosion Factor (K) and coating Life (C) . . 299

53. Cross-Sectional Area Remaining after 50 yrs
for Normal Soils . . . . . . . . . . . 300

54. Cross-Sectional Area Remaining after 50 yrs
for Selected Backfills . . . . . . . 301

55. Criteria for Selected Granular Backfills . . . 303

56. Average Pitting Rates for Pipes in Various 304

57. Evaluation Results of Durability of Indiana Bottom Ashes... . . . . . . . . . 307

58. Evaluation Results of Corrosiveness of Indiana
Bottom Ashes (1) . . . . . . . . . . 309

59 Evaluation Results of Corrosiveness of Indiana Bottom Ashes (2) . . . . . . . . . . . 311 


\section{LIST OF FIGURES}

Figure

Page

1. Characteristics curves as a Function of Time • . 26

2. Development of Internal stresses in concrete due to a Thermal Gradient. . . . . . . . . . 36

3. Anomalous Behavior of the Specific Volume or Density of Water-Ice . . . . . . . . 43

4. Hydraulic Pressure and Formation of Cracking • 44

5. Correlation between Pore-Size in Concrete and Melting Temperature of Water . . . . . . . 48

6. Expansion-Contraction of Sorption-Sensitive Carbonate under Variable conditions of Saturation and Temperature . . . . . . . . 50

7. Steps in a Meaningful Durability Test to Predict Service Life. . . . . • . . . . . . . 60

8. Characteristics Curves of Laboratory Accelerated Test and Long-Term Field Test . . . . . . . 68

9. Typical Exponential Corrosion Curves for Ferrous Pipe. . . . . . . . . . . . 84

10. Difference between the Real Life Expectancy and that by a constant Corrosion Rate . . . . . . 87

11. Galvanic Cell (dry cell) • • • • • • • • 92

12. Galvanic Cell for Unlike Metals . . . . . . 97

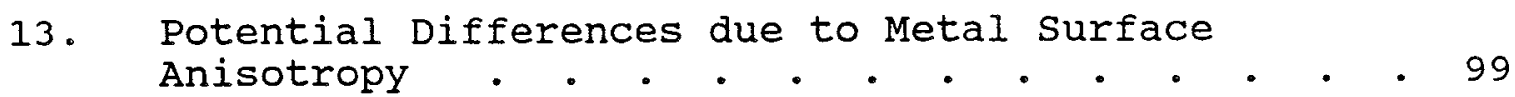

14. Salt concentration Cell . . . . . . . . 100

15. Differential Aeration Cell • • • • • • • . 101

16. Differential Aeration cell Formed by Rust on Iron . . . . . . • • • • • • . . 102 
17. Differential Aeration Cell Illustrated by Water-line corrosion . . . . . . . . . . 103

18. Sketch of Deepest Pit with Relation to Average Metal Penetration and Pitting Factor... . . 107

19. Stray-Current Corrosion of Buried Pipe . . . . 113

20. Stray-Current Damage due to Ship by Welding Generator.. • • . . • . . • • . . • . 115

21. Effect of Current Flowing along a Buried Pipeline on Corrosion near Insulated Couplings . 116

22. Corrosion of a steel Pipe in a Disturbed Soil . . 122

23. Underground Corrosion of a steel Pipe at the Waterline . . . . . . . . . . . . 123

24. Weight Loss versus Soil Resistivity . . . . . 127

25. Metal Loss versus Soil pH . • . . . . . . 136

26. Observed Soil pH versus Soil:Water Ratio . . 138

27. Polarization Curves of Black Iron and

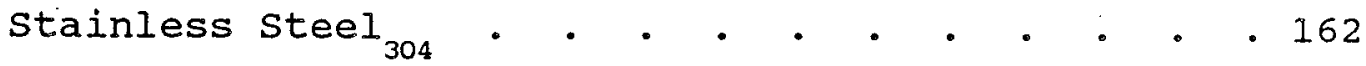

28. Approximate Locations of Bottom Ash Sources in Indiana . . . . . . . . . . . . . 179

29. Wiring Diagram for Typical dc Vibrator-Current Source • . . • . • • • • • • • • . . 186

30. Connection of R-40C Meter with Electrodes . . 187

31. Sectional View of the Automatic Freezing and Thawing Equipment . . . . . . . . . . 203

32. Typical Connections for Use of Soil Boxes with Various Types of Instruments . . . . . . . 210

33. Configuration of Sample Box . . . . . . . . 211

34. Connection of R-40C Meter with Sample Box . . . 212

35. Weighted Loss versus Particle Size . . . . . 225

36. $\mathrm{pH}$ value of Gibson Ash versus Ash:Water Ratio. . 248 
Figure

Page

37. Six Climatic Regions in the United States . . 260

38. Relationship between Sodium sulfate and Magnesium Sulfate Test . . . . . • . . 265

39. Oil Company Policy for Corrosion of Underground Gas Storage Tanks . . . . . • • • • . 282

40. Consulting Engineering Company Criteria for Buried Metallic Structures . . . . . . . . 283

41. Minimum Thickness of Metal Pipe for 50-year Maintenance Free Service Life . . . . . . . 284

42 Extrapolated corrosion Curves for Plain Steels . 289

43. Extrapolated Corrosion Curves for Galvanized Steels.......... . . . 290

44 Chart for Estimating Years to Perforation of steel Culverts . . . . . . . . . . . 296

45. Chart for Estimating Time to Corrosion of Reinforced Substructures . . . . . . . . . 297

46. Laboratory Set-Up for Polarization Techniques . 322

47. Example of Field set-Up for Polarization Techniques 


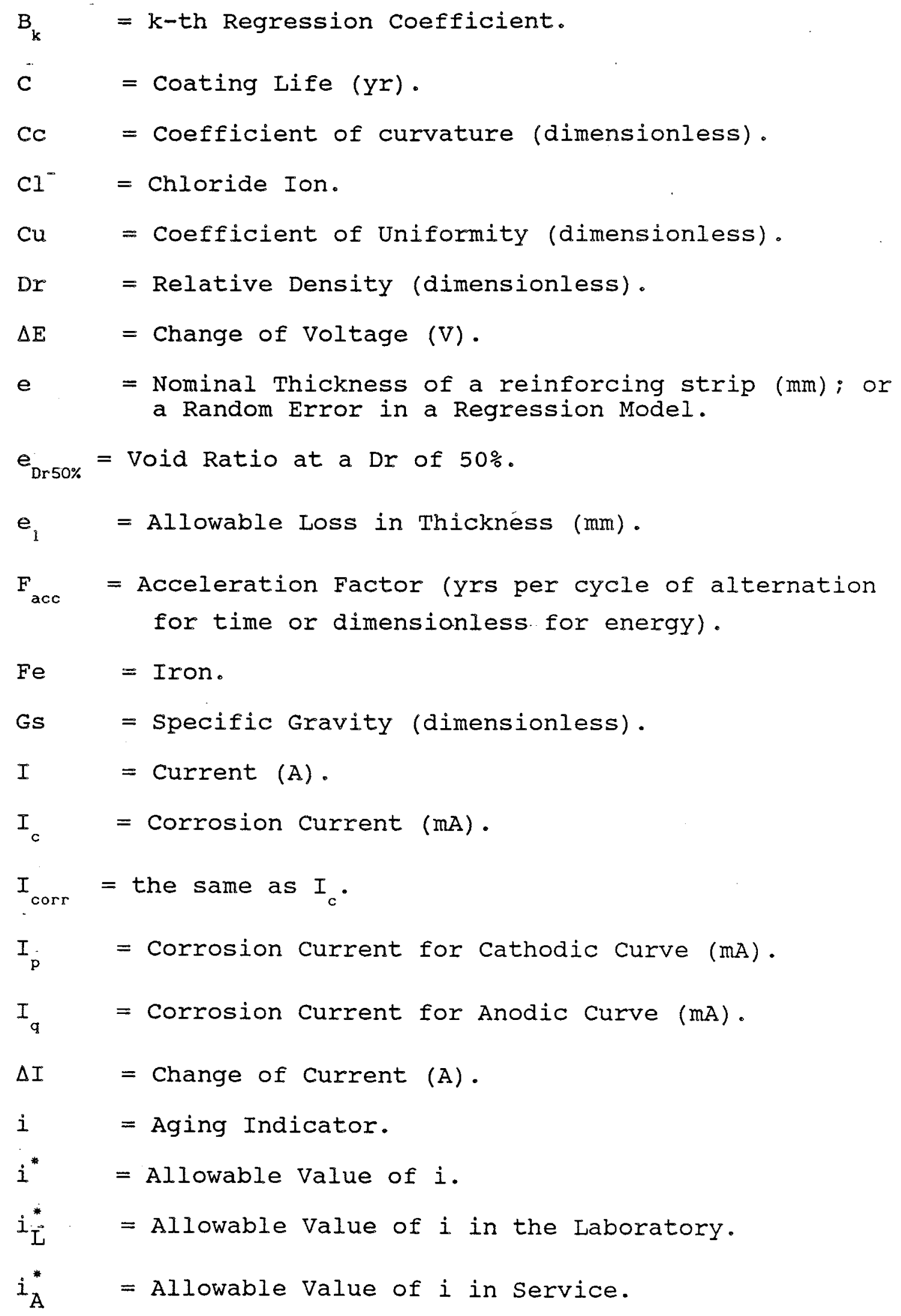




$$
\begin{aligned}
& \mathrm{K}=\text { corrosion Rate Factor (in/yr). } \\
& \mathrm{k} \quad=\text { Site Factor, for the Equation: } \mathrm{x}=\mathrm{k} \mathrm{t}^{\mathrm{n}} \text {; or } \\
& \text { Electrochemical Equivalent (gm/Coulomb). } \\
& \mathrm{MgSO}_{4}=\text { Magnesium sulfate. } \\
& \mathrm{Na}_{2} \mathrm{SO}_{4}=\text { sodium sulfate. } \\
& \mathrm{N}=\text { Coordination Number. } \\
& \mathrm{n} \quad \text { Site Factor, for the } \mathrm{EQ}: \mathrm{X}=\mathrm{k} t^{\mathrm{n}} \text {. } \\
& x=\text { Resistance (ohm) or coefficient of correlation. } \\
& r^{2}=\text { Coefficient of Determination. } \\
& \mathrm{SO}_{3}=\text { sulfide. } \\
& \mathrm{SO}_{4}^{2-}=\text { Sulfate. } \\
& \mathrm{T}=\text { Temperature }\left({ }^{\circ} \mathrm{C} \text { or }{ }^{\circ} \mathrm{F}\right) \text {. } \\
& \mathrm{T}_{0} \quad=\text { Initial Temperature }\left({ }^{\circ} \mathrm{C} \text { or } \mathrm{F}^{\circ}\right) \text {. } \\
& \Delta \mathrm{T}=\text { Change of Temperature }\left({ }^{\circ} \mathrm{C} \text { or }{ }^{\circ} \mathrm{F}\right) \\
& t \quad=\text { Time (yrs). } \\
& t_{A D} \quad=\text { Design Life (yrs). } \\
& t_{\mathrm{AE}} \quad=\text { Termination Time for a Field Durability Test (yrs). } \\
& t^{*} \quad=\text { Life Expectancy (yrs) } \\
& t_{L}^{*} \quad=\text { Life in the Laboratory (yrs or the number of cycles). } \\
& t_{\mathrm{A}}^{*} \quad=\text { Life Expectancy in Service (yrs). } \\
& \text { WL = Weighted Loss (\%) for Durability Tests or Metal } \\
& \text { Loss }\left(\mathrm{gm} / \mathrm{cm}^{2} \text { or } \mathrm{cm}\right) \text {. } \\
& \mathrm{WL}^{\prime}=\text { Metal Loss Rate }\left(\mathrm{gm} / \mathrm{cm}^{2} / \mathrm{yr} \text { or } \mathrm{cm} / \mathrm{yr}\right) \text {. } \\
& w_{\text {eq }}=\text { Equivalent water content. } \\
& X \quad=\text { Metal Loss }\left(\mathrm{gm} / \mathrm{cm}^{2} \text { or } \mathrm{cm}\right) \text {, in the } E Q: X=k t^{n} \text {. }
\end{aligned}
$$




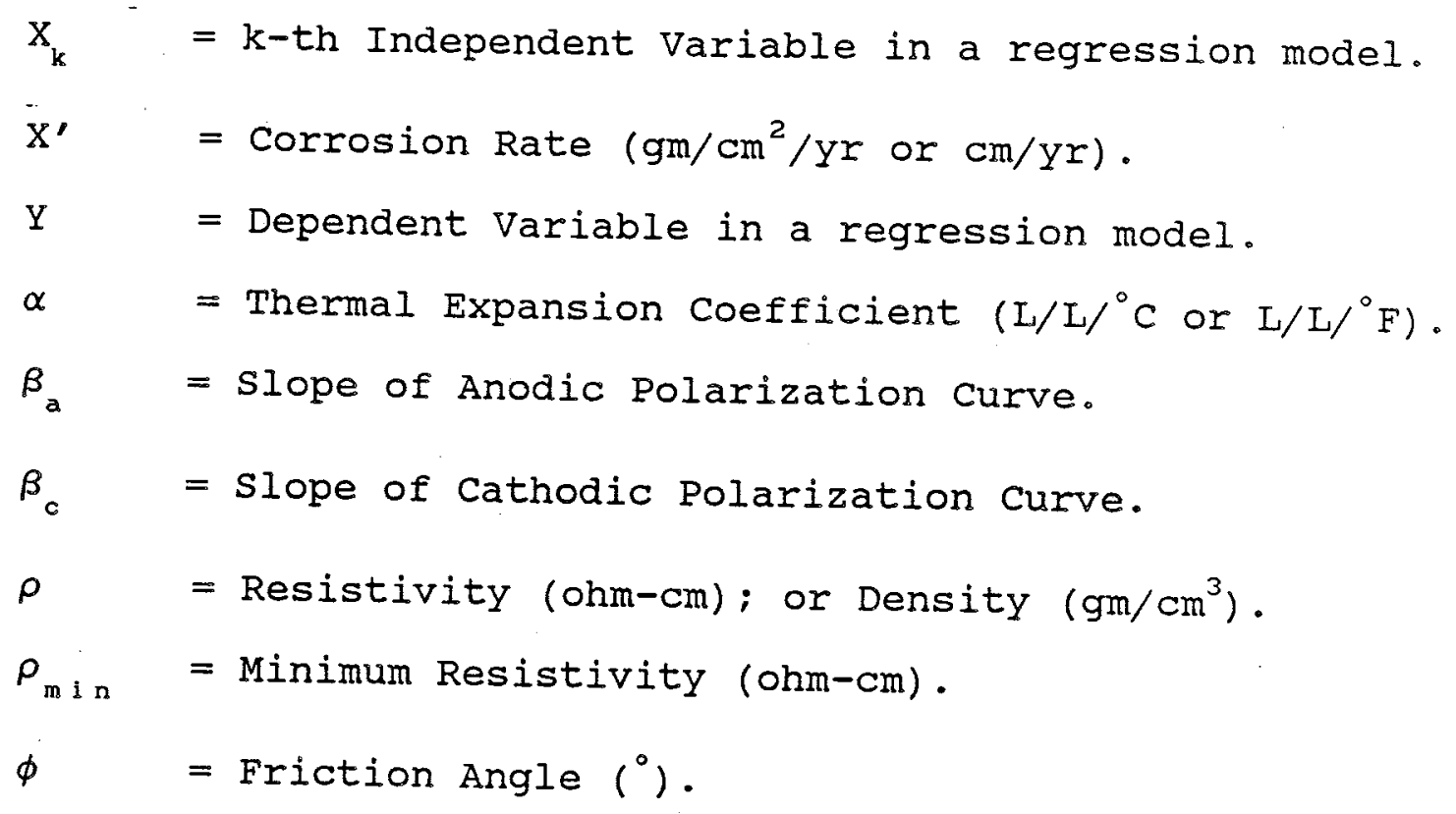




\section{HIGHLIGHT SUMMARY}

A decreasing supply of natural high-quality construction materials has motivated the search for innovative materials. On the other hand, every year a huge quantity of industrial by-products is produced. Disposal of these by-products is costly and may cause an environmental hazard. If the utilization of industrial by-products as a construction material is feasible, it not only solves a potential solid waste disposal problem but also provides an economic alternative construction material. In this study, bottom ash is the one of interest.

However, prior to extensive utilization, chemical and physical properties and mechanical behavior of bottom ash should be investigated to meet the existing requirements of commonly used aggregates. The main goal of this study is to examine durability and corrosiveness of bottom ash. Durability is one of the most substantial properties of construction materials, relating to their long-term engineering performance, especially when subjected to cyclic changes in the service environment. If bottom ashes are used as backfills for reinforced earth structures or other fill materials adjacent to metal structures, the 
corrosiveness of bottom ash to the nearby metal structures is a matter of concern.

Through literature review, the concepts of meaningful durability tests and underground corrosion were presented, and available durability tests and corrosion-related parameters were selected. Four bottom ashes produced in Indiana were selected as candidate ashes to be examined. Sodium sulfate soundness tests and freeze-thaw tests were performed to assess the durability of bottom ash, following ASTM C 88 and AASHTO $T$ 103, respectively. Four electrochemical characteristics of bottom ash, viz., soluble chloride, soluble sulfate, resistivity and $\mathrm{pH}$, were chosen to estimate the corrosiveness of bottom ash. Determinations of these four characteristics essentially followed nonstandard test methods, i.e., California Test methods. The sensitivity of California Test methods was examined and discussed. To increase the data base for evaluation, additional tests were performed on the other 7 ashes sampled earlier.

Based on existing specifications of soils and aggregates, the evaluation criteria for durability and corrosiveness of bottom ash were established. The evaluation results of Indiana bottom ashes provide a base necessary for projecting the future utilization of bottom ash, as far as durability and corrosiveness are concerned. 
In conclusion, the evaluation results of (totally) 11 Indiana bottom ashes examined indicate that: (1) Indiana bottom ashes are durable, and can be extensively used in highway construction; and (2) Indiana bottom ashes may be corrosive, and those bottom ashes with a high corrosion potential should not be utilized in highway construction where steel structures are involved. 


\section{CHAPTER I INTRODUCTION}

\section{Background}

Deficiency of Natural Mineral Aggregates

Despite the large amounts of natural mineral resources which exist on earth, they may be insufficient in the face of increasing exploitation. And, of course, they are not renewable.

The potential availability of high-quality mineral aggregates was recently reported to be in severely short supply in about one-third of the 48 contiguous states of the United states (Witczak et al., [1]). The diminishing supply of such aggregates had had many adverse effects associated with it. Among these is a predictably poorer long-term performance of structures, and higher maintenance costs, if relatively inferior materials must be used.

A search for high-quality innovative materials or re-use of industrial by-products is imperative. Recently, particular attention has been paid to industrial by-products, which were commonly regarded as waste materials. If the utilization of such by-products as a 
construction material is feasible, it not only solves a potential solid waste problem but also compensates for a decreasing supply of high-quality aggregates.

\section{Mass Production of Coal Ash}

With diminishing quantities of oil, the use of coal as a major energy source has been given a stimulus. At the present, about one hundred million tons of coal ash are produced every year in the United States. As far as the environmental hazard is concerned, disposal of coal ash is a serious and expensive problem, especially in urban areas. Although at least $28 \%$ of coal ash is reused, disposal costs for the remaining $72 \%$ represent a major cost to utilities (Golden, [2]). On a national scale, the unit cost of ash disposal ranged from $\$ 5$ to $\$ 10$ per ton, and the total cost to the electrical utility industry in 1980 ranged from $\$ 375$ to $\$ 740$ million ([3], as cited in Huang and Lovell, [4]). The economical and environmental concern urges the increase in re-use of coal ash, if coal ash can be successfully shown to be a suitable construction material.

\section{Type and Nature of Coal Ash}

coal ash is the uncombustible mineral matter, which accounts for 10-20\% (by weight) of the coal consumed in power plants. Coal ash includes two types: fly ash and 
bottom ash. Fly ash is the fine-grained dusty material that is recovered and collected from furnace flue gases by ash precipitators. Fly ash contains silt-sized or finer particles with a very low bulk density. Bottom ash is the slag which builds up on the heat absorbing surfaces of the furnace, and which subsequently falls through the furnace bottom to the ash hopper below (Huang and Lovell, [4]). Depending on the cooling procedure for the molten ash, bottom ash is divided into two categories: dry bottom ash and wet bottom ash. Dry bottom ash solidifies and agglomerates into coarse particles and then falls into the ash hopper. The ash particles are vesicular and irregularly shaped, and have a rough, gritty texture. Wet bottom ash, often referred to as boiler slag, is formed by quenching the molten ash in the water-filled hopper. The word "wet" refers to the molten state of the ash which leaves the furnace as a liquid. Wet bottom ash is a hard, black, glassy, and angular material with a smooth surface texture.

The type of coal ash produced at a power plant is determined mainly by the design and operation of the boiler units (Huang, [5]). At present, there are three categories of coal burning boilers: pulverized coal-fired furnace, cyclone furnace, and stoker-fired furnace. Pulverized coal-fired units are most widely used in electrical utilities, especially for new power installations. The units consist of dry-bottom boilers and wet-bottom boilers. In a 
dry-bottom boiler, $60-80 \%$ of the coal ash is produced in the form of fly ash and the remainder in the form of dry bottom ash; while in a wet-bottom boiler, about half of the coal ash is produced in the form of fly ash and the remainder in the form of wet bottom ash. Cyclone furnace contain a relatively small horizontal cylinder, into which crushed coal and air are introduced tangentially at high velocity. Heat released is high enough to melt the ash into a liquid slag, which forms a layer on the walls of the cyclone. Typically, 70 - 85\% of the ash melt is tapped from the furnace as wet bottom ash, leaving 15 - 30\% as fly ash. stoker-fired boilers are practical only for power plants generating less than 40 megawatts. [5]. These units produce 10 - 55\% of coal ash in the form of fly ash and the reminder in the form of dry bottom ash. The dry bottom ash produced by stoker-fired units is coarser and more porous than that produced by other boilers. In addition to boiler type, ash characteristics are affected by the source of coal burned.

\section{Bottom Ash: An Engineering Material}

Among the two types of coal ash, bottom ash may be a good alternative construction material. However, due to the higher production and various applications in soil stabilization and cement replacement in concrete, investigations have been concentrated upon the behavior of fly ash rather than bottom ash. The first systematic study 
of bottom ash was made by seals et. al. [6], who inspected the general properties, chemical composition, and mechanical behaviors of West Virginia bottom ashes. They advocated that bottom ash could be an engineering material used in fill and pavement construction. Shuler [7] examined the effects of Indiana bottom ashes on bituminous sand mixtures, and indicated that the addition of bottom ash both enhanced skid resistance and increased stability in the water sensitivity tests. Huang and Lovell [4] extended the previous studies to include environmental aspects. They concluded that: bottom ash has mechanical behavior comparable to natural sands; is nonhazardous; and has minimal effects on the quality of ground water. This was based on. their test results from Indiana bottom ashes.

With the decrease in high-quality natural mineral aggregates and improved understandings of bottom ash, one is encouraged to consider bottom ash as a useful engineering material, rather than as a burdensome waste product.

\section{The statement of the Problem}

As mentioned above, previous studies seem to justify the use of bottom ash in some kinds of highway construction, e.g., embankment, subbase, and base. However, with respect to commonly-used natural materials such as soils and rocks, bottom ash is relatively new, artificial, and unfamiliar to 
most engineers. Without extensive research, confidence in ash use wili be lacking in practice. Durability and corrosiveness of bottom ash which have been little studied are of major concern in this research.

\section{Lack of Durability}

Unlike natural materials, the formation of bottom ash is a synthetic process. The characteristics of bottom ash are dependent on the source of coal burned and boiler type, as well as storage environment and storage time. It is initially presumed that bottom ash is not as stable as natural materials which have already been exposed to their environment for geological time.

The physical durability of bottom ash needs to be determined, when subjected to changes of service environment at the proposed site. A lack of physical durability may prevent the use of a bottom ash.

\section{Corrosiveness to Adjacent Metal structures}

Because of the complex chemical composition of bottom ash, its electrolytic mechanism and the nature of its leachate are unknown. Bottom ash is suspected of having high contents of soluble salts, since it is the residual product of coal combustion. 
If metal structures are near or even enclosed by the bottom ash fill, potential corrosion caused by interactions among bottom ash, metal structures, and the environment is of concern. Those bottom ashes having a high corrosion potential tend to damage adjacent metal structures.

\section{Research objectives}

The research objectives are to supplement the existing understandings of the physical durability and corrosiveness of Indiana bottom ashes, whose index properties and mechanical behavior have already been studied by Huang [5] .

\section{Physical Durability}

Bottom ash can be used as an aggregate in concrete, a fill material, or a pavement course. For each of these uses, a potential lack of physical durability will result in poor performance, large deformation or durability failure, and an increase in maintenance costs. Therefore, this important property of bottom ash must be explicitly evaluated prior to its successful utilization. This research will provide a simple testing procedure for such assessment.

\section{Corrosiveness}

Reinforced earth structures are comprised of granular fill with reinforcing metal strips. If bottom ash is used as 
the backfill, corrosion of the strips may occur. Such corrosion could lead to the failure of the structure if the tensile stress of the uncorroded (surviving) strips exceeds their tensile strength. Appropriate prediction of the intensity of this problem will also be addressed in this research.

\section{Evaluation criteria}

No direct measures of the properties of concern are convenient or economical. Instead, indirect and highly-correlated parameters are to be determined by specified methods. Once the test results are obtained, evaluation criteria should be established, based on these indirect tested values, to judge the suitability of the material.

\section{Research Approach}

Candidate bottom ashes for testing will be selected from the eleven ashes already sampled and studied by Huang and Lovell [4]. Information about index properties, chemical composition, and mechanical properties of these ashes have been reported by Huang [5].

Among available durability tests, the simpler and less time-consuming ones were selected. However, they still are able to discriminate among the ashes as to suitability in 
different functional situations. These tests need, in general, to increase in severity from embankment, to subgrade, to subbase, and even base course applications. Frost action is the predominant action causing durability distress in Indiana. Thus, these tests must also be able to simulate the cyclic changes of freeze-thaw. Sodium sulfate soundness tests and freeze-thaw tests were then chosen to evaluate the durability of bottom ashes. The concept of meaningful durability tests and the discussions of existing durability tests will be presented in the next chapter.

A set of electrochemical characteristics were chosen to be the corrosiveness indicators of bottom ash. They are: soluble chloride content, soluble sulfate content, ash resistivity, and ash $\mathrm{pH}$. The selection process of these parameters and underground corrosion mechanisms will be presented in the next chapter. The determinations of these characteristics are mostly based on the test methods used by the California Department of Transportation (CALTRANS). A combination of the parameters determined will be used to estimate the corrosion potential of bottom ash.

The proposed evaluation criteria for bottom ash are to be established, based on available experiences developed on aggregates and soils. The candidate bottom ashes will then be classified as durable or nondurable and corrosive or noncorrosive. 
Based on the available data bases of bottom ashes examined, their suitability for different applications will be discussed. The validity of the proposed evaluation criteria and the reliability of testing methods should be justified in future field tests or by other direct measures. 


\section{CHAPTER II LITERATURE REVIEW}

Durability and corrosiveness are two major properties of bottom ash to be examined in this research. The knowledge and investigation of such properties on commonly used materials have been accumulated for a long time, perhaps dating back to the dawn of civilization. Stone tools and animal bones can last for thousands of years (in a favorable environment) and bronze rusts in the moist atmosphere or soil. The following sections successively describe definition, significance, relevant mechanisms, measures, and test methods of durability, and then those of corrosiveness.

\section{Durability}

Due to the relatively short lifetime of human beings, structures which survive for several centuries are generously admired(here structure is defined as any man-made object). Praise may also be extended to the corresponding creators (designers or builders), named or nameless. Egypt is well-known for its great ancient pyramids existing beside the River Nile for over four thousand years; China is well known for its Great wall. This human creation can even be 
seen from outer space. Being remembered in history thus, the engineer is encouraged to design or build not only a safe and comfortable structure, but also one which can last as long as possible. The first criterion is that the material chosen for the structure be durable. However, what is meant by "durable" or "durability"? Why is it so important? Next, what are its elements and related mechanisms? And last, can it be quantified (measured in quantitative term(s)) and how can it be tested?

\section{Definition}

Although the first durability test was performed around two thousand years ago by Vitruvius (Pihlajavaara, [9]), the concepts of durability are still poorly understood. At present, there are several definitions of the word "durability". Unfortunately, most of them do not include all necessary elements.

The dictionary defines durability as "the quality of being durable; ability to last in spite of frequent use or hard wear" as cited in Frohnsdorff and Masters [8]. This implies that durability is an intrinsic ability to endure. The difficulty in applying such a definition to engineering materials is that no item will last indefinitely, and the same item may be able to last for a long period in one environment while deteriorating rapidly in another. For 
example, adobe brick may last for thousands of years in an arid climate, but may disintegrate rapidly in a wet one. This illustrates that durability is not a absolute quality, but a term expressing a human perception of a quality which changes with the "environment" at a certain "rate". However, the above definition does not include the related environment and time concepts.

Pihlajavaara [9] presented another similar definition of durability as follows:

"Durability of a material is its ability to resist change of its state or, in other words, of its properties."

Again, such a definition emphasizes that durability is the ability of a material to resist change of properties of concern. Generally, the "change" here refers to an unfavorable event, i.e, deterioration. A more durable material possesses minimal tendency to deteriorate, due to its inherently good chemical and physical characteristics. However, like the previous example, this definition is too brief to cover the effects of time and the environment involved. Recall that no material is, of itself, durable or nondurable; it is the interactions of the elements of the environment with the material that determines its durability or its corresponding life expectancy.

Farhi [10] indicated that the various international 
technical bodies seem to agree that durability means maintaining performance through time. In other words, satisfactory long-term performance is an approximate synonym for durability. Two more rigorous definitions of durability and one of a related concept, serviceability, appear in standards prepared by ASTM Committee E-6 on Performance of Building Construction (as cited in Frohnsdorff and Masters [8]). These are:

durability -- the safe performance of a structure or a portion of a structure for the designed life expectancy. (from ASTM Recommended Practice for Increasing Durability of Building Constructions Against Water-Induced Damage(E $241-77))$

durability -- the capacity of maintaining the serviceability of a product, component, assembly, or construction over a specified time. (from ASTM Recommended Practice E 632)

serviceability -- the capacity of a building product, component, assembly or construction to perform the function(s) for which it is designed and constructed. (from ASTM Recommended Practice E 632)

These definitions reveal that durability of a material also depends upon the designed serviceability over the designed life span. The designed serviceability could be 
used to determine the Iife expectancy. However, the service environment is not included.

Finally, as stated by Pihlajavaara [9], adequate procedures and intervals of maintenance on a material can reduce or isolate any attack from the environment, resulting in an increase of its life expectancy.

In conclusion, the elements of durability involve: the material itself, time or life expectancy, serviceability, service environment, and maintenance. They will be discussed in detail later on. Table 1 , presented by Pihlajavaara [9], shows the exemplary relations among elements with the assumption of no maintenance applied and generally required levels of serviceability.

To resolve differences in the definition of durability, let us accept the following:

Durability of a material is its ability to maintain the designed serviceability over the designed lifetime in the predicted service environment, with a specified maintenance activity.

once a definition is accepted, it is helpful to describe durability of a material in a scientific way. Two possible ways are listed below.

1). Qualitative expression: If a material, which is 
Table 1 . Classification of the Age or Service Life of Materials under various Conditions.

(from Pihlajavaara, [9])

\begin{tabular}{|c|c|c|c|c|}
\hline \multirow[b]{3}{*}{ Materials } & \multicolumn{4}{|c|}{ Class of Degradation Factors and Expected Age } \\
\hline & $\frac{1}{\text { Very Severe Exposure }}$ & $\stackrel{2}{\text { Severe Exposure }^{b}}$ & $\begin{array}{c}3 \\
\text { Mild Exposure }^{\epsilon}\end{array}$ & $\begin{array}{l}4 \\
\text { Very Mild } \\
\text { Exposure }^{d}\end{array}$ \\
\hline & \multicolumn{4}{|c|}{ Age in Years } \\
\hline Precious metals & 1000 to 10000 & 100000 & 1 million & $>10$ million \\
\hline Strong natural rocks & 100 to 1000 & 1000 to 10000 & 100000 & $>1$ million \\
\hline Natural rocks & 10 to 100 & 100 to 1000 & 10000 & $>100000$ \\
\hline Strong ceramic materials & 100 to 1000 & 1000 to 10000 & 1 million & $>10$ million \\
\hline Ceramic materials & 1 to 100 & 100 to 1000 & 10000 & $>100000$ \\
\hline High-strength concrete & 10 to 100 & 100 to 1000 & 10000 & $>100000$ \\
\hline Concrete & 1 to 100 & 50 to 500 & 2000 & $>10000$ \\
\hline Mortars & 1 to 10 & 10 to 100 & 2000 & $>10000$ \\
\hline Gypsum & & 1 to 10 & 500 & $>2000$ \\
\hline Metals (for example, iron) & 1 to 10 & 10 to 100 & 5000 & $>10000$ \\
\hline Wood & 1 to 10 & 10 to 100 & 1000 & $>10000$ \\
\hline Plastics & 1 to 10 & 10 to 50 & 100 & $>1000$ \\
\hline Paints & ... & 2 to 20 & 500 & $>2000$ \\
\hline Leather & 1 & 10 to 50 & 500 & $>2000$ \\
\hline Textiles of natural fibers & & 1 to 10 & 500 & $>2000$ \\
\hline Bone, hair & 10 to 100 & 100 to 1000 & 10000 & $>100000$ \\
\hline
\end{tabular}

${ }^{a}$ Frost, snow, ice, thawing, great changes in temperature and humidity, erosion, dissolution, strong sunlight, pollution, conditions with strong corroding effects, for example, seawater, polluted water, corroding chemicals, etc.

${ }^{b}$ Average variable outdoor conditions, moderate changes in freezing and thawing.

'Moderate temperature, dry, slight changes in environment.

${ }^{d}$ Dry, very slight ventilation, low temperature, no sunlight, constant conditions. 
exposed to a specified environment and has a proposed - maintenance program, maintains the required serviceability over the desired period (i.e., design service life), then it is said to be durable.

2). Quantitative expression: Durability of a material is interpreted by its life expectancy within which it is exposed to a specified environment, and has a proposed maintenance program, and after which it can no longer provide the required serviceability.

In fact, both expressions are equivalent. If the environment, maintenance, and serviceability of concern are the same, the material with a longer life expectancy is more durable than one with a shorter expectancy. However, the latter expression is more useful, since quantitative values can be easily compared and transferred to different applications. Recently, there have been more efforts to predict the life expectancies of commonly used materials or, more challengingly, the expectancies of new and innovative materials under certain specified conditions, applying several developed or developing durability tests.

\section{Significance}

Before presenting a more detailed discussion of durability elements, let us focus upon the importance of durability. Why has it received increasing attention? 
The main answer lies in the economic impact of durability. Although durability and strength are considered generally to be the two most important properties of materials in civil engineering construction, the need to design and build for durability is not appreciated to the same extent as the need for structural strength. Therefore, it is not surprising that failures due to lack of durability are much more common than structure failures.

According to Blais [11] (as cited in Keyser [12]), the losses generated by materials deterioration in canada are of the order of $\$ 5$ billion per year. A cursory examination shows that a significant portion of these losses occur as: deterioration of bridges, exposed structures, tunnel linings, catch basins, sidewalks, pavements, etc. All of these are of great economic importance. As an example, the recent repair of elevated structures in Montreal's Metropolitan Boulevard cost several million dollars per mile. If durability had been a greater factor of concern when the structure was designed and built 25 years ago, at least 50 percent of this cost could have been avoided (Keyser [13]).

In addition to excessive maintenance costs, disasters may occur due to durability failures. Among several major failures of dams in Europe, one arched dam (Malpasset) in France which failed in 1959 is a good example. Before 
construction the base rock beneath the proposed dam was. examined in the dry season and determined to be a adequate foundation.. However, due to its high chloride composition, the base rock was softened several months after full storage of water behind the dam. It subsequently lost bearing capacity, causing a downstream shift of the dam. The flood resulting from the crack between the dam and the base rock led to more than 400 deaths, even though the main body of the dam was left without any structural damage. If the water-vulnerable nature of the base rock had been investigated and corrective treatments undertaken, such a tragedy could have been avoided.

To minimize long-term maintenance costs and even possible failures, durability of all materials used in a major project must be extensively examined and evaluated.

\section{Elements of Durability}

The following subsections will describe in detail of durability elements in sequence.

\section{Material properties}

Breakdown and decomposition of a material is one part of the earth ecocycie, and soils are the final products of their native rocks after various types of weathering processes. As a rule of thumb, a material with a stronger 
intrastructure has higher resistance to surrounding attacks and the associated deterioration. From Table 1 , and under the same environment, natural rocks can last much longer than wood. Therefore, the first important element of durability of a material is its inherent nature, such as its physical and chemical bonds, and the contained minerals and composition.

Weathering processes include mechanical weathering and chemical weathering (for details see Environmental Agents, page 30). Mechanical weathering leads to disintegration of large particles into smaller pieces without change of chemical composition. The strength of interatomic bonds of a material reflects its resistance to such a breakdown process. The three primary bonds are: covalent, ionic, and metallic. Two main secondary bonds are the hydrogen bond and the van der Waals bond. The bonding forces decrease in the order cited above, i.e., covalent bonding is the strongest, and van der Waals bonding is the weakest.

Atomic packing is another influencing factor. The most stable arrangement of atoms in a structure is that which minimizes the energy per unit volume (Mitchell, [14]). The number of nearest neighbor anions which a cation possesses in a structure is defined as the coordination number $(N)$. Hence, the valence of the cation divided by $N$ provides $a$ very approximate indication of the relative bond strength, 
which, in turn, is related to the structural stability of the unit. Table 2 lists some of the structural units commonly found in soil minerals and their relative bond strengths.

When chemical weathering occurs, the bonding force is not the only source of protection from chemical attack, such as ion exchange, hydration, hydrolysis, etc. The activity of the mineral in the environment should also be considered. Bowen in 1922 presented the hypothesis of magmatic differentiation to explain the phenomena of fractional crystallization (Her, [15]). Bowen's Reaction Series describes the formations of different minerals in sequence (of temperature) from the same source of magma. Usually, the mineral which forms in the early stage of Bowen's Reaction series is more likely to deteriorate than that forming later. This statement is in accordance with chemical stability of a mineral. For example, quartz which forms in the latest sequence of the above-mentioned series is one of the most stable and resistant materials; while olivine which forms earliest is vulnerable to moist surroundings.

In general, a knowledge of chemical composition and minerals can provide an approximate description of the durability of a material. It can be predicted that a material consisting of very stable minerals with strong 
Table 2 Relative stabilities of some Soil Mineral Structural Units. (from Mitchel1, [14])

\begin{tabular}{|c|c|}
\hline Structural Unit & $\begin{array}{c}\text { Approximate } \\
\text { Relative Bond } \\
\text { Strength } \\
(\text { Valence } / N) \\
\end{array}$ \\
\hline $\begin{array}{l}\text { Silicon Tetrahedron, }(\mathrm{SiO})^{4-} \\
\text { Aluminum Tetrahedron, }\left[\mathrm{Al}(\mathrm{OH})_{1}\right]^{1-} \\
\text { Aluminum Octahedron, }\left[\mathrm{Al}(\mathrm{OH})_{6}\right]^{3-} \\
\text { Magnesium Octahedron, }\left[\mathrm{Mg}(\mathrm{OH})_{6}\right]^{4-} \\
\mathrm{K}-\mathrm{O}_{12}^{-23}\end{array}$ & $\begin{array}{l}4 / 4=1 \\
3 / 4 \\
3 / 6=1 / 2 \\
2 / 6=1 / 3 \\
\\
1 / 12\end{array}$ \\
\hline
\end{tabular}


bonding will possess a relatively long life expectancy. However, recall that deterioration of a material involves interactions with the environment. Furthermore, it is difficult to predict the durability behavior of a material of complicated composition because of complex combined reactions. The same is true for innovative or waste materials. Therefore, intrinsic material properties can not provide the whole story of durability.

\section{Serviceability}

Serviceability refers to the design performance which the structure can offer. Its importance lies in its providing a guide to life expectancy, i.e., the quantitative expression of durability of a material in a specified environment. However, the following two questions arise.

1). Requirement of Quantification. It is necessary to quantify serviceability and express it as one or several physical term(s), which can be easily understood. For example, tensile strength is a indicator of performance for any tensile member. Strength angle and cohesion are combined ones for soils and crushed rocks; resisting modulus is another one for subgrade materials, and so on. The quantification rule requires that selected physical term(s) should be highly correlated to the performance of concern. In fact, performance in a engineering field, 
which includes safety and comfort, can be easily expressed in terms of strength and deformability parameters. In contrast, for decorative objects, performance depends much on their color, appearance, luster, etc., which are more difficult to quantify.

2). Dependence of Functional Use. It is not surprising that the same material has different major performance indicators in different functional uses. Consider steel as an example. For structural steels, strength and modulus are of concern; for underground steel pipes, thickness change (loss due to corrosion) and cracking are necessary considerations; for steel artwork, luster and appearance are of greater concern.

In summary, to provide a evaluation guide of durability, the first step is to quantify the involved serviceability into several physical terms. The physical term(s) dictated by the functional use will be regarded as the aging indicator(s) to be used in the durability test. Such tests will determine the life expectancy of the material subjected to the actual service environment.

Time and Life Expectancy

Referring to the definition of durability, it is over time that deterioration of a material occurs. Without the passage of time, every thing retains its current state 
without change. Time reveals the mechanisms involved, and ultimately allows the development of a prediction for life expectancy. Subsequently, the life expectancy of the material can be involved in the cost analysis of construction to decide whether or not it can be economically used.

If the intensity of environmental agents is constant, several deterioration characteristic curves, showing the change in the aging indicators as a function of the time factor, may be given as in Figure 1 (after Farhi [10]).

Curve I means that the material is very stable with time and always has a constant aging indicator value greater, by a large amount, than that of minimum acceptable performance $\left(i^{*}\right)$. Here the corresponding durability can be assessed as "very good" since its life expectancy ( $\left.t^{*}\right)$ is infinite.

Curve II means that the material is very stable with time, but always has a constant aging indicator value lower, by a large amount, than that of $i^{*}$. Here the corresponding durability has no meaning since the value of $t^{*}$ is zero. This type of material should be rejected in an early stage of design.

"Curve III illustrates that the measurable value of the aging indicator decreases asymptotically to a value 
(a) Constant type

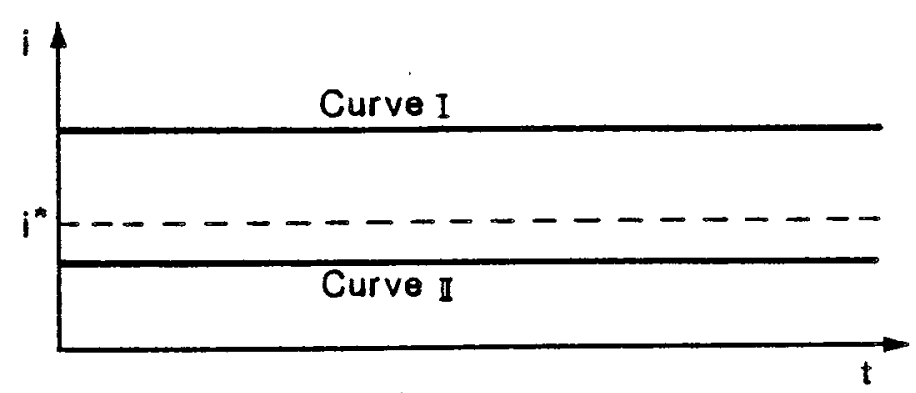

(b) Concave type

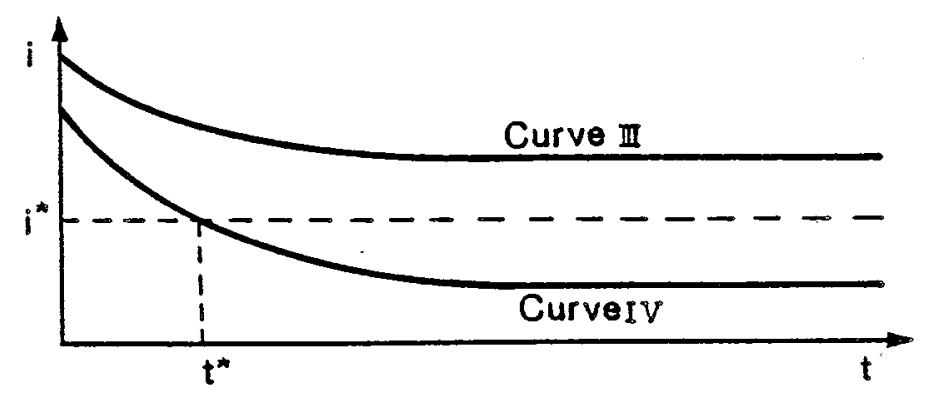

(c) Constantly decreasing type

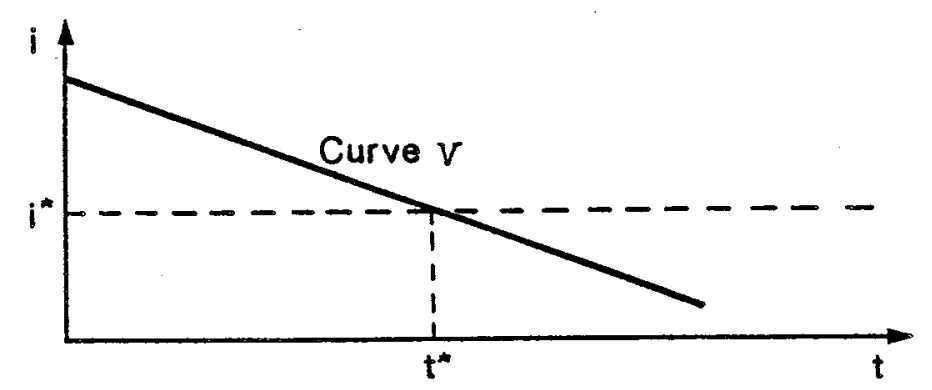

(d) Convex type

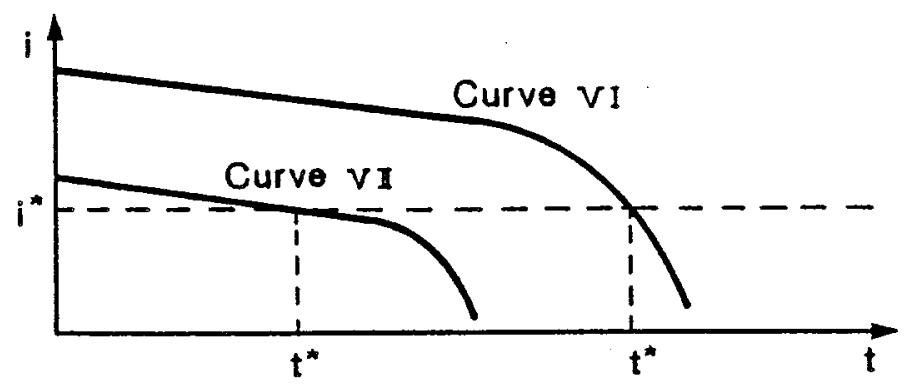

- Figure 1 Characteristics Curves as a Function of Time, (from Farhi, [10]) 
greater than $i^{*}$. The durability can be assessed as "good", with a infinite value of $t$.

Curve IV illustrates the same shape of characteristic curve, but the asymptotical value of the aging indicator is lower than $i^{*}$. For field tests, the abscissa of the point of intersection of the characteristic curve and that corresponding to the acceptable threshold of performance $i^{*}$ is the actual $t^{*}$ (in the specified service environment). For laboratory tests, the actual $t^{*}$ can be obtained after multiplication of some actual time factor depending on correlation of field tests and laboratory tests.

Curve $V$ corresponds to a durability which decreases linearly with time. The actual $t^{*}$ can be determined in the same manner as curve IV. In a mathematical description, the aging indicator approaches zero at several times of $t^{*}$. But this is not at all important, since the behavior of a material after its service life is not of engineering interest.

Curve VI and VII provide the thorniest problem, where the forecasting of durability is concerned. It is essential to know at what moment this sudden drop in the value of the aging indicator will occur. It must also be known whether it will occur more or less rapidly, or whether, on the contrary, it will occur at the end of a very long 
time. The actual $t^{*}$ can be determined in the same manner as for curve IV. If the aging indicator is a strength parameter, Curve VI is more unfavorable than curve VII, because the abrupt drop of strength takes place some time before $t^{*}$, and no advance warning is given to the users. Therefore, all materials having a similar shape of characteristic curve should be given increased attention to understand the actual mechanism involved.

(Note: If the measurable value of the aging indicator of a material goes below $i^{*}$, it is said to have failed. In that case, only material with a shape of Curves IV, V, VI, or VII is of interest, since the life expectancy is defined by this event.)

At this time, this writer should emphasize that the characteristic curve of different aging indicators of the same material may have different shapes. If the intensities of the studied environment change, the shape of characteristics of the same material may change. More importantly, the same material will probably have different shapes of characteristic curves in laboratory tests and in field tests, even in an equivalent environment. Hence, interpretation between results of laboratory and field becomes more difficult.

Examples of materials, presented by Farhi [10], and corresponding to the curves shown in Fig 1, are listed 
below:

Curve I corresponds to cement-based adhesives, taking: (a) as ordinate (the aging indicator), the pull-off strength of the adhesive, and (b) as abscissa, the wetting and drying cycles.

Curve II corresponds to very soft clayey soils (proposed to support a very heavy building), taking: (a) as ordinate, the bearing capacity of the soils, and (b) as abscissa, the actual years. (As expected, even with the clay not changing with time, it is too soft to support the proposed building.)

Curve III or IV corresponds to certain waterproofing membranes based on synthetic rubber, taking (a) as ordinate, the extension at rupture, and (b) as abscissa, the action of heat as a function of time.

Curve $V$ corresponds to a rigid polyvinyl chloride, taking (a) as ordinate, the dehydrochlorination index, and (b) as abscissa, the action of ultraviolet radiation as a function of time.

Curve VI or VII corresponds to rigid polyvinyl chloride, taking (a) as ordinate, the tensile-impact strength, and (b) as abscissa, the action of ultraviolet radiation as a function of time. 
In summary, the aging indicator versus time curve, i.e., the characteristic curve, is needed to understand the time-dependent response of a material to the environment.It provides a method of defining the corresponding life expectancy, the quantitative expression of durability, based on meaningful interpretation between laboratory results and field results.

Environmental Agents and Related Mechanisms

As mentioned earlier, deterioration of a material is the interaction of the material and the environmental agents. The material itself offers the internal resistance; while the environmental agents provide the external. deterioration forces. Thus, the durability, or life expectancy, can be defined. If the service environment were not specified, durability would no longer be an absolute term. For example, archaeological evidence indicates rather clearly that the survival of material objects depends highly on the environment to which they are exposed. Only old objects exposed to a favorable environment survive and can be appreciated. The same objects would not be available if subjected to a less favorable environment.

There are many terms which express the external forces applied to materials. For example, in some cases the word "durability" refers only to the ability of materials to 
resist actions such as weathering, corrosion, erosion, abrasion, and freezing (Pihlajavaara [9]). Here, all five actions are external forces. Sereda and Iitvan [16] write: "For centuries, man has struggled against the forces of nature to provide durable structures and to preserve worthy structures from the past as cultural heritage..." Here, "the forces of nature" are also external forces. For other examples, Frohnsdorff and Masters [8] used degradation factors to represent external forces; Farhi [10] added user stresses; and Haynie [17] used climatic factors. This writer prefers to use "environmental agents", because this word includes all kinds of forces, either physical or chemical, existing in the environment to which materials may be exposed.

There are numerous environmental agents existing in the world. It may be necessary to classify them into several subgroups. There are mechanical agents and chemical agents. The mechanical agents involve the physical degradation process, resulting in the formation of cracks or ruptures, breakdown of a large piece into small pieces, and reduction of mechanical properties. The chemical agents involve chemical decomposition, resulting in ion exchange of minerals, decrease of bonding strength, and loss of mass by solution. Both kinds of agents may exist in the same time and space, and reinforce each other, increasing the deterioration rate. 
other subgroups may be established by defining environmental agents. If water serves as the action medium, there are water-dependent agents and water-independent ones. The change of agent intensity separates static agents and dynamic (or cyclic) ones.

There are also natural agents and man-made ones. In fact, such classifications are useful only for the location of special interest. For example, the freezing and thawing process may be classified as a mechanical, water-dependent, cyclic, and natural agent. Frohnsdorff and Masters [8] prepared a detailed list of possible existing environmental agents. With some modifications by this writer, this list is shown in Table 3. Five of them and their corresponding deterioration mechanisms are discussed in the following.

Temperature Change

The linear thermal expansion coefficient $(\alpha)$ is one of the essential properties of a material. Materials expand to some extent depending on the magnitude of $\alpha$, with a positive change of temperature $(+\Delta T)$. Contraction is the response to $-\Delta \mathrm{T}$. However, if such thermal deformation is constrained to a certain degree by surrounding boundaries, or if a rapid rate of heat gain or loss occurs, a corresponding thermal stress will be induced. Constrained expansion yields compression within the system and constrained contraction 
Table 3. List of Environmental Agents.

(after Frohnsdorff and Masters, [8])

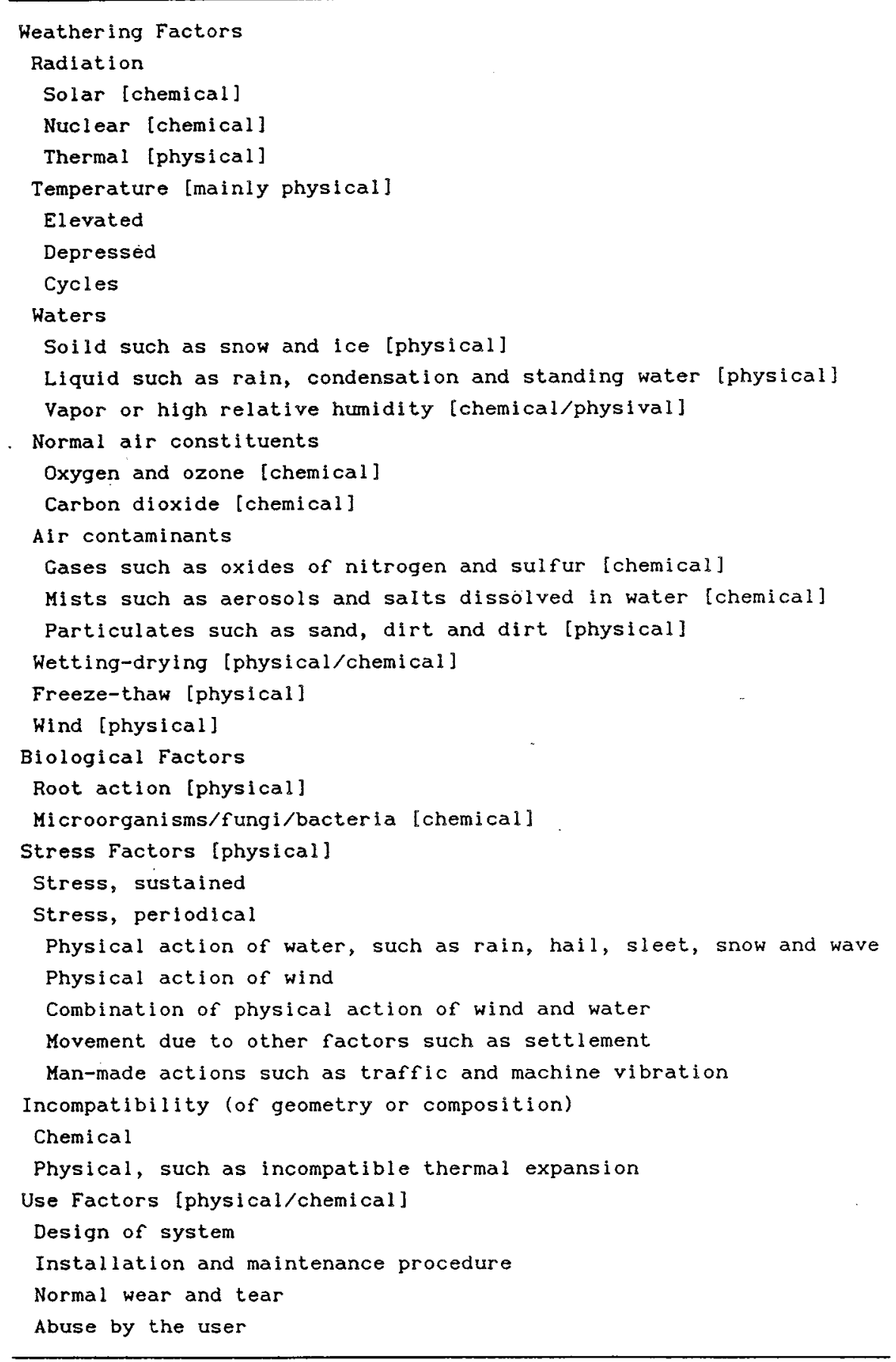


yields tension.

Except for materials of high tensile strength, most material particles are more vulnerable to tension states than to compression state. As thermally-induced tension becomes larger than the tensile strength of a material, microcracks appear, probably followed by enlarging macrocracks, or even disintegration. It is not usual for thermally-induced compression to exceed a material's compressive strength. The material will be crushed, or may explode when subjected to extremely high thermal compression (or high temperature). For example, during a large forest fire, strong natural rocks may be subjected to enough heat to cause them to explode. On the other hand, when dealing with metamorphic rocks (Her, [15]), heat and pressure are two major agents of metamorphism.

It can be predicted that long-term change of temperature (within or over a range), and induced stresses, will gradually change the internal structure or mineral content of a material, resulting in deterioration. Three main mechanisms (or phenomena) are illustrated below.

Thermal gradient: Envision a large particle being placed in a single environment for a long time. After the balance of heat flux, it has the same temperature $\left(\mathrm{T}_{0}\right)$ as the environment. If the environment has a sudden temperature 
change of $\Delta T$, the surface of the particle will have the same change of $\Delta T$, but the center may still remain at $T_{0}$. Thus a thermal gradient forms from the surface to the center of the particle. Assume that the particle is made up of many thin perimetric layers. Due to different temperatures among these thin layers, the layers restrain the thermal deformation of one another, and unbalanced thermal stresses appear.

Rösli and Harnik [18] presented a method of calculating such thermal stress for the case of a one-dimensional thermal gradient. They used the conditions of equilibrium and those of compatibility to develop the computation. Figure 2 shows one example, given a negative $\Delta T$ applied to the surface. The magnitude of induced tension near the surface, which causes cracking, is of major concern. Given the same material and the same $\Delta T$ on the surface, larger particles are more susceptible to thermal gradient attack, because it takes a longer time to relieve the thermal gradient from the surface to the interior.

Cyclic change of temperature: This is one of the principal mechanical weathering processes in deserts. A daily temperature difference of about $50^{\circ} \mathrm{C}$ means an alternate change of volumetric strain of $(1+50 \times \alpha)^{3}$ between noon and midnight (here, $\alpha$ is in units of $\mathrm{m} / \mathrm{m} /{ }^{\circ} \mathrm{C}$, and the material is assumed to be homogeneous and isotropic). If the 

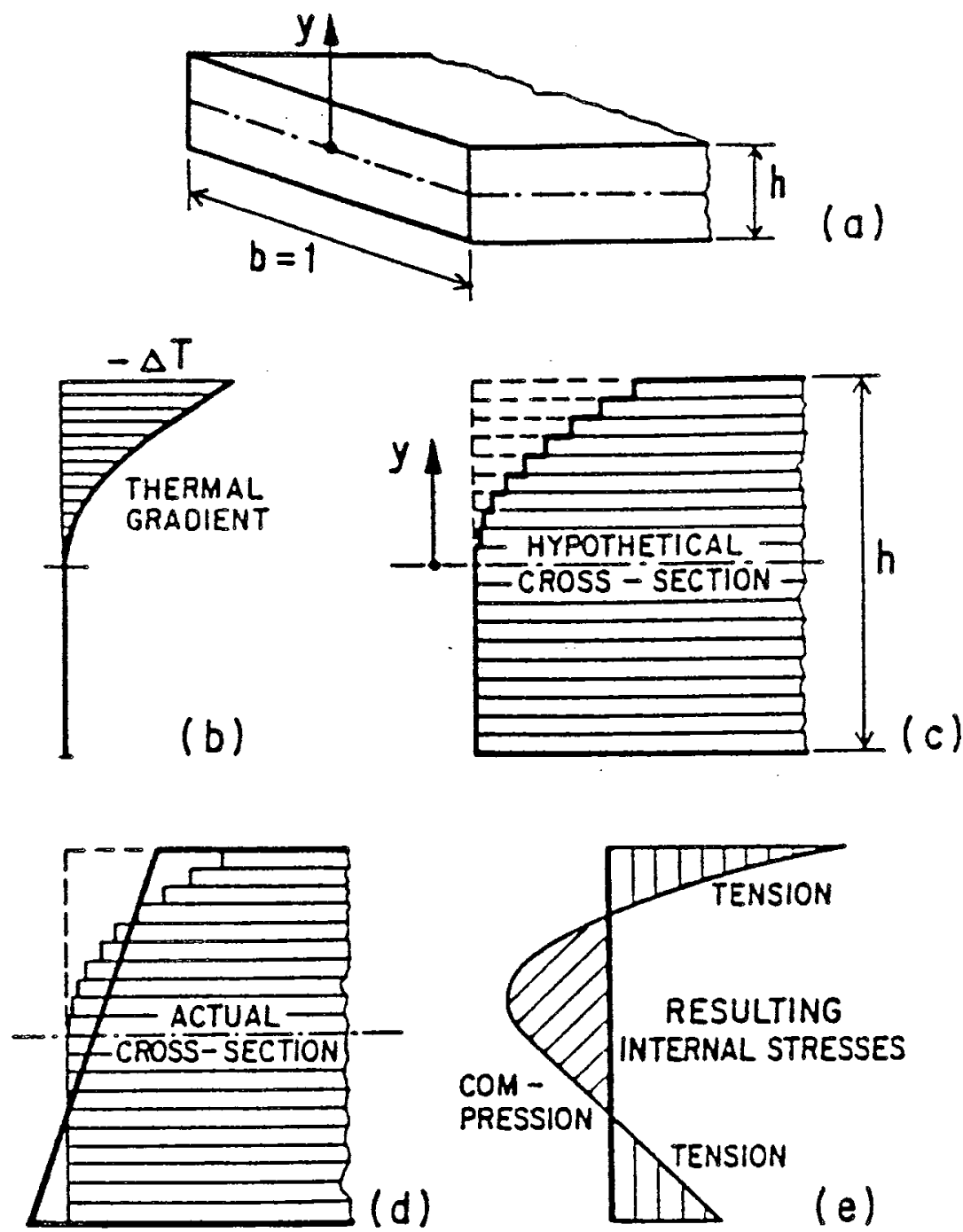

Figure 2 Development of Internal Stresses in Concrete due to a Thermal Gradient. (from Rösli and Harnik, [18]) 
material is relatively brittle (not ductile), the cyclic change of dimension will lead to the formation of microcracks, possible fatigue, and the associated reduction of bonding strength. In addition, any unbalanced (residual) thermal stress occurring during the alternate change of temperature within the material particle (similar to a thermal gradient) will intensify this tendency. The disintegration potential depends on the magnitude of $\Delta \mathrm{T}$, the number of cycles, and the material itself.

Incompatible Thermal Expansion: This mechanism is always found in composite materials, each component having different values of thermal expansion coefficient. Assume that each interface between any set of two components is in a perfect bonding condition. When $\mathrm{a}+\Delta \mathrm{T}$ is imposed, the component with larger $\alpha$ will be subjected to compression and that with lower $\alpha$ will be under tension along the interface direction. When $a-\Delta T$ is imposed, the inverse phenomenon occurs. In both cases, a shear stress is induced along interface. Whenever components break or shear along the interface, the composite material will change character.

Wetting and Drying

"Water" is the most troublesome substance with which geotechnical engineers deal - Whenever water is involved, the safety of related structure(s) is a challenge due to 
lubrication or softening of soils, undissipated excess pore water pressure, seepage, or swelling. Another approach to water-caused deterioration focuses upon porous materials, within which water can flow more or less freely.

From a chemical view, one water molecule contains two hydrogen bonds which actively react with other ions (cations) of the same level of activity. Therefore, water is attracted to clay minerals, in particular, the montmorillonite group (Mitchell, [14]). Water easily enters into the interlayers of the clay elements, and causes expansion as well as softening of the clay. Based on this water-clay interaction, the amount of clay mineral may be regarded as a durability indicator for rocks. In the process of wetting, the rock with a higher content of clay mineral will lose more strength, despite its favorable behavior when dry. other weak cement-type bondings will be easily destroyed by water. When subjected to moisture, the bonding of such a material will dissipate and the material will totally disintegrate. Other chemical reactions such as ion exchange in the presence of water will be discussed later.

From a mechanical view, the role of capillary forces is of concern. In the drying process, the porous material begins to shrink (under compression) due to outward capillary force action as water evaporates. For relatively 
fine materials, some pseudo cohesion will remain in the structure after drying. However, in the wetting process, an inward capillary force attempts to break into the interior void space of the material, placing the porous material under tension. Not only fine materials but also coarser ones may be broken down if the induced compression by the inward capillary force is too large. Generally, the smaller the pores the greater the induced compression (also proportional to capillary tension). Secondly, in both wetting and drying processes, water can erode the pore wall through which it flows. The erosion rate depends on the flow velocity.

In the atmosphere, the wetting and drying cycle can not happen isothermally, in particular the drying process. Therefore, the aforementioned effect of temperature change to deterioration must be considered. If the range of $\Delta T$ involved is small, the corresponding effect will be low.

Freeze and Thaw

Destruction of porous bodies caused by freezing and thawing has been of great concern to engineers for more than 200 years [19] (as cited in Litvan [20]). Under severe freezing climatic conditions, frost action is probably the most important cause of deterioration of exposed porous solids, such as concrete, stone, brick, and coarse 
aggregates. Not surprisingly, the pertinent literature dealing with the mechanical breakdown of building materials due to frost action, and with the general problems of phase changes of water absorbed in the the pores of porous solids, is voluminous. However, most is based on experience rather than on understanding of the true mechanism.

Litvan [20] presented the following important observations relating to frost action.

(A).The severity of mechanical damage is directly proportional to the water content of the porous solid. In the fully saturated state, few, if any, systems, can endure even a single freezing and thawing cycle without injury.

(B). Physical size of the porous solid affects susceptibility; frost resistance improves with reduction in size. (Note: Frost heaving potential increases with reduction in size (Holtz and Kovacs [21]. Two different phenomena are involved.)

(C). Mechanical damage is enhanced with increased cooling rates. Even the most vulnerable system can be taken through freeze-thaw cycles without injury if the freezing rate is very low.

(D).Solids with either very high or very low porosity usually have a good service record. Brick and marble are examples of such materials. Hydrated cement paste with intermediate porosity is usually vulnerable unless special 
precautions are taken. This is particularly true in the case of high water-cement ratio pastes. (E).Air entrainment, which consists of the addition of a surface-active agent to the plastic mix resulting in the formation of small air bubbles, around which the paste subsequently hardens, has proven to be an excellent method of increasing the frost resistance of cement and concrete. (F). The main features of frost action appear to be common to all classes of porous solids.

$(G)$. The characteristics of frost action with systems containing organic liquids are similar to those observed with water.

(H). Repeated freezing and thawing under natural conditions usually results in desiccation and in accumulation of the formerly pore-held liquid outside of the body (lens formation).

(I). Mechanical damage is more severe if the porous solid contains a solution instead of a pure liquid. The use of deicing salts is detrimental. Again, the nature or the extent of the damages does not depend on the chemical nature of the solute. The severity of the damage is a function of the solution concentration. The most severe damages occur at relatively low concentrations, in the 2 to 5 percent range.

The observations of (A) to (E), except (D), can be explained in the following proposed mechanism. The detailed 
explanation of the air entrainment effect on concrete to frost resistance can be found in the papers of Khalil et al. [22] and Rigan [23]. The adverse effects of deicing salts on concrete such as temperature shock and supercooling are discussed by other investigators (Rösli and Harnik [18], Harnik et al [24], and MacInnis and Nathawaad [25]).

To describe the breakdown process due to frost action, examine the most important phenomenon involved, i.e., the phase change of water between liquid and solid at its freezing or melting temperature of $0^{\circ} \mathrm{C}$. Figure 3 (from Harnik et al., [24]) shows the variation of specific volume of water with the temperature. During cooling, the specific volume of water attains its minimum at $+4^{\circ} \mathrm{C}$, then increases rapidly by about 9 percent at the freezing point and slowly decreases on further cooling. If such volume increase of phase change is subjected to boundary constraints, a hydraulic pressure (hydrodynamic effect) is induced. This happens in the pore system of a porous solid containing water when temperature drops below $0^{\circ} \mathrm{C}$.

To estimate the magnitude of hydraulic pressure, consider a one-dimensional pore system as shown in Figure 4. The portion $A B$ of a planar pore filled with water is of interest, and the portion BC represents the diffusion path through which water can flow in or out of the system. The size and length of this diffusion path controls the rate of 


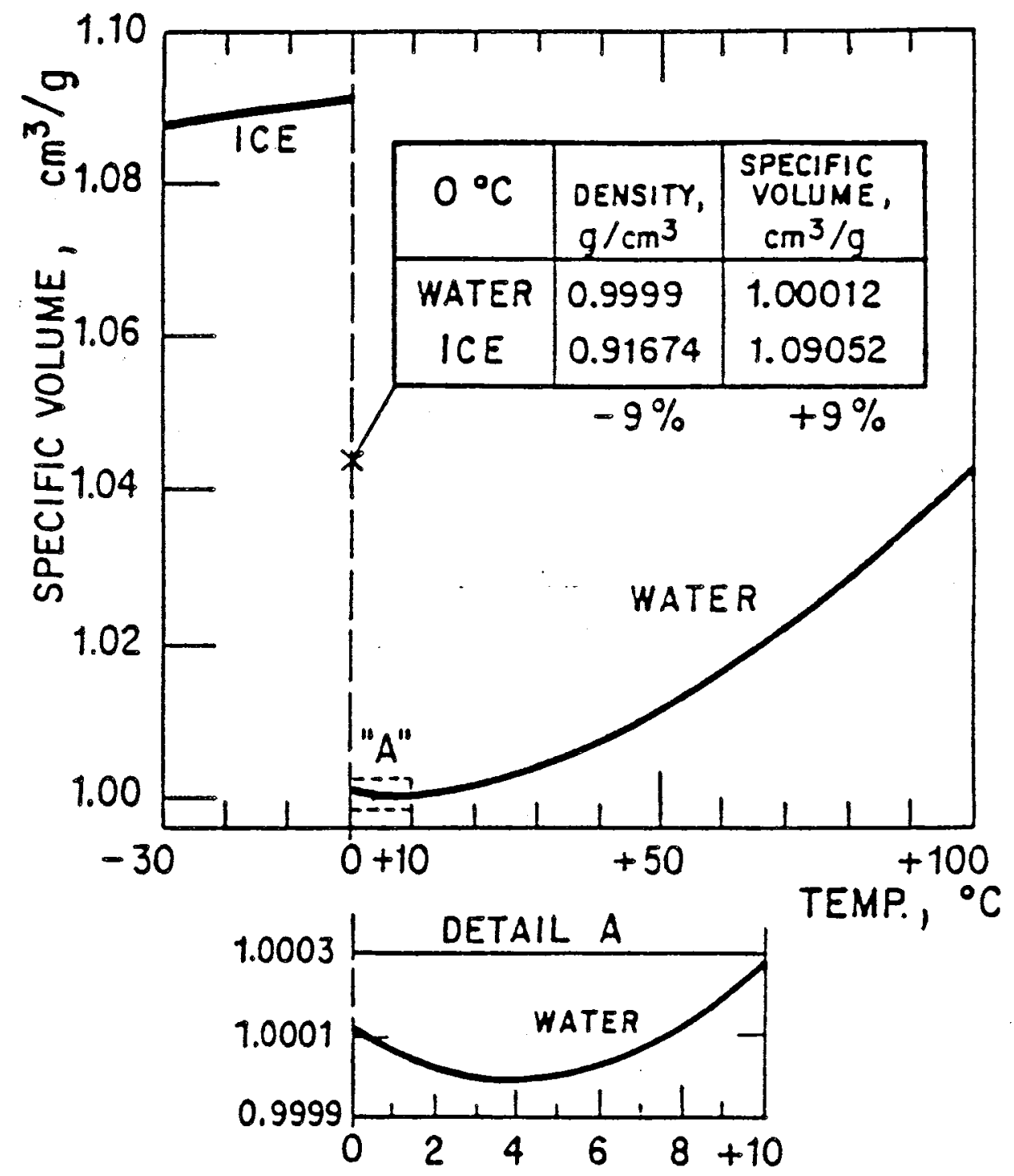

Figure 3 Anomalous Behavior of the Specific Volume or Density of Water-Ice.

(from Harnik et al., [24]) 
(a) Initial condition at $\mathrm{T} \geqslant 0^{\circ} \mathrm{C}$

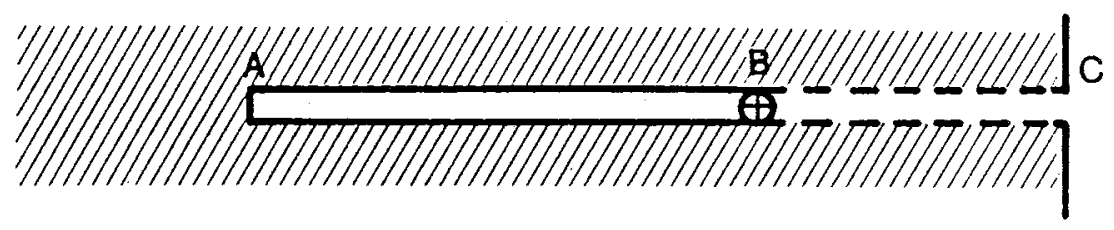

(b) Extreme condition of isolated A-B at $T<0^{\circ} \mathrm{C}$
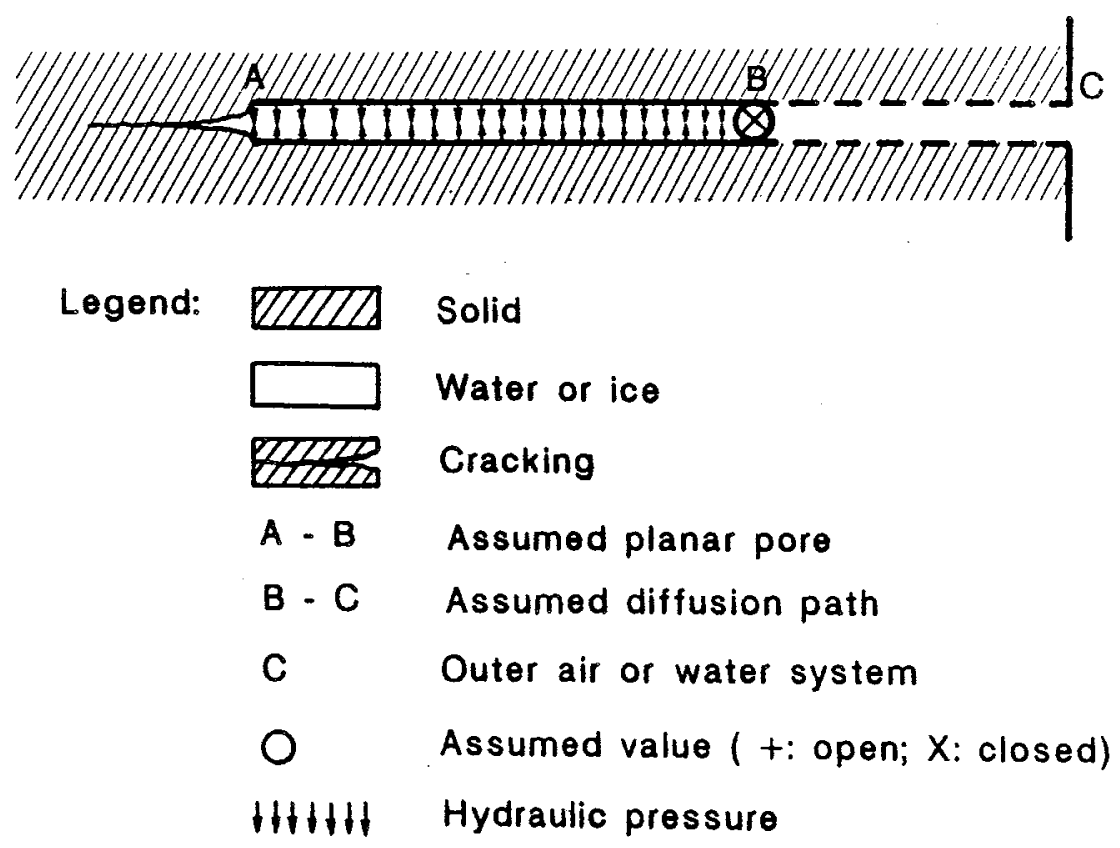

Figure 4 Hydraulic Pressure and Formation of Cracking 
inflow or outflow. For convenience, a hypothetical valve at point $B$ is used to simulate the function of the diffusion path. When the temperature reaches the freezing point of the water in the pore, ice crystals begin to form within the pore and attempt to expel excess un-iced water out of the portion $A B$ because of its limited capacity. (Note: the pore wall also contracts into the pore AB during cooling.) In the extreme case, no water will be expelled, if the valve $B$ is totally closed, which simulates the condition where the diffusion path is too long or narrow or it is totally blocked by previously-formed ice. (Note: This phenomenon is very similar to consolidation at the initial time, and the induced hydraulic pressure is like the initial excess pore water pressure.) If the cooling rate is so high that ice crystals instantly fill the entire pore $A B$, the induced hydraulic pressure in the vertical direction is caused by the production of a $9 \%$ volume increase and the constrained modulus of water $\left(E_{w}=2 \times 10^{9} \mathrm{pa}\right)$, i.e., $1.8 \times 10^{8} \mathrm{pa}$ or 26000 psi. This value is much larger than the compression strength of most rocks. Therefore, a new crack will form and propagate to the left of pore $A B$, creating more room to accommodate the excess volume of ice. As the crack propagates, the hydraulic pressure decreases gradually until equilibrium of the whole ice-solid system is achieved. The enlarged space attracts more water from the surroundings for subsequent cycles and further damage occurs. 
The above hypothetical model reveals that the maximum hydraulic pressure occurs at totally isolated locations of $A B$, thus causing the maximum damage. If the portion $A B$ is not initially saturated (having some air voids), the diffusion path is neither long nor small, and the ice crystallization is not very high (or the cooling rate is low), the un-iced water may have enough time to dissipate either to occupy a air void nearby or to move through diffusion paths into the outer system. Therefore, all factors influencing the dissipation rate of un-iced water (during cooling) are directly related to the frost resistance of porous solids.

Like the porous solid having low water content (or low saturation), air entrained concrete offers more air voids (pores), which will be occupied by enlarged ice bodies during cooling, reducing the corresponding hydraulic pressure and damage(explaining the above observations (A) and (E)). The larger size of the porous solid implies a longer diffusion path for un-iced water, resulting in higher probability of occurrence of hydraulic pressure within the solid and the associated damage (explaining the above observation (B)). Other factors such as permeability, void ratio, and pore size distribution of the porous material, also affect the dissipation rate of un-iced water. A high cooling rate has two adverse effects on frost resistance: rapid ice crystallization velocity which makes it more 
difficult to expel un-iced water out of the pore system within the porous solid, and production of incompatible (unbalanced) thermal stress within the whole water-ice-solid system, which can be regarded as a composite structure (explaining the observation (C)).

The melting (or freezing) point of. water depends upon the pore size in the porous solid. Harnik et al. [24] demonstrated such a relation for concrete, as shown in Figure 5. The water contained in the smaller pores freezes at a lower temperature. In the extreme case, the water in the gel pores of concrete does not freeze until the temperature drops below about $-50^{\circ} \mathrm{C}$. However, water, in the common air voids, fissures, and cracks, still freezes at. temperatures ranging from $0^{\circ} \mathrm{C}$ to $-0.1^{\circ} \mathrm{C}$.

Litvan [20] suggested that in order to avoid mechanical damage due to frost action, the moisture content should be such that the amount of excess water generated in unit time is less than the quantity lost by the porous solid to the exterior in the same period. This condition will exist if the total moisture content of the body is low, the permeability is high, the cooling rate is low, and the size of solid is small. These concepts can be used to improve the frost resistance of porous solids.

Freeze-thaw damage incorporates not only the above-mentioned mechanism but also damage due to change of 


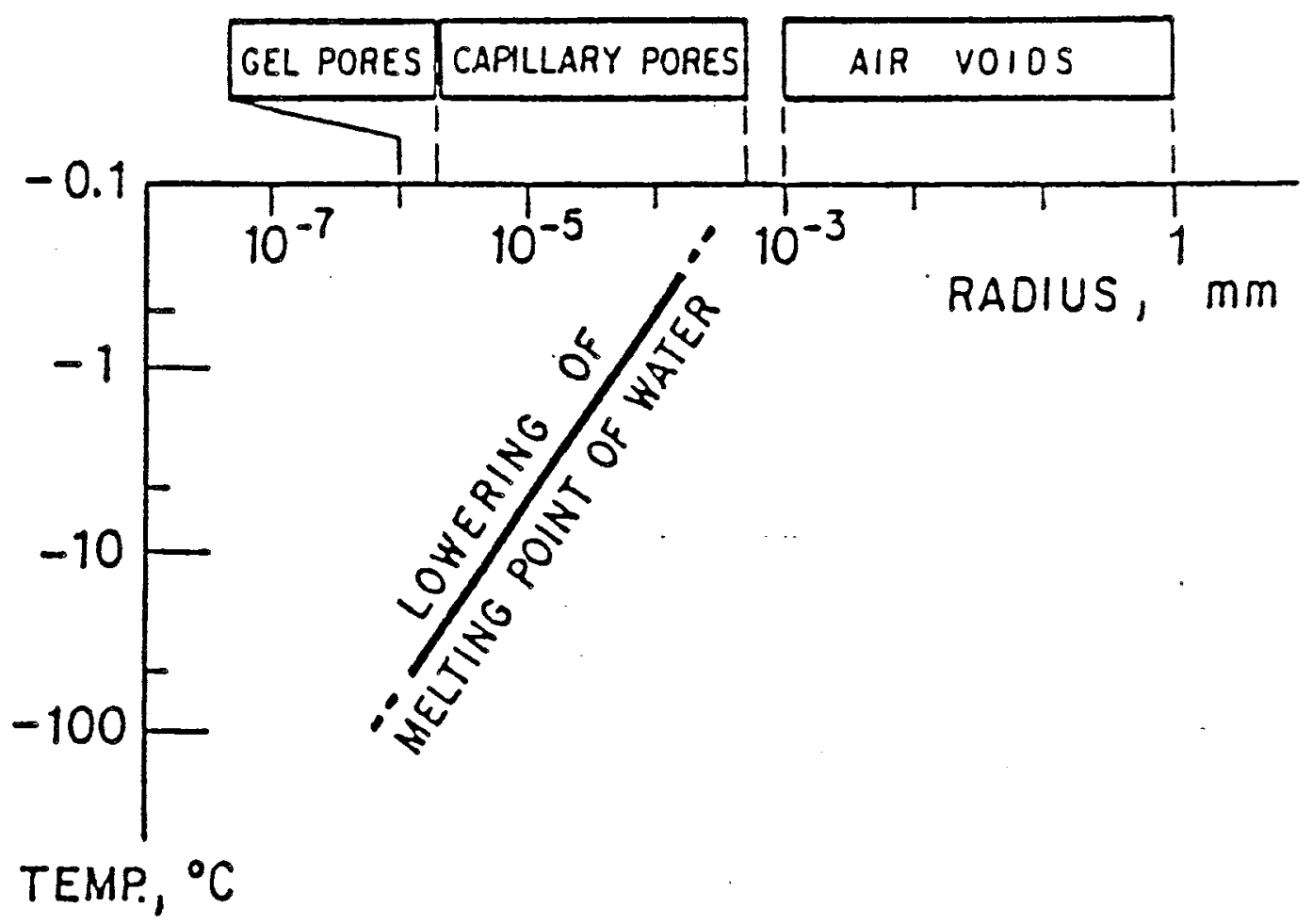

Figure 5 Correlation between Pore-Size in concrete and Melting Temperature of Water.

(from Harnik et al., [24]) 
temperature and the wetting-drying process. Hudec [26] presented a concept that freezing can be regarded as a drying process, viz., thus freezing and thawing is simply drying and wetting in the freezing range. A model for a nondurable carbonate rock is illustrated in Figure 6 . This rock has different expansion coefficients in dry and wet conditions. At a given temperature, the difference between wet expansion and dry expansion is called isothermal expansion, which may be related to damage potential. The isothermal expansion close to the freezing point may simulate the freezing process. But more research is needed to prove this theory.

Dynamic Loading

Dynamic loading is a loading which varies in magnitude or in direction with time. A material, subjected to dynamic loading, will exhibit the phenomenon of fatigue. The severity of fatigue depends on the nature of the material, the range of loading, and frequency of change. The responses of a material to fatigue include formation of microcracks, reduction of strength, and a increase of creep rate in a direction other than the alternate loading direction. The true mechanism of fatigue is not well understood on a micro scale. Hypothetically, the atoms (or particles) of the substance tend to relocate their positions along the loading direction to reach the minimal level of 


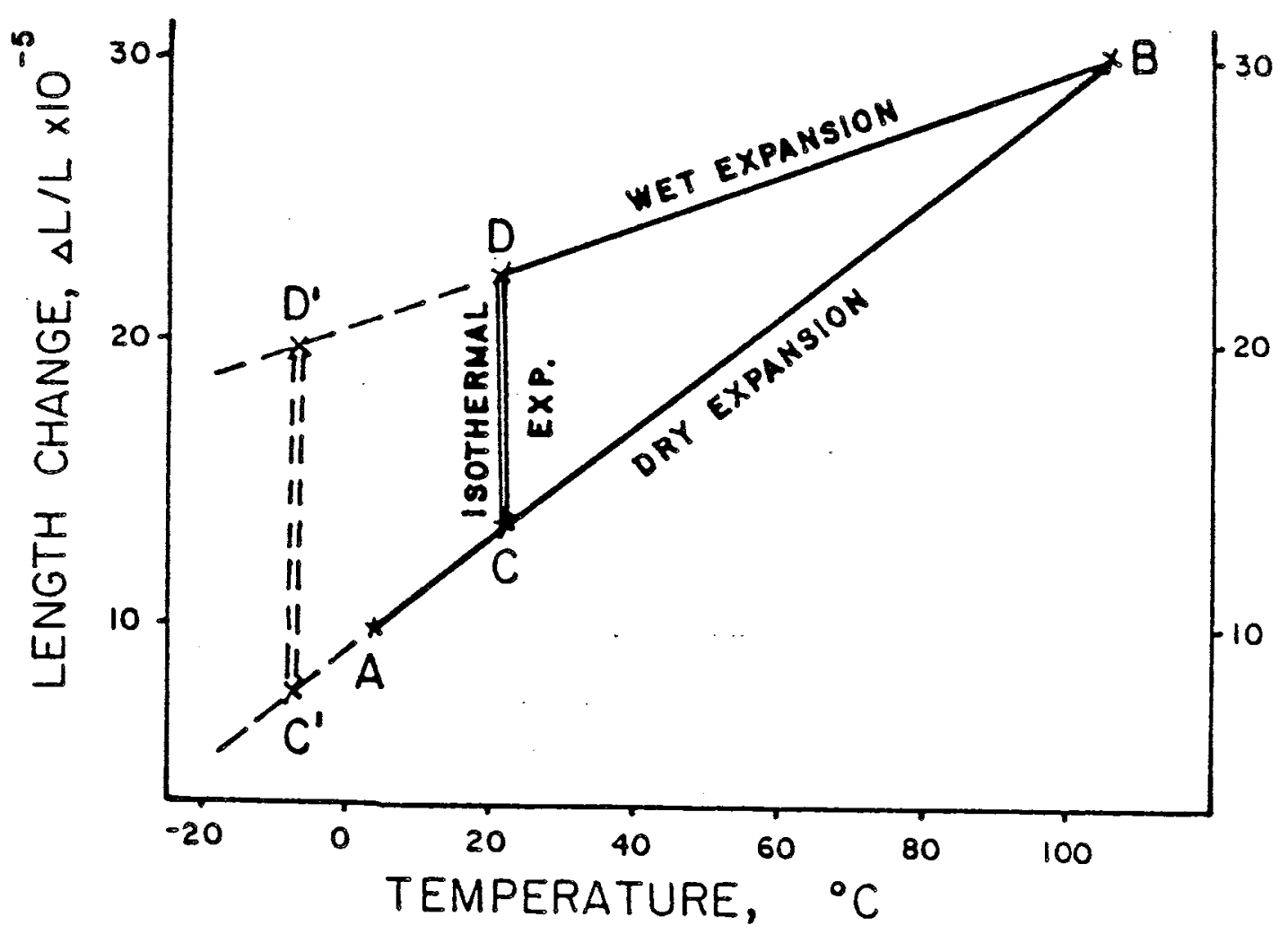

Figure 6 Expansion-Contraction of Sorption-Sensitive Carbonate under Variable conditions of Saturation and Temperature. (from Hudec, [26]) 
total energy (strain : energy minus external work). When subjected to dynamic loading, the substance never reaches the most stable state but may experience unbalanced energy shock due to alternate change of stress transfer in directions, thus causing deterioration.

Dynamic loading covers most forces. Natural forces include wave action, wind action, precipitation, earthquake, and climatic change (such as the aforementioned mechanisms (1), (2), and (3)). Man-made forces consist of traffic action, machine vibration, and even foot abrasion (on the ground). No substance can forever sustain its state without change in the changeable environment. Thus once again, the significance of durability is emphasized.

\section{Chemical Weathering}

In general, chemical reactions, including oxidation and reduction, take place at any time, moving materials into more stable states with a lower energy level. Here, the emphasis is on chemical weathering only which may change a material into a less favorable state. Chemical weathering is also called decomposition, a means by which the composition of the original material changes and secondary minerals or products are created (Her, [15]).

Water is not only the most important medium through which substances can easily react with each other in ionic 
or electrolytic states, but also is one of the most important agents whose dipolar nature attracts surface ions from the solid (i.e., dissolution process). Other agents include acids (from the atmosphere, plant, or industrial sources), and heat (high temperature or radiation).

Chemical weathering can proceed in the following ways.

(1) oxidation. A substance reacts with oxygen in the air or water to form a oxide. For example, $\mathrm{Fe}$ can be oxidized to be Feo, and further to be $\mathrm{Fe}_{2} \mathrm{O}_{3}$ (rust). Oxidation of metals is termed corrosion, which will be discussed later. sulphide can be oxidized to sulphuric acid, which is very aggressive to most substances. Plastic materials can be oxidized when exposed to a high intensity of ultraviolet radiation.

(2) Hydrolysis. Water molecules combine with the structure of a mineral and their hydrogen ions replace the original metal ions which subsequently dissolve in the water (ion exchange). For example, potassium feldspar will become kaolinite through hydrolysis. Acid will enhance the speed of such weathering.

(3) Carbonation. This is a special kind of acidic action. The agent is $\mathrm{H}_{2} \mathrm{CO}_{3}$. If dissolved in water, it will be decomposed into $\mathrm{H}^{+}$and $\mathrm{HCO}_{3}{ }^{-}$, both being very aggressive to many materials, especially carbonate rocks and metals. Karst topography is good example of the result of carbonation of limestones. 
(4) Hydration. Water molecules are absorbed into the mineral structure, but do not become a permanent component of the mineral. Such added water can be expelled by heating. Most clay minerals have a high potential for hydration, especially the swelling clays. The swelled structure caused by hydration may be so soft as to have a very low strength. Hudec [24] stated that clay content may be a useful indicator of the durability of carbonate rocks.

In conclusion, chemical weathering deteriorates a material by changing its composition into a weaker one through oxidation, ion exchange and hydration, and by dissolving its component(s) through hydrolysis and carbonation. In conditions of high temperature, high moisture, high acidity, and high specific surface of a material, chemical weathering speed is increased.

\section{Maintenance}

Adequate maintenance during its service life will definitely lengthen the life expectancy of a material, i.e. enhance its durability. Therefore, when "durability" or "life expectancy" is defined, the program and interval of maintenance should be specified. For this reason, maintenance is regarded as the fifth element of durability.

There are two kinds of maintenance to be considered. one is to improve the resistance of a material to 
environmental agents or replace its impaired parts by new ones. Pavement rehabilitation is one good example. Another is to isolate the attack of or reduce the intensity of environmental agents. For example, seamless paintings or coatings can provide a protective layer for metal against outer corrosion attack. Therefore, maintenance considers a combination of two elements, the material itself and environmental agents. Maintenance shifts their interactions (deterioration) toward the favorable side.

To make maintenance efficient, the deterioration mechanisms in any specified environment must be thoroughly understood. For example, fungal decay of an organic material only occurs when there are: spores, oxygen, suitable temperature and moisture conditions, and the organic matter has not been treated with a fungicidal substance (Garden, [27]). If any one of these five factors is appropriately controlled, rot will not occur. Another example is isolating concrete members from an outer moist atmosphere with polyvinyl chloride (PVC) to prevent freeze-thaw damage.

on the other hand, any level of maintenance adds cost. Accordingly, to retain the required performance over a design life, which is longer than the life expectancy of the material, the required maintenance cost becomes another economic indicator of durability. Lounela and Patrikka [28] prepared a summary of the recommended maintenance intervals 
of sélected paintings and coverings as shown in Table 4 (as cited in Pihlajavaara (9]).

However, to give an equal basis for comparison, it is suggested that first no maintenance be considered. In this case, the life expectancy represents the true durability of a material in one certain environment, irrespective of its price and maintenance cost. Based on life expectancy, material price, and the required performance, the most suitable (or economic) material will be chosen. In contrast, if design life is the preferred criterion, the best material will be selected on the basis of the combined expense of material cost and its maintenance cost over the design life. Here, maintenance cost includes not only the expense of maintenance itself but also of user loss during maintenance.

\section{Meaningful Durability Tests}

As emphasized earlier, durability is, technically and economically, one of the major considerations in selecting construction materials. Through the understanding of deterioration mechanisms and the related elements of durability, meaningful and rational tests can be developed. These determine the durability or more desirably, the quantitative term, life expectancy. However, this is not simple. 


\section{Table 4 Recommended Intervals of Selected Paintings and coverings (in years). (from Lounela and Patrikka, [28])}

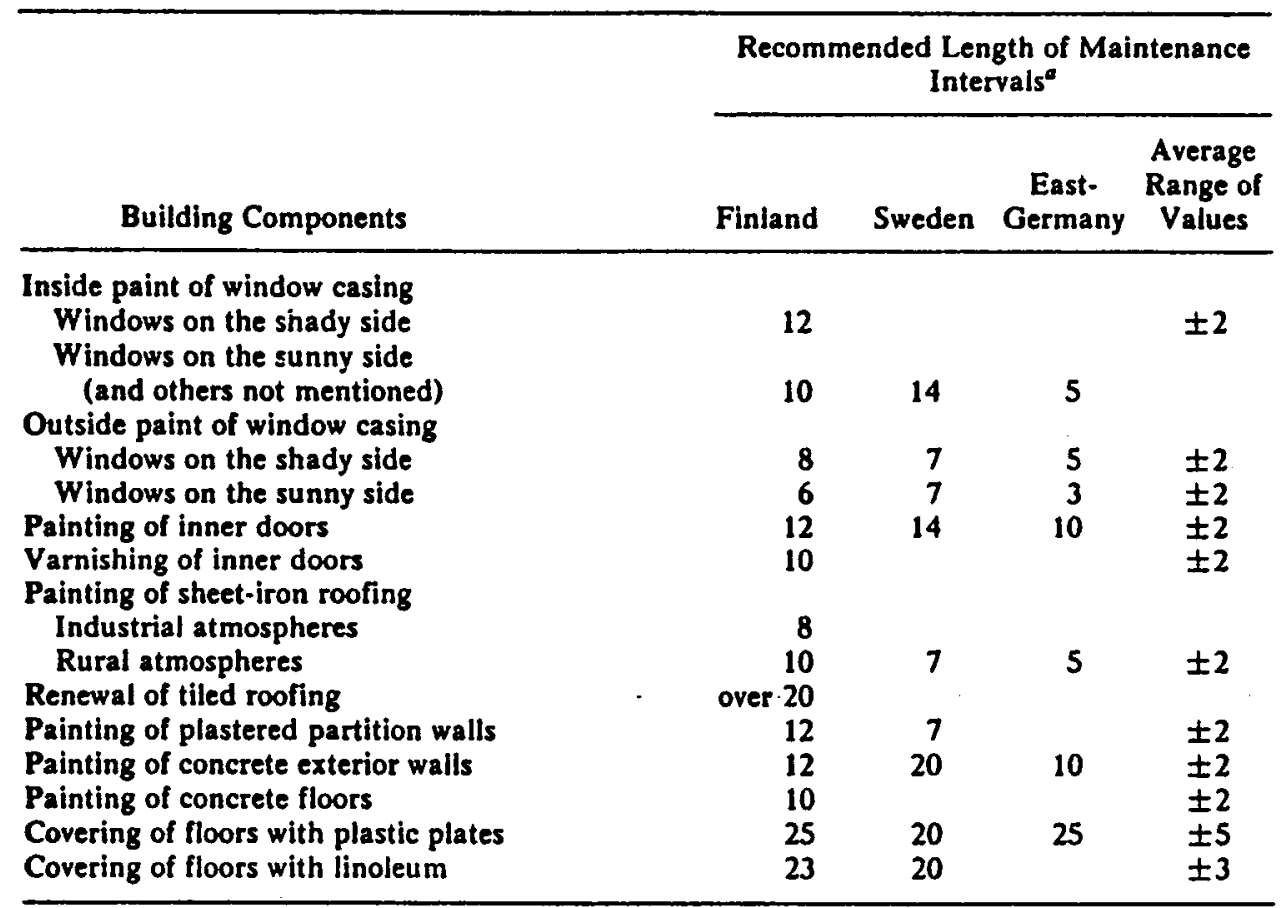

- The intervals can be rounded to a six-year period when several phases of work are carried out simultaneously. 
Durability testing is not new. As mentioned before, testing of building material for durability was certainly carried out as early as Roman times. (Roman architect Marcus Vitruvius Pollio described a two-year weathering test of building stone in about 25 B.C.) (Pihlajavaara, [9]). It is logical to assume that some testing procedures must have been used earlier than Pollio's time.

A number of durability tests have been developed as the importance of predicting durability has increased. Unfortunately, the state of durability evaluation is still incomplete, as was pointed out by Masters et al. [29]. Frohnsdorff and Masters [8] indicated that although many durability tests are described in standards and specifications for building materials, there is seldom any satisfactory way of correlating them, with each other or with in-service performance. Keyer [12] described the unsatisfactory correlations between several commonly used durability tests. Examples include comparisons among the magnesium sulfate test, the absorption test, and the petrographic number (for aggregates), as well as between the sodium sulfate test and the magnesium sulfate test.

Among the common shortcomings of standard durability tests are the following (Frohnsdorff and Masters [8]): (a) methods are usually not provided for correlating laboratory tests with field performance; (b) provisions are usually not 
made for taking into account different applications; and (c) recommendations are seldom made as to how the results of standard tests for different materials should be compared with each other. This writer suggests three additional limitations: (d) laboratory tests yield only the results of "relative" durability among different materials, but do not evaluate life expectancy; (e) laboratory accelerated tests may distort the actual deterioration mechanisms in the field; and (f) the aging indicator(s) most related to in-service performance may not be used in laboratory tests. One example of laboratory distortion of in-situ phenomena is the use of extreme conditions, such as subjecting the material to a temperature higher than its critical temperature, leading to results different from field tests.

Confidence in the performance of traditional materials in the normal range of environments can be based on past experience, but it is difficult to establish the same confidence in the performance of innovative materials (bottom ash is one example), or of traditional materials in environments outside the normal range of experience (e.g, solar and nuclear energy applications). Additionally, unless methods can be established for providing the confidence at an acceptable cost, a severe barrier to innovation will continue to exist.

All the above facts reinforce the need for development 
of a systematic approach for evaluation of durability performance. Subcommittee E6.22 on Durability Performance of Building Constructions of ASTM Committee E6 has developed the ASTM Recommended Practice for Developing short-Term Accelerated Tests for Prediction of the Service Life of Building components and Materials (E 632). This practice emphasizes the necessity of knowing as much as is practical about the nature of the item, the condition to which it will be exposed in service, and the degradative processes which can occur within it, in order to make a prediction. Figure 7 summarizes the flow chart of this practice. Frohnsdorff and Masters [8] (also, Frohnsdorff et al. [30]) described the corresponding steps in detail. Because of their great value, these descriptions are adapted as follows.

For convenience, the practice is divided into four parts: (1) Problem Definition, (2) Pre-Testing, (3) Testing, and (4) Interpretation and Reporting of Data. In Part 1, referring to the numbered boxes in Figure 7 , step 1 is to define the performance requirements to be met by the material or component in service, and the quantitative criteria it must meet if it is to perform satisfactorily. These criteria provide an objective basis for recognizing when failure has occurred. It should be noted that the criteria for failure of a given material or component may be different in different applications. 


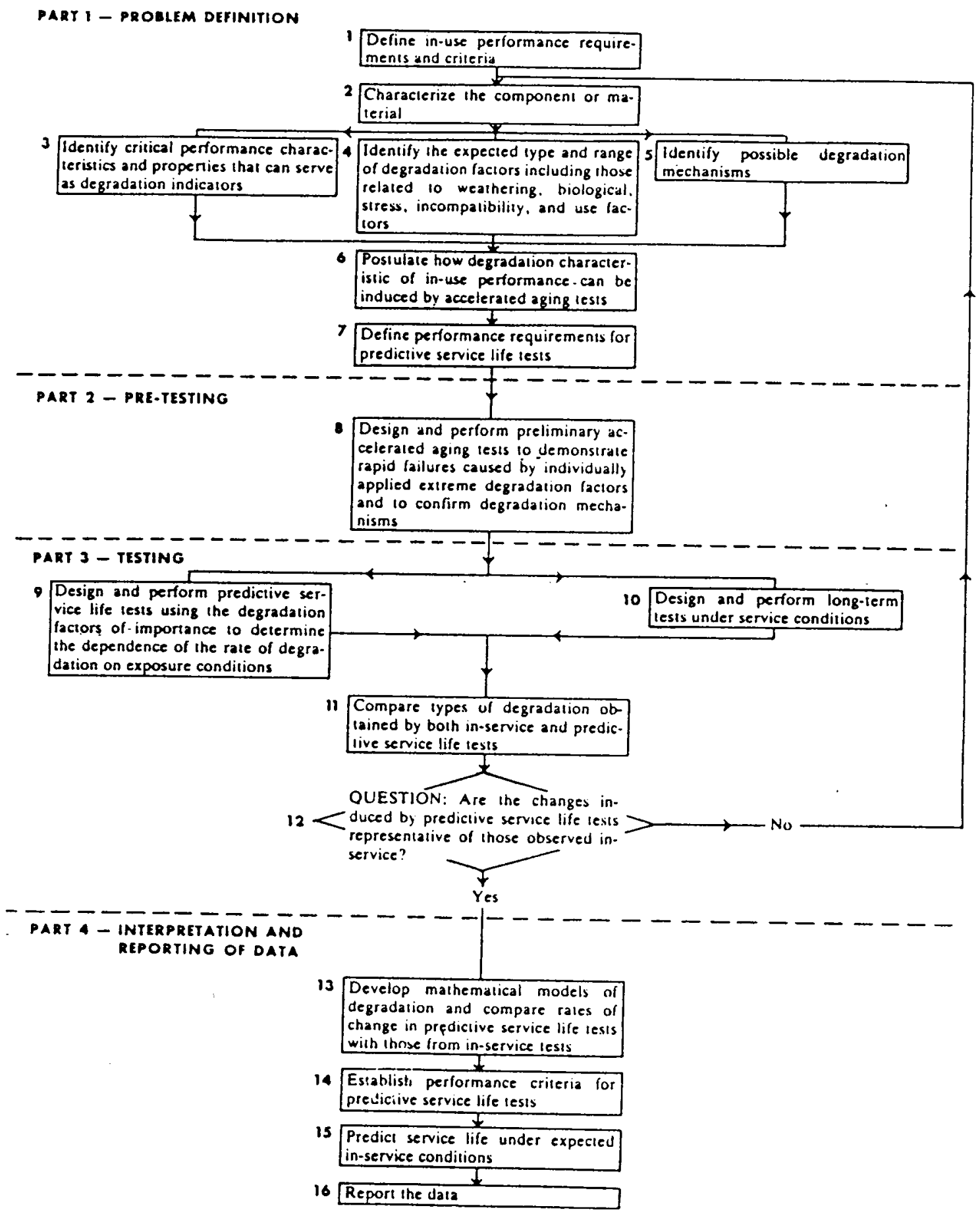

Figure 7 steps in a Meaningful Durability Test to Predict Service Life. (from Frohnsdorff and Masters, [8]) 
Next, in step 2, if the material or component is not homogeneous, it should be characterized as thoroughly as possible in terms of the individual materials and the interfaces between the individual materials. This information is important for gaining insights into the possible degradation mechanisms, so that the most appropriate tests can be sought. It is essential to note that, because of synergistic effects, composites can have durability and properties far different from those of the constituents.

In step 3, critical performance characteristics which must not be allowed to fall below the criteria, for reason such as safety are identified, together with properties that can conveniently be used as indicators of degradation.

In step 4, the expected range of degradation factors including weathering, biological, stress, incompatibility, and use factors should be identified to help define the conditions to which the material or component is likely to be exposed in service. Synergistic effects between environmental agents also must be considered. At the same time, step 5, the possible degradation mechanisms can be identified.

With this knowledge it may be postulated (step 6) how degradation characteristics of in-service performance can be induced by the accelerated aging procedures; also, the 
performance requirements to be met by predictive service Iife tests can be stated (step 7). It must be recognized that much of the knowledge desired may not always be available. In such cases, assumptions based on the best available experience should be made and recorded.

When Part 1 is completed, Part 2, Pre-Testing, can be initiated. This is step 8 in Fig 7. Its purpose is to demonstrate that rapid failures by the degradation mechanisms postulated in part 1 can be caused by individually applied degradation factors of enhanced intensity. This provides background for Part 3 which begins with the establishment of more realistic accelerated tests (Step 9) to provide kinetic data which ultimately will be used for predicting the service life. The accelerated tests should then be carried out using different levels of the important degradation factors.

At the same time (step 10), long-term tests under service conditions should be initiated so that, in case it can be accomplished in the time available for the test program, the consistency of the results of the short-term accelerated tests and the long-term tests can be established (Step 11 and 12). This is to minimize the possibility that the mechanisms of degradation in short- and long-term tests will be different. If they appear to be different, the short-term test conditions could be 
reviewed to decide whether they are too severe and are causing degradation by the wrong mechanisms, or whether they are omitting an important degradation factor.

If the results of the short-term accelerated tests and the long-term tests are consistent with each other, Part 4, Interpretation and Reporting of Data, can be undertaken. This includes use of experimental data to predict the course of degradation under expected service conditions (step 13), and to predict the actual time at which failure, as defined by the performance criteria, will occur (step 14 and 15). The performance criteria for failure in the predictive service life tests may differ from those of the in-service tests, because of different specimen configurations and nonlinearity of response to degradation factors. The practice concludes with the reporting of data (step 16) in which, it must be emphasized, all assumptions made should be stated explicitly so that others who wish to understand the logic and check the conclusions can do so.

Frohnsdorff and Masters [8] qualified the features of this ASTM recommended practice as follows: (a) although it is desired to have complete data on the material or component, the conditions to which it is to be exposed and the degradation mechanisms, assumptions about any of these will often have to be made to keep within the constraints 
imposed by time and funding; (b) the predicted service life of a material or component will depend upon the range and intensity of the degradation factors used in testing and the severity of the failure criteria; and (c) the possible sources of error in the predictions should be identified and an attempt made to assess the magnitudes of the possible errors.

In addition, they presented a list of degradation factors (as shown earlier in Table 3) and that of degradation indicators. With some additions by this writer, the possible aging (degradation) indicators, either visual or measurable, are listed in Table 5. To illustrate the application of this ASTM recommended practice, Frohnsdorff and Masters gave two examples in the latter part of their paper [8].

(Note : In the above cited paragraphs, applications, degradation, degradation mechanism, indicator of degradation, degradation factors, and predictive service life are equivalent to functional use, deterioration, deterioration mechanism, aging indicator, environmental agents, and life expectancy, respectively, as suggested by this writer.)

with respect to the above, this writer would like emphasize that: (a) the in-service environment, either known or predicted, dominates the deterioration mechanisms and 
Table 5 List of Aging Indicators and Measures. (after Frohnsdorff and Masters, [8])

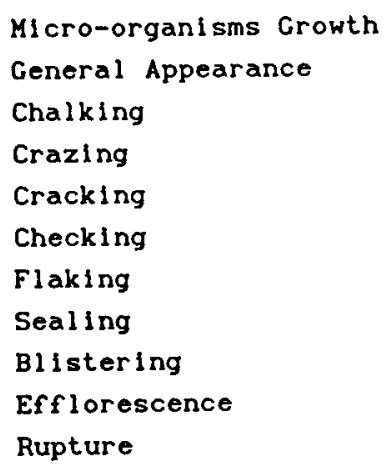


selection of the short-term accelerated tests; (b) the functional use and the material type govern the performance characteristics and selection of aging indicators; (c) to shorten the test time, the accelerated tests should not be performed with so high an intensity of environmental agents that the actual in-service deterioration mechanisms are distorted; (d) only the consistency of the results of the long-term field tests and the short-term accelerated tests guarantees the reliability of prediction of in-service life expectancy of a material; (e) the errors of prediction of durability will be minimized if and only if all elements of durability are well-defined and properly specified; and (f) for convenience of operation; the effects of maintenance in actual service does not have to be included in the short-term accelerated test.

Before discussing the validity of the short-term accelerated tests, the word "accelerated" must be understood. Laboratory tests can be called controlled tests, because all conditions in the laboratory are controlled as the investigator desires. If the intensity of laboratory-controlled environmental agents is enhanced, the exposed material will deteriorate much more quickly than that subjected to the actual in-service environment. Therefore, "accelerated" means that using a higher intensity of agents accelerates the deterioration process. 
Furthermore, Nireki [31] defined Acceleration Factor $\left(\mathrm{F}_{\mathrm{acc}}\right)$ in two ways: (1) a ratio of physical value of irradiated energy between the actual environment and the given condition in the laboratory; and (2) a ratio of certain periods that yields the "same" level of deterioration in the actual environment and in the laboratory test on the basis of certain performance. criteria, such as color difference, strength, and others (i.e., aging indicators). Due to the complicated types of energy involved in deterioration, the latter definition is more applicable for practice, and is used in the following.

Recall in Figure 2 that the deterioration characteristic curve reflects the nature of deterioration mechanisms corresponding to a certain environment. If the short-term accelerated test with a higher intensity of agents does not distort the actual deterioration mechanisms in service, the characteristic curves of both the short-term accelerated test and the long-term field test will have the same shape (after normalization of the time factor). This is true no matter what aging indicator is used, as shown in Figure 8.

In this case, the ratio of $t_{A P}$ to $t_{L P}$ for $i_{P}$ should be the same as that of $t_{A Q}$ to $t_{L Q}$ for $i_{Q}$ (see Figure $8 ; i_{P}$ and $i_{Q}$ are arbitrary but different from each other). This ratio is the Acceleration (Time) Factor, $\mathrm{F}_{\mathrm{acc}}$, as introduced 
(a) Laboratory accelerated test

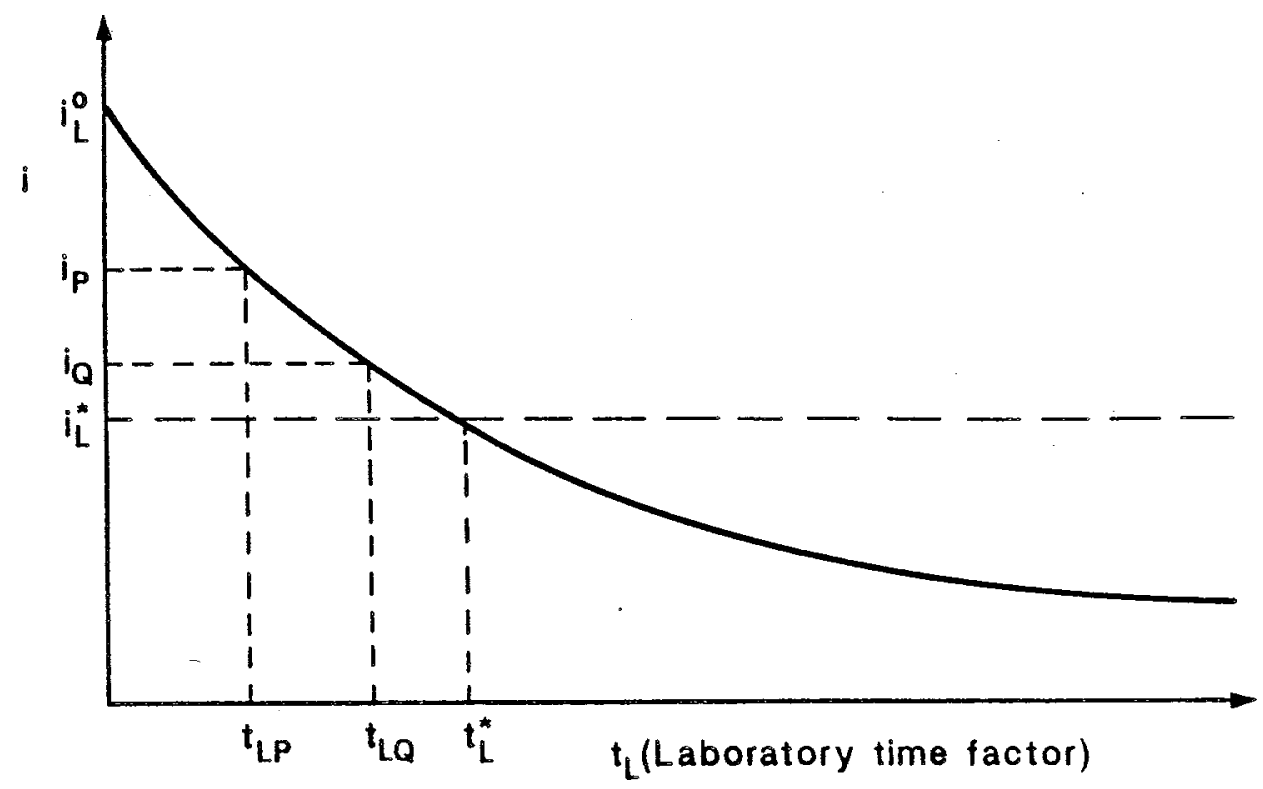

(b) Long-Time field test

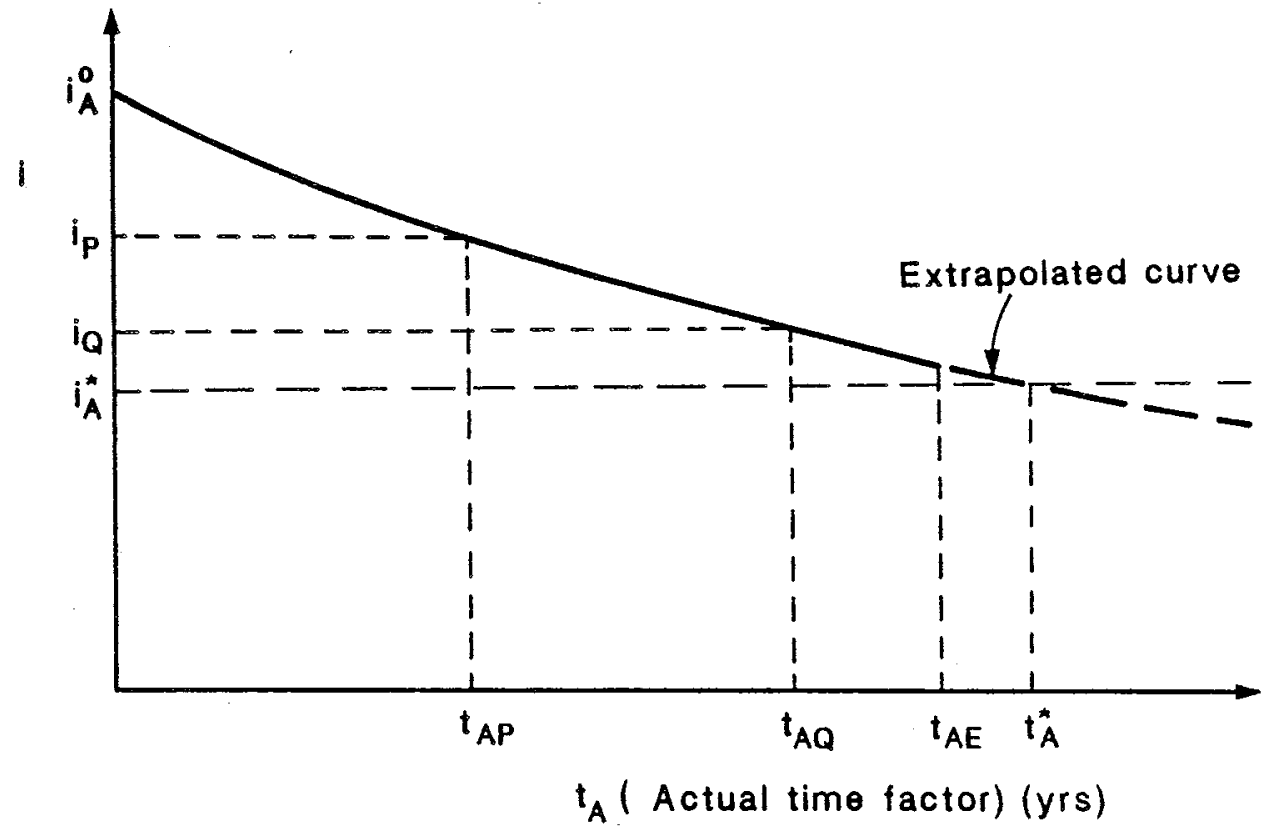

Figure 8 Characteristics Curves of Laboratory Accelerated Test and Long-Term Field Test 
above. (Note: In general, the allowable values of the aging indicator equivalent to the minimum requirement of performance for the short-term accelerated test and the in-service condition are the same, $i . e ., i_{L}^{*}=i_{A}^{*}$; so are the initial values of aging indicators, $i_{. e}, i_{L}^{0}=i_{A}^{0} \cdot$ )

The long-term field test seldom continues to be performed until failure, especially for innovative materials (It is not possible to wait long enough to get the final results and then use them). The field test may be stopped in $T_{A E}$ years (see Figure 8 (b)). Assume that the characteristic curve of the field test after $T_{A E}$ has the same shape as that of the short-term accelerated test, as shown by the dashed line of Figure 8 (b). Accordingly, the actual life expectancy in service, $t_{A}^{*}$, will be obtained by the product of $F_{a c c}$ and $t_{L}^{*}$, the service life in the laboratory. However, if time and funding are available, the field test should be continued to verify the above assumption.

other performance observations of the same material in a similar environment are also helpful. It should be noted that the Acceleration Factor $\left(F_{a c c}\right)$ is a function of environment (in-service and laboratory) and material type, but independent of $i_{L}^{*}$ or $i_{A}^{*}$ (however, the $t_{L}^{*}$ and $t_{A}^{*}$ depend upon these two values). When the same material is exposed to another environment, it is certain that different values of $F_{\text {acc }}$ will be obtained. 
It is of interest to determine how to apply the $F$ acc obtained to a similar type of materials for the same functional use in the same environment, using the same short-term accelerated test. Referring to the section "Definition", page 15, durability is expressed as life expectancy. Being "durable" is interpreted as one material sustaining a required performance during its design life under a specified condition (environment and maintenance). Frohnsdorff and Masters [8] tried to distinguish between these two, and termed the condition of durability as "being reliable". Consequently, reliability is concerned with the probability of successful performance for the design life, while durability is concerned with probable life in the design use. To compare the durability of an innovative material with a material of similar functional use in the same environment, multiply $F_{a c c}$ by the value of $t_{A}^{*}$ obtained by performing the same short-term accelerated test. On the other hand, to examine its reliability within the design life $\left(t_{A D}\right)$ in the same environment, the corresponding laboratory design life $\left(t_{L_{D}}\right)$ can be calculated by dividing $t_{A D}$ by $F_{a c c}$. Next, the same short-term accelerated test is performed and the characteristic curve is plotted. The material is said to be reliable (or durable) if and only if the value of $i_{L}$ at $t_{L D}$ is greater than $i_{L}^{*}$; and vice versa.

The concepts of meaningful durability tests have been presented by many investigators. For example, Keyer [12] 
suggested a "system approach" to solve complicated durability problems, one part of which is the need of meaningful durability tests. Farhi [10] presented the methodologies for assessing durability of new materials and components in building, which mainly includes selection of a significant aging indicator (as a function of use), plotting of the characteristic curve, and correlation between a laboratory time factor and the actual time factor (i.e., the Acceleration Factor, $F_{\text {acc }}$ ).

Test Methods to be Used

The material of interest in this research is bottom ash, an innovative material whose properties are still not well known. It is a collection of synthetic, discretized, and more or less coarse particles. The service environment is one of a cold latitude, where frost action prevails in the winter. Therefore the freeze and thaw process is the main environmental agent. The possible functional uses (applications) of bottom ash are for embankment, subgrade, and subbase materials. The significant aging factors may be shear strength ( $\phi$ and c), compression modulus, California Bearing Ratio, resisting modulus, and permeability.

It is practically impossible to follow the aforementioned general approach as outlined in ASTM E632 in this research due to limited time and funding. A search has 
been conducted to identify a simple, rapid, inexpensive, and more or less reliable existing durability test. Some durability tests assess the durability of a material merely by its natural properties at the initial stage (as-received). For example, the petrographic number, water absorption (at different relative humidities), thermal expansion (in wet or dry conditions), mineralogy (Hudec, [26]), the crushing index, and other as-received strength parameters have been used. However, their reliability is doubtful and their correlation with the actual durability is approximate or unknown, particularly in different environments. There is no trade-off between simplicity and precision. Likewise, most simple and rapid tests can not yield reliable and practical results. Other tests such as Los Angeles Abrasion test, do not impose the same deterioration mechanism as does freeze-thaw. ASTM includes two standard test methods involving the freeze-thaw action: (1) ASTM C-666, Rapid Freeze-Thaw Test, and (2) ASTM C-671, Critical Dilation Test. However, these two tests are useful only for concrete or cement and paste solids, not for discretized particles such as bottom ash.

The only standard test for discretized particles emulating cyclic changes of freeze-thaw is the standard Method of Test for Soundness of Aggregates by Freezing and Thawing given by AASHTO T103 [31]. It contains three operational procedures, each corresponding to different 
conditions: total immersion of water, partial immersion of water, and partial immersion in an alcohol-water solution. The corresponding required numbers of freezing-thawing cycles are 50, 16, and 25, respectively. The freezing period is around two hours and the thawing period is a half hour.

The aging indicator is the weighted loss of sample after the specified number of freeze-thaw cycles. The weighted loss is defined as the sum of the product of the fraction of each given size range and its corresponding weighted loss after test. The particles finer than $0.3 \mathrm{~mm}$ (opening size of No.50 sieve) are assumed to have a 0 percent loss. The scope of this test states that the results of this method are considered more reliable for determining the quality of aggregates than those obtained by other methods of soundness tests on discrete particles of aggregates.

The followings are the personal views of this writer on the above AASHTO test:

(1) This test uses the size reduction of the particles weighted loss, as a aging measure. The larger the weighted loss the larger the loss of strength, modulus, and permeability. However, what is the true relationship between them? Is it linear or nonlinear? The author questions how the performance criteria based on weighted Ioss were established. 
(2) The measurement method (mechanical sieving) of weighted loss is somewhat destructive. Therefore, if the whole characteristic curve is needed (to find the life expectancy of a material), a number of "identical" samples should be prepared, each being tested for a different number of cycles. It is a cumbersome task. Therefore, as the AASHTO test suggests, only the number of cycles equivalent to the design life in one environment of interest is chosen. However, the corresponding design life for the three procedures are not provided. Even if the performance criteria are established, the "design life" within which the material can perform satisfactorily is not known.

(3) Based on knowledge of the freezing mechanism, the freezing rate indeed affects the deterioration severity. In addition to a suggested freezing period and thawing period, the AASHTO test should limit the minimum freezing temperature $\left(\mathrm{T}_{\mathrm{min}}\right) \cdot \mathrm{T}_{\mathrm{min}}$ divided by two hours is approximately the freezing rate.

(4) Based on knowledge of the freezing mechanism, the smaller the particle (porous solid) the less the induced damage. Therefore, it is reasonable to neglect the weighted loss of the finer fraction. However, why is the threshold size of $0.3 \mathrm{~mm}$ chosen, and what should be done when the fine fraction is large?

(5) The diffusion path for a small scale sample in the 
laboratory is much different from that in the field. The rate of energy transfer is also quite different.

(6) Small scale laboratory samples do not take into account the effect of the field overburden pressure coupled with frost action.

Another standard test "simulating" the freezing and thawing process is the standard Test Method for "Soundness of Aggregates by Use of Sodium Sulfate or Magnesium Sulfate" given by ASTM C88 [32] (or AASHTO T104 [33]). The sieved sample is totally immersed in a saturated solution of sodium sulfate $\left(\mathrm{Na}_{2} \mathrm{SO}_{4}\right)$ or magnesium sulfate $\left(\mathrm{MgSO}_{4}\right)$ for $16-18$ hours. Subsequently, after free drainage for about $15 \mathrm{~min}$, the sample is placed in a $110^{\circ} \mathrm{C}$ oven for the time required to attain a constant weight of sample. The drying process dehydrates the salt $\left(\mathrm{Na}_{2} \mathrm{SO}_{4}\right.$ or $\left.\mathrm{MgSO}_{4}\right)$ precipitated in the intra-aggregate pores or cracks. Upon re-immersion, the internal expanding force derived from the rehydration of the salt simulates the hydraulic pressure of water on freezing. The weighted loss is selected to be the measure of performance in this case also. The particles finer than 0.3 $\mathrm{mm}$ (opening size of No.50 sieve) are also assumed to have $0 \%$ loss.

The same criticism applies to this test as the AASHTO test. Additionally, this writer feels concerned about the following. 
(7) After drying, only intra-aggregate pores are fully filled with salt precipitation. Therefore, the expansion force derived from salt rehydration is mostiy applied to the intra-aggregate pore walls and not to those of the inter-aggregate pore. It is also unknown what degree of saturation of water in service is simulated by this test. The concept of diffusion path is changed.

(8) The rise of temperature $\left(0\right.$ to $\left.110^{\circ} \mathrm{C}\right)$ during drying is an additional agent which does not exist in the natural freeze and thaw environment.

(9) The expansion pressure of salt rehydration is different from that of ice formation. Not surprisingly, the damage caused by one cycle of the ASTM method is different from that of the AASHTO test. (Note : In general, (perhaps due to the larger ion radius of $\mathrm{Mg}^{2-}$ ) the expansion force of $\mathrm{MgSO}_{4}$ is larger than that of $\mathrm{Na}_{2} \mathrm{SO}_{4}$, thus causing a higher weighted loss, for the same material and the same conditions.)

Although there are many questions relating the interpretation of data to durability, the above two methods are selected because of their common usage, ease, and brevity (especially the ASTM method). The total immersion procedure of the AASHTO freezing and thawing test is chosen, to simulate the the most severe condition of frost action. The ASTM soundness test is performed by use of sodium sulfate, since $\mathrm{Na}_{2} \mathrm{SO}_{4}$ is more available and less expensive 
than $\mathrm{MgSO}_{4}$. Five testing cycles are used. The discussion of performance criteria and possible design life corresponding to the specified cycles is left to chapter VI.

Seals and et al. [6] performed the soundness test by use of sodium sulfate on bottom ashes produced from power plants within West Virginia. The value of weighted loss on wet bottom ashes was about 4 percent, while that on dry bottom ashes varied from 6 to 17 percent. This implies that wet bottom ash is more durable than dry bottom ash.

\section{Summary}

In design and construction,... durability has not been given the same attention as strength requirements. Failure due to lack of durability of materials was common in the past and has caused large financial losses. For the purpose of economy and efficient usage of materials, durability should be thoroughly understood, well expressed, and adequately considered in future construction.

In a precise sense, durability is defined as follows:

Durability of a material is its ability to maintain the designed functional use over its life expectancy in the predicted service environment with a specified maintenance.

This definition implies that durability includes five 
elements. Life expectancy is the quantitative expression of durability. Functional use defines which performance criteria are used to examine durability. The interactions between material nature and environmental agents govern the deterioration mechanism related to durability. Maintenance may affect such interactions to some extent.

In order to predict durability of a material with confidence, meaningful durability tests should be established. ASTM Committee E6 suggested a systematic approach to obtain life expectancy in a certain environment on the basis of correlation of laboratory accelerated tests and long-term field tests. Once the results of one material are obtained by use of this approach, it is possible to predict the durability of similar innovative materials in the same environment by use of the same laboratory accelerated test. Either life expectancy or durability (reliability) must be predicted over the service life of interest.

Frost action is prevalent in the northern U.S., including Indiana, where the freeze and thaw process may be the most dominant environmental agent. Because of the limited time and funding of this research, it is impossible to follow a general approach to determination of the durability of bottom ash exposed to the freezing-thawing environment. Instead, the freeze and thaw test based on 
AASHTO and the soundness test by use of sodium sulfate based on ASTM were chosen. By comparing test results and proper specifications, prediction about the durability of bottom ash over the design life are practicable.

\section{Corrosiveness}

The physical deterioration of metals is of no interest in this study and attention is directed only to chemical attacks (corrosion) of metals. Metals by naturally corrode with time because they have been deprived of their oxides (metal ores). The result is that they are in a less stable state than their naturally occurring form (Hanna, [34] and McMullen, [35]). Through the corrosion process metals gradually return to their most stable state in the form of oxides or cations, and simultaneously lose some favorable characters. This change can result in unsatisfactory performance or failure of a metal structure, both of these events being of economic concern. Unless appropriate action is taken to prevent corrosion, metals will usually react with oxygen and water in the environment, which may be represented as follows:

$$
\text { Metal }+\mathrm{O}_{2} \stackrel{\mathrm{H}_{2} \mathrm{O}}{\longrightarrow} \operatorname{Metal}(\mathrm{OH})_{x}
$$

This chemical reaction results in metal loss and the conversion of water and oxygen to $\mathrm{OH}^{-}$ions. The rate or the severity of corrosion depends on the nature of the metal and 
the type of the environment in which the metal is placed. .

Three types of environments are considered by corrosion engineers: atmospheric, aqueous, and underground environments, each including a special combination of media with different electrochemical properties (Tomashov, [36]). Atmospheric environment includes natural gases, water vapor, polluted air or dust issued by industries, and the interactions among them. Aqueous environments correspond to water containing all soluble substances (salts, ions, and dissolved gases), suspended particles, and undissolved air bubbles. The marine environment is one particular example of an aqueous environment, which is the most corrosive to metals due to its high salt content. The underground environment is the most complicated one, consisting of aqueous solution, air, solid media, and their interactions.

This research is focused on underground corrosion, in which bottom ashes represent the solid media. Although past studies on underground corrosion were concentrated on soils, such experience accumulated for soil corrosivity may be successfully applied to bottom ashes, which exhibit many properties similar to soil materials. subsequently, the corrosiveness of bottom ash to a certain type of metal can be evaluated so that engineers can overcome a previous deterrant to bottom ash utilization caused by lack of knowledge of its potential corrosivity. 
The following discussion sections will be written: Definition of Corrosion and Corrosiveness; Significance; Basic Corrosion Mechanism; Underground Corrosion; A Review of Test Methods; and Past Corrosion studies on Bottom Ash. summary is included as the last section.

$$
\text { Definition of corrosion and corrosiveness }
$$

The term "corrosion" should be restricted to chemical attacks on "metal", as stressed by Uhlig and Revie [38]. only metals corrode and therefore, it is not proper to apply "corrosion" as a chemical deterioration process for nonmetallic materials. Furthermore, the term "rusting" applies only to the corrosion of iron or iron-base alloys with formation of corrosion products consisting largely of hydrous ferrous oxides. Nonferrous metals, thereby "corrode" but do not "rust".

It is necessary to distinguish between corrosion and corrosiveness. As a rule of thumb, corrosion is related to metals; while corrosiveness is related to their exposed environments. Corrosion can be defined as the deterioration of a metal, usually caused by chemical or electrochemical reaction with the surrounding environment (McMullen, [35] and Uhlig and Revie [37]). It demonstrates the nature and the process of chemical deterioration of a metal exposed to a certain environment. Here, the substance that corrodes is 
metal. On the other hand, corrosiveness (also called corrosivity) can be defined as the extent and the severity of one environment causing corrosion of a metal which is placed in it. This means that the environment provides the external agents which result in corrosion of a metal. Corrosion depends primarily upon the interactions of the metal and the exposed environment.

Recall in the section on Durability that this writer has made an effort to give a precise and quantitative definition of durability. In fact, corrosion is one special kind of deterioration mechanism for metals. The durability of a metal with respect to corrosion can therefore be expressed as the "Iife expectancy", over which the metal maintains its designed functional use, under the exposure of one specified environment with a certain level of maintenance. This defined life expectancy could be the quantitative term evaluating the combined outcome of interactions between a metal and an environment, regardless of the corrosion resistance of the metal or the corrosivity of the environment. However, this concept has not received widespread attention in corrosion engineering.

Another advantage of using "life expectancy" for a metaliic structure is to avoid misunderstanding the corrosivity of its exposed environment. In general, corrosion engineers classify the corrosivity of the 
surrounding medium where a metal is placed, based merely on the metal loss rate. However, in actual cases, the corrosion rate of a metal exposed to one environment is not always constant and varies with time. Palmer [38] presented a typical exponential corrosion loss curve versus time for ferrous pipes, as shown in Figure 9. This figure suggests that corrosion on ferrous pipes occurs initially at a high rate and then continues with a decreasing rate. Romanoff [39] presented a power-law equation to describe the time-dependent corrosion as follows:

$$
x=k t^{n}
$$

where $\mathrm{x}$ is the weight loss of a metal or the penetration depth in time $t ; k$ is the site character; and $n$ also depends on the site and is always less than 1.0. Romanoff reported that values of $n$ for steels range from about 0.1 for $a$ well-aerated soils, to 0.9 for a poorly-aerated soils. The corrosion rate can be expressed as the first derivative of $X$ with respect to $t, i . e .:$

$$
\begin{aligned}
x^{\prime} & =n k t^{n-1} \\
& \text { or } n k \\
& =\frac{n k}{t^{1-n}} \quad(\text { since } n<1)
\end{aligned}
$$

where $x^{\prime}$, the corrosion rate, is also a function of $t$, and decreases with time, except for the special case of $n=1$.

Accordingly, when classifying corrosivity of an 


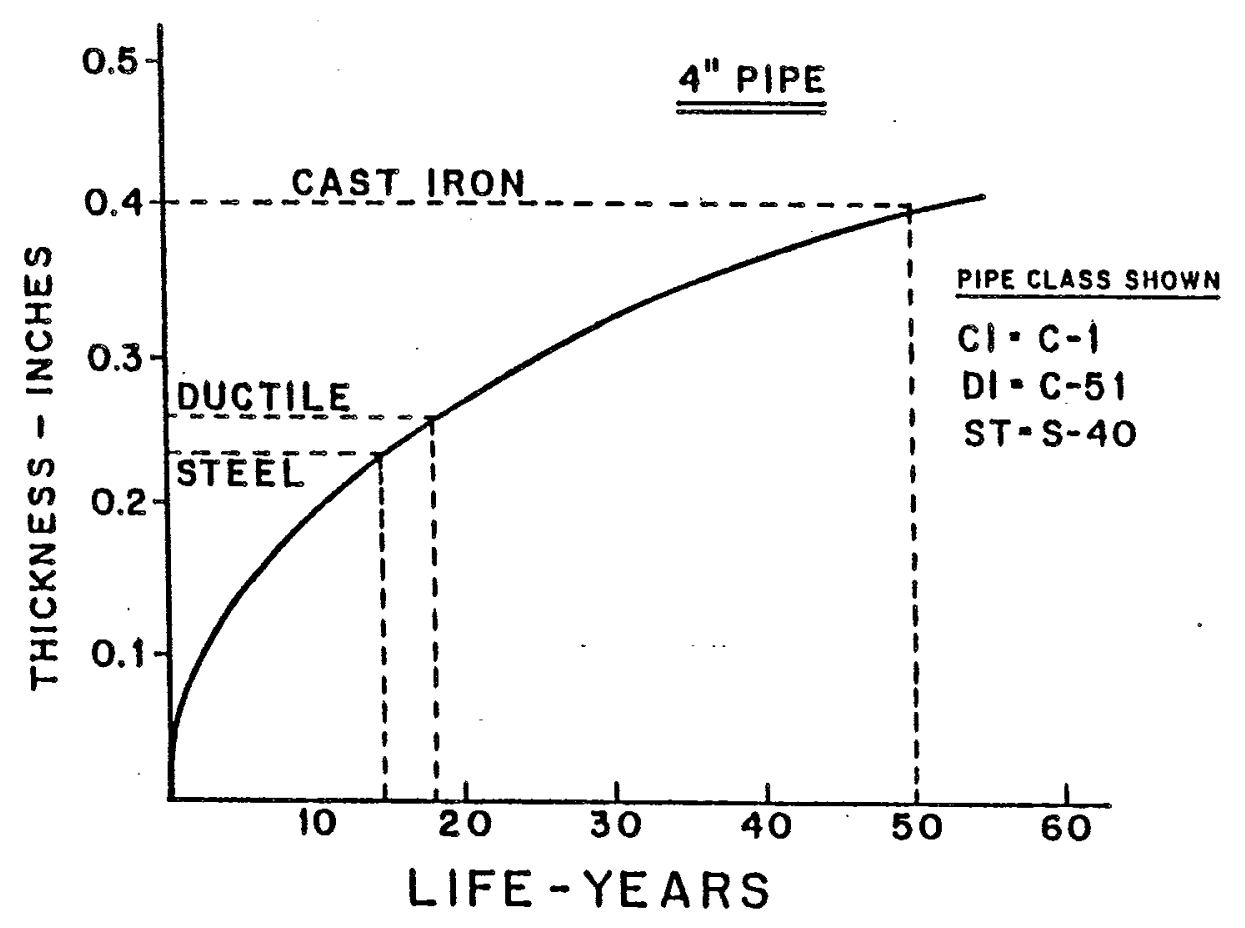

Figure 9 Typical Exponential Corrosion Curves for Ferrous Pipe.(from Palmer, [38]) 
environment using the corrosion rate, the question is how to select the needed corrosion rate which takes place at a certain time $t$. In most cases, corrosion engineers use the average corrosion rate over the first 5 or 10 years. Such a selection method is not fair in the case where the corrosion rate quickly decreases to be zero after 5- or 10-year exposure.

Consider an extreme case: medium $A$ is classified as corrosive due to the high 5-yr corrosion rate of a metal, but its corrosion rate after 5 year approaches zero; and medium $B$ with a constant corrosion rate of the same metal is classified as moderately corrosive. It is not surprising that the total weight loss of the metal in medium $B$ will exceed that in medium $A$ at some time ( $t$ ) greater than 5 years. It implies that the tested metal may fail earlier in medium $B$ than in medium $A$, even though by classification medium $A$ is more corrosive than medium $B$.

If life expectancy is used, the concept will become more clear. If the life expectancy obtained from the exposure test is larger than the given design life, then the exposed metal is said to have a good corrosion resistance or the environment (medium) is said to be non-corrosive. on the other hand, if the average corrosion rate over the first $t_{i}$ years is used to calculate the life expectancy, the same problem is encountered. Set $L_{i}$ to be the weight loss at time 
$t_{i}$ : If the allowable weight loss is larger than $L_{i}$ (i.e., the general case), a shorter life expectancy will be obtained; and vice versa (Figure 10).

The concept of replacing the classification of corrosivity by life expectancy, however, is very difficult to implement, because it is necessary to perform long-term burial tests to obtain the life expectancy. At present, no accelerated tests exist to predict the life expectancy.

\section{Significance}

In the corrosion process, a metal may gradually dissolve in the surrounding. electrolyte (in the form of cations) or produce corrosion products having a much inferior property, such as low density and low strength. In either case, a metal structure will lose its effective cross section to carry loads, resulting in higher stress or even failure. This is a direct economic loss.

Uhlig and Revie [37] described the significance of corrosion in three ways:

(1) Economic loss includes the metal losses resulting from the corrosion of piping, tanks, metal components of machines, ships, bridges, marine structures, and so on.

(2) Reduced safety for the operating equipment which, through corrosion, may fail with catastrophic consequences. Examples are pressure vessels, boilers, metallic containers 


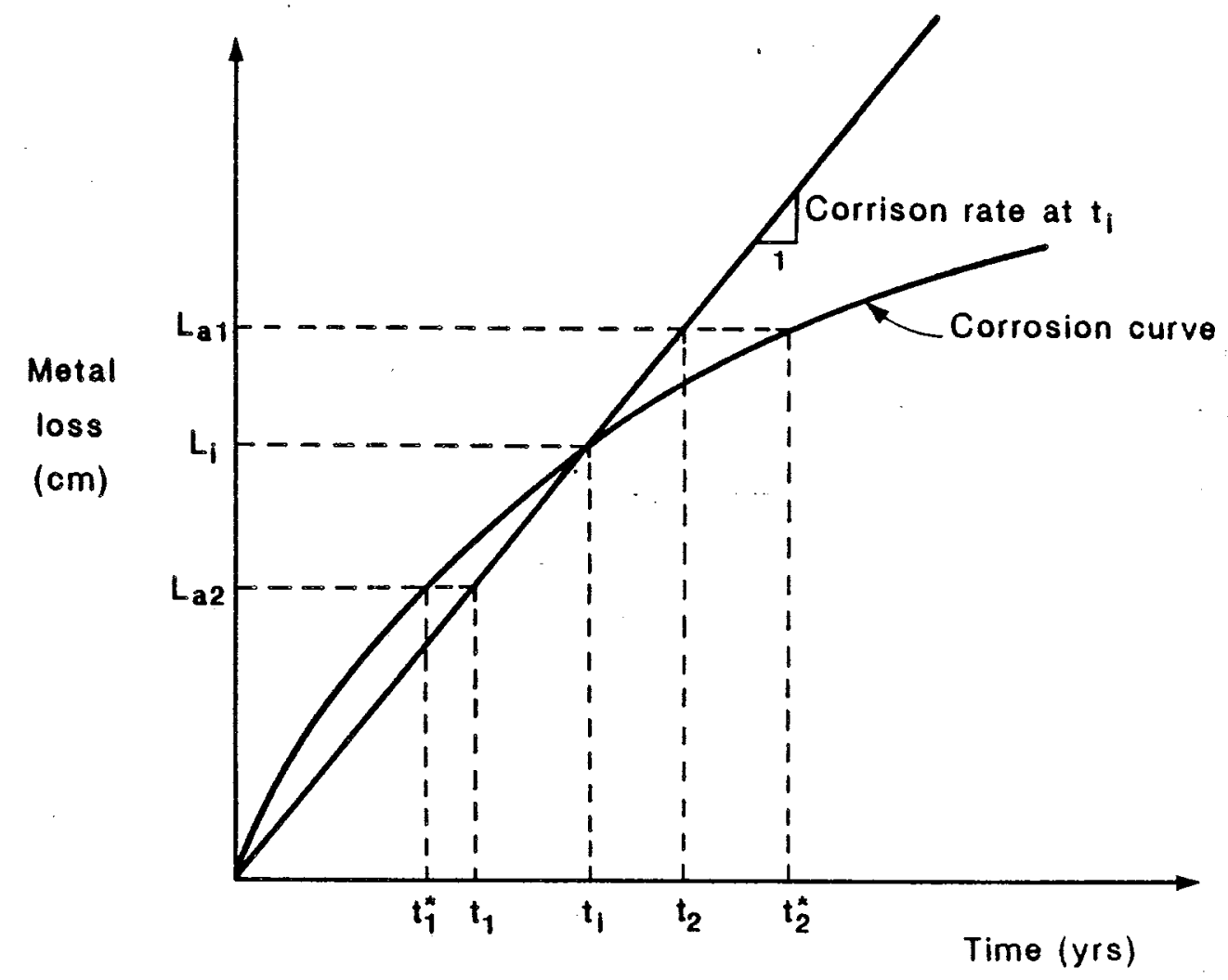

Figure 10 Difference between the Real Life Expectancy and that by a Constant Corrosion Rate 
for toxic materials, turbine blades and rotors, bridges, airplane components, and automotive steering mechanisms. Safety is a prime concern in the design of equipment for nuclear-power plants and for disposal of nuclear wastes.

(3) The loss of a valuable and irreplaceable natural resource is also important. The supply of these materials is limited, and the waste of them involves a corresponding loss of energy and water reserves associated with the production and fabrication of metal structural components. Also important is the accompanying conservation of human effort for the replacement of corroded metal elements.

The economic factor is the major motive for much of the current research on corrosion. Economic losses are divided into direct losses and indirect losses. Direct losses are the costs of replacing corroded structures and machinery or their components, and of repainting them or protecting them by cathodic protection techniques. Direct losses also include: the extra cost of using corrosion-resistant metals and alloys, instead of carbon steel; of galvanizing or nickel plating of steel; and of adding corrosion inhibitors to water or of dehumidifying storage rooms for metal equipment.

De-icing salt applications to roads and bridges have been estimated by one source to cause direct corrosion damage to motor vehicles in the order of $\$ 2$ billion 
annually, and to roads and bridges in the order of $\$ 0.5$ billion annually (slater, [40]). Cost of corrosion and its control paid by one pulp and paper company was estimated to be $\$ 20$ million annually. The total combined losses of this kind to the United states alone are estimated conservatively to be about $\$ 70$ billion annually, or $4.2 \%$ of the Gross National Product (GNP) (Bennett, [41]). It has been estimated that about $15 \%$ of this total could be avoided if currently available corrosion technology were effectively applied. In other developed countries such as Great Britain and Japan, the cost of corrosion is approximately $3-4 \%$ of the GNP.

Indirect losses are more difficult to assess, but a brief survey of typical losses of this kind concludes that they add several billion dollars to the direct losses already outlined. Examples of indirect losses are shutdown of equipment during repair, loss of product due to leakage of corroded containers, loss of operation efficiency on corroded equipment, contamination of products by adjacent materials, and overdesign of structure to compensate for corrosion loss. Other examples, such as loss of health or life by leaked toxic materials from corroded containers, by unpredictable failure of chemical equipment, and by wreckage of airplanes, trains, and automobiles through sudden failure due to corrosion of critical parts, are still more difficult to evaluate and are beyond interpretation in terms of 
dollars.

In conclusion, the combined total of direct losses and indirect losses associated with safety considerations demonstrates the severity and importance of the corrosion problem. To mitigate such corrosion loss, more research should be undertaken on the understanding of complicated corrosion mechanisms in different environments, and on the development of more effective protection techniques.

\section{Basic Corrosion Mechanism}

Corrosion of metals is electrochemical in character, a fact that allows scientists to examine the corrosion process by electrical means (Darbin et al, [42]; Uhlig and Revie, [37]; and Escalante, [43]). Furthermore, the corrosion process is very similar to the electrochemical action that takes place in an ordinary dry cell of a flashlight during use. This dry cell is also one kind of galvanic cell, which is a combination of two electrical conductors (electrodes) immersed in a electrolyte, converting chemical energy into electrical energy.

A galvanic cell must have three components for it to function (Escalante, [43]). These are: (1) an anode/cathode system; (2) an electrically conducting path between the anode and cathode; and (3) an electrolyte in contact with the anode/cathode. system. The cathode is the electrode at 
which chemical reduction occurs (or + current enters the electrode from electrolyte); while the anode is the electrode where chemical oxidation occurs (or + current leaves the electrode and enters the electrolyte). Later on, it will be shown that corrosion of metals usually occurs at the anode. In the dry cell illustrated in Figure 11, the zinc case and the carbon rod make up the anode/cathode system. The electrolyte (with a certain degree of conductivity) is the chemical medium, normally an aqueous gel (e.g., $\mathrm{NH}_{4} \mathrm{Cl}$ solution), between the zinc case and the carbon rod. The conducting path between the anode and the cathode is provided externally by the flashlight body which passes the current through the bulb for illumination.

In this type of dry cell, the zinc case and the carbon rod are the anode and the cathode, respectively. When the system is completely connected, a potential difference occurs between two electrodes. Therefore, the zinc case goes into solution (dissolves) in the electrolyte and corrodes in the process of giving up electrons for production of electricity. As a result, a zinc atom is oxidized to a positive ion (cation). The electrons flow toward the cathode through the external conducting path, while the zinc cations either combine with some other species or diffuse through the electrolyte toward the cathode where they gain electrons and are reduced. Thus, the induced current is directly related to the dissociation of zinc, the corrosion process 


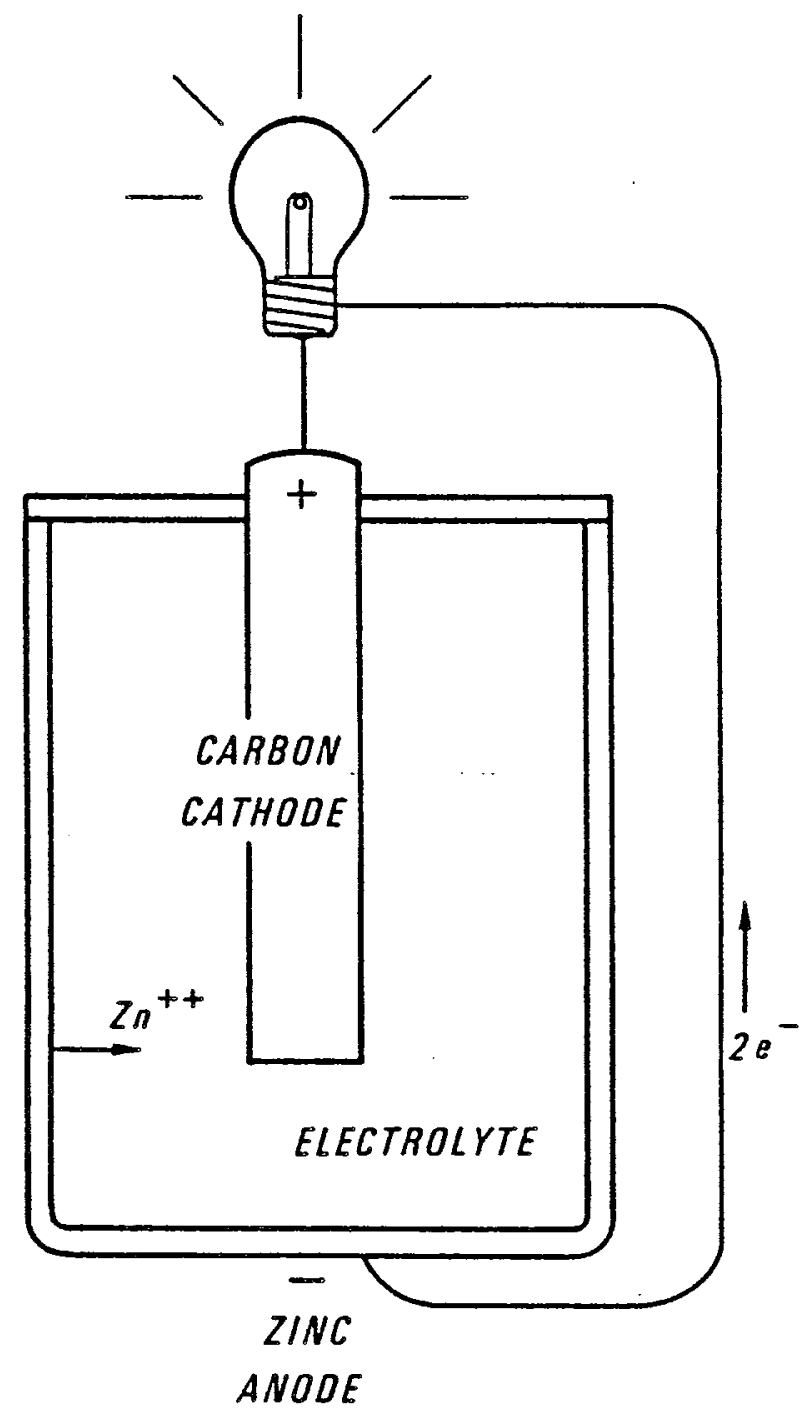

Figure 11 Galvanic cell (dry cell). (from Escalante, [43]) 
taking place at the anode. The greater the flow of electricity through the cell, the greater is the amount of zinc that corrodes. The relationship is given by Faraday's law:

$$
\text { weight of metal reacting }=k I t
$$

where $I$ is the current in amperes (A), $t$ is time in seconds (s), and $\mathrm{k}$ is a constant called electrochemical equivalent (in the case of zinc, $k$ is $3.39 \times 10^{-4} \mathrm{~g} / \mathrm{C}$ (gram per coulomb)). The metal loss rate $\left(W L^{\prime}\right)$ is obtained by dividing the weight of metal reacting by $t$, i.e., $W^{\prime}=k I$. A basic principle is thus illustrated, showing that the average rate of metal loss can be indirectly determined by the corrosion current measured by the electrochemical techniques (which will be introduced later on). Furthermore, the penetration rate can be obtained by dividing $k$ I by $\rho A$, where $\rho$ is the metal density and $A$ is the exposed area.

Turning to the dry cell in Figure 11, positive ions in the electrolyte are attracted to the carbon rod (cathode), where they are reduced by picking up one or more electrons at the carbon surface. Reduced ions, such as hydrogen, can adhere to the cathode surface and form a barrier, diminishing further reaction, or they may diffuse away from the surface, allowing the reaction to proceed. Since a reduction process rather than a dissolution process is taking place at the cathode, this electrode does not go into 
solution and is described as being under "cathodic protection". This simple dry cell provides a basic concept of corrosion as an electrochemical process. The rate of oxidation (corrosion) at the anode depends on the potential difference (the driving force) between two electrodes, the transmissibility of the electrolyte, and the conductivity of the conducting path. Control any of these, and the corrosion process is controlled. However, the real corrosion process is more complicated than the dry cell. UhIig and Revie [37] presented three main types of corrosion cells as follows:

(1) Dissimilar electrode cell. This is similar to the dry cell as mentioned above. Two unlike metals are brought into electrical contact and a corresponding voltage differential develops, followed by corrosion of the anodic metal. The relative chemical performance (anode or cathode) of two metals can be judged by examining a galvanic series as shown in Table 6 (this series is based on empirical results determined in seawater by Laque [44] or the Emf series (Uhlig and Revie [37]) as shown in Table 7. The materials are ranked from the most active (anodic) at the top to the most noble (cathodic) at the bottom of Table 6 . In Table 7 , a metal with a more negative standard potential is more anodic. Thus, if any two metals are connected in a galvanic cell as shown in Figure 12, the more active will act as an anode and corrode, while the other will act as the cathode and be (cathodically) protected. Another example relies on 
Table 6 Galvanic Series in seawater. (from Laque, [44])

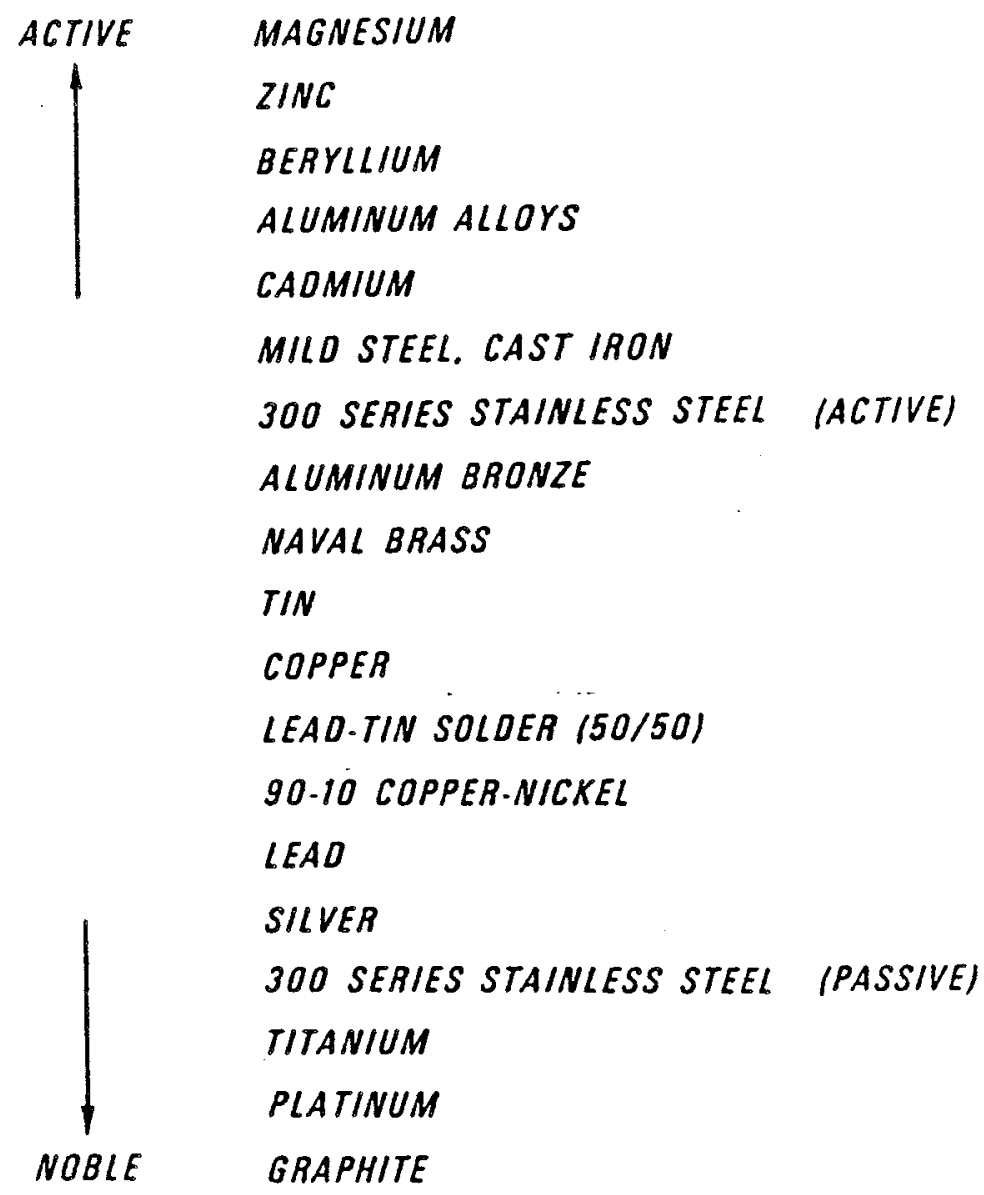


Table 7 Electromotive Force Series. (from Uhlig and Revie [37])

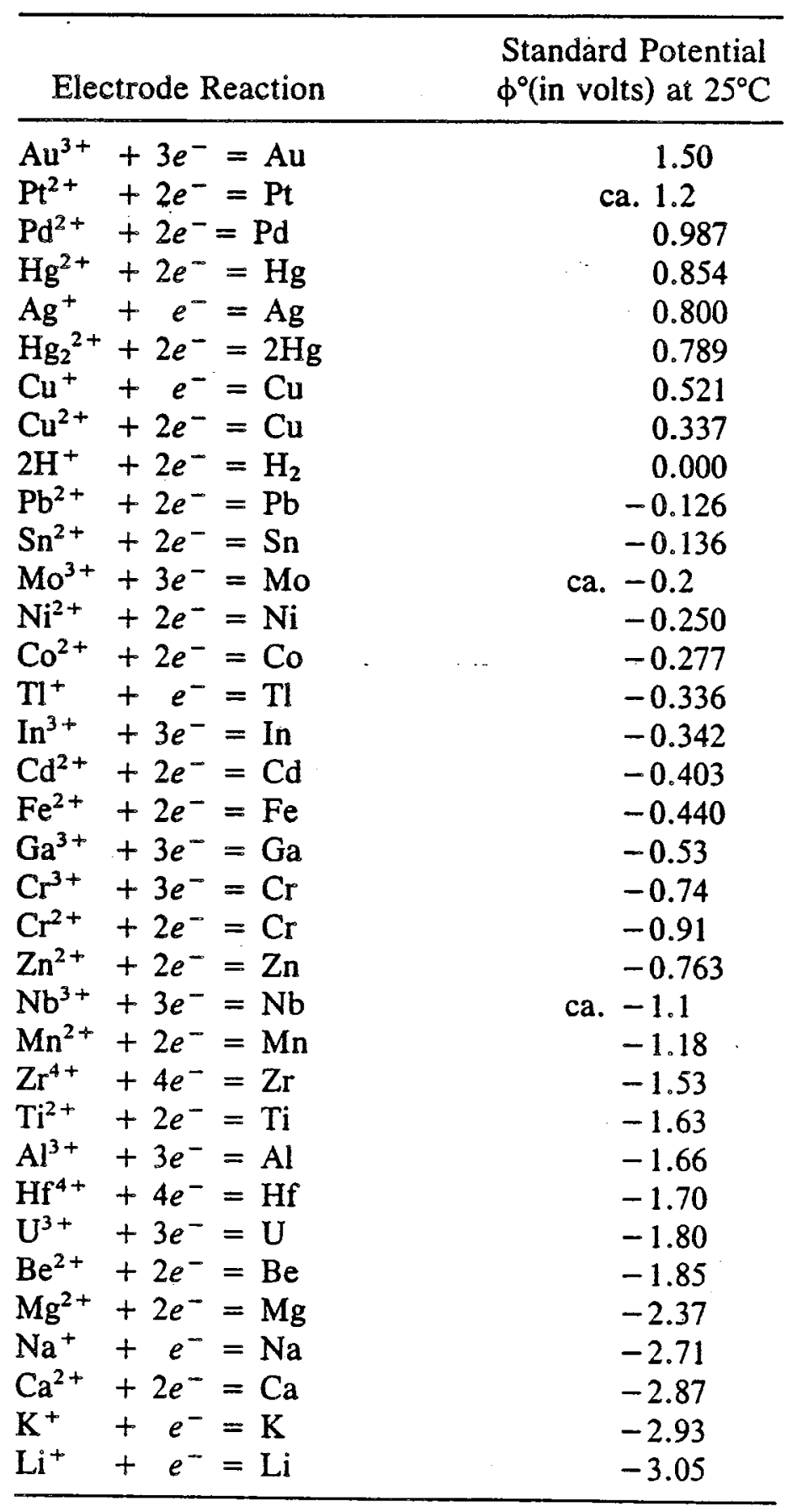




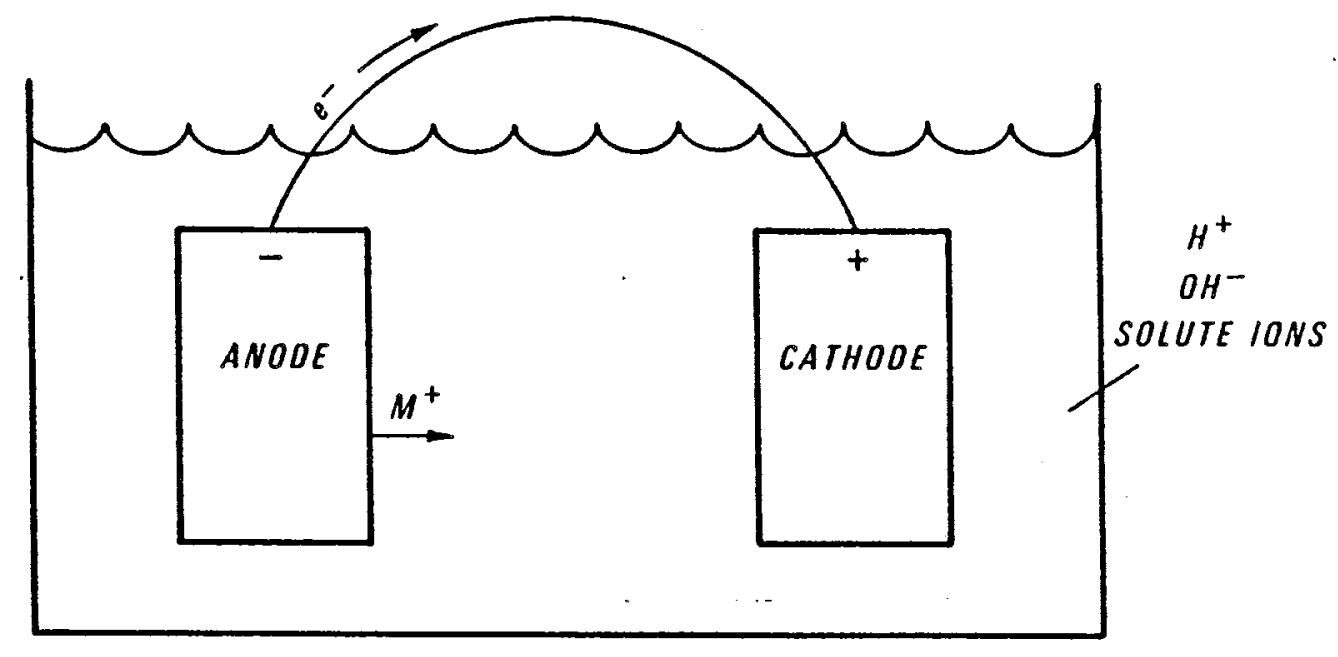

Figure 12 Galvanic Cell for Unlike Metals. (from Escalante, [43]) 
the difference in grain orientation of a metal developing a potential difference on the surface of the metal, with some grains as anodes and the others as cathodes, as shown in Figure 13. In addition, chemical anisotropy, inclusions, strained and unstrained areas, and other imperfections on the surface of a metal can give rise to these potential differences, providing a driving force for the corrosion process.

(2) Concentration cell. This cell has two identical electrodes each in contact with a solution of differing composition (inhomogeneity in the electrolyte). There are two kinds of concentration cells. The first is called a salt concentration cell. For example, if one copper electrode is exposed to a concentrated copper sulfate solution, and the other to a dilute copper sulfate solution (Figure 14), on short-circuiting such a cell, copper dissolves from the electrode in contact with the dilute solution (anode) and plates out on the other electrode (cathode). This reaction brings the solutions to the same concentration. The second type of concentration cell, which in practice is the more important, is called a differential aeration cell. Figure 15 shows one example. A difference in oxygen concentration produces a potential difference and causes current to flow (corrosion occurring at the electrode exposed to the deaerated solution). Figures 16 and 17 also show the corrosion process due to differential aeration. Those 


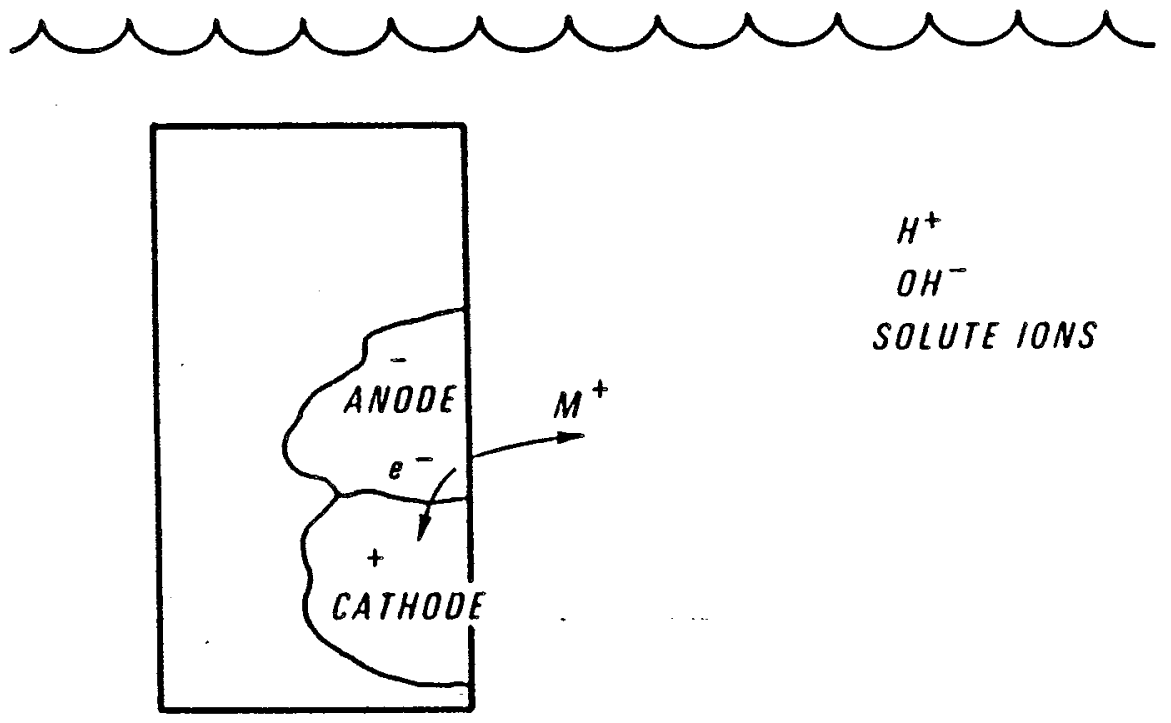

Figure 13 Potential Differences due to Metal Surface Anisotropy.

(from Escalante, [43]) 


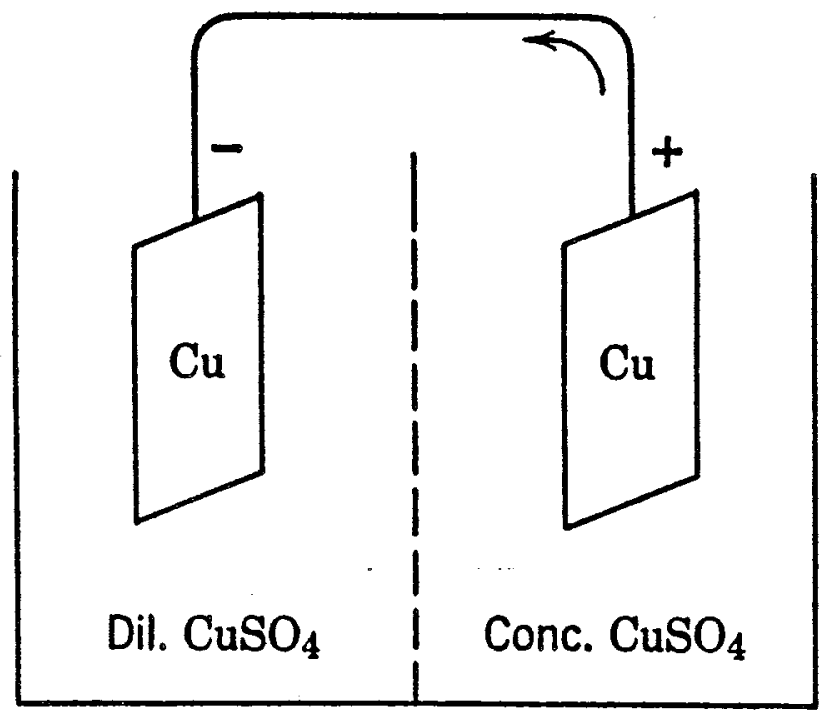

Figure 14 salt Concentration Cell. (from Uhlig and Revie, [37]) 


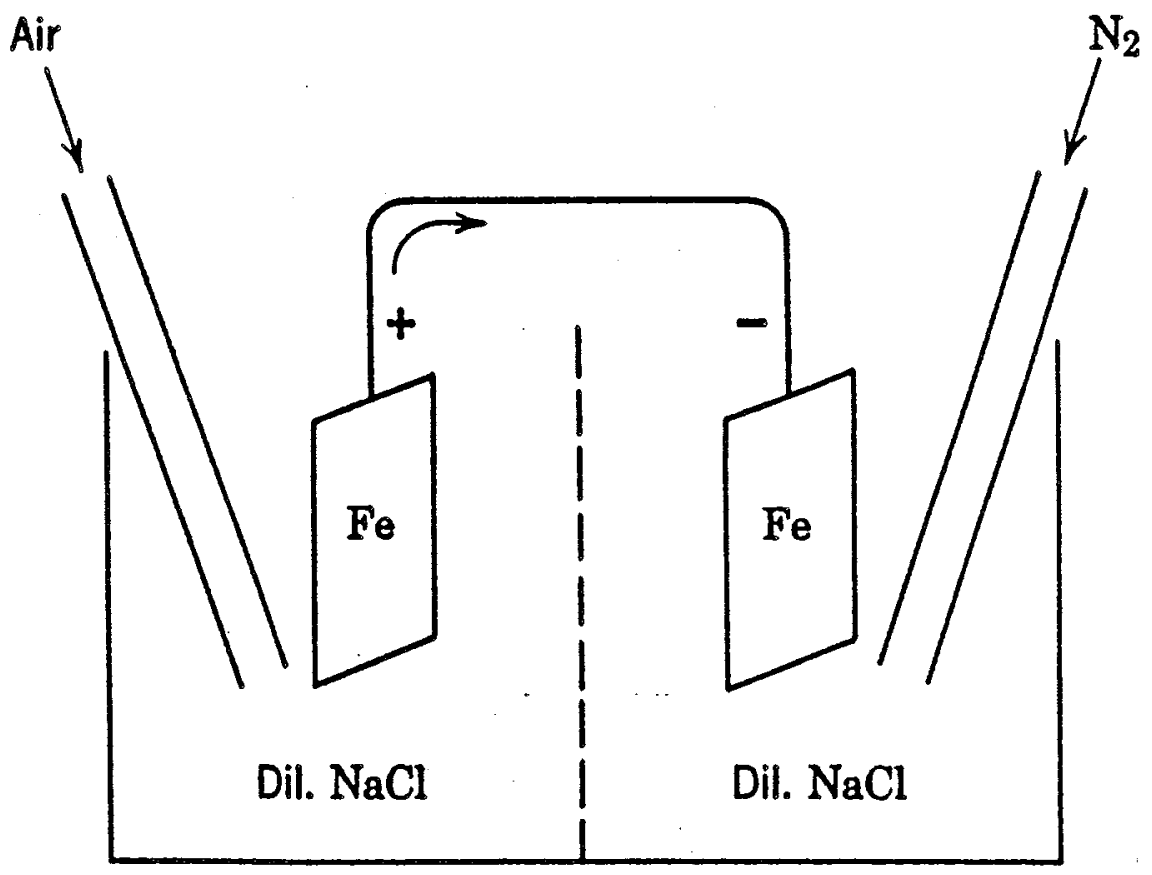

Figure 15 Differential Aeration Cell.

(from Uhlig and Revie, [37]) 


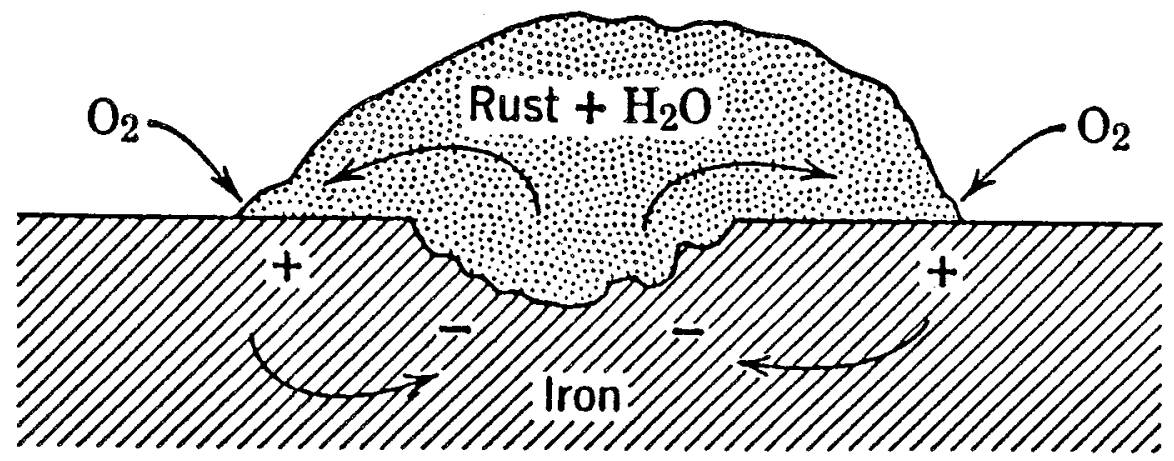

Figure 16 Differential Aeration Cell Formed by Rust on Iron. (from Uhlig and Revie, [37]) 


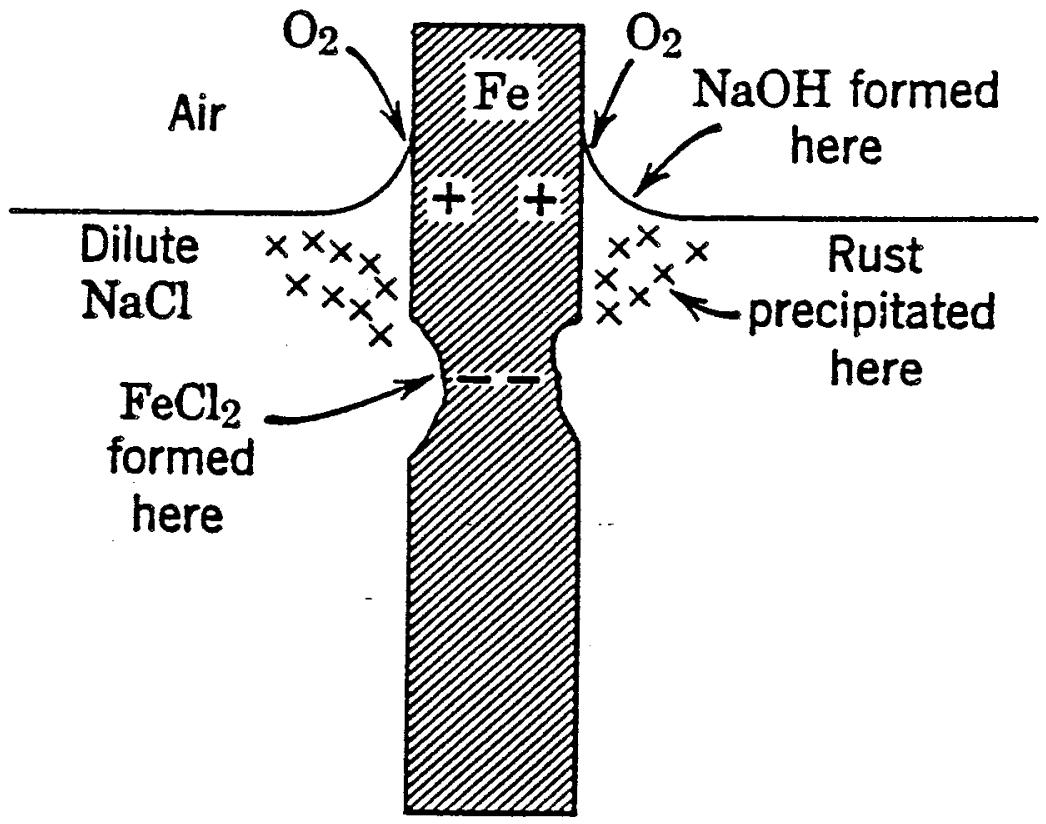

Figure 17 Differential Aeration cell Illustrated by Water-line Corrosion.

(from Uhlig and Revie, [37]) 
reactions are associated with pitting damage under rust and at the water-line interface, respectively. Differential aeration cells usually initiate pits (crevice corrosion) in stainless steels, aluminum, nickel, and so-called passive metals when they are exposed to aqueous environments, such as seawater.

(3) Differential temperature cell. Components of these cells are electrodes of the same metal, each of which is at a different temperature, immersed in an electrolyte of the same initial composition. Less is known about the practical importance and fundamental theory of differential temperature cells than the cell previously described. They are found in heat exchangers, boilers, immersion heaters, and the like. In a copper sulfate solution, the electrode made of copper or lead, at the higher temperature, is the cathode, while for silver the polarity is reversed. For iron immersed in a dilute aerated sodium chloride solution, the hot electrode is anodic to the colder one; but after several hours, the polarity may reverse.

In practice, cells responsible for corrosion may be a combination of these three types, depending on heterogeneity of metal, electrolyte, and other environmental factors.

With respect to various types of corrosion cells, corrosion damage of metals also occurs in different ways. Rusting, tarnishing, cracking, and loss of strength or 
ductility are examples. In general, most types of damage öcur by an electrochemical mechanism, but corrosion products are not necessarily observable and metal weight loss need not be appreciable. The five main types of corrosion classified with respect to outward appearance or altered physical properties are [37]:

(1) Uniform attack. This includes the commonly recognized rusting of iron or tarnishing of silver. "Fogging" of nickel and high-temperature oxidation of metals are also examples of uniform attack. This type of corrosion damage is more favorable than other regional or irregular damages, because the resulting uniform metal loss can be easily used to assess the severity of corrosion of a metal or to calculate its life expectancy if it is also proportional to time. Rate of uniform attack is reported in various units, an accepted terminology being milimeters penetration per year (mm/y) and grams per square meter per day (gmd). The units, inches penetration per year (ipy) and mils per year (mpy), are also frequently cited. For handing chemical media whenever attack is uniform, Uhlig and Revie [38] classified metals into three groups according to their corrosion rate. This classification is:

A. $\quad 0.15 \mathrm{~mm} / \mathrm{y}$ - Metals in this category have good corrosion resistance to the extent that they are suitable for critical parts, for example, valve seats, pump shafts, and springs. 
B. 0.15 to $1.5 \mathrm{~mm} / \mathrm{y}$ - Metals in this group are satisfactory if a higher rate of corrosion can be tolerated, for example, for tanks, piping, and valve bodies.

c. $>1.5 \mathrm{~mm} / \mathrm{y}$ - Usually not satisfactory.

(2) Pitting. This is a localized type of attack, the rate of corrosion being greater at some areas than at others. If appreciable attack is confined to a relatively small fixed area of a metal, acting as the anode, the resultant pits are described as deep. In contrast, if the area of attack is relatively large and not as deep, the pits are called shallow. The character of pitting is sometimes expressed by the term "pitting factor", the ratio of deepest metal penetration to average metal penetration as determined by weighted loss of the specimen (see figure 18). A pitting factor of unity represents uniform attack. Iron buried in soils corrodes with formation of shallow pits, whereas stainless steel immersed in seawater characteristically corrodes with formation of deep pits. Many metals, when subjected to high-velocity liquids, undergo a pitting type of corrosion called impingement attack, or corrosion-erosion. Copper and brass condenser tubes, for example, are subjected to this type of attack. Cavitation-erosion resulting from formation and collapse of vapor bubbles at a dynamic metal-liquid interface (as in rotors of pumps or on trailing faces of propellers) causes a 


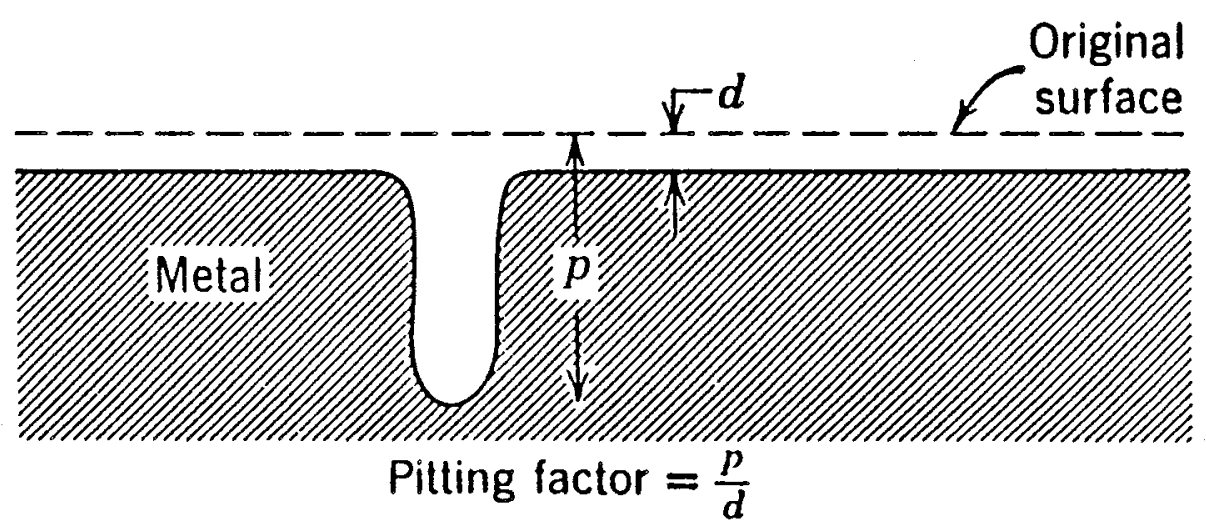

Figure 18 Sketch of Deepest Pit with Relation to Average Metal penetration and Pitting Factor. (from Uhlig and Revie, [37]) 
sequence of pits, sometimes appearing as a honeycomb of small relatively deep fissures. Fretting corrosion, which results from slight relative motion (as in vibration) of two substances in contact, one or both being metals, usually leads to a series of pits at the metal interface. Metal-oxide debris usually fills the pits so that the pits become visible only after corrosion products are removed.

(3) Dezincification and parting. Dezincification is a type of attack occurring with zinc alloys (e.g., yellow brass) in which zinc corrodes preferentially, leaving a porous residue of copper and corrosion products. The alloy so corroded often retains its original shape, and may appear undamaged except for surface tarnish, but its tensile strength and, especially, its ductility are seriously reduced. Parting is similar to dezincification in that one or more reactive components of the alloy corrode preferentially, leaving a porous residue that may retain the original shape of the alloy.

(4) Intergranular corrosion. This is also a localized type of attack at grain boundaries of a metal, resulting in loss of strength and ductility. Grain-boundary material of limited area, acting as an anode, is in contact with large areas of grains acting as cathodes. The attack is often rapid, penetrating deeply into the metal, and sometimes causing catastrophic failures.

(5) Cracking. If a metal cracks when subjected to repeated 
or alternate tensile stresses in a corrosive environment, it is said to fail by corrosion fatigue. On the other hand, if a metal, subjected to a constant tensile stress and exposed simultaneously to a specific corrosive environment, cracks immediately or after a given time, the failure is called stress-corrosion cracking.

Based on the above discussions of different types of corrosion cells and of corrosion damage, this writer concludes that the structural factors of a metal which can seriously influence the corrosion rate are:

(1) Metallurgy - oxidation potential.

(2) Type and condition of coatings - surface protection.

(3) Dimension - contact area.

(4) Length - long-line corrosion across different media.

(5) Temperature - change of metallurgy.

(6) Movement or vibration - fatigue effect.

(7) Stress level and stress distribution - fatigue effect.

(8) Presence of dissimilar metal - galvanic cell.

(9) surface inhomogeneity - localized galvanic cell.

\section{Underground Corrosion}

As described earlier, bottom ash can be used as embankment fill, subgrade, and subbase materials. In each application, metal structures, such as reinforcing strips, tensile anchors, piping, metal drainage system, and so on, 
may be embedded in bottom ash. The system of bottom ash/water/air is a new and largely unknown one for underground corrosion. It is necessary to understand this environment prior to an extensive utilization of bottom ash. In the past, studies on underground corrosion were performed on soils. Although different formation processes characterize soils and bottom ashes, the same experiences can apply, if given careful attention. The following will describe several causes of underground corrosion presented by previous investigators, in which soils represent the main underground corrosive media.

Underground corrosion contributes greatly to the total economic losses due to corrosion. In the United States alone there are more than one million miles of buried oil, water, and gas pipelines. Corrosion of these structures necessitates maintenance and replacement costs. The estimated total cost in 1975 for corrosion of piping in the United States is $\$ 158$ million (Bennett et al., [41]). If the corrosion loss of other buried metal structures and the threat (to the public) of toxic or radioactive wastes leaking from corroded piping are included, underground corrosion is of major concern.

The transition from a relatively simple system, such as a-dry cell (described in the previous section), to the complex cell developed in an underground structure is a 
major one. However, the concepts of the corrosion process remain the same, i.e., corrosion occurs at the anodes and its intensity depends on metal, electrolyte, and local effects. Here, the electrolyte involved is the complicated combination of soil, water, and air.

Escalante [45], proposed four types of underground corrosion, based on the previous studies: (1) corrosion in disturbed soils; (2) corrosion in undisturbed soils; (3) bacterial corrosion; and (4) corrosion by stray current. This writer would like to present them in a reverse order, because stray current had first been considered the cause of underground corrosion, and corrosion in disturbed soils is the most complicated.

\section{Corrosion by stray current}

At the turn of the century, all corrosion was attributed to stray current from rail traction systems trolley cars and subways (Romanoff, [39]). In 1910, Congress authorized the National Bureau of standards (NBS) to initiate a study of this stray current electrolysis that was causing so much damage. In the course of this study, however, NBS discovered that corrosion would also occur in soils where no stray current was present.

Stray currents are those that follow paths other than the intended circuit, or they may be any extraneous currents 
in the earth. If currents of this kind enter a metal structure, they cause corrosion at areas where the currents leave to enter the soils, water, or adjacent materials (Uhlig and Revie, [37]). Usually, natural earth currents are not important from a corrosion standpoint because their magnitude is small or because their duration is short. Damage by alternating current (ac) is less than by direct current $(d c)$.

Sources of stray dc current are commonly electrical railways, grounded electric dc power lines, electric welding machines, cathodic protection systems, and electroplating plants. Sources of stray ac currents are usually grounded ac power lines or currents induced in a pipeline by parallel power lines. Figure 19 shows an example of stray dc current from an electric street railway system in which steel rails are used for current return to the generating station. Because of poor bonding between rails, some of the return current enters the soil and finds a low-resistance path such as a buried gas or water main. In Figure 19, the owner of a household water service pipe at "A" benefits by cathodic protection and experiences no corrosion; but the owner "B", to the contrary, is harassed by corrosion failures because the service pipe of his house is anodic with respect to the rail.

Another example of stray-current corrosion is 


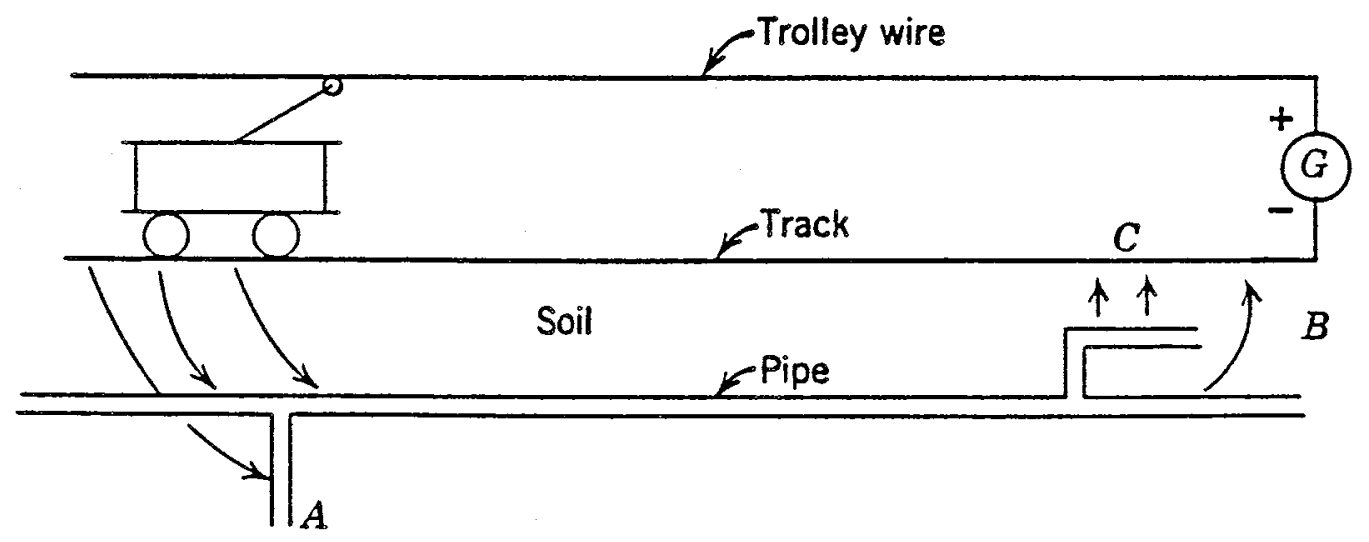

Figure 19 Stray-Current Corrosion of Buried Pipe. (from Uhlig and Revie, [37]) 
illustrated in Figure 20. A welding motor generator located on shore with grounded dc lines to a ship under repair can cause serious damage to the hull of the ship by current returning in part from the welding electrodes through the ship and through the water to the shore installation. In this case, it is better to place the generator on board ship and bring ac power leads to the generator, since ac currents leaking to ground cause less damage. Figure 21 depicts the effect of current flowing along a buried pipeline on corrosion near insulated couplings. The amount of metal corroding at anodic areas due to stray current can also be calculated using Faraday's law. Table 8 lists the weighted losses of typical metals for the equivalent of 1 ampere flowing for one year.

\section{Bacteria Attack}

At the start of the century, corrosion of metals was believed to occur only in a aerobic environment, where dissolved oxygen exists and plays a role called depolarization, i.e., accelerating hydrogen evolution at cathodic areas as well as corrosion of metals at anodic areas. Accordingly, in deaerated water metal should not corrode appreciably. However, the corrosion rate in some natural deaerated environments is found to be abnormally high. These high rates have been traced to the presence of sulfate-reducing bacteria (SRBs), e.g., desulfovibrio 


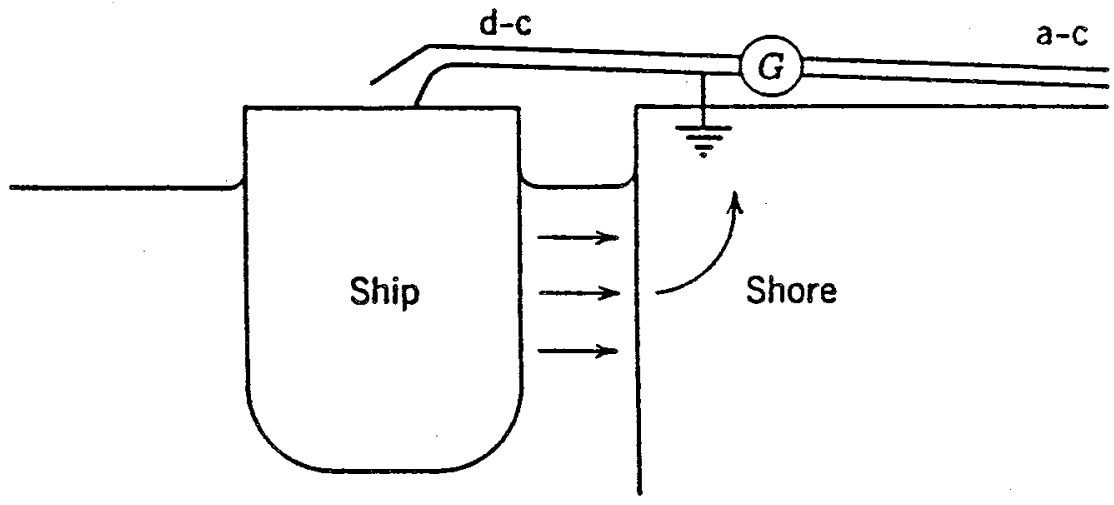

Figure 20 stray-Current Damage due to Ship by Welding Generator.

(from Uhlig and Revie, [37]) 


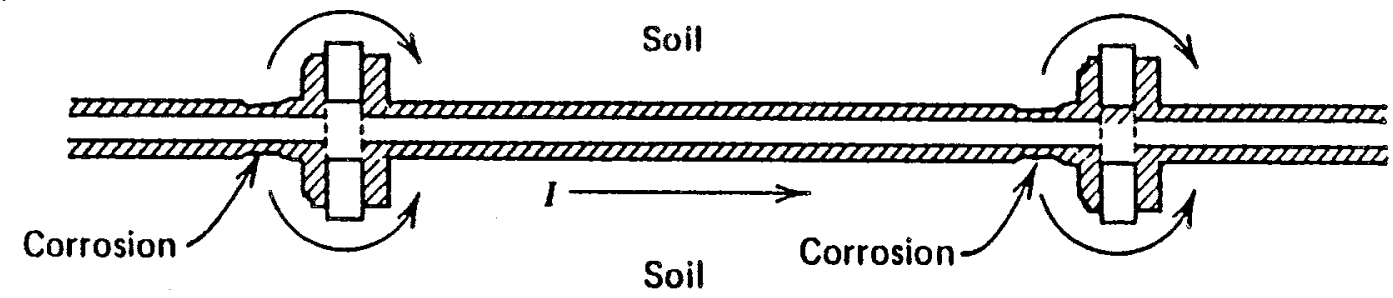

Figure 21 Effect of Current Flowing along a Buried Pipeline on Corrosion near Insulated Couplings. (from Uhlig and Revie, [37]) 


\begin{tabular}{|c|c|c|c|}
\hline Metal & Equivalent Weight & \multicolumn{2}{|c|}{$\begin{array}{l}\text { Weight of Metal } \\
\text { Corroded per } \\
\text { Ampere-year }\end{array}$} \\
\hline $\mathrm{Fe}$ & $\frac{55.85}{2}$ & $20.1 \mathrm{lb}$ & $9.1 \mathrm{~kg}$ \\
\hline $\mathrm{Cu}$ & $\frac{63.57}{2}$ & 22.8 & 10.4 \\
\hline $\mathrm{Pb}$ & $\frac{207.2}{2}$ & 74.5 & 33.8 \\
\hline $\mathrm{Zn}$ & $\frac{65.38}{2}$ & 23.6 & 10.7 \\
\hline $\mathrm{Al}$ & $\frac{26.98}{3}$ & 6.5 & 2.9 \\
\hline
\end{tabular}


desulfuricans. Their relation to an observed accelerated corrosion rate in soils low in dissolved oxygen was first presented in Holland by von Wolzogen Kuhr (Uhlig and Revie, [37]). The bacteria are curved, with a size of $1 \times 4 \mu \mathrm{m}$, and are found widespread in many soils and waters. They thrive only under anaerobic conditions in the pH range of 5.5 8.5. Some species multiply in fresh water and in sulfate-rich soils, others in brackish water and marine soils, and still others are stated to exist in deep soils at temperatures as high as $60-80^{\circ} \mathrm{C}$.

sulfate-reducing bacteria easily reduce inorganic sulfates to sulfides in the presence of hydrogen or organic matter, and are aided in this process by the presence of an iron surface. Iron provides a supply of hydrogen which is normally adsorbed on the metal surface, and which the bacteria make use of in the reduction of $\mathrm{SO}_{4}^{2-}$. For each equivalent of hydrogen atoms they consume, one equivalent of $\mathrm{Fe}^{2+}$ enters solution to form rust and Fes. The bacteria essentially act as depolarizers. The reaction sequence can be outlined as follows (Uhlig and Revie, [37]):

Anode: $\quad 4 \mathrm{Fe} \longrightarrow 4 \mathrm{Fe}^{2+}+8 e^{-}$ EQs (5)

Cathode: $8 \mathrm{H}_{2} \mathrm{O} \longrightarrow 8 \mathrm{H}_{\mathrm{ads} \text { on } \mathrm{Fe}}+8 \mathrm{OH}^{-}-8 \mathrm{e}^{-}$

$$
\begin{aligned}
& 8 \mathrm{H}_{\mathrm{ads}}+\mathrm{Na}_{2} \mathrm{SO}_{4} \longrightarrow \mathrm{H}_{2} \mathrm{O}+\mathrm{Na}_{2} \mathrm{~S} \\
& \mathrm{Na}_{2} \mathrm{~S}+2 \mathrm{H}_{2} \mathrm{CO}_{3} \longrightarrow 2 \mathrm{NaHCO}_{3}+\mathrm{H}_{2} \mathrm{~S}
\end{aligned}
$$


Summary: $4 \mathrm{Fe}+2 \mathrm{H}_{2} \mathrm{O}+\mathrm{Na}_{2} \mathrm{SO}_{4}+2 \mathrm{H}_{2} \mathrm{CO}_{3} \longrightarrow$

$$
3 \mathrm{Fe}(\mathrm{OH})_{2}+\mathrm{FeS}+2 \mathrm{NaHCO}_{3}
$$

The conditions in which the sulfate-reducing bacteria can survive are natural soils which are rich in sulfate or organic matter, totally saturated, and anaerobic. The reduction-oxidation (redox) potential is a good measure of whether the soil environment is aerobic or anaerobic. Low redox potential implies that the soil is in an anaerobic condition (McMullen, [35] and Fitzgerald, [46]). Other biological tests which indicate the presence of SRBs include total viable counts of sulfate reducers, measurement of the hydrogen evolution of a soil, and formation of $\mathrm{H}_{2} \mathrm{~S}$ by adding drops of $\mathrm{HCl}$ to the rust of buried iron (Iverson, [47]). Severe damage caused by SRBs has been observed particularly in oil-well casing, buried pipelines, water-cooled rolling mills, or in pipes from deep water wells. Chlorination, aeration, and addition of certain bactericides are three methods to reduce the damage due to bacteria attack. Other bacteria which thrive in organic soils can consume the organic matter and produce acid in an aerobic condition, also causing a serious corrosion of buried metallic structures.

Corrosion in Undisturbed soils

A disturbed soil is a soil in which digging, 
backfilling, explosion, or other such soil upheaval has taken place, destroying the original soil fabric and aeration (Escalante, [43]). In contrast, an undisturbed soil has not been disrupted in such a manner. Thus, boring a pile in the ground causes minimum change in the soil mass. Driving a pile causes an intermediate degree of disturbance, which depends upon the amount of soil displaced by the the driving.

Corrosion in disturbed soils, which is discussed later, is highly dependent on the electrochemical characteristics of the soils and the site conditions. Early studies on steel piles driven underground indicated that the corrosion observed over a period of several years was much less than expected on the basis of totally disturbed soil tests. Furthermore, it was noted that such corrosion in undisturbed soils was independent of the soil conditions, such as soil resistivity, soil pH, and soil chemical content (Romanoff, [48], as cited in Escalante, [43]). The role of oxygen in an undisturbed soil overrides the above soil electrochemical effects on disturbed soils where oxygen is, relatively, more readily available. The diffusion of oxygen in an undisturbed soil, and particularly below the water table, is so sufficiently "low" that the corrosion process is stifled.

-. It is important to point out that where a metallic structure passes through a disturbed soil/undisturbed soil 
interface, the section of the structure in the disturbed soil is cathodic to the rest of the structure in the undisturbed region, as illustrated in Figure 22 (from Escalante, [43]). As a result, the most severe corrosion occurs on the section of the structure just below the disturbed layer. The effectiveness of this anode/cathode system relies on the oxygen differential between the disturbed and undisturbed layers. Similarly, a pile located in undisturbed soils with a high water table can suffer some corrosion attack at the waterline as illustrated in Figure 23 (from Escalante, [43]). This combination does not result in serious attack, but it is believed that the situation is aggravated by a continuously changing water table, which would supply oxygen as the waterline dropped. In addition, the undisturbed soil below the water table may be susceptible to the attack of SRBs, if an anaerobic condition prevails and the soil is sulfate rich or organic matter is present.

Corrosion in Disturbed Soils

By 1920, NBS had concluded that soil corrosion was equally as serious as corrosion caused by stray currents. Subsequently, in 1922 NBS extended the previous study to determine the causes of soil corrosion. Finding that some soils were more corrosive than others, NBS continued to determine what soil parameters were responsible for the 


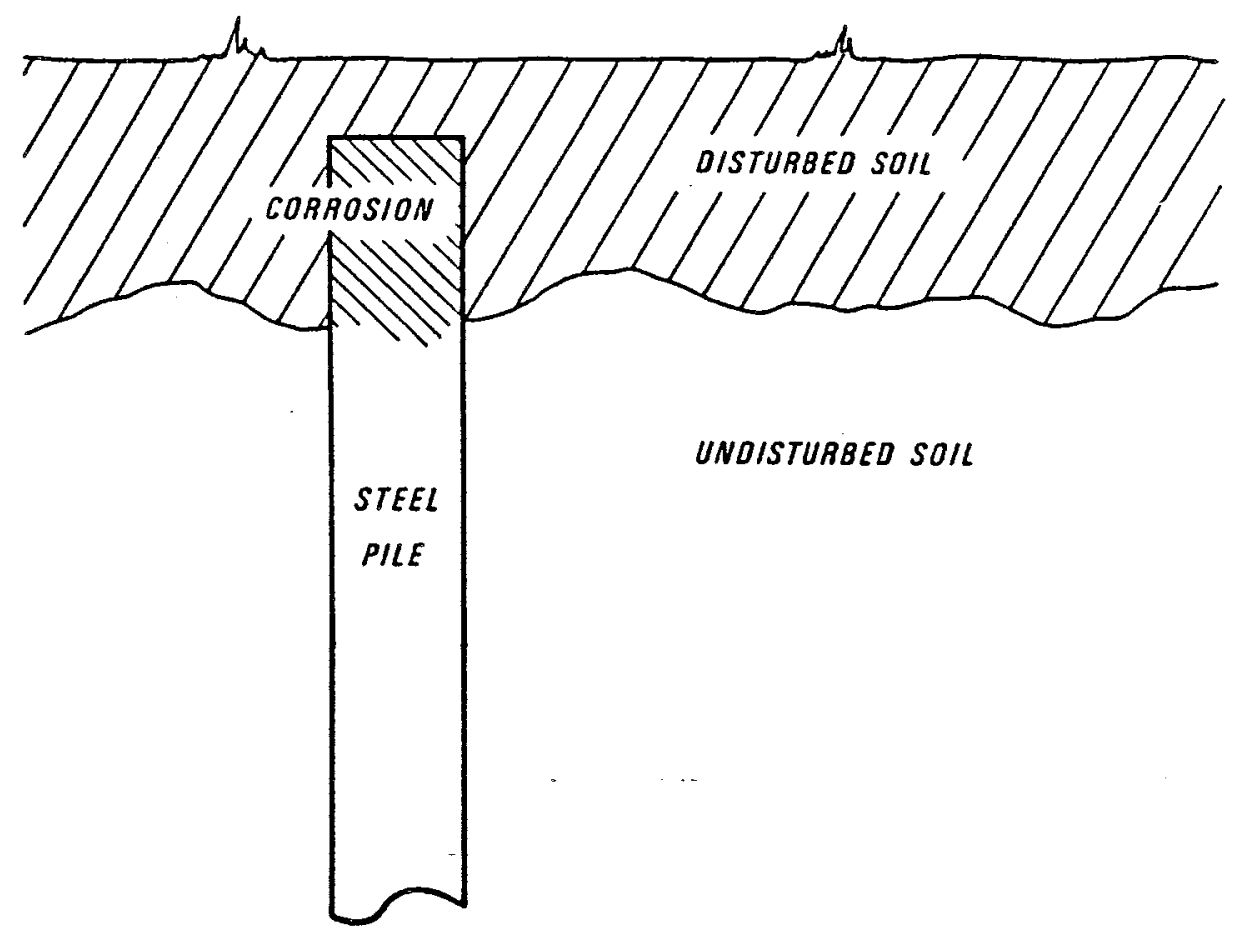

Figure 22 Corrosion of a steel Pipe in a Disturbed Soil. (from Escalante, [43]) 

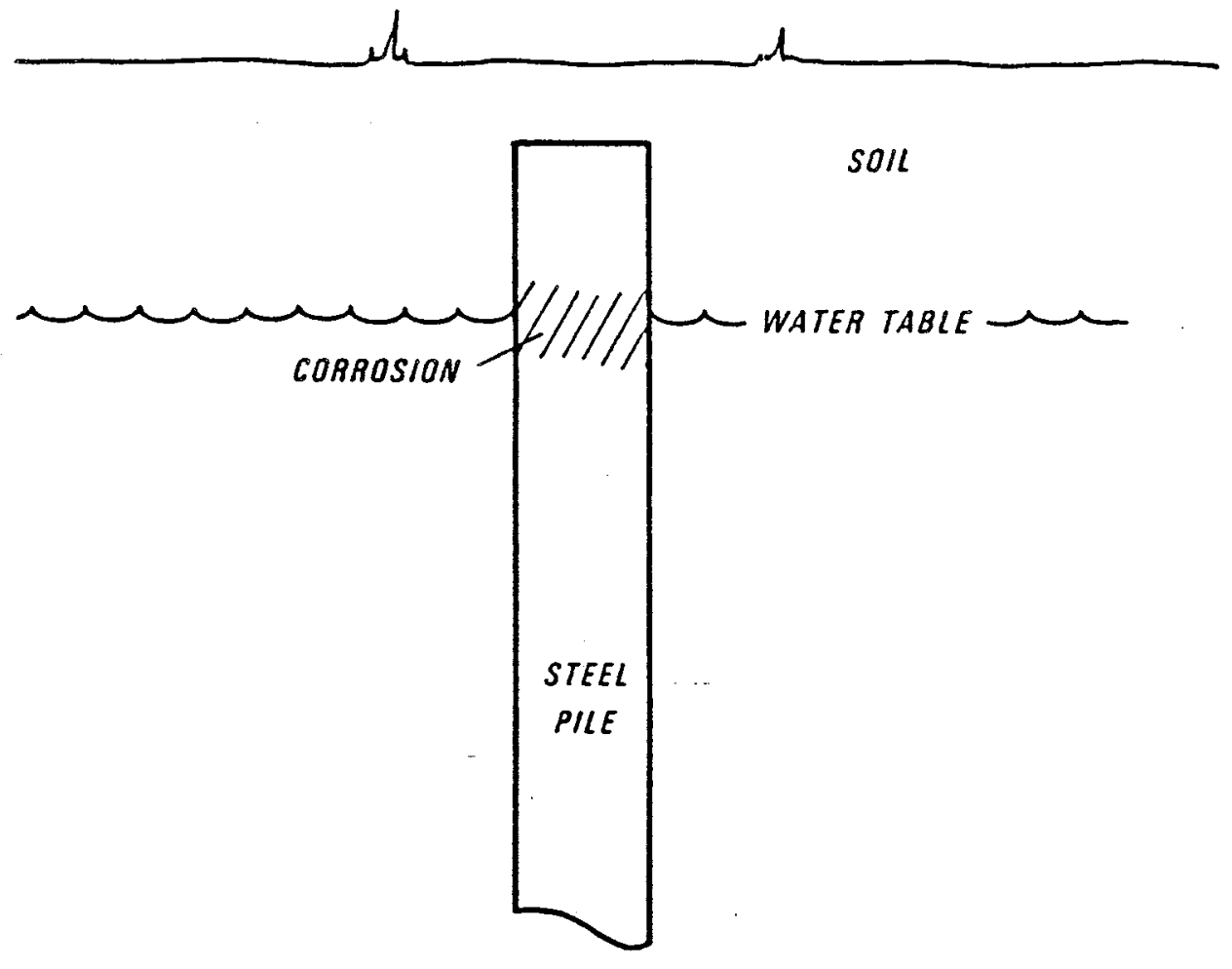

Figure 23 Underground corrosion of a steel pipe at the Waterline. (from Escalante, [43]) 
corrosion of metals. They found that the corrosivity of a particular soil is based on the interaction of several parameters - resistivity, dissolved salts, moisture content, presence of bacteria, amount of oxygen, and so on. However, no single parameter could be taken as indicative of the corrosivity of a given soil, as NBS (Romanoff, [39]) stated, soil corrosion is too complex to permit correlation with any one parameter.

NBS's buried tests established the severity of corrosion to be expected for various metals in various soils. These data were very useful for comparison purposes (Fitzgerald, [46]). Following NBS's tasks, many investigators continued to study the complicated interaction of soil parameters and to determine the most dominant parameter(s) related to soil corrosivity. However, to date no consistent conclusion has been reached. In the following, this writer will describe each corrosion-related parameter, interaction with other(s), and its appropriateness.

Before going into detail, an introduction to the complicated elements of the soil environment, the soil/water/air system or electrolyte with respect to the burial metals, is necessary. The soluble chemical components of a soil will enter the surrounding pore water, forming the soil leachate. This leachate contains the main electrochemical characteristics of the soil environment. 
These characteristics include resistivity, water content, redox potential, $\mathrm{pH}$ (acidity), and dissolved salts $\left(\mathrm{SO}_{4}^{2-}\right.$, $\mathrm{Cl}^{-}, \mathrm{Fe}^{2+}, \mathrm{SO}_{3}, \mathrm{Mg}^{2+}, \mathrm{Ca}^{2+}$, and etc.). Soil fabric includes soil aeration and internal drainage (permeability), both influencing the diffusion of oxygen and dissolved salts. Site factors consist of temperature, fluctuation of water table, water movement, inhomogeneity of soil composition and soil structure, and alien inclusions or contamination. It should be emphasized that each soil environmental parameter is not exclusively independent of one another. For example, some soil parameters have opposite effects on different metals; the value of a soil parameter determined in the laboratory may be different from that in situ; and the degree of the correlation between soil electrochemical properties and the observed corrosion of metals in situ depends highly on the site factors.

\section{Soil Electrochemical Characteristics}

\section{Electrical Resistivity}

Soil resistivity is probably the parameter most often looked upon as indicative of a soil's corrosivity (Fitzgerald, [46]). Corrosion is due directly to the presence of an electrical current flowing through the metal and the electrolyte between the cathodic and anodic zones, and the rate of metal loss at the anode is proportional to 
the intensity of the current (Faraday's law), which is directly dependent on the electrical resistance of the electrolyte between the two poles of the cell (Darbin et al., [42]). Alternately, soil resistivity, the reciprocal of conductivity, indicates the ability of the soil to carry corrosion currents (Palmer, [38]), or is a measure of how easily a soil will allow a corrosion current to flow through it and how effectively the soil acts as an electrolyte (Escalante, [43]).

In general, the lower the soil resistivity, the higher the corrosion rate of a metal. Romanoff [39] described an approximate relationship between soil resistivity and its corrosiveness, as shown in Figure 24. This figure displays much scatter but indicates a decrease in metal loss with increasing resistivity. Also, based on his studies on seven sites, Escalante [43] proposed that a soil with a resistivity below $500 \mathrm{ohm}-\mathrm{cm}$ is corrosive, regardless of other soil parameters, but above $2000 \mathrm{ohm-cm}$ the relation of soil resistivity to soil corrosivity is less reliable.

Although soil resistivity is the most commonly agreed-upon criterion to rank the degree of soil corrosivity, it is not valid in the presence of severe microbiological activity (e.g, SRBs), dissimilar metals, soils of differing composition, and oxygen concentration cells (aeration differential) (Uhlig and Revie, [37]; 


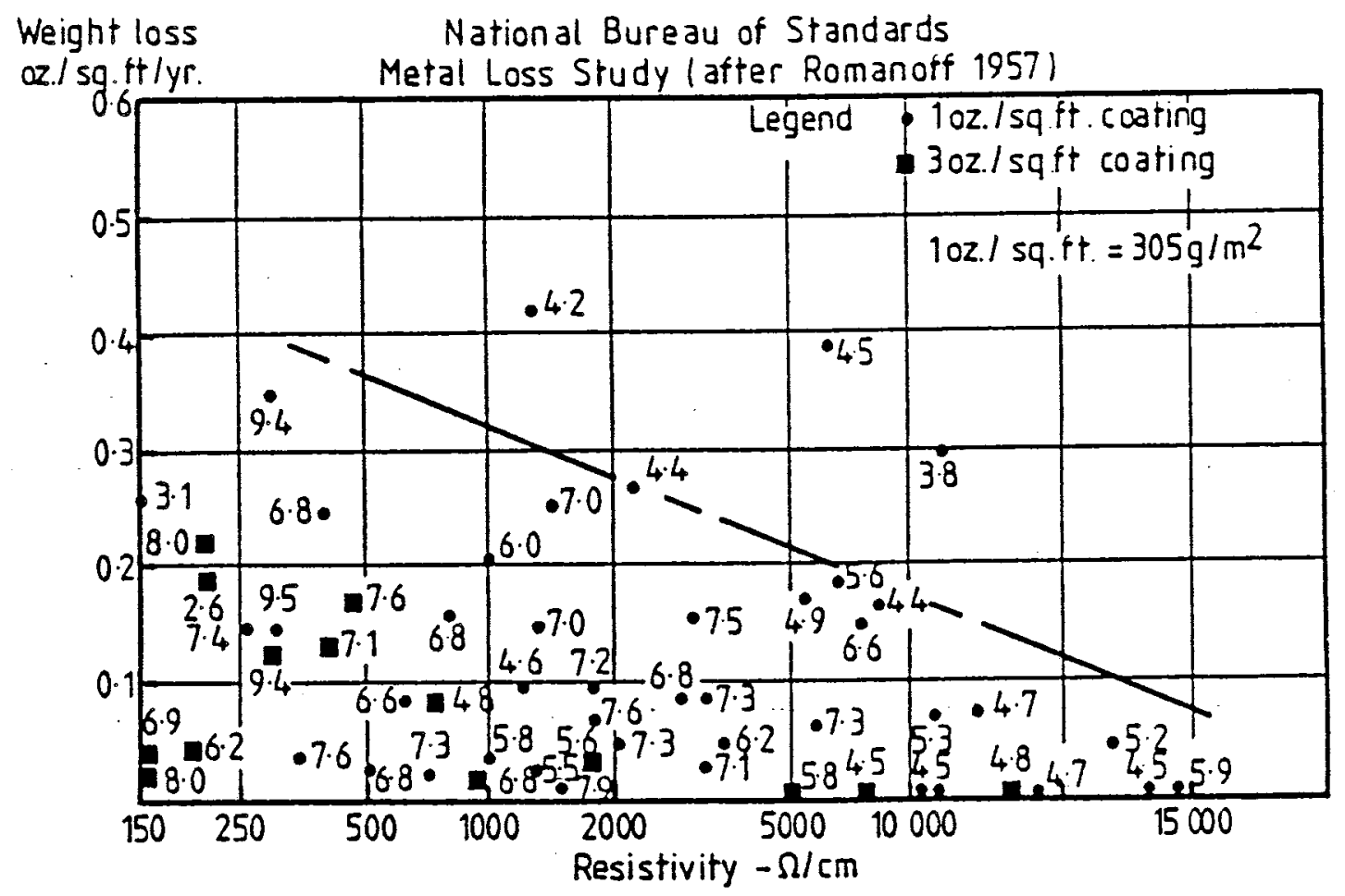

Figure 24 Weight Loss versus Soil Resistivity. (from Romanoff, [39]) 
Fitzgerald, [46]; and Palmer, [38]). Field resistivity determinations can be performed in accordance with the ASTM Method for Field Measurement of Soil Resistivity Using the Wenner Four-Electrode Method (G57) [75]. Laboratory tests can be conducted on sieved soil samples with a certain water content which is packed into a standard soil box. Resistivity is measured by a resistivity meter. California test 632 [81], "Method for Estimating the service Life of Steel Culvert", provides a method for determining the soil resistivity in the laboratory.

Soil resistivity is a function of the water content and the concentration of current-carrying soluble ions (or salts) (Palmer, [38] and Edgar, [49]). Usually, the greater the soluble salts, the lower the soil resistivity. This is not a one-to-one ratio, however, since the different ions available have different electrical charges. Different site conditions will affect the amount of dissolved salts of a soil. High water contents typically produce low-resistivity values since there are both larger areas of water for the current to flow through and more complete hydrolysis of ions.

Because the water content of the soil may change with time in situ or be modified in the laboratory, the question of. which water content to be used to measure soil resistivity as related to corrosivity has been debated. From 
a conservative standpoint, i.e., considering the worst condition, Darbin et al. [42] suggested using the minimum resistivity as the criterion which occurs at 100 percent saturation of a soil. McMullen [35] stated that an early study of the Des Moines Water Works soil investigation indicated that the saturated resistivity was the best single-parameter predictor for potential corrosive soils. Edgar [49] concluded from his observations on a number of in-service culverts that there is a good relationship between observed corrosion and field resistivity. Field resistivity is usually higher than the minimum resistivity, since field moisture never reaches the state of a full saturation. The debate is still in progress.

\section{Water content}

Under most circumstances, soil water content is directly related to corrosion rates (Bushman and Mehalick, [50]). Most corrosion reactions take place quickly or even proceed at any rate only in a aqueous solution. Water is necessary for both the formation and the reaction of an electrolyte in the environment surrounding the metal. Thus, soluble salts and dissolved oxygen enter into water, constituting the electrolyte. The dissolved salts enhance the conductivity of a soil/water/air system and the dissolved oxygen acts as a depolarizer; both accelerate the corrosion rate of the metal. 
In a totally dry environment, a corrosion current cannot flow through the dry medium which has a high electrical resistance, and corrosion can not occur. As mentioned earlier, higher water content can produce low resistivity, and thereby increase the corrosion rate. Booth et al. [51], in his assessment of various soils for corrosivity, proposed that a $20 \%$ water content of the soil be used to resolve borderline cases of soil aggressivity as determined by resistivity and redox potential. (see Table 9).

The corrosivity of a soil can increase with moisture to a critical point and beyond that point a drop in corrosion activity occurs. Gupta and Gupta [52] (as cited in Headon and Chan, [53]) reported that the critical water content is usually between 25-35\%, depending on types of metals.

\section{Redox Potential}

The redox or oxidation-reduction potential is the potential of a platinum electrode in an electrolyte versus a reference half-cell converted to the standard hydrogen scale (Escalante, [43] and Iverson, [47]). The redox potential of a soil gives an indication of the proportions of oxidized and reduced species in that soil. This parameter attempts to distinguish between aerobic soils and anaerobic soils that could support sulfate-reducing bacteria (SRBs) activity (Palmer, [38]). Very high corrosion rates of metals have been observed in poorly aerated soils where SRBs often 
Table 9 Relationship of Soil Aggressivity to Resistivity and Redox Potential. (from Booth et al., [51])

\begin{tabular}{lcc}
\hline & Aggressive & Nonaggressive \\
\hline $\begin{array}{l}\text { Resistivity (ohm-cm) } \\
\text { and/or }\end{array}$ & $<2000$ & $>2000$ \\
$\begin{array}{c}\text { Redox potential at } \\
\mathrm{pH}=7 \text { (V N.H.E.) }\end{array}$ & $\begin{array}{c}<0.400 \\
<0.430 \text { if clay) }\end{array}$ & $\begin{array}{c}>0.400 \\
\text { (or }>0.430 \text { if clay) }\end{array}$ \\
$\begin{array}{l}\text { Borderline cases to } \\
\text { be resolved by: } \\
\text { water content }(\% \mathrm{w} / \mathrm{w})\end{array}$ & $>20$ & $<20$ \\
\hline
\end{tabular}


thrive. In 1945, Starkey and wight [54] (as cited in Iverson, [47] and Escalante, [43]) reported on an extensive investigation of the redox potentials of various soils along pipeline distribution systems, and correlated these results with the severity of corrosion on the pipes. Their derived relationship between redox potential and soil corrosivity is given in Table 10. Costanzo and Mcvel [55] also reported similar findings. A simple redox probe having commercially available electrodes was assembled at the National Bureau of standards. It consisted of two platinum electrodes and a glass electrode mounted in a rubber housing at the end of a plastic tube (Iverson, [47]). Palmer [38] pointed out that to be valid, the test should be performed in situ (only in moist soils) or immediately after soil sampling. The tests requires careful electrode preparation and calibration.

Although low redox potentials have been associated with a high corrosion rate, the corrosion rates and the redox potential (about $-200 \mathrm{mV}$ ) of a moist clay soil site were both found to be very low (Iverson, [47). Palmer [38] also mentioned that other investigators such as Kuhlman did not succeed in correlating redox potential with corrosion rate. Escalante [43] and McMullen [35], based on separate studies, concluded that soil redox potential is a poor indicator of soil corrosivity. It is believed that the redox potential is a good measure of the anaerated condition of a soil, in which SRBS can survive. But SRBs also require sulfate or 
Table 10 Relationship between Redox Potential and soil corrosivity.

(from starkey and Wight, [54]).

Range of Soil

Redox Potential

Below $100 \mathrm{mV}$

100 to $200 \mathrm{mV}$

200 to $400 \mathrm{mV}$

Above $400 \mathrm{mV}$
Classification of Corrosiveness

Severe

Moderate

Slight

Noncorrosive 
organic matter to thrive. Therefore, low redox potential can not definitely prove the existence of SRBs and any associated high soil corrosivity.

\section{4. $\underline{\mathrm{pH}}$ and Acidity}

It is well known that an acidic solution can cause a metal to dissolve, and the more acidic the solution the higher the dissolution rate of the metal. Upon full hydrolysis, the acidic ions act as depolarizers, enhancing the rate of hydrogen evolution at the cathodic zone of the metal, as well as the rate of dissolution at the anodic zone of the metal. The same conclusion can apply to the soil/water/air system (electrolyte). There is no meaning of $\mathrm{pH}$ in a dry soil; thus soil $\mathrm{pH}$ values refer to the $\mathrm{pH}$ values of the soil having certain amounts of water content. Soil pH is conventionally defined by the equation (Jackson, [56]):

$$
\operatorname{soil} \mathrm{pH}=\log \frac{1}{\mathrm{aH}^{+}}=-\log _{10} \mathrm{aH}^{+}
$$

in which the activity of $\mathrm{H}^{+}$in the soil suspension, $\mathrm{aH}^{+}$, is expressed as gm-ions per liter. The effective concentration of hydrogen ions includes all sources arising by dissociation of soluble acids and those leached out from soil particles. Soil $\mathrm{pH}$ is usually measured with a glass electrode due to its multiple advantages over the hydrogen electrode. Hydration or $\mathrm{pH}$ paper may not be appropriate to measure soil pH because of probable interference of soil 
turbidity.

With a lowering of $\mathrm{pH}$ in a soil, corrosivity can rise markedly. Acid soils have $\mathrm{pH}$ values ranging from 3 to 6 . Alkaline soils having a pH ranging from 7.5 to 9.5 can be beneficial to buried steel (Headon and Chan, [53]). For ferrous metals, soil corrosivity commonly decreases as its $\mathrm{pH}$ rises. Clean steel does not corrode in a pure alkaline solution ( $\mathrm{pH}$ above 11.5 ). In the $\mathrm{pH}$ range of 4 to 8.5 , iron can be immune (not corroding), passive (corroding very slowly), or corroding actively, depending on its corrosion potential (Palmer, [38]). Oxides formed on the metal surface are insoluble and within a certain $\mathrm{pH}$ they are protective of the base metal. In the case of zinc, experience has shown that the corrosion products of zinc are insoluble within a $\mathrm{pH}$ of 5 to 12 (Darbin et al., [42]); and the work of Camitz and Vinka on Swedish soils [57] indicated that at low pH the formation of a protective layer of corrosion products is counteracted and the base zinc continues to corrode. As pH increases above 10, corrosive conditions become increasingly more passive.

Unfortunately, the corrosion of aluminum and galvanized steel can increase in the more alkaline solutions (Headon and Chan, [53]). Accordingly, without considering other factors such as metallurgy, soil pH does not seem to be directly related to soil corrosivity. In Figure 25, attempts 


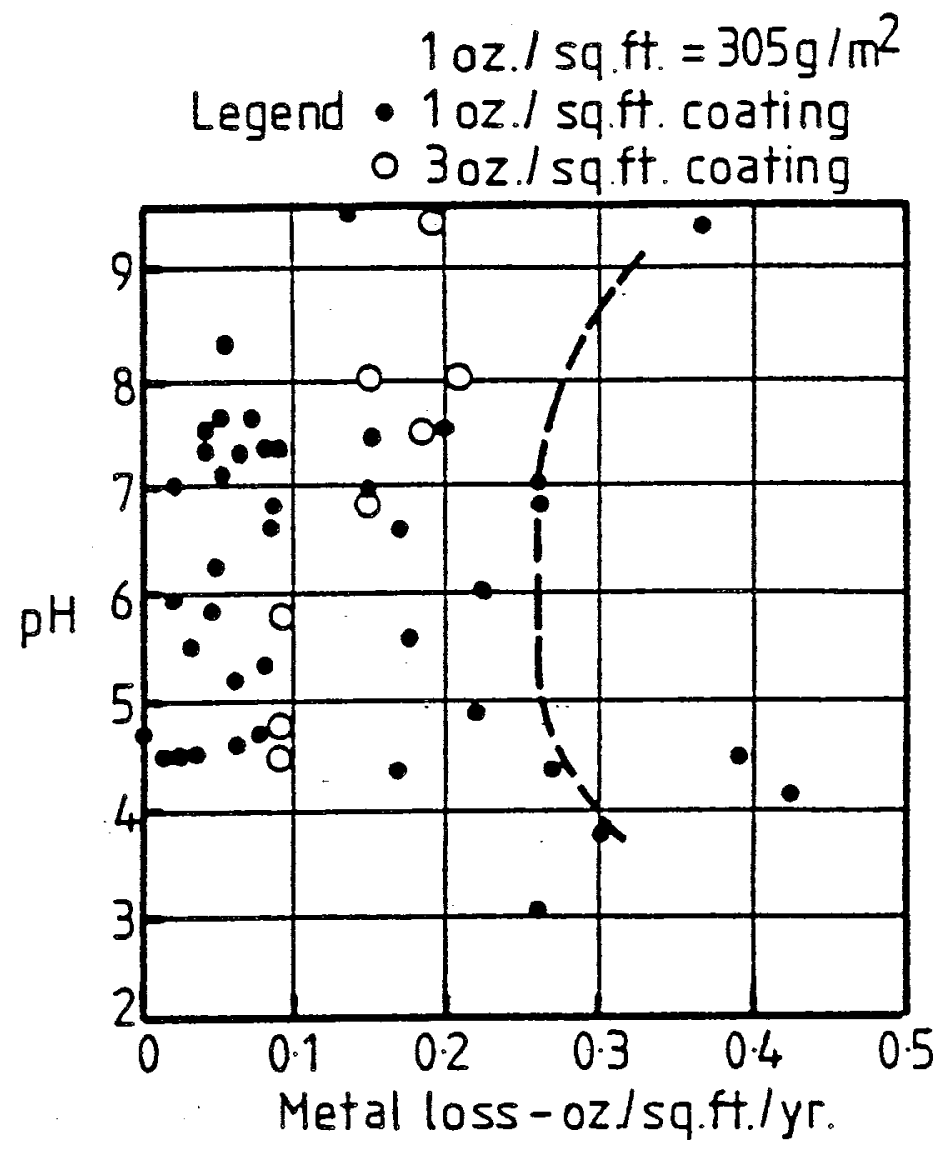

Figure 25 Metal Loss versus Soil $\mathrm{pH}$. (from Romanoff, [39]) 
made by Romanoff [39] to quantify the influence of $\mathrm{pH}$ value were not very successful, but for very acidic environments the metal loss was greater. Edgar [49] in his study on culverts stated that for the group of soils tested, the effect of $\mathrm{pH}$ is negligible, which is consistent with the findings of Haviland et al. [58] that soils with a pH between 6 and 9 have little or no effect on corrosion. Based on his previous tests in seven soils with a $\mathrm{pH}$ of 4.3 to 8.8, Escalante [43] also concluded that soil pH is a poor indicator of soil corrosivity. Palmer [38] stated that soil pH measurements may be useful in identifying unusual soil conditions but in most cases are only significant in distinguishing between otherwise similar soils.

Escalante [43] stated that most soils and all loams are fairly well buffered, resulting in a soil $\mathrm{pH}$ that is not affected by rainfall. However, Jackson [56] presented the contrary idea that a soil pH always varies with its water content. In the laboratory test, the more dilute the soil suspension the higher the soil pH value found, whether the soil is acid or alkaline (see Figure 26). In Figure 26, the rise in soil pH with dilution, from soil:water ratio of $1: 0.5$ to $1: 10$, is usually of the order of 0.2 to $0.5 \mathrm{pH}$ units, but may be 1 or more pH units. Therefore, for the same soil, different $\mathrm{pH}$ values will be obtained if a different soil:water ratio is used in the laboratory. Edgar [49] conducted the laboratory $\mathrm{pH}$ test by using a soil mixed 


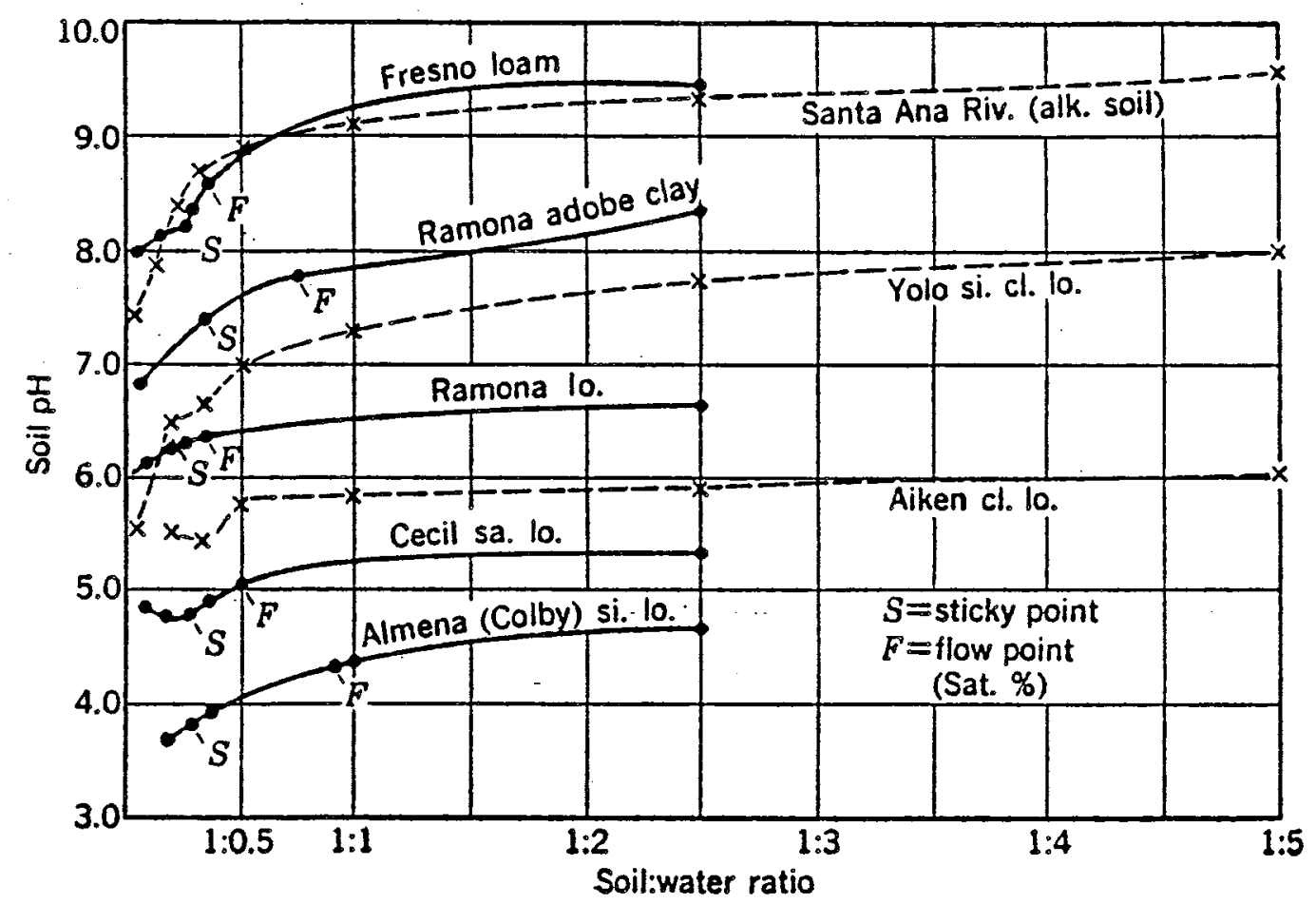

Figure 26 Observed Soil pH versus Soil:Water Ratio. (from Jackson, [56]) 
at a $1: 1$ ratio by weight with distilled water.

It should be noted that laboratory soil-pH tests must be conducted as quickly as possible after soil sampling, lest aeration of the as-received soil sample during transportation and storage change its $\mathrm{pH}$ value. Escalante [43] emphasized the importance of making $\mathrm{pH}$ measurements in situ rather than on samples carried back to the laboratory. An in situ measurement technique is described in the ASTM Test Method for $\mathrm{pH}$ of Soil for Use in Corrosion Testing (G 51-77) [83]. But it is difficult to attain the pH value of dry or low-moisture soils in situ (in dry seasons or above the water table), unless water is added.

Soil $\mathrm{pH}$ is the acidity or alkalinity of the soil media (on the logarithm scale). The total acidity of a soil is the sum (by weight) of all acid agents contained in the soil. Several investigators found that the measured total acidity on some organic soils appeared to be a better index of its corrosivity than pH alone (Denison and Hobbs [59]; Uhlig and Revie, [37]; and Iverson, [47]). Methods for determination of total acidity have been described by Romanoff [39]. The technique in determination of the total acidity was so laborious that its application to corrosivity prediction has been limited (Iverson, [47]). 


\section{Soluble Salts}

All solid materials contain a certain amount of salts as their constituents. Most salts are soluble, i.e., they can dissolve in water and become ions. When a soil particle is in contact with water, which has very low concentration of soluble salts, the soluble salts of the particle will tend to migrate from its interior to its surface and dissolve in the water. The dissolved amount of salts of the particle depends on its surface condition, its interior porous system (interior diffusion path for salts), the external salt concentration in water, the total amount of salts contained, and the time and the area in contact with water. The process of soluble constituents dissolving into the surrounding liquid is called leaching and the liquid with such dissolved salts is called leachate.

As mentioned earlier, the more soluble salts a soil has, the lower its resistivity. Darbin et al. [42] stated that if the flow of the electrochemical cell is regulated by the resistivity of the electrolyte, the difference in potential between the elements of the cell is dependent on the ion strength in the electrolyte. The ion strength is directly proportional to the concentration of dissolved salts (from a soil) in the water. Accordingly, soluble salts of a soil appear to be related to its corrosivity in some degree. A wide variety of salts typically exists in soils. 
The most common cations in the soil-water solution are potassium, sodium, magnesium, and calcium, and common anions include carbonates, sulfates, chlorides, and oxides. Each of these ions has its own reactivity with metal surfaces. Edgar [49] stated that two soils having the same minimum resistivity may react differently depending on the specific ions in each. Thus, the "total" amount of. salts available may not be indicative of the corrosivity of, the solution if certain combinations of compounds are formed.

Certain ions are aggressive, such as chlorides and to a lesser degree, sulfates. Headon and Chan [53] stated that in some instances, it has been possible to correlate the presence of large amounts of chloride and sulfate with increased soil corrosivity. Similarly, Uhlig and Revie [37] added that high concentrations of sodium chloride and sodium sulfate in poorly drained soils, such as are found in parts of southern California, made the soil very corrosive. In contrast, others, such as magnesium and calcium act as inhibitors of corrosion, because they tend to form insoluble oxide films on metal surfaces (Edgar, [49]). Carbonate precipitates in basic environments can also create a protective layer over metal surfaces and reduce the corrosion.

- Bushman and Mehalick [50] indicated that chloride ions act as the cathode depolarizes and thereby lower the soil 
resistivity. Palmer [38] reported that chloride ions tend. to break down the protective surface deposits and result in an increase of corrosion rate of a base metal. It should be emphasized that other than from the soil itself, another source of chlorides is from the application of deicing salts to highway facilities to avoid ice formation. A concentration of chloride ions in excess of $0.01 \%$ (by weight), in the environment, is considered indicative of accelerated corrosion (Palmer, [38]).

Most soils will show at least a trace of sulfides $\left(\mathrm{SO}_{3}\right)$ and/or sulfates $\left(\mathrm{SO}_{4}^{2-}\right)$, but this may only be significant in conjunction with a low redox potential (<+100 mV), i.e., a anaerated condition (Palmer, [38]). The presence of increasing sulfides is often an indicator of SRBs, and is always associated with a higher corrosion rate (Bushman and Mehalick, [50], Iverson, [47], and Darbin et aI., [42]). Edgar [49] presented two explanations of relating sulfates to corrosion: the basic "food" the SRBs consume, and the proportional amount of $\mathrm{H}^{+}$with respect to hydrolysis of sulfuric acid. A high level of sulfate contained in a soil is also harmful to adjacent concrete structures, and a sulfate level greater than $0.1 \%$ (by weight) indicates that a sulfate-resistant cement is required (Palmer [38] and Edgar [49]). As described in the section on Bacteria Attack, iron sulfate is one of two by-products created by SRBs. Booth et al. [51] (as cited in Iverson, [47]) found that all soils 
with a mean soluble iron content greater than $120 \mu \mathrm{g}$ per gram of soil were aggressive, if SRB activity exists. Soluble iron, soluble sulfide, and soluble sulfate, are related to the presence of SRBs, and are thus related to soil corrosivity. If a soil is free of SRBs, these three soluble ions (except for soluble sulfate) are less significant.

Edgar [49] in his study on culverts found that there did not appear to be any significant relationship between metal loss and total percentage of soluble salts. As described earlier, when the percentage of ionic salts increases in the water, the conductance of the soil-water solution also increases. Therefore, Edgar thought that it was redundant to check for both minimum resistivity and soluble salts. Here, this writer would like to state that the dissolution of the salts of a soil takes place only when water surrounds it, and thereby dissolved salts are related to soil corrosivity rather than total salts. Only the soluble salts, the portion of total salts which can dissolve in the water, participate in the corrosion activity occurring in the electrolyte. Smith [60] (as cited in Iverson, [47]) was unsuccessfully in correlating chemical composition (total salt content) of soils with their corrosiveness. 
Soil Fabric

A soil mass is composed of interconnected pores and soil particles, often collected into aggregates.. The pores of a soil include the intra-aggregate pores (existing within an aggregation of soil particles) and the inter-aggregate pores (existing between these soil particle aggregations), and they may contain water, air, or both. Soil fabric is the porous system in which the soil particles and aggregations of particles of different sizes are packed. The porous system influences the diffusivity of gases and dissolved salts, depending on saturation of the soil. The porous system first affects the aerated condition of the soil.

\section{Aeration}

A porous soil may retain moisture over a longer period of time or allow optimum aeration, and both factors tend to - increase the initial corrosion rate (Uhlig and Revie, [37]). Good aeration allows more oxygen to dissolve in the soil solution and the dissolved oxygen acts as a cathode depolarizer. The situation is more complex, however, because corrosion products formed in an aerated soil may be more protective than those formed in an anaerated soil. In most anaerated soils, observed corrosion takes the form of deep pitting, which is obviously more damaging to a pipeline than a higher overall corrosion rate occurring more uniformly. 
Another factor associated with the poorly aerated soils is the presence of SRBs, as mentioned earlier. Aeration of soils may affect corrosion not only by direct action of oxygen in forming protective films, but also indirectly through the influence of oxygen reacting with and decreasing the concentration of the organic matters or depolarizers naturally present in some soils. The effect of aeration has been summarized by Romanoff [39]. In general, good aeration is desirable from the standpoints of corrosion engineers.

\section{Internal Drainage (Permeability)}

The porous system of a soil also affects its internal drainage. The internal drainage is the property of the soil that describes the water retention ability of a soil (Escalante, [43]). Internal drainage of a soil influences its water content, concentration of soluble salts, and the potential height of the water table. Generally, a soil with a higher internal drainage can drain quickly when the water table arops (tending to hold a low water content), and its soluble salts are more easily leached out (resulting in decreasing soluble salts with time); while a soil with a low internal drainage will remain saturated once it becomes saturated, maintain a high water table, and also keep a constant or even increasing concentration of soluble salts ir the surrounding water. Accordingly, a higher internal drainage is preferred. 
As far as the porous system is concerned, it is possible to approximately evaluate soil corrosivity based on soil types. For example, clay, having the finest particle size and the smallest pore sizes, tend to reduce the movement of air and water and therefore can develop conditions of poor aeration and low internal drainage; while sand has the reverse behavior. Camitz and Vinka [57] from their study on Swedish soils concluded that the corrosion rate of several metals in the original soil is lowest in sand and highest in clay. However, this approximate rule is not valid if other significant electrochemical characteristics of a soil are involved.

site factors

The site condition is a variable of time and space. For example, the soil composition will change with time due to the leaching process of rainfall or industrial contamination, and a "variety" of soils rather than one soil may exist in a small area of interest, i.e., the buried site of metals. Accordingly, it is not surprising that the long-term performance of metals in situ is different from the results obtained by laboratory testing under controlled (predicted) conditions or by field tests conducted over a narrow zone in a certain season. 


\section{Temperature}

Temperature can certainly affect the rate of chemical reaction. Cooler temperatures reduce the chemical activity of the corrosion cell and the conductivity of the electrolyte, thus decreasing the corrosion rate of metals (Edgar, [49]). Escalante [43] found that the resistivity of a soil is inversely proportional to temperature and a higher soil temperature would increase its corrosivity. However, an increase in temperature also reduces the solubility of oxygen, and thus reduces the rate of reaction at the cathode. The net result is that temperature does not have as large an effect on underground corrosion as one might expect (Escalante, [61]).

on the other hand, cyclic changes of temperature may create a series of differential cells within the soil profile and should receive attention.

\section{Fluctuation of Water Table}

Camitz and Vinka [57] in their studies of Swedish soils found that the corrosion rate is considerably higher above than below the water table. They believed that the water table acts as a barrier to the transportation of oxygen through the soil. This transportation takes place primarily by diffusion. Above the groundwater table the soil pores are mostly air filled, which means that oxygen can be 
transported by diffusion in the gas phase. This give rise to more rapid transportation of oxygen to any metal surface situated above the water table, which in turn can stimulate the cathode process and increase corrosion attack. In contrast, oxygen transported by diffusion in the aqueous phase below the water table results in a considerably slower transportation, which reduces the cathode process as well as the corrosion rate. Furthermore, as mentioned before (Escalante, [43]), corrosion attack may concentrate on the portion of a metallic pile at the waterline, due to differential aeration at the water table interface (see Figure 23).

If the water table continuously changes with time, the soil within the zone of fluctuation will be alternately wet and dry, i.e., air filled followed by higher degrees of saturation. This gives rise to more differential aeration cells forming in the water table fluctuation zone, within Which corrosion attack on the metals will be aggravated.

\section{Water Movement}

A plentiful water source and good soil drainage are two requirements for water movement through a soil. Like the temperature effect, water movement has two opposite impacts on soil corrosivity. A high water movement, coupled with a high internal drainage, may remove the protective film earlier formed on metal surfaces and thus increase the 
corrosion rate. In contrast, it may also remove a portion of the dissolved salts and acidic ions from the native soil system and decrease the potential corrosivity of the soil. Accordingly, the net effect depends on the relative magnitudes of occurrence in situ.

4. Inhomogeneity of Soil Composition and Soil Fabric

The soil mass in situ is by nature nonhomogeneous to a certain degree. Thus, it is not surprising that there should be a variation in the measured value of a soil parameter at different tested points at the same site.

The inhomogeneity of soil composition, i.e., different types of soils existing on the site of buried metals, can form salt differential cells, as illustrated in Figure 14 (two different soils representing two different concentrations of solutions). The inhomogeneity of soil fabric, either in the same soil or in different soils, can also produce differential aeration cells. When one buried metal structure lies across such non-homogeneous subsoils, the two corrosion-induced cells will definitely enhance its corrosion rate. This variation of soil environments in situ may explain why corrosion predictions based merely on the electrochemical characteristics of a soil sample are much different from the results observed in the field.

The causes of non-homogeneous soil composition result 
from naturally occurring differences in soil types, leaching process due to variable regional rainfall, or inclusion of alien substances. The causes of non-homogeneous soil fabric may be different types of soils, localized disturbances, or unequal compaction. For natural soils, their composition and fabric may reach a stable and constant level or vary with time, depending on their surrounding environment.

\section{Alien Inclusions or Contamination}

Alien inclusions may produce heterogeneity in native soils. One example is backfill material, which is usually superior to the native soil. Serious corrosion might occur on the portion of a pipe branch traversing both the backfill and the native soil, since a concentration cell for corrosion may appear. Careful attention is required in the case of burying metallic structures in backfills.

Alien contamination can change the nature of the native soil-water electrolyte. Contamination sources can be industrial wastes (in a solid or aqueous state), acid rain, and other alien substances such as deicing salts. In most cases, the resulting soil environment will be much more aggressive than before.

Thus far, this writer has presented many concepts on underground corrosion. As demonstrated above, each corrosion mode (stray current, bacteria attacks, and undisturbed 
soils) may be somewhat related to one another, and furthermore be related to the elements of corrosion in disturbed soils. Their complicated relationships are shown in Table 11. The writer would like to sum up the discussion of underground corrosion with the following:

(1) Underground corrosion of metals is basically electrochemical. Its severity depends not only on the magnitude of the corrosion current but on the potential difference between two corrosion electrodes. The corrosion current is directly related to the conductivity of, or inversely proportional to the resistance of, the electrolyte. Therefore, the soil resistivity at a certain moisture content (matching the real site condition) can be taken as a strong indicator of the soil corrosivity or corrosion potential of metals buried in such a soil.

(2) However, the corrosion rate is also controlled by several depolarizers such as dissolved oxygen, acids (pH), chlorides, other soil electrochemical characteristics, and sulfate-reducing bacteria. On the other hand, the potential difference is dependent upon the types of corrosion cells, and thereby the soil fabric and site factors also influence the actual corrosion rate of metals in situ. And lastly, metallurgy and metal structure factors should also be considered, since each metal has a different response to the same underground environment.

(3) In conclusion, underground corrosion itself is not as 
Table 11 Relationship between Corrosion Type and Elements of Corrosion in Disturbed Soils

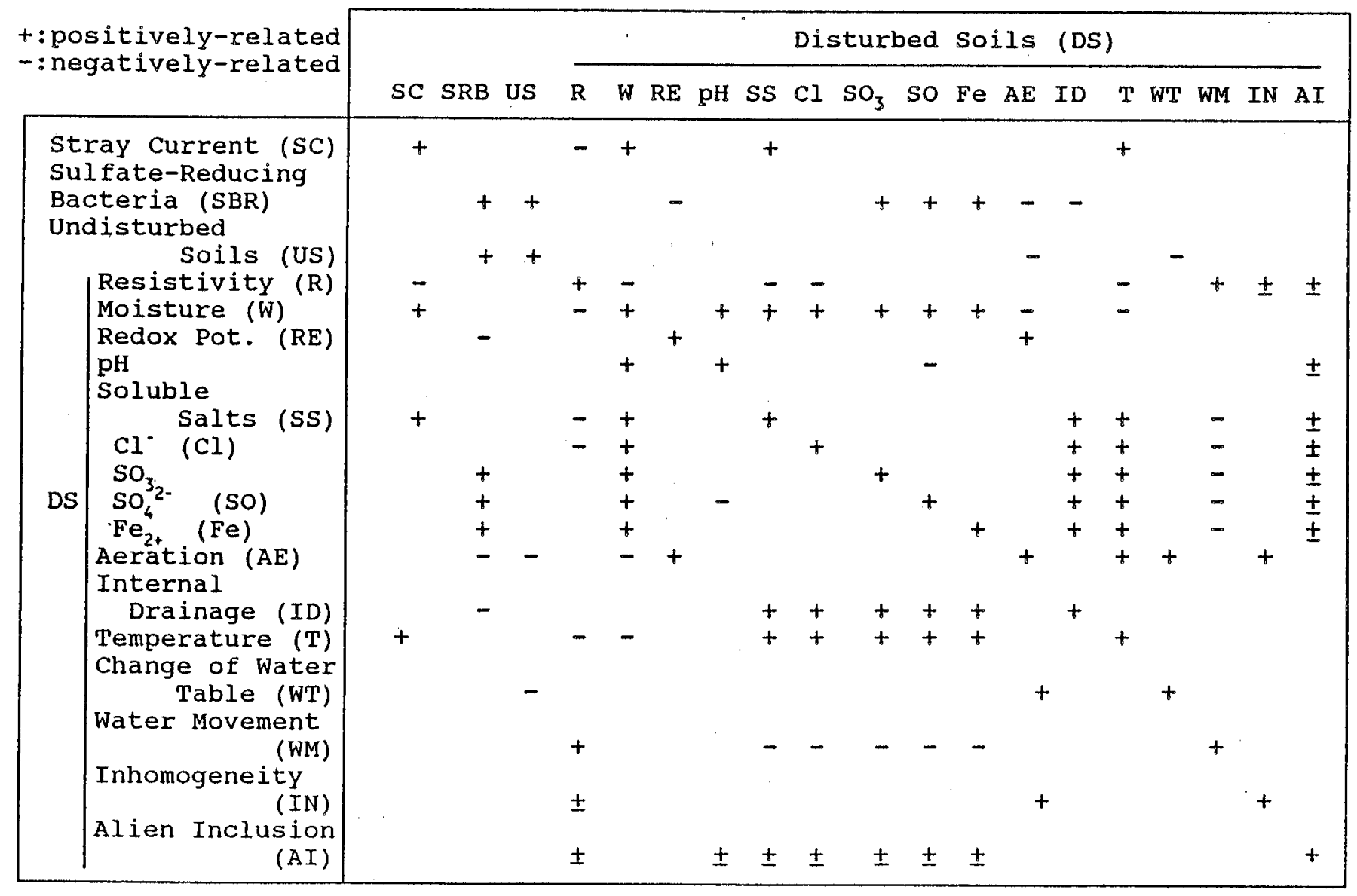


complicated as expected. If the complicated site factors are totally known and controlled, an accurate prediction of corrosion rate or soil corrosivity can be made.

Turning to the potential use of bottom ash, it is necessary to select the suitable concepts from the above understandings on soils. Since bottom ashes are used as a construction material, they can be considered as totally disturbed soils, and their initial storage state may be of little interest. Immediately after their production in the coal boiler, bottom ashes are surely free of any bacteria. Although bottom ashes may contain an amount of sulfate higher than natural soils and small amounts of residual carbon (an organic matter), they may be exempt from the risk of SBR activity even in the long term because of their relatively coarse particle size and good internal drainage. If it is assumed that the construction site is far from any electrical facility (i.e. without stray current), site variation conditions do not exist, and the bottom ash is totally saturated (i.e., the pessimal condition for corrosion), then the parameters of concern for corrosivity are the ash minimum resistivity, ash $\mathrm{pH}$, ash chlorides, and ash sulfates. The site factors should be taken into account for future construction to obtain the correct prediction of corrosion rates for metals buried in the bottom ash. 


\section{A Review of Test Methods}

A variety of test methods have been developed for ascertaining the corrosiveness of the soil. Some of them are laborious, others are quite simple. Some are for use primarily in the laboratory, others for use in the field, and still others for use in both places.

To assess the severity of corrosion of a buried metal or the corrosion resistance of the metal to one soil environment, the direct method is to measure the metal loss rate (by weight) or the penetration rate of the metal. Subsequently, based on the observed corrosion results of the buried metal, soil corrosivity can be classified. The soil burial method is a direct method. Indirect methods include the electrochemical techniques and the correlations between soil corrosivity and soil environmental parameters. Each method has its corresponding advantages and demerits, in terms of reliability, economy, and ease of operation. These methods are described below.

\section{Burial Method}

The classical method of soil corrosion testing has been to bury a large number of weighted metal specimens in a designated soil, removing them at various time intervals and determining the change in weight (Iverson, [47]). Extensive data have been obtained by the National Bureau of Standards 
(NBS) using this technique on approximately 37,000 specimens, representing more than 330 variety of metals, alloys, and protective coatings.These specimens have been exposed up to 17 years in 128 test locations throughout the United States (Romanoff, [39]). Initially 10 to 12 specimens were removed at intervals of about 2 years. Later the times between the removals were varied, depending on the corrosiveness of the soils to which they were exposed. These field tests were begun in 1910 by K. H. Logan and continued until 1955. The test results were collected in "Underground corrosion" by Romanoff [39]. Although these data do not allow correlation between any single soil parameter and soil corrosivity, they are very useful for predicting corrosivity of a soil similar to the ones in which the tests were made. Uhlig and Revie [37] selected a few typical metal corrosion rates averaged over many soils from Romanoff's data [39] as shown in Table 12. This table reveals that on the average copper corrodes at about one-sixth the rate of iron; lead corrodes at about half the rate of iron; and zinc corrodes at about two-third the rate of iron.

In addition to the main benefit of the burial method its reliability (i.e., directly measuring the corrosion loss of a metal exposed to one soil environment), its superiority to any technique yet devised is the capability of demonstrating how a soil environment will pit a given metal or alloy, as well as producing any other localized corrosion 
Table 12 Corrosion of Steels, Copper, Lead, zinc in Soils. (from Uhlig and Revie, [37])

\begin{tabular}{|c|c|c|c|c|c|c|c|c|c|c|c|c|}
\hline \multicolumn{13}{|c|}{$\begin{array}{l}\text { Maximum penetration in mils }(1 \mathrm{mil}=0.001 \text { in. }=0.025 \mathrm{~mm}) \text { for total exposure period. } \\
\text { Average corrosion rates in } \mathrm{g} \mathrm{m}^{-2} \mathrm{~d}^{-1}(\mathrm{gmd}) \text {. }\end{array}$} \\
\hline \multirow[b]{3}{*}{ Soil } & \multicolumn{2}{|c|}{$\begin{array}{l}\text { Open Hearth } \\
\text { Iron }\end{array}$} & \multicolumn{2}{|c|}{ Wrought Iron } & \multicolumn{2}{|c|}{$\begin{array}{l}\text { Bessemer } \\
\text { Steel }\end{array}$} & \multicolumn{2}{|c|}{ Copper } & \multicolumn{2}{|c|}{ Lead } & \multicolumn{2}{|c|}{ Zinc } \\
\hline & \multicolumn{2}{|c|}{$\begin{array}{c}\text { 12-Year } \\
\text { Exposure }\end{array}$} & \multicolumn{2}{|c|}{$\begin{array}{c}\text { 12-Year } \\
\text { Exposure }\end{array}$} & \multicolumn{2}{|c|}{$\begin{array}{c}\text { 12-Year } \\
\text { Exposure }\end{array}$} & \multicolumn{2}{|c|}{$\begin{array}{l}\text { 8-Year } \\
\text { Exposure }\end{array}$} & \multicolumn{2}{|c|}{$\begin{array}{l}\text { 12-Year } \\
\text { Exposure }\end{array}$} & \multicolumn{2}{|c|}{$\begin{array}{l}\text { 11-Year } \\
\text { Exposure }\end{array}$} \\
\hline & gmd & mils & gmd & mils & gmd & mils & gmd & mils & gmd & mils & gmd & mils \\
\hline $\begin{array}{l}\text { Average of several } \\
\text { soils }\end{array}$ & \multicolumn{2}{|c|}{ (44 soils) } & \multicolumn{2}{|c|}{ (44 soils) } & \multicolumn{2}{|c|}{ (44 soils) } & \multicolumn{2}{|c|}{$\begin{array}{c}0.07<6 \text { soils }) \\
(29 \text { ) }\end{array}$} & \multicolumn{2}{|c|}{$\begin{array}{l}0.052>32 \\
(21 \text { soils })\end{array}$} & \multicolumn{2}{|c|}{$\begin{array}{c}0.3 \quad(12 \text { soils }) \\
\text { (1) }\end{array}$} \\
\hline $\begin{array}{l}\text { Tidal marsh, } \\
\text { Elizabeth, N.J. }\end{array}$ & 1.08 & 90 & 1.16 & 80 & 1.95 & 100 & 0.53 & $<6$ & 0.02 & 13 & 0.19 & 36 \\
\hline $\begin{array}{l}\text { Montezuma clay } \\
\text { Adobe, San Diego, } \\
\text { California }\end{array}$ & 1.37 & $>145$ & 1.34 & $>132$ & 1.43 & $>137$ & 0.07 & $<6$ & $\begin{array}{r}0.06 \\
(9.6\end{array}$ & ars) & - & - \\
\hline $\begin{array}{l}\text { Merrimac gravelly } \\
\text { sandy loam, } \\
\text { Norwood, } \\
\text { Massachusetts }\end{array}$ & 0.09 & 28 & 0.10 & 23 & 0.10 & 21 & $\begin{array}{l}0.02 \\
(13.2\end{array}$ & $\begin{array}{r}<6 \\
<a r s)\end{array}$ & 0.013 & 19 & - & - \\
\hline
\end{tabular}


patterns (Iverson, [47]). The metal loss after a period of exposure can be determined by weighing the metal specimen treated by certain acid solution which can "erase" the corroded metal from its surface, and calculating the difference between the initial weight and the treated weight of the specimen. For a pattern of uniform corrosion, the one-side corrosion penetration can be calculated by dividing the the metal loss by the product of exposure area and the density of the metal. The pitting depth can measured by use of a needle instrument after the acid treatment.

The major disadvantage of the burial method is that it is very time consuming. If it is desirable to obtain a long-term corrosion rate profile of a metal exposed to one soil environment, perhaps a number of decades are needed. When a "new" material environment such as bottom ash is involved, it is not feasible to wait for the outcome of a burial test of one metal and then judge whether the new material environment is corrosive. Besides, the burial method necessitates the employment of a considerable number of specimens to be of statistical significance (Iverson, [47]), and to avoid the possible errors of measurement. In an actual construction application, the metal specimens should be placed at the same level of the future metal structures, since the corrosivity of the material may change with depth. Rabeler [62] in his corrosion studies on screw anchors stated that the data in Romanoff [39], in which the 
specimens were buried at a relatively shallow depth, may not be indicative of deeply embedded specimens such as driven piles or screw anchors.

In most cases, the burial method is the preferred field test. Some investigators such as Headon and Chan [53] performed a short-term metal loss test in the laboratory. However, it is always difficult for a laboratory test to cover the complicated variation in corrosion conditions in situ.

Without the capability of performing time-consuming field burial tests, this writer was interested in determining the possibility of using the aforementioned accelerated tests for determination of durability, if the dominant deterioration mechanism is corrosion. Unfortunately, the answer is negative. The reason is that in this case the bottom ash environment is what needs to be studied. First, this writer can not increase the corrosivity derived from the electrochemical characteristics of the material of interest, since a "new" material is being examined. Secondly, the most unfavorable site factors may be used for the laboratory soil samples to increase the corrosion rate of the buried metal, but this condition may distort the field corrosion process so that the obtained acceleration factor $\left(F_{a c c}\right)$ is of no meaning. Therefore, in corrosion, no totally appropriate accelerated test has yet 
been developed and documented.

The burial method still plays an important role in providing a reference guide which has been considered the most reliable. Other new methods must be proven valid on the basis of a comparison between the results of these new methods and of the burial methods. Only the methods which yield consistent results with the burial method can replace the lengthy burial method.

\section{Electrochemical Techniques}

New tests have been developed primarily to replace or supplement the very reliable but lengthy soil burial method. The application of electrochemical techniques is one example. The concepts of the electrochemical techniques are not new. The electrochemical techniques have been successfully applied to corrosion monitoring in industrial plants (Moran and Labine, [63]). Iverson [47] introduced several electrochemical techniques such as specimen-to-soil potentials, galvanic couple tests, accelerated corrosion tests, oxygen concentration cells, and polarization techniques. Among these the polarization techniques, when applied to buried specimens, may prove to be close to a single and reliable method. Accordingly, only the polarization techniques are discussed here. They include the polarization resistance method and the polarization break 
method, both allowing the calculation of the corrosion rate of metals.

The polarization resistance method (or linear polarization technique) is based on the following relationship derived by stern and Geary [64]:

$$
\frac{\Delta E}{\Delta \bar{I}}=\frac{1}{2.3 I_{c o r r}} \frac{\beta_{a} \beta_{c}}{\left(\beta_{a}+\beta_{c}\right)}
$$

where $\Delta \mathrm{E}$ is the overvoltage of the corroding electrode produced by a polarizing current $\Delta I ; \Delta E / \Delta I$ is the slope of the polarization curve (termed "polarization resistance"); $\beta_{a}$ and $\beta_{c}$ are the slopes of the anodic and cathodic polarization curves, respectively, in the Tafel region (a linear portion of the polarization curve); and $I_{c o r r}$ is the corrosion current. The $\Delta I / \Delta E$, rather than the reciprocal, is used since this ratio is directly proportional to the corrosion current $\left(I_{\text {corr }}\right)$, as indicated below:

$$
\Delta I / \Delta E=2.3 I_{\operatorname{cor} r} \frac{\left(\beta_{a}+\beta_{c}\right)}{\beta_{a} \beta_{c}}
$$

The ratio $\Delta I / \Delta E$ has been termed "polarization admittance" by Annand [65], and thereby the polarization resistance method is also called the polarization admittance method. The constants $\beta_{a}$ and $\beta_{c}$ were both assumed to be equal to 0.1 in this investigation (Iverson, [47]). This results in the following equation: 


$$
\begin{aligned}
& I_{c o r r}(m A)=\frac{1}{0.0023} \frac{\Delta I}{\Delta E} \frac{\beta_{a} \beta_{c}}{\left(\beta_{a}+\beta_{c}\right)} \\
& \quad \operatorname{or} \\
& I_{c o r r}(m A)=21.7 \frac{\Delta I(m A)}{\Delta E(m V)}
\end{aligned}
$$

The polarization break method originally proposed by Schwerdtfeger and McDorman [66] is based on the observation that anodic and cathodic polarization curves consist of straight-line segments having different slopes. The current at which the "change" in slope (break) occurs is designated $I_{p}$ for the cathodic and $I_{q}$ for the anodic curve. The corrosion $I_{c}$ can be calculated from the following relationship, which was derived by Pearson [67]:

$$
I_{c}=\frac{I_{p} I_{q}}{\left(I_{p}+I_{q}\right)}
$$

Figure 27 shows the break values in typical polarization curves of iron and stainless steel (Iverson, [47]). It should be emphasized that these curves are to be plotted on linear scales as first proposed by Schwerdtfeger [66] to find the breaks. The use of a semilog plot (log current versus linear potential) should be restricted to display of data which cover a wide current range and to the replotting of curves for which definite breaks can be obtained on the linear scale. In several cases the break may even be made more obvious by plotting on a semilog scale. When there are no linear breaks (because of polarization with an unsatisfactory range of currents), the plotting of 


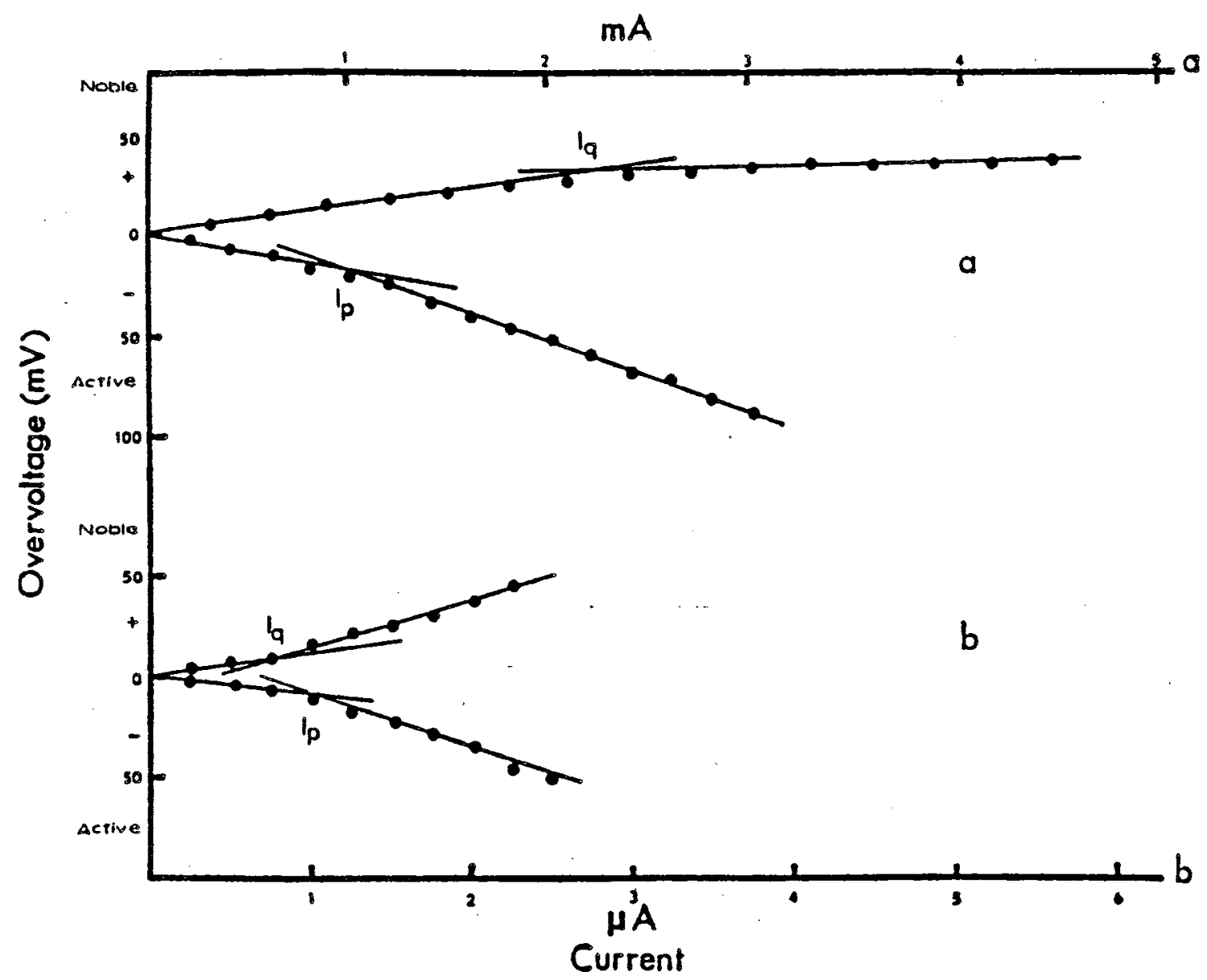

Figure 27 Polarization Curves of (a) Black Iron and (b) Stainless Steel $_{304}$ (from Iverson, [47]) 
data on semilog paper may result in the interpretation of false breaks (Iverson, [47]).

As described above, both the polarization resistance and polarization techniques can calculate only the corrosion rate. Faraday's law must then be used to convert from the corrosion current to the corrosion rate, either in units of rate of metal loss (by weight) or of penetration (by length). Headon and Chan [53] gave the conversion factors of several metals as shown in Table 13 .

Rabeler [62] in his studies on screw anchors found that both polarization methods can predict the measured corrosion rate and the polarization break technique appeared to most accurately reflect weight loss measurements. other investigators such as Headon and Chan [53], Darbin et al. [42], Serra and Mannheimer [68], and Fisher and Bue [69], based on their findings, also encouraged the use of the polarization techniques for prediction of the corrosion rate of metals. Like the burial method, the polarization techniques conducted in the field are more desirable, because they take into account the true conditions in situ. However, Headon and Chan [53] and Darbin et al. [42] also successfully applied the polarization resistance technique to samples in the laboratory. Basic equipment includes a potentiostat and appropriate electrodes. The instrumentation is different in the field and in the laboratory, and some 
Table 13 Conversion Factors of Current Density to Corrosion Rate.

(from Headon and chan, [53])

\begin{tabular}{lr} 
Element or Alloy & $\begin{array}{r}\text { Corrosion rate equivalent } \\
\text { to } 1 \mathrm{\mu A} / \mathrm{cm}^{2} \\
(\mathrm{~mm} / \mathrm{Y})\end{array}$ \\
\hline Carbon steel & 0.012 \\
304 stainless steel & 0.011 \\
Aluminum & 0.011 \\
Zinc & 0.015 \\
Copper & 0.012 \\
\hline
\end{tabular}


modifications should be employed to fill the special requirements of each.

As Darbin et al. [42] stressed, the polarization techniques are not accelerated tests, because they do not accelerate the corrosion process. Therefore, if the long-term corrosion behavior of a metal in one soil environment is of interest, the polarization measurements must be taken over a long period of time, as with the burial method. One marked difference between them is that the measurements of polarization techniques do not require the removal of specimens from the soil. Also, not as many specimens are required as with the burial method. Because of their ease of operation and nondestructive measurements, it is expected that the polarization techniques will become more feasible in the future and gradually replace the time-consuming burial method. However, there still exist several limitations and errors in their operations [70], and caution needs to be exercised in any application of these techniques.

\section{Correlations with Soil Environmental parameters}

Although it seems that none of the soil environmental parameters can be taken as single predictors of soil corrosivity, a certain combination of them may give a reasonable estimate. Fitzgerald [46] indicated that previous 
workers have failed to correlate different soil characteristics with soil corrosivity. Today the statistical analysis of several soil characteristics may be a good indication of the effects of a soil on various metals. However, even a combination of the soil characteristics is not enough to predict the actual soil corrosivity. As this writer emphasized earlier, the true corrosion behavior of a metal exposed to one soil environment depends not only on the soil environmental parameters, but also on the metal structural parameters.

Bushman and Mehalick [50] used the statistical analysis of soil characteristics to predict the Time to corrosion Failure (TCF) for underground metallic structures. They employed eleven soil environmental parameters and eight metal structure factors as the independent variables, and used a multivariate linear regression method of analysis. The proposed regression model is based on the general form:

where

$$
\mathrm{Y}=\mathrm{B}_{0}+\mathrm{B}_{1} \mathrm{X}_{1}+\ldots+\mathrm{B}_{k} \mathrm{X}_{k}+\ldots+\mathrm{B}_{\mathrm{n}} \mathrm{X}_{\mathrm{n}}+\mathrm{e} \mathrm{EQ} \text { (12) }
$$

$\mathrm{Y}=$ the dependent variable (for example, time to corrosion failure or average metal loss rate),

$\mathrm{x}_{\mathrm{k}}=$ the $\mathrm{k}$-th independent variable which impacts the dependent variable such as the above-mentioned 19 parameters,

$\mathrm{B}_{\mathrm{k}}=$ the regression coefficient to be determined for $X_{k}$ based on its relative contribution to $Y$, 


$$
\begin{aligned}
& \mathrm{B}_{0}=\text { constant or } \mathrm{Y} \text { intercept, } \\
& \mathrm{n}=\text { the total number of independent variables, and } \\
& \mathrm{e}=\text { random error possessing a normal probability. }
\end{aligned}
$$
distribution and having a mean of zero and a constant variance.

The appropriateness of any multiple regression equation obtained can be evaluated by a variety of statistical inferences (Neter et al., [71]). Among them, the measure $r^{2}$, the coefficient of multiple determination, is the simplest one. It is defined by:

$$
r^{2}=\frac{\text { SSR }}{\text { SSTO }}
$$

where SSR is the regression sum of squares and SSTO is the total variation of $Y$. The $r^{2}$ can be interpreted as the proportional reduction of the total variation associated with the employment of the regression model. The larger $r^{2}$, the more the ssTo of $Y$ is reduced by the model, i.e., the more appropriate is the model.

After determination of $a$ set of $B_{k}$ values using the least square method, Bushman and Mehalick [50] calculated the predicted time to corrosion failure (MTCF). Although they did not show the actual value of $r^{2}$, the obtained regression equation appears satisfactory based on the comparison of actual data and MTCF. They also demonstrated the inability to use any single parameter to predict the 
TCF, and concluded that the multivariate statistical analysis technique provides an extremely powerful tool to deal with the complicated problem of soil corrosion.

Here, this writer would like to comment: (1) in a regression model, all independent variables should be exclusively independent of one another, but several soil environmental parameters are somewhat related; (2) although the larger the number of independent variables used, the better the fit of the regression model, the larger number of independent variables implies a large number of measurements which need to be performed, i.e, more time and expense; (3) the success of the regression analysis is restricted to the number of available data sets $\left(Y, X_{1}, \ldots, X_{n}\right)$ and more data sets always improve the fitting and reliability of the model; and (4) some corrosion-induced parameters, such as soil fabric and metallurgy, are difficult to quantify. Accordingly, and with the aid of computers the multivariate regression analysis is not constrained by the number of independent variables, but it is not wise to select as many related parameters as one desires. If a well-fitted multivariate regression model needs ten soil parameters, a researcher would rather perform the lengthy burial test than spend more time and money in measuring these ten soil parameters. So far, no comprehensive and general multivariate regression model, which fits any application and medium, has been established. 
Because of the above-mentioned reason and limited data sets on bottom ash, it is impossible to apply the powerful multivariate regression model to bottom ash. Additionally, due to the limited research funding and time, it is impossible to perform the long-term burial test or polarization techniques for evaluating the corrosivity of bottom ash. As discussed earlier, the most relevant parameters for the corrosivity of bottom ash are resistivity, $\mathrm{pH}$, chloride, and sulfate, if the site factors are excluded. Several available criteria of soil corrosivity have also been established, based on these four parameters. Therefore, these four parameters have been selected to assess the corrosivity of bottom ash. The experimental tests will include only the determinations of these four characteristics of candidate bottom ashes. In Chapter VI, these four ash electrochemical characteristics are compared with the available criteria on soils, and subsequently are used to evaluate the bottom ash corrosivity or even the service life of some metallic structures embedded in bottom ash.

A recent report by Kroon [72] on data obtained at 2894 underground tank facilities (7590 tanks) ranging in age from 1 to 31 years demonstrated a significant variation in the soil characteristics. Bushman and Mehalick [50] summarized these soil data (only the portion of the above four 
characteristics) as shown in Table 14. Darbin et al. [42] provided the statistical results of the electrochemical analysis of soils used by the Reinforced Earth Company as shown in Table 15. Upon the determinations of four electrochemical characteristics of candidate bottom ashes, a comparison will also be made with those of soils in Table 14 and 15.

\section{Past corrosion studies on Bottom ash}

Early corrosion studies on power plant ash were focused on fly ash and most of them were made by European investigators. Due to its commonly alkaline pH, fly ash was considered an excellent inhibitor of steel corrosion initially, but such inhibition effects might decrease with time as the alkaline $\mathrm{pH}$ is gradually reduced.

Recent studies on corrosion of metals in bottom ash are limited. Headon and Chan [53] in 1982 used the polarization resistance technique and the short-term metal loss method to evaluate the corrosivity of one bottom ash produced in Toronto. These tests were used, since it was believed that any combination of soil physiochemical characteristics could not reliably represent the soil corrosivity or that of bottom ash. The bottom ash tested had a minimum resistivity of $850 \mathrm{ohm}-\mathrm{cm}$ and the test results showed that the corrosion rate of metals in this bottom ash depends on the types of 
Table 14. Statistic Results of Four Electrochemical Characteristics on Soils. (from Bushman and Mehalick [50])

(1) Soil resistivity (mean value at site)

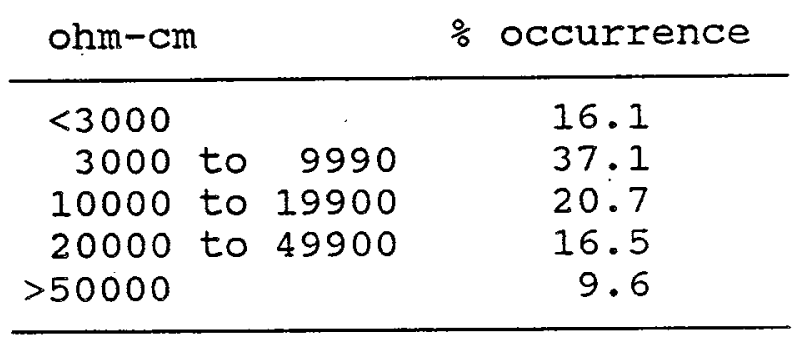

(2) Soil $\mathrm{pH}$ (mean value at site)

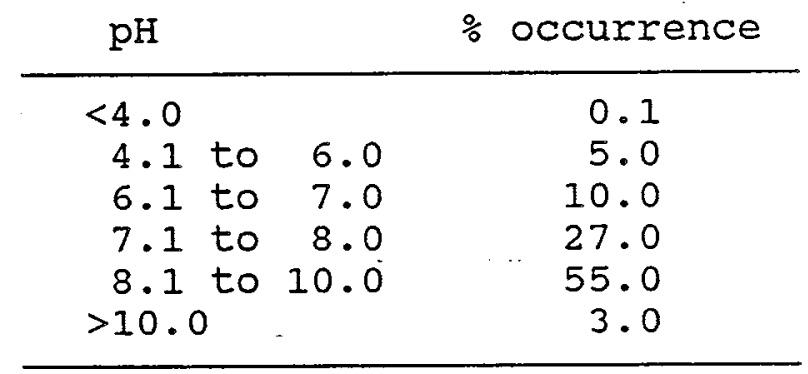

(3) $\mathrm{Cl}^{-}$concentration (maximum at site) mg per liter \% occurrence

\begin{tabular}{rr}
0 to 9 & 43.4 \\
10 to 19 & 19.9 \\
20 to 49 & 16.3 \\
50 to 99 & 7.8 \\
$>100$ & 12.6 \\
\hline
\end{tabular}

(4) $\mathrm{SO}_{3}$ concentration (maximum at site)

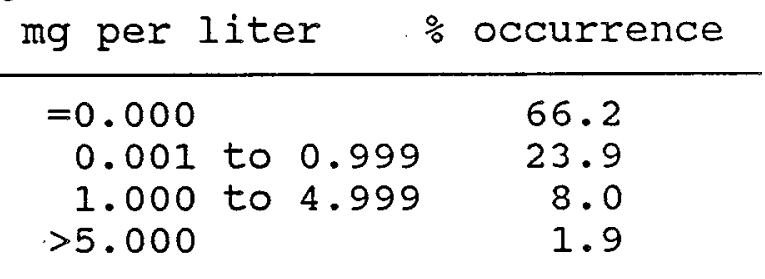


Table 15 Statistic Results of Four Electrochemical Characteristics on Metal-Reinforced Soils. (from Darbin et al. [42])

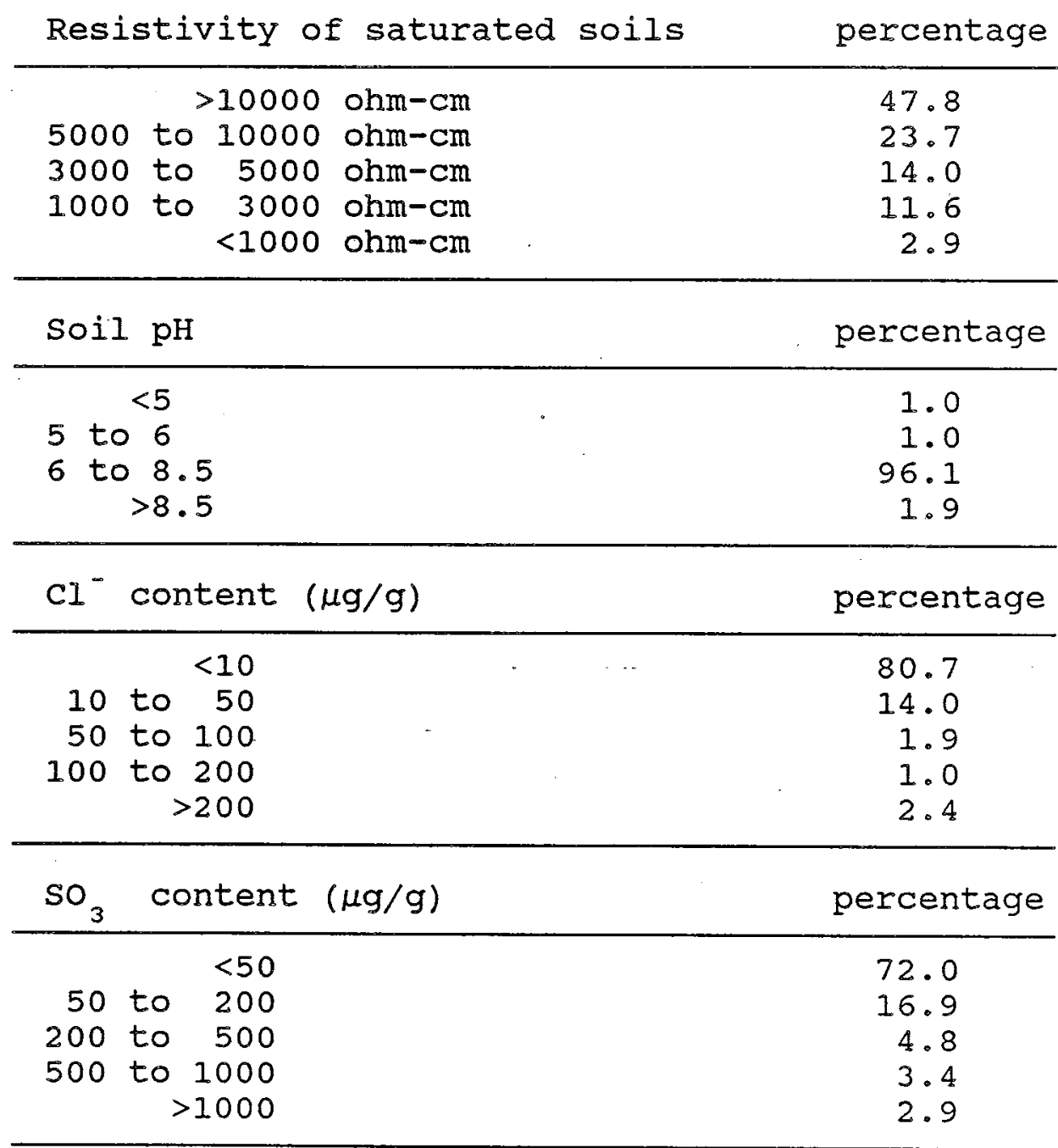


metals and the degree of saturation of bottom ash. They did not attempt to correlate the metal loss rates obtained by the above two methods with the physiochemical characteristics of bottom ash.

Jablonski and Aliff [73] conducted both laboratory tests and field tests on ashes produced from 18 American Electric Power Plants. The laboratory tests included: $\mathrm{pH}$, solution resistivity, soluble sulfates, saturated resistivity, and redox potential. The ranges of $\mathrm{pH}$ value, soluble sulfate, and saturated resistivity on the tested dry bottom ashes are $4-9,<2 \%$, and $150-2900$ ohm-cm, respectively; and those on wet bottom ashes are $4.5-7$, < $2 \%$, and $700-7700 \mathrm{ohm}-\mathrm{cm}$, respectively. They then used four evaluation criteria to rank the corrosivity of the ashes. Subsequently they selected the more corrosive ashes and performed the field burial tests. The first 24-month exposure results indicated that bottom ashes are no more corrosive than sand or native soil. One of their valuable findings is that the time-dependent electrochemical properties of the ash in situ implies a decrease in its corrosivity with time. Not completed yet are the Phase II studies in which they will correlate the observed corrosion in situ and the ash properties. 
Summary

Metals will corrode with time naturally, because they have been derived from their oxides with the result that they are in a less stable state than their naturally occurring ores.

The term "corrosion" should only be used on metals. Therefore, corrosion is defined as the deterioration of a metal, usually caused by a chemical or electrochemical reaction with the surrounding environment. Corrosivity is related to the surrounding environment and is defined as the severity of the environment causing corrosion of a metal which is placed in it.

The result of corrosion is an economic loss. The annual direct losses due to corrosion in United States are about 4.2\% of the Gross National Product (GNP). The combination of direct losses and indirect losses is forcing engineers to further understand the complicated corrosion mechanism and to find more effective protection techniques.

A corrosion environment includes atmospheric, aqueous, and underground environments. Considering the proposed use of bottom ash, only the underground corrosion is of concern. corrosion of a metal is essentially an electrochemical process. Based on knowledge of the basic corrosion mechanism, the complications of underground corrosion were 
presented. Understanding of these mechanisms has been developed through experiences with soils. The causes of underground corrosion are stray current, bacteria attacks, corrosion in undisturbed soils, and corrosion in disturbed soils, which is the most complex one and includes a variety of elements. Considering the utilization of bottom ash, the most relevant parameters to the corrosivity of bottom ash are its resistivity, $\mathrm{pH}$, soluble chlorides, and soluble sulfates, if the site factors are excluded.

The most reliable method to evaluate either the corrosion resistance of a metal or the corrosivity of a media is the burial method, in which the metal loss due to corrosion can be directly measured and the localized corrosion damage such as pitting can be observed. Because of the time-consuming feature of the burial method, new methods have been developed. These include several electrochemical techniques. Among them, the polarization techniques (Iinear polarization and polarization break methods) are considered to have a reliability similar to the burial method. In the past, most investigators failed to correlate multiple soil parameters with soil corrosivity.

The modern multivariate regression analysis, in which both soil characteristics and metal structure factors are involved, may be a powerful tool to deal with the complex corrosivity of a media. However, the need to spend more time 
and money on determination of many related parameters reduces the attractiveness of such a regression model. Due to the limitation of funding and time, the aforementioned four electrochemical characteristics were selected to evaluate the corrosivity of bottom ash, based on several criteria for soil corrosivity.

So far, very few studies on bottom ash corrosivity have been conducted. The scope of this research is to extend the previous knowledge and to establish a.simple criterion through which to determine the acceptability of bottom ash in construction sites where metallic structures may be present. 


\section{Chapter III TESTING MATERIALS}

In this study, four different bottom ashes were selected from three utility power stations in Indiana (Perry, Gibson, and Schahfer stations). The selected ash materials consisted of three dry bottom ashes and one wet bottom ash. The physical appearance of the ash ranged from gray, friable, and porous to black, hard, and glassy. As soil types differ from place to place, bottom ash varies in appearance and character among power stations. The variation is due to different coal sources and different boiler types used in each power station (Jablonski and Aliff, [73]). Described below in sections that follow are: selection of Ash Samples; Sampling Procedure and Field Testing; and Sampling, Description and known Properties of candidate Ashes.

\section{Selection of Ash Samples}

The selection of the ash samples was essentially based on the current study undertaken by Huang [5]. He selected 11 bottom ashes from 10 power stations located in Indiana, based on: a previous study on Indiana fly ashes [74]; geographic distribution of power stations; coverage of 
utility companies; and station capacities. Figure 28 shows the approximate locations of these power stations. Table 16 lists their locations and rated capacities; and Table 17 summarizes the major coal sources and the resulting types of bottom ash for these stations.

It is advantageous for this study to select several candidate ashes from the above 11 bottom ashes whose properties has been generally examined. Huang [5] has reported the chemical composition, engineering characteristics, and environmental effects of these bottom ashes. In fact, a main goal of this study is to supplement the above investigation with respect to durability and corrosiveness of bottom ash. The combined endeavors of Huang and this writer will provide a data base to evaluate the suitability of bottom ash for use as a construction material in a variety of applications, whether or not metal structures are involved.

The next problem lies in selecting candidate bottom ashes. Since "bottom ash" is the only material of interest in this study, a dominant criterion for selection is whether or not the bottom ash is stored separately from fly ash at the storage site. Specifying the conditions of storage is important since stockpiling of the bottom ash at storage sites will be necessary for "large-volume" uses (Huang, [5]). This writer collected the data on ash storage 


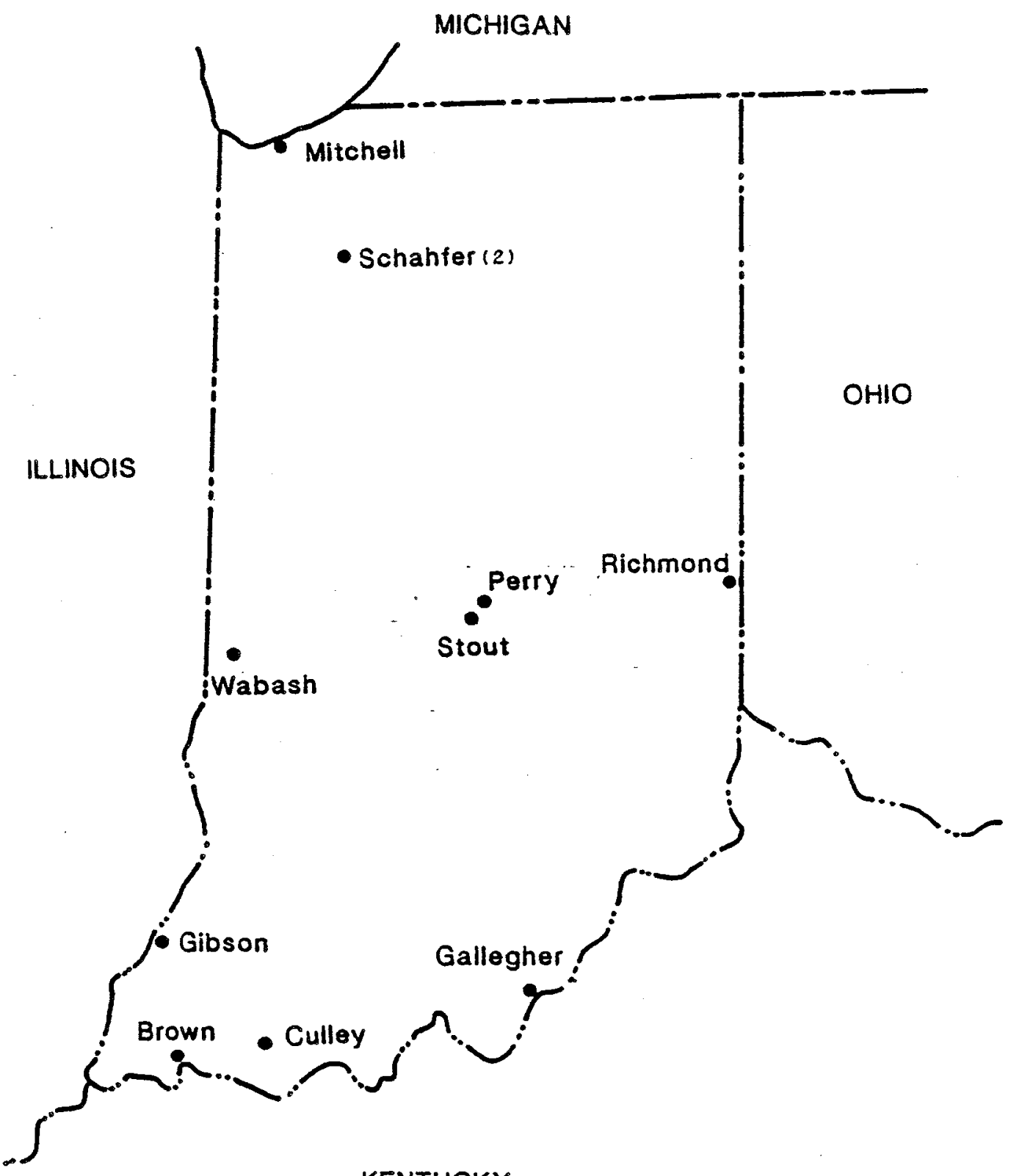

KENTUCKY

$\therefore$ Figure 28 Approximate Locations of Bottom Ash Sources in Indiana. (from Huang, [5]) 
Table 16 Indiana Bottom Ash Sources. (from Huang, [5])

\begin{tabular}{lllr}
\hline $\begin{array}{l}\text { Utility } \\
\text { Company }\end{array}$ & Station & $\begin{array}{l}\text { Location } \\
\text { (county) }\end{array}$ & $\begin{array}{c}\text { Capacity } \\
\text { (MW) }\end{array}$ \\
\hline NIPSCO & R. M. Schahfer, Unit 14 & Jasper & 370 \\
NIPSCO & R. M. Schahfer, Unit 17 & Jasper & 420 \\
NIPSCO & D. H. Mitchell & Lake & 505 \\
PSI & Gibson & Gibson & 3,340 \\
PSI & R. A. Gallagher & Floyd & 500 \\
PSI & Wabash River & Vigo & 788 \\
SIGECO & A. B. Brown & Posey & 500 \\
SIGECO & F. B. Culley & Warrick & 395 \\
RPL & Whitewater Valley & Wayne & 100 \\
IPL & C. C. Perry & Marion & 46 \\
IPL & E. W. Stout & Marion & 750 \\
\hline
\end{tabular}

a Northern Indiana Public Service Co.

b Public Service Indiana

c Southern Indiana Gas and Electric co.

d Richmond Power and Light

e Indianapolis Power and Light 
Table 17 coal Source and Ash Type. (from Huang, [5])

\begin{tabular}{llc}
\hline $\begin{array}{c}\text { Power } \\
\text { station }\end{array}$ & $\begin{array}{l}\text { Coal type } \\
\text { and source }\end{array}$ & $\begin{array}{c}\text { Bottom } \\
\text { ash type }\end{array}$ \\
\hline $\begin{array}{l}\text { Schahfer } \\
\text { Unit 14 }\end{array}$ & $\begin{array}{l}\text { Illinois bituminous } \\
\text { Unit 17 }\end{array}$ & $\begin{array}{c}\text { wet } \\
\text { dry }\end{array}$ \\
Mitchell & Western Iignitea & dry \\
Gibson & Illinois bituminous & dry \\
Gallagher & Indiana bituminous & dry \\
Wabash & Indiana bituminous & dry \\
Brown & Indiana bituminous & dry \\
Culley & Indiana bituminous & dry \\
Richmond & Indiana bituminous & dry \\
Perry & Indiana bituminous & dry \\
Stout & Indiana bituminous & wet \& dry \\
\hline
\end{tabular}

a From Wyoming 
conditions from Huang's study and presents it in Table 18. This table shows that all bottom ashes produced in the above 10 stations are processed separately from fly ashes, but may be combined in the final storage sites, either in ash ponds or in landfills. Only three bottom ashes are not mixed with fly ashes when they are stockpiled in ash ponds, for this reason these ashes were selected as the candidate ashes in this study. They include Gibson ash, and the ashes produced from Unit 14 and Unit 17 of the Schahfer station. The Gibson station is located in southwestern Indiana and the Schahfer station in northern Indiana. This primary selection did not balance the geographic distribution and rated capacity of power stations in the state. For this reason, Perry $K$ ash, which is produced from section $K$ of the Perry station located in Indianapolis, was added, making a total of four candidate ashes to be investigated.

\section{Sampling Procedure and Field Testing}

\section{Sampling Procedure}

In most power plants, bottom ash is transported to disposal lagoon as a slurry flowing through closed conduits (Huang, [5]). The closed ash transport and handling systems are seldom equipped with sampling ports at convenient locations. In these cases, bottom ashes were collected as grab specimens from the ash deposit at the outlet of the 


\section{Table 18 Ash Storage conditions}

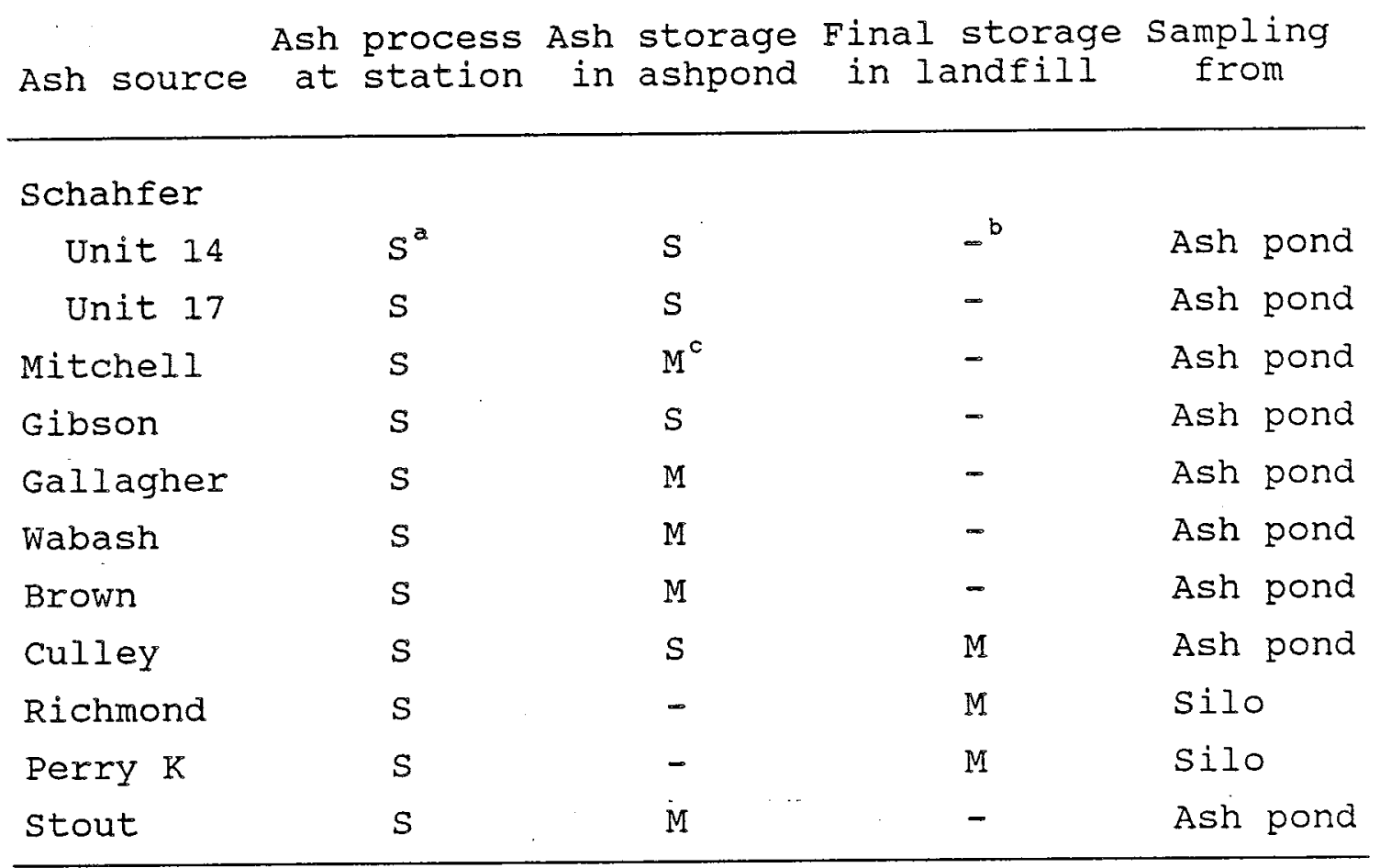

a bottom ash being stored separately with fly ash.

b bottom ash being mixed with fly ash.

c not applicable. 
sluice pipe. Only one station disposed of its ash by a dry method, in which ashes are temporarily placed in storage silos prior to being trucked to landfills. Sampling of all ashes was aided by the information and advice provided by plant staff in charge of ash handling and disposal for each power station. of four candidate ashes, one (i.e., Perry $K$ ash) was sampled from bottom ash silos. The other three were sampled from ash lagoons storing bottom ash only, and these sampled ashes were judged to be representative of the ash materials available for future reclamation.

The actual collection in situ was performed by hand-loading a 20-gallon plastic can. Care was taken to, obtain as representative a sample as possible; however, this was difficult to accomplish because of the huge volume of the ash deposit. Only the surface layer of the ash deposit was sampled. Each sample was properly tagged in situ, returned to the laboratory, and carefully stored in a designated area for subsampling. Care was taken to avoid any change of chemical and physical properties of ash samples during the storage period before laboratory testing.

\section{Field Testing}

Two field tests were conducted at each sampling site, except Perry $K$ station where the ash sample was taken from ash silos. 
The first field test was the determination of field apparent resistivity. The determinations were conducted in accordance with the ASTM Designation G 57 "Standard Method for Field Measurement of Soil Resistivity Using the Wenner Four-Electrode Method" [75]. A precise description of determination of soil resistivity can be found in the "Earth Resistivity Manual" published by SoilTest Inc. [76]. Instead of the complicated dc electronic equipment shown in the above ASTM method (Figure 29), a compact resistivity meter R-40C, produced by soilTest Inc., was used. The set-up of four electrodes (Wenner configuration) associated with the R-40C meter is illustrated in Figure 30. Assuming homogeneity of the ash deposits and operation of $\mathrm{R}-40 \mathrm{C}$ by only a single person, an equal distance of 1 meter between adjacent electrodes was chosen. This provided measurement of the resistivity of the ash deposit at a shallow depth. The apparent resistivity can be calculated by the following equations ([75] and [76]):

- $\rho(\mathrm{ohm}-\mathrm{Cm})=2 \pi$ a R

where $a$ is the electrode separation (in $\mathrm{cm}$ ) and $R$ is the measured resistance (in ohm). If a equals to $100 \mathrm{~cm}$, then

$$
\rho(\mathrm{ohm}-\mathrm{cm})=628 \times \mathrm{R}
$$

$\therefore$ On the other hand, to obtain the critical (minimum) field resistivity (i.e., the resistivity of the saturated 


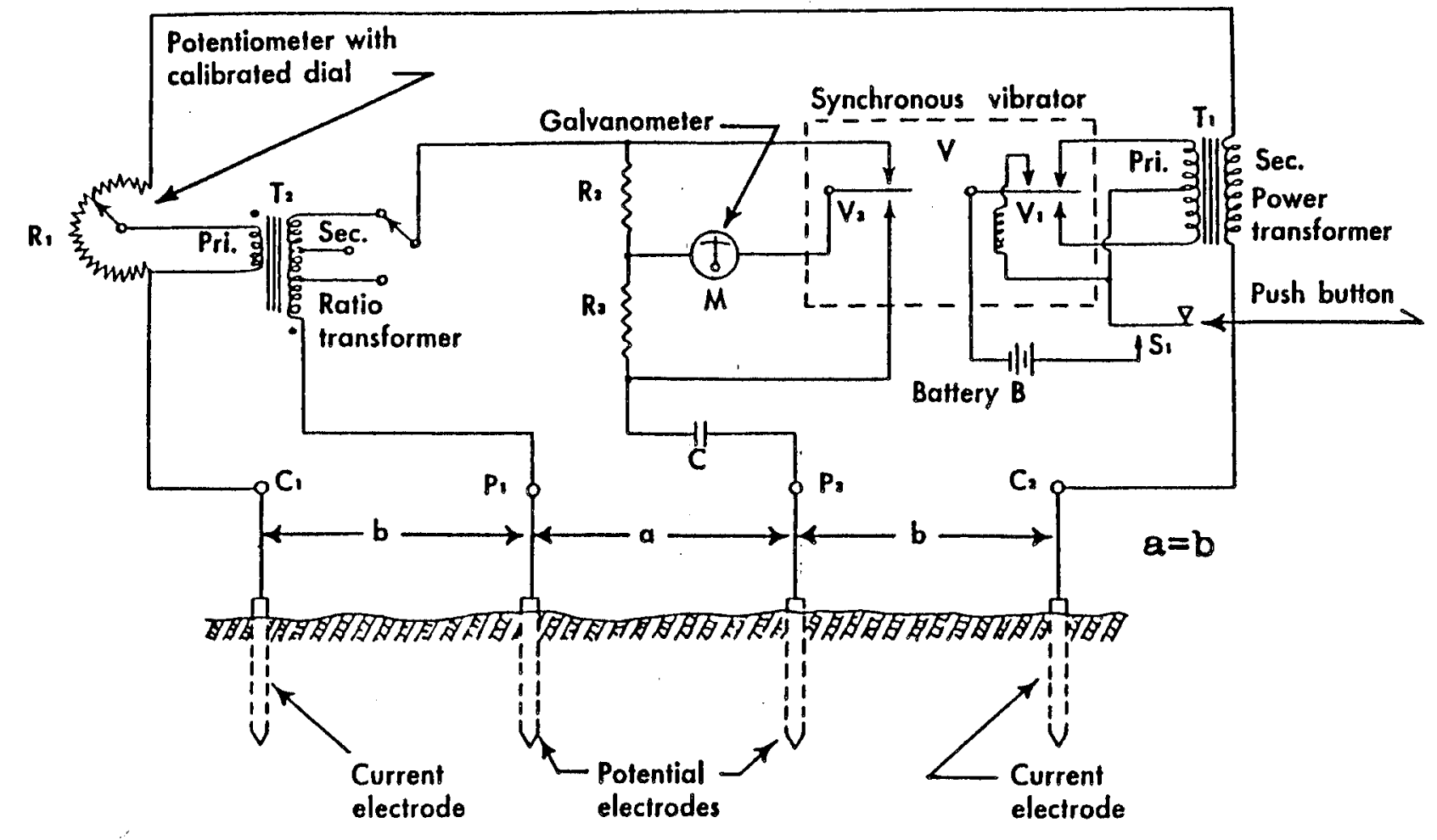

Figure 29 Wiring Diagram for Typical dc Vibrator-Current source, (from ASTM G57, [75]) 


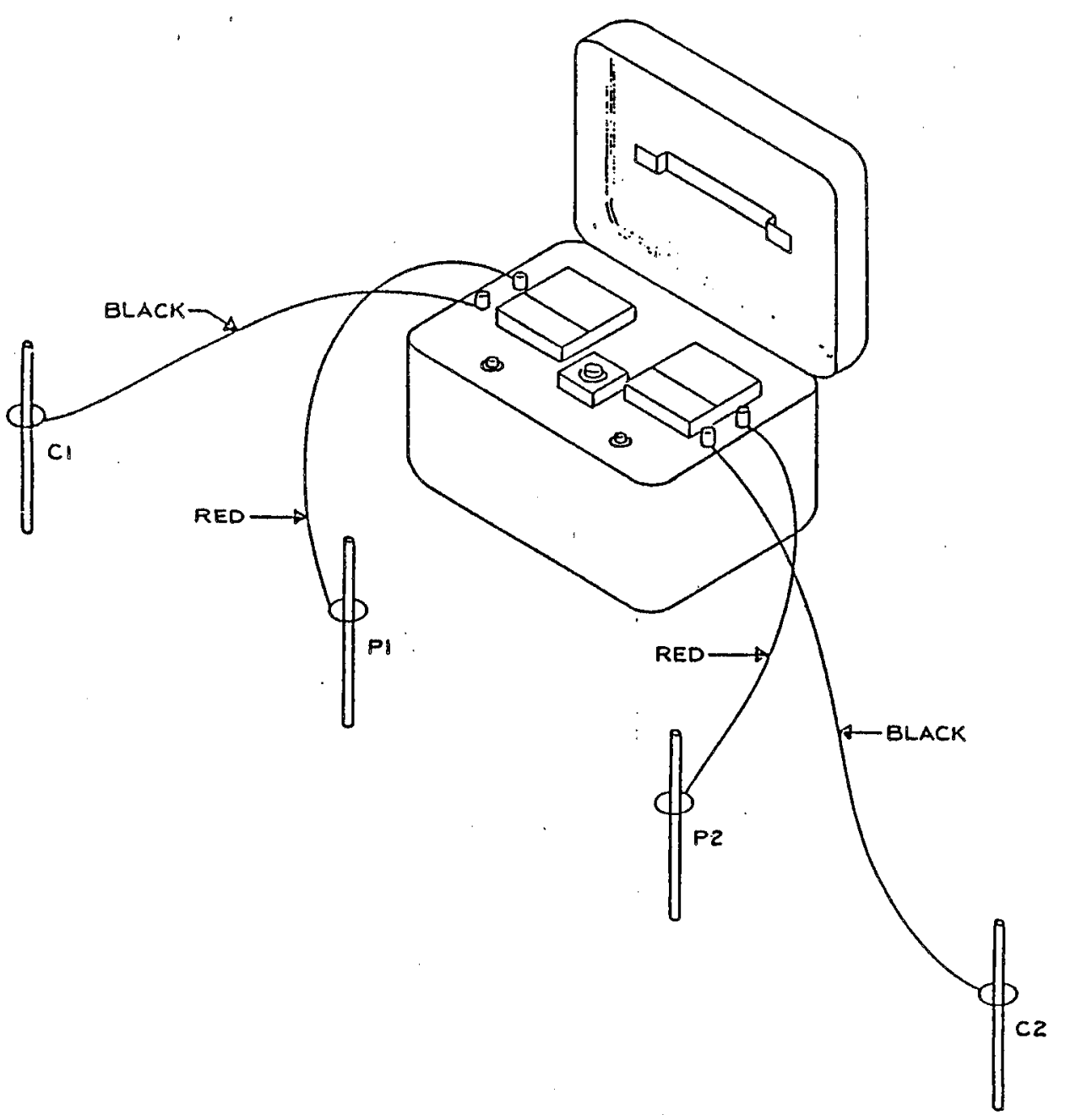

Figure 30 Connection of R-40C Meter with Electrodes, (from [82]) 
medium), this writer attempted to perform the determination of resistivity along the ponded area of the ash deposits. Some attempts were discontinued due to the safety consideration of the operation in situ. To reduce the error of measurements, care was taken to keep the alignment of four electrodes as linear as possible, and to choose relatively plane sites for testing. Before measurements, the resistivity meter $R-4 O C$ had been carefully calibrated following the instruction manual of the manufacturer.

The second field test was to determine the field $\mathrm{pH}$. Since at the time of sampling no portable $\mathrm{pH}$ meter was available to this writer, only $\mathrm{pH}$ paper with the trademark of colorpHast (made by MCB Manufacturing Chemists Inc.) was used. The precision of this $\mathrm{pH}$ paper is $\pm 0.15 \mathrm{pH}$ unit. The $\mathrm{pH}$ determinations were made on the sites as close as possible to those of the resistivity determination. If some difficulty was encountered, the $\mathrm{pH}$ determinations were conducted on pond water within the ash deposits.

Sampling, Description, and Known Properties of

Candidate Ashes

All sampling tasks in this study were carried out in March and April of 1989, after freezing weather, permitting easy access to the field sites. The results of field testing are summarized in Table 19. The results of the general 
Table 19 Field Resistivity and $\mathrm{pH}$ of Candidate Bottom Ashes

\begin{tabular}{lcccc} 
Ash source & Perry $K$ & Gibson & $\begin{array}{c}\text { Schahfer } \\
\text { Unit } 14\end{array}$ & $\begin{array}{c}\text { Schahfer } \\
\text { Unit } 17\end{array}$ \\
\hline $\begin{array}{l}\text { Date for } \\
\text { sampling }\end{array}$ & $03 / 09 / 89^{a}$ & $03 / 17 / 89$ & $04 / 05 / 89$ & $04 / 05 / 89$ \\
$\begin{array}{l}\text { Field } \\
\text { resistivity } \\
\text { (ohm-cm) } \\
\begin{array}{l}\text { Field pH } \\
\text { ( }\end{array}\end{array}$ & $-{ }^{b}$ & 4020 & 5254 & 7791 \\
\hline
\end{tabular}

a month/day/year.

b not applicable

c determined by hydration $(\mathrm{pH})$ paper 
properties, chemical composition, and engineering characteristics of selected bottom ashes given by Huang [5] are listed in Table 20. His examination of the reproducibility of bottom ash indicated that if the coal source burned in a power station does not change, the variation of properties of the produced bottom ash is not significant. Therefore, the values of Table 20 can be applied to the corresponding candidate ashes without great error, except Perry $K$ ash which was produced at the time of sampling by a different coal source from those in Huang's study.

Table 20 contains the results of the Los Angeles abrasion tests and the degradation tests. Referring back to Table 5, these two tests determine the abrasion resistance and the impact resistance of a material, respectively. Although, they correspond to environmental agents different from the freeze-thaw action, the intrinsic material strength may yield similar responses (tendencies) to these two tests and the freeze-thaw test. Accordingly, the results of these tests can be used to predict the sequence of durability (weathering resistance to frost action) among candidate ashes. The following sections describe the ash sampling method adopted at each power station, physical appearance and field testing results, and a number of known properties of each candidate ash (given by Huang, [5]). 
Table 20 Chemical Composition and Engineering Properties Properties of Candidate Bottom Ashes. (after Huang, [5])

\begin{tabular}{|c|c|c|c|c|}
\hline Ash source & Perry $\mathrm{K}$ & Gibson & $\begin{array}{c}\text { Schahfer } \\
\text { Unit } 14\end{array}$ & $\begin{array}{c}\text { Schahfer } \\
\text { Unit } 17\end{array}$ \\
\hline \multicolumn{5}{|l|}{$\begin{array}{l}\text { Chemical } \\
\text { composition }\end{array}$} \\
\hline $\mathrm{SiO}_{2}$ & 50.7 & 56.2 & 56.8 & 55.1 \\
\hline $\mathrm{Fe}_{2} \mathrm{O}_{3}$ & 14.1 & 17.7 & 5.6 & 19.2 \\
\hline $\mathrm{Al}_{2} \mathrm{O}_{3}$ & 18.7 & $14 \cdot 5$ & 12.0 & 13.0 \\
\hline $\mathrm{CaO}$ & 0.9 & 2.9 & 17.6 & 5.9 \\
\hline Mgo & 0.4 & 0.9 & 5.7 & 0.9 \\
\hline $\mathrm{K}_{2} \mathrm{O}$ & 2.3 & 2.0 & 1.1 & 1.7 \\
\hline $\mathrm{Na}_{2} \mathrm{O}$ & 0.6 & 0.5 & 0.4 & 0.3 \\
\hline $\mathrm{SO}_{3}$ & 0.6 & 1.2 & 1.1 & 1.9 \\
\hline $\begin{array}{l}\text { loss in } \\
\text { ignition }\end{array}$ & 6.7 & 0.7 & 0.2 & 0.5 \\
\hline $\begin{array}{l}\text { Specific } \\
\text { gravity }\end{array}$ & 2.03 & 2.62 & 2.82 & 2.59 \\
\hline $\begin{array}{l}\text { Particle size } \\
\text { classification }\end{array}$ & $w / g^{b} \operatorname{sand}$ & $w / g$ sand & $\begin{array}{l}\text { uniform } \\
\text { coarse } \\
\text { sand }\end{array}$ & $\begin{array}{c}\text { w/g sand } \\
\text { with } \\
\text { gravel }\end{array}$ \\
\hline $\begin{array}{l}\text { Permeability } \\
\quad(\mathrm{cm} / \mathrm{sec})\end{array}$ & 0.014 & 0.005 & 0.101 & 0.034 \\
\hline Friction angle ${ }^{d}$ & $40-50^{\circ}$ & $45-55^{\circ}$ & $35-45^{\circ}$ & $40-50^{\circ}$ \\
\hline $\begin{array}{l}\text { Crushing index } \\
(\%)\end{array}$ & 32.6 & 10.0 & 4.8 & 11.5 \\
\hline$\%$ wear $^{f}$ & 54 & 34 & -9 & 38 \\
\hline
\end{tabular}

based on United Soil Classification System (USCS) [21].

b well-graded.

c good drainage if $\mathrm{k}=1$ to $10^{-4} \mathrm{~cm} / \mathrm{s}$ [21].

d $\phi$ is $32-46^{\circ}$ for medium sand [5].

e the results of regradation test.

$f$ the results of Los Angeles abrasion test; 50, allowable value for subbase, base, and surface (ASTM D 1241).

g denotes sample with $<10 \%$ coaser than the No. 8 sieve. 
Perry $\mathrm{K}$ Ash

This ash originated from the c. C. Perry station (Section $\mathrm{K}$ ) of Indianapolis Power and Light Co. (IPL) in downtown Indianapolis. The station had the smallest rated capacity of 46 Megawatt among candidate stations and was burning Indiana bituminous coal obtained from different sources. The bottom ash here was produced in stoker furnaces and temporarily stored in silos before it was trucked to a landfill. Bottom ash and fly ash are stored separately in silos at the station, but subsequently they are combined at the landfill several miles away. Access to the landfill is good. The ash was not being marketed at the time of sampling.

The sampling was conducted on March 9, 1989 from a port underneath the ash hopper. Hence, this ash was the only sample that had never been washed by water. No field testing was performed on such a dry ash. The physical characteristics of Perry $\mathrm{K}$ ash were quite different from the other dry bottom ashes. This ash had so low a specific gravity that some particles floated in water. Ash particles were light weight, highly porous, and appeared red to brown in color, with a popcorn-like surface texture. Some particles were very friable, and crushing of these particles with the fingers was easily accomplished. Without the treatment of crushing, this sampled ash contained much 
coarser particles than others.

Although this newly sampled ash and the old Perry $K$ ash sampled by Huang [5] ware produced from different coal sources, the physical appearances of them were so similar that the corresponding values of Table 20 presented by Huang [5] may also be applicable to this ash. The feature of a popcorn-like surface texture is attributed to stoker furnaces. The low specific gravity may be due to the higher content of $\mathrm{Al}_{2} \mathrm{O}_{3}$. The Perry $\mathrm{K}$ ash sampled earlier was classified as a well-graded sand and had a medium permeability (Table 20). The newly sampled ash would be classified as well-graded gravel and has a higher value of permeability because of its coarser texture. The previously-studied ash had a high angle of friction; however, it seemed to be non-durable because of its high crushing index and percentage of wear after the Los Angeles test, which coincides with its friable feature. The durability of the new-sampled ash will be verified by two durability tests described in the following chapter.

\section{Gibson Ash}

Gibson station is the largest in the state, and is located in southwestern Indiana. The ash was produced from burning Illinois basin bituminous coal in a pulverized dry bottom furnace. Bottom ash and fly ash are stored separately 
at the station. Bottom ash is sluiced to the ash pond, and the position of the sluice pipe is frequently moved to facilitate ash storage. A considerable amount of bottom ash has been accumulated in the ash pond and the station is producing bottom ash at a rate of 200,000 tons per year (Huang, [5]). The bottom ash lagoon is easily accessible by trucks and other construction equipment. At the time of sampling (March 17, 1989), the ash was being mined by a concrete block firm to supplement natural aggregates.

Two 20-gallon plastic cans of sample were taken at a point about 20 feet away from ponded area. The sampled ash was quite moist and exhibited a dull appearance associated with a shiny luster. The gradation of this ash seemed to be good, with some gravel-sized particles. Four determinations of field resistivity were performed along the shoreline of the ash pond. The measured field resistivity ranged from 3700 to $4350^{\circ}$ ohm-cm. Four pH values measured from the ash-water near the outlet of the sluice pipe varied between 5.9 and 6.5 .

From Table 20, Gibson ash was classified as a well-graded sand and therefore had the lowest permeability among four candidate ashes (but it was still moderately permeable). This ash had a very high angle of friction and seemed to have a fair ability to resist weathering. 
Schahfer Unit 14 Ash (later abbreviated as Schahfer 14 ash)

This unit, part of the large R. M. Schahfer station of the Northern Indiana Public Service Co. (NIPSCO), burned pulverized IIIinois bituminous coal in a cyclone furnace and produced wet bottom ash. This was the only material in this study that was exclusively wet bottom ash. Bottom ash was stored separately from fly ash, and was being marketed through an ash broker using the trademark "black beauty" (Huang, [5]). Bottom ash was sluiced to a well-maintained ash pond.

On April 5, 1989, the ash was sampled from the ash shore near the outlet of sluice pipe. The sampled ash was in a relatively dry state since the sluice pipe was not discharging slurry at time of sampling. The physical appearance of this wet bottom ash was very different from those of dry bottom ashes. The ash was hard, dense, and shiny black in color. Its gradation was quite uniform, and there was a small percentage of needle-shaped particles present in the ash. Unlike dry bottom ash, wet bottom ash particles have a smooth surface (non-porous) texture and look much like crushed glass (but without sharp edges). Two determinations of resistivity were conducted near the outlet of the sluice pipe and the measured values averaged 5300 ohm-cm. The pH measurements were performed at the water level of the ash pond and had an average value of 5.3 . 
From Table 20, Schahfer 14 ash. was classified as uniform coarse sand and had a very high permeability. It also had a friction angle comparable to that of a typical medium sand and had good weathering resistance.

Schahfer Unit 17 Ash (later abbreviated as Schahfer 17 ash)

This unit, also part of the R. M. Schahfer station of NIPSCO, burned the same bituminous coal as unit 14, but produced dry bottom ash. The disposal procedure and storage method was the same as unit 1.4. At the time of sampling, this ash was not being marketed.

The ash sampling was carried. out at the same time as unit 14. This sampled ash was predominantly clean sand-sized and gravel-sized particles with a low water content. It was relatively porous and dark gray in color. The field resistivity was about $7800 \mathrm{ohm}-\mathrm{cm}$; and that performed at a drier site was up to $30000 \mathrm{ohm-cm}$. The average value of field $\mathrm{pH}$ in the ash pond was 5.2 .

From Table 20, Schahfer 17 ash was classified as well-graded sand with gravel and had a moderate permeability. It also had a high friction angle and should be fairly resistant to weathering. 


\section{Comments}

Data given by Huang [5] provide useful indications for predicting the sequence of weathering resistance among candidate ashes. Based on the results of his degradation tests and Los Angeles abrasion tests, the order of the weathering resistance of four candidate bottom ashes (from high to low) would be Schahfer 14, Gibson, Schahfer 17, and Perry $\mathrm{K}$ ash. This assumed sequence of weathering resistance will be verified by two durability tests later on. Secondly, Holtz [21] stated that a soil with a permeability between 1 and $10^{-4} \mathrm{~cm} / \mathrm{sec}$ has good drainage and typical soils of this kind are clean sands and sandy gravels. From Table 20, all four candidate ashes fall within this category, i.e., each is well-drained. In addition, this writer would like to make two comments about Table 20:

(1) As indicated by Hudec [26], the content of sio (quartz) may be a indicator of durability for carbonate-like rocks. Consulting Table 20 , the dominant constituent for each candidate ash is $\mathrm{SiO}_{2}$, and therefore all candidate ashes should be resistant to weathering. However, the popcorn-like features of the Perry $K$ ash invalidate this hypothesis. Consequently, in addition to mineralogy, there are other factors influencing the durability of a material exposed to a given environment.

(2) Table 20 also indicates that four candidate ashes contain a certain amount of $\mathrm{SO}_{3}, \mathrm{Fe}_{2} \mathrm{O}_{3}$, and residual 
carbon. Due to the shallow depth of ash sampling (good aeration), this amount of $\mathrm{SO}_{3}$ and $\mathrm{Fe}_{2} \mathrm{O}_{3}$ was regarded as part of the native constituents of bottom ash and not a by-product of SRBs present in the ash deposit. To date no one has shown that the residual carbon (a kind of organic matter) of bottom ash provides food for bacteria. The high permeability of each candidate ash precludes the long-term potential existence of SRBs on an engineering site. 


\section{CHAPTER IV EXPERIMENTAL PROGRAM}

\section{Introduction}

As mentioned in chapter II, the experimental program of this study consisted essentially of laboratory testing. Its objective was to obtain the values of parameters relevant for evaluation of durability and corrosiveness of candidate ashes. Durability tests included soundness tests using sodium sulfate and freezing-thawing tests. Corrosiveness tests consisted of determinations of chloride content, sulfate content, resistivity, and pH of candidate ashes.

This chapter describes the test methods used. Some of the methods used are standard ASTM or AASHTO test methods. For such methods, only one test per candidate ash was performed. In cases where nonstandard testing procedures were used, a number of tests per candidate ash were conducted to obtain a statistically based result, and to determine the sensitivity of relevant factors influencing the testing results.

At the onset of this study, some tests were performed or the second suite of samples taken by Huang [5]. These samples will be referred to as "old" samples in the testing 
results. In the previous chapter, it stated that the reproducibility of ash properties seemed to be good if no change of coal fired source occurred. For this reason, it is appropriate to combine the results obtained from the old samples and those of the current study for evaluation of durability and corrosiveness.

\section{Durability Tests}

The following two durability tests were conducted in accordance with standard ASTM or AASHTO test methods, but there were some modifications to the testing procedure.

\section{Sodium sulfate Soundness Test}

As mentioned in Chapter II, this test is designed to simulate the frost action of ice forming in the pore system of a medium. This is accomplished by repeatedly immersing the medium in a saturated solution of sodium sulfate followed by oven drying to dehydrate the $\mathrm{Na}_{2} \mathrm{SO}_{4}$ precipitated in permeable pore spaces. The expansive internal force, derived from the rehydration of the $\mathrm{Na}_{2} \mathrm{SO}_{4}$ upon re-immersion, resembles the expansion of water on freezing. The test was performed in accordance with ASTM Designation C 88 [32] or AASHTO Designation T 104 [33].

Before testing, the gradations of candidate ashes were determined by ASTM Designation C 136, which is designed for 
aggregates. Thereafter, for each candidate ash, the ash particles finer than $3 / 8$ in. were tested following the procedure for fine aggregate, while the coarse particles were tested based on the procedure for coarse aggregate. Two sets of perforated containers for immersing the fine sample and the coarse sample in the solution were fabricated in accordance with the requirement of the standard test methods. The saturated sodium sulfate solution was prepared at $22^{\circ} \mathrm{C}$ by adding $250 \mathrm{~g}$ of anhydrous $\mathrm{Na}_{2} \mathrm{SO}_{4}$ per litre of water. The solution was maintained with a specific gravity between 1.151 and 1.174 . The weighted losses after five cycles of immersion and oven-drying were then calculated by summing the products of each retained fraction and the corresponding weighted loss percentage.

These tests were performed on the old samples. Because the Perry $K$ station changed coal sources, one additional test was conducted on the newly sampled Perry $K$ ash. The difference between the old Perry $K$ ash and the new one will be briefly discussed in the next chapter.

Freeze and Thaw Test

The purpose of this test is to determine the resistance of a material to disintegration by alternate changes of freezing and thawing. The testing procedure is described in AASHTO Designation T 103 [31]. There are three different 
immersion conditions to be chosen. The total immersion condition was selected, since it examines the most critical case.

Like the soundness tests mentioned above, the fine portion and the coarse portion of each candidate ash were treated separately, each having a different preparation procedure. The freezing and thawing equipment used in this study was manufactured by Logan Freeze-Thaw MFG. CO.. This machine was originally designed for standard concrete specimens, and its sectional view is shown in Figure 31. To adapt it to the testing for aggregates or bottom ashes, the method of specimen installation was modified.

Inside each specimen container, five zippable plastic bags were placed, each containing $100 \mathrm{~g}$ of dry ash specimen and $200 \mathrm{mI}$ of deionized water. The placement of ash into each bag with water produced a saturated condition for the ash. Free air was expelled before closure.

The control specimen contained $500 \mathrm{~g}$ of ash and was also bagged with water. A thermostat bulb and a recording thermometer bulb were inserted at two sides of the control specimen, respectively. The function of the control specimen was to display the specimen temperature and to control the process of freezing and thawing. Water was then poured into each specimen container, to a depth of $4 \mathrm{~cm}$. The maximum and the minimum temperature levels were set to be $+55^{\circ} \mathrm{F}$ and $0^{\circ} \mathrm{F}$, 


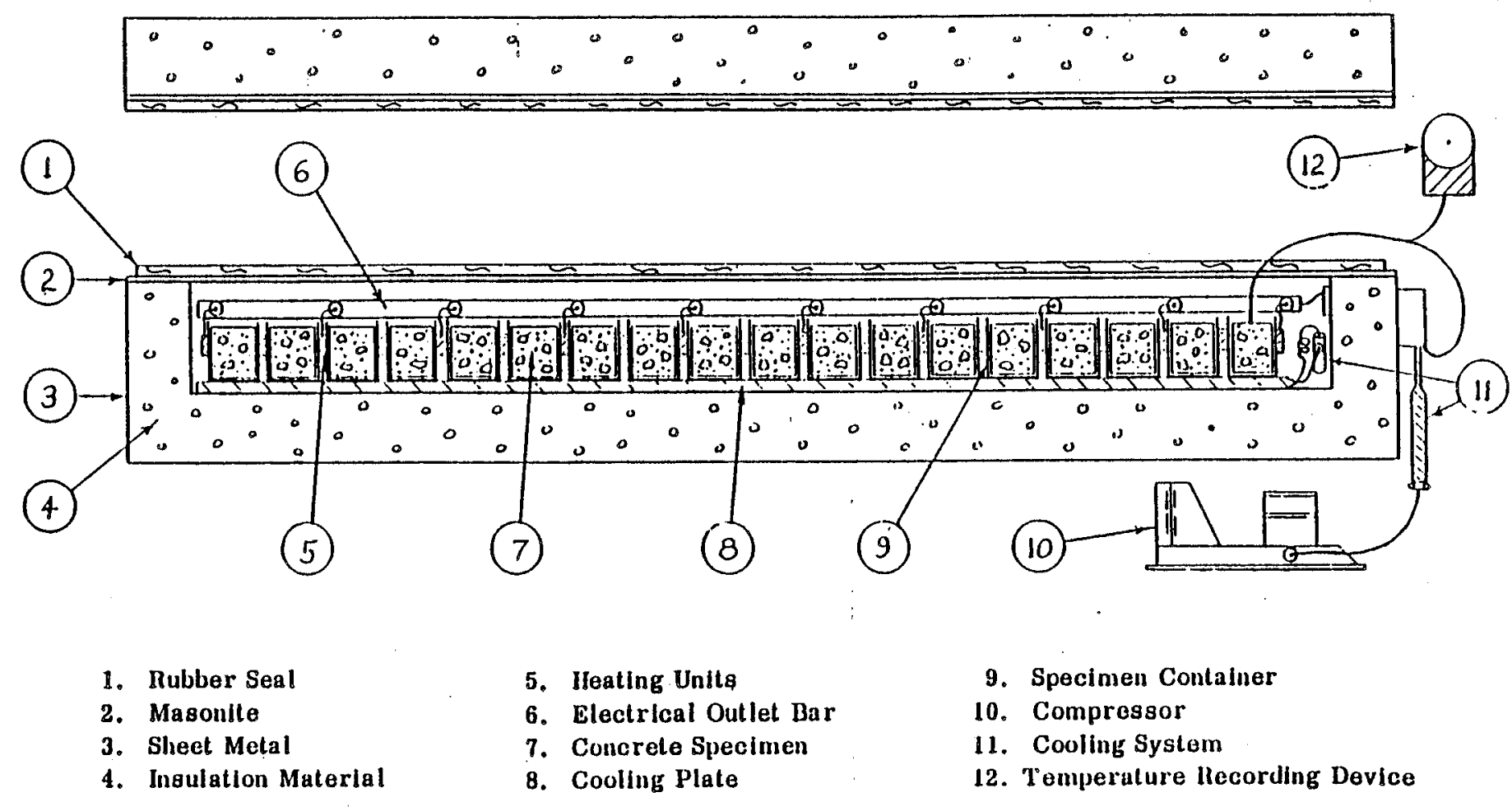

Figure 31 Sectional View of the Automatic Freezing and Thawing Equipment 
respectively. Once the machine was started, the freezing and thawing process continued automatically until the switch was turned off. The weighted loss after 50 cycles of freezing and thawing was calculated by the same process as the soundness test.

This test was conducted on the new samples. During testing, is was visually verified that the temperature readings were consistent with the physical states of the ash specimens. If a contraiy phenomenon was observed, the control specimen was reinstalled.

\section{Corrosiveness Tests}

Generally, the determinations of the four electrochemical characteristics of bottom ash were based on

designed for soils. However, some revision of testing procedures was necessary due to the instruments available in the laboratory or due to the distinctive nature of bottom ash. The determinations of chloride content and sulfate content were made on the old samples; while those of resistivity and $\mathrm{pH}$ were performed on the new samples.

\section{Chloride content}

Basically, the determination of water soluble chloride of the ashes was performed following California Test 422 
[77]. However, instead of a potassium chromate indicator, a chloride ion specific electrode was used to indicate the end point of titration of soluble chloride and silver nitrate $\left(\mathrm{AgNO}_{3}\right)$.

Quantities of $100 \mathrm{~g}$ of representative ash and $300 \mathrm{ml}$ of deionized water were placed in a $500 \mathrm{ml}$ flask. The ash-water solution was then shaken rigorously for 20 seconds. The shaking was repeated in one hour. After overnight settlement, the ash water was filtered through a dry whatman No.41 filter paper. A quantity of $30 \mathrm{ml}$ of the filtered ash-water was titrated with $0.0022 \mathrm{~N} \mathrm{AgNO}_{3} . \mathrm{An}$ orion combination chloride electrode (Cat. No. 961700) was used to provide data for plotting the titration curve, i.e., the indicated $\mathrm{mV}$ versus $\mathrm{ml}$ of $\mathrm{AgNO}_{3}$ titrated curve. This curve was plotted on special titration paper, the Gran's Plot Paper by Orion Research Inc. Extending the straight line of the final data points to the $\mathrm{x}$-axis, the abscissa intercept is the end point, which is the actual $\mathrm{ml}$ of $\mathrm{AgNO}_{3}(0.0022 \mathrm{~N})$ needed to react with $\mathrm{Cl}^{-}$contained in $30 \mathrm{ml}$ of ash-water. Subsequently, the ppm of soluble chloride, in unit of $\mu \mathrm{g}$ of $\mathrm{Cl}^{-}$per gram of ash, was calculated by the equation:

$$
C_{C l}=\frac{N_{A g} E_{p} G_{C 1} W_{a 11}}{M_{\text {ash }} W_{\text {test }}} \times 10^{6}(\mathrm{ppm})
$$

where $\mathrm{C}_{\mathrm{Cl}}$ is the content of chloride (ppm);

$\mathrm{E}_{\mathrm{p}}$ is the end point (in $\mathrm{ml}$ ); 
$\mathrm{N}_{\mathrm{Ag}}$ is the normality of $\mathrm{AgNO}_{3},(0.0022 \mathrm{~N}$ is used):

$G_{C_{1}}$ is the gme of $\mathrm{Cl}$, i.e., 0.03546 , the atomic weight of $\mathrm{Cl}$ divided by 1000;

$\mathbb{M}_{\text {ash }}$ is the mass of ash sample, i.e., 100 gram;

$W_{a 11}$ is the amount of water added, i.e., $300 \mathrm{ml}$; and

$W_{\text {test }}$ is the amount of ash-water solution for

testing, i.e., $30 \mathrm{ml}$.

A blank determination was made on deionized water, i.e., measuring the chloride content $\left(\mathrm{B}_{\mathrm{Cl}}\right)$ present in deionized water. The actual soluble $\mathrm{Cl}^{-}$content $\left(\mathrm{C}_{\mathrm{Cl}}^{*}\right)$ of a ash was thereby attained by:

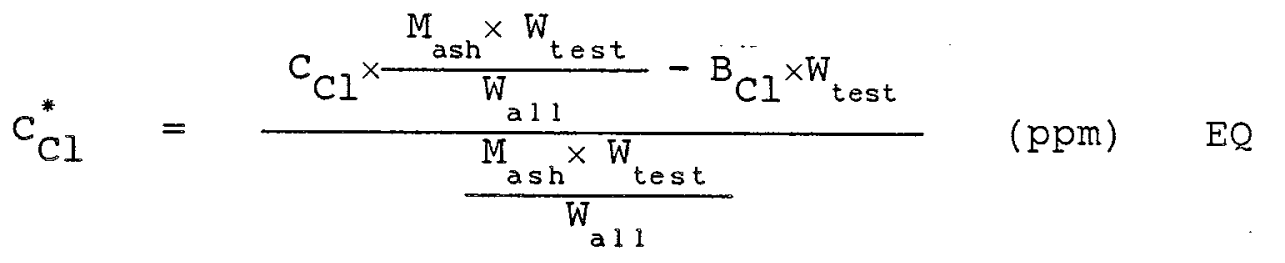

This writer also performed an additional test to examine the effect of shaking time on the soluble $\mathrm{Cl}^{-}$. The maximum amount of soluble $\mathrm{Cl}^{-}$can not exceed the total content of chloride contained in the ash. The determination of total chloride requires a dissolution ash technique which is described in ASTM Designation C 311 [78]. Once the dissolved ash water is obtained, the chloride content can be found following the same procedure as above, i.e., titration with $\mathrm{AgNO}_{3}$ of a known normality.

Here, the soluble $\mathrm{Cl}^{-}$is expressed on the basis of the 
ash weight, i.e., $\mu \mathrm{g}$ of $\mathrm{CI}^{-}$per gram of ash (ppm on a basis of solid weight). However, the term actually influencing corrosion is the concentration of $\mathrm{Cl}^{-}$in the surrounding water in situ, which is in units of $\mu \mathrm{g}$ of $\mathrm{Cl}^{-}$per litre of water (also ppm but on a basis of water volume). Unfortunately, it is different to predict what will be water content or how it will change with time for bottom ash in service. Therefore, soluble or soluble $\mathrm{Cl}^{-}$must be expressed as ppm on an ash weight basis. However, once the ash structure is completed, the $\mathrm{Cl}^{-}$of the water sample extracted from the ash can be expressed in units of ppm based upon water volume.

Sulfate content

The determination of water soluble sulfate of ash was performed in accordance with California Test 417 [79], except that a filtration method was used to determine the amount of $\mathrm{BaSO}_{4}$, instead of a turdidimeter. The latter was not available in the laboratory.

The ash-water suspension was prepared in the same way as for determining the chloride content. Next $30 \mathrm{ml}$ of filtered ash-water was boiled for one minute and about $25 \mathrm{ml}$ of hot $10 \%$ barium chloride $\left(\mathrm{BaCl}_{2}\right)$ was added to the solution. After the solution was digested overnight, the precipitate $\left(\mathrm{BaSO}_{4}\right.$ ) was filtered using a ceramic filter of 
known weight. The ceramic filter was then oven dried and the weight of $\mathrm{BaSO}_{4}$ determined by difference. The soluble $\mathrm{SO}_{4}^{2-}$ was calculated from the weight of $\mathrm{BaSO}_{4}$. The calculation equation is:

$$
\mathrm{C}_{\mathrm{SO}_{4}}=\frac{W_{B} \times 0.4116}{\mathrm{M}_{\mathrm{ash}} \times \frac{W_{\text {test }}}{W_{\text {a } 11}}}
$$

where $W_{B}$ is the determined weight of $\mathrm{BaSO}_{4}$;

0.4116 is the ratio of $\mathrm{SO}_{4}^{2-}$ weight to $\mathrm{BaSO}_{4}$ weight;

and $\mathrm{M}_{\text {ash }}, \mathrm{W}_{\text {test }}$ and $\mathrm{W}_{\mathrm{al1}}$ are defined as above.

Because bottom ash may contain a high percentage of soluble $\mathrm{SO}_{4}^{2-}$, it was not considered necessary to determine a blank value for deionized water to obtain the precise soluble sulfate content, as in the case of soluble chloride.

The effect of shaking time was also examined. The total content of sulfate was determined using the same dissolution technique (ASTM Designation C 311) and the above filtration method.

\section{Resistivity}

As expected, all current methods of determining sample resistivity in the laboratory are designed for soils. The ASTM. Designation G 57 [75] describes the testing procedure of resistivity of a soil sample contained in a soil box. 
Figure 32 shows several typical connections for use of the soil box with various types of instruments. However, the objective of this study was to obtain the minimum resistivity of bottom ash, and therefore the determinations were mainly performed as specified in california Test 532 [80] or 643 [81].

The configuration of the sample box used in this study is illustrated in Figure 33. The resistivity meter $\mathrm{R}-40 \mathrm{C}$ can be used for both field and laboratory determinations. Fig 34 [83] shows the connection of the R-4OC meter with the sample box. The sample resistivity can be calculated by the equation:

$$
\rho(\text { ohm-cm })=\text { Box Factor } \times \mathrm{R}
$$

where $R$ is measured resistance (read from the meter) in ohms, and the Box Factor (BF) is defined as $A / D$, in which $A$ is the area of one electrode in $\mathrm{cm}^{2}$ and $D$ is the distance between electrodes in $\mathrm{cm}$. From Fig 33, BF is computed to be $6.67 \mathrm{~cm}$ and thereby

$$
\rho(\mathrm{ohm}-\mathrm{cm})=6.67 \times \mathrm{R}
$$

As specified in California Test 532 or 643 , only the particles passing the No. 8 sieve are to be used for the test. About $1300 \mathrm{~g}$ of ash particles finer than the No. 8 sieve were needed per test. If the sieved sample was dried, $150 \mathrm{ml}$ of deionized water was added to and thoroughly mixed 

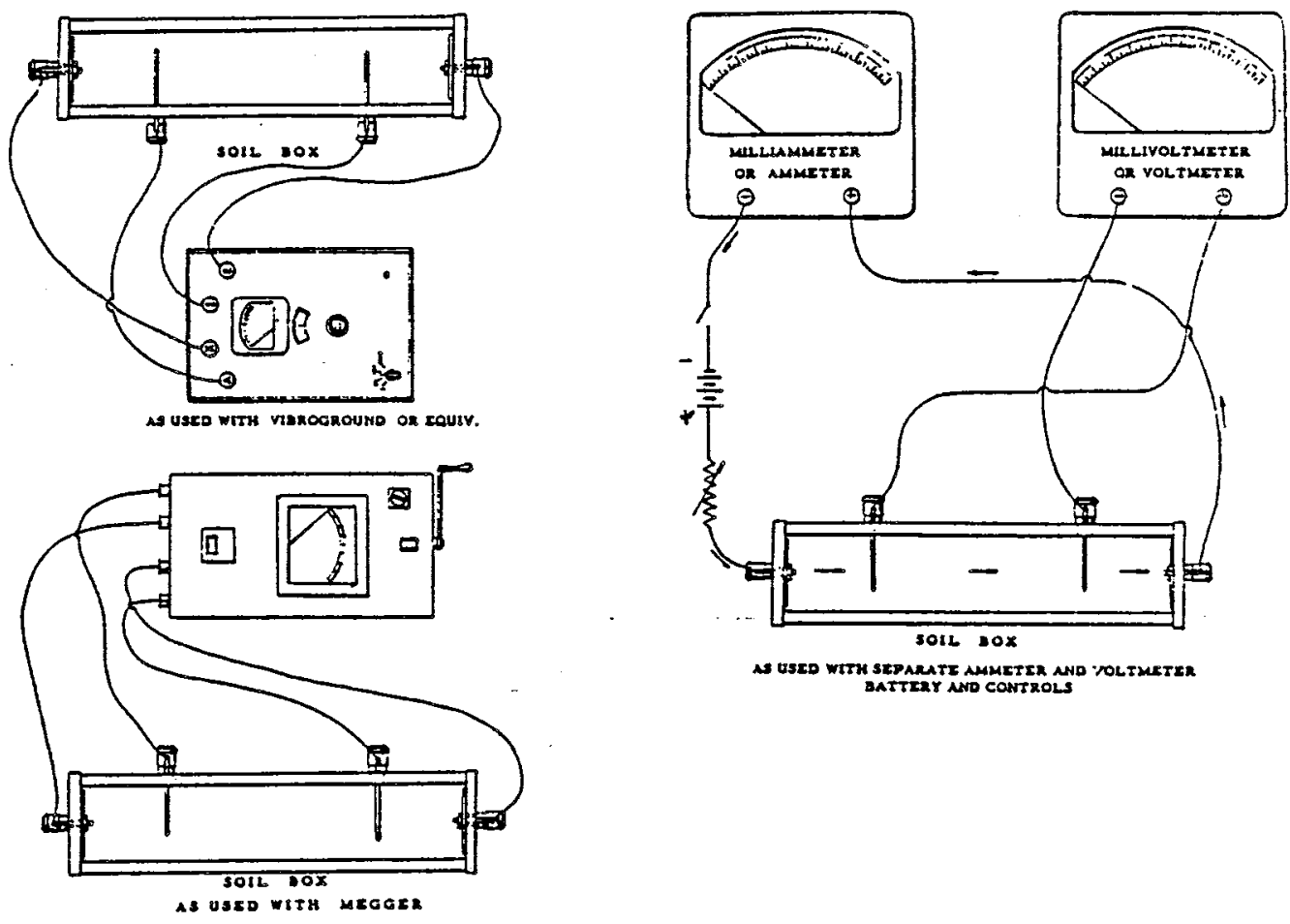

Figure 32 Typical connections for Use of Soil Boxes with Various Types of Instruments.

(from ASTM G57, [75]) 


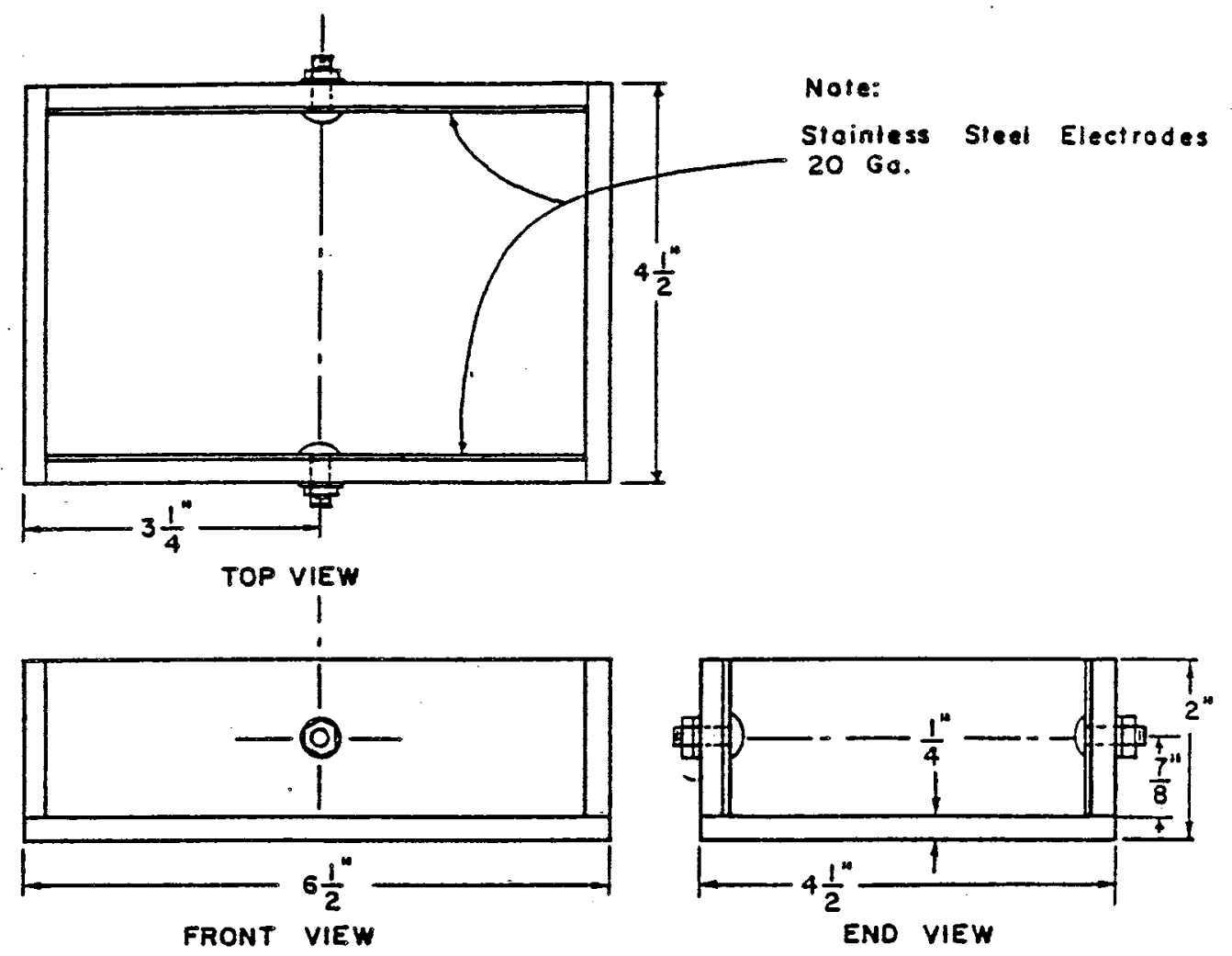

\section{Material: 1/4" Plastic}

Bottom - I PC. $6 \mathrm{~V} / 2^{\prime \prime} \times 41 / 2^{\prime \prime} \times 1 / 4^{\prime \prime}$

Ends -2 Pcs. $41 / 2^{\prime \prime} \times 13 / 4^{\prime \prime} \times 1 / 4^{\prime \prime}$

Sides -2 Pcs. $6^{\prime \prime} \times 13 / 4^{\prime \prime} \times 1 / 4^{\prime \prime}$

Electrode -2 Pcs. 20 Go. Stoinless Steel $6^{\prime \prime} \times 13 / 4^{\prime \prime}$

2 Eo. No. 8-32 $\times 3 / 4$ "Round Head Stainless Steel

- Machine Screw with Rubber Washer and Stainless Steel

Washer and Nut.

Figure 33 Configuration of Sample Box. (from [80]) 


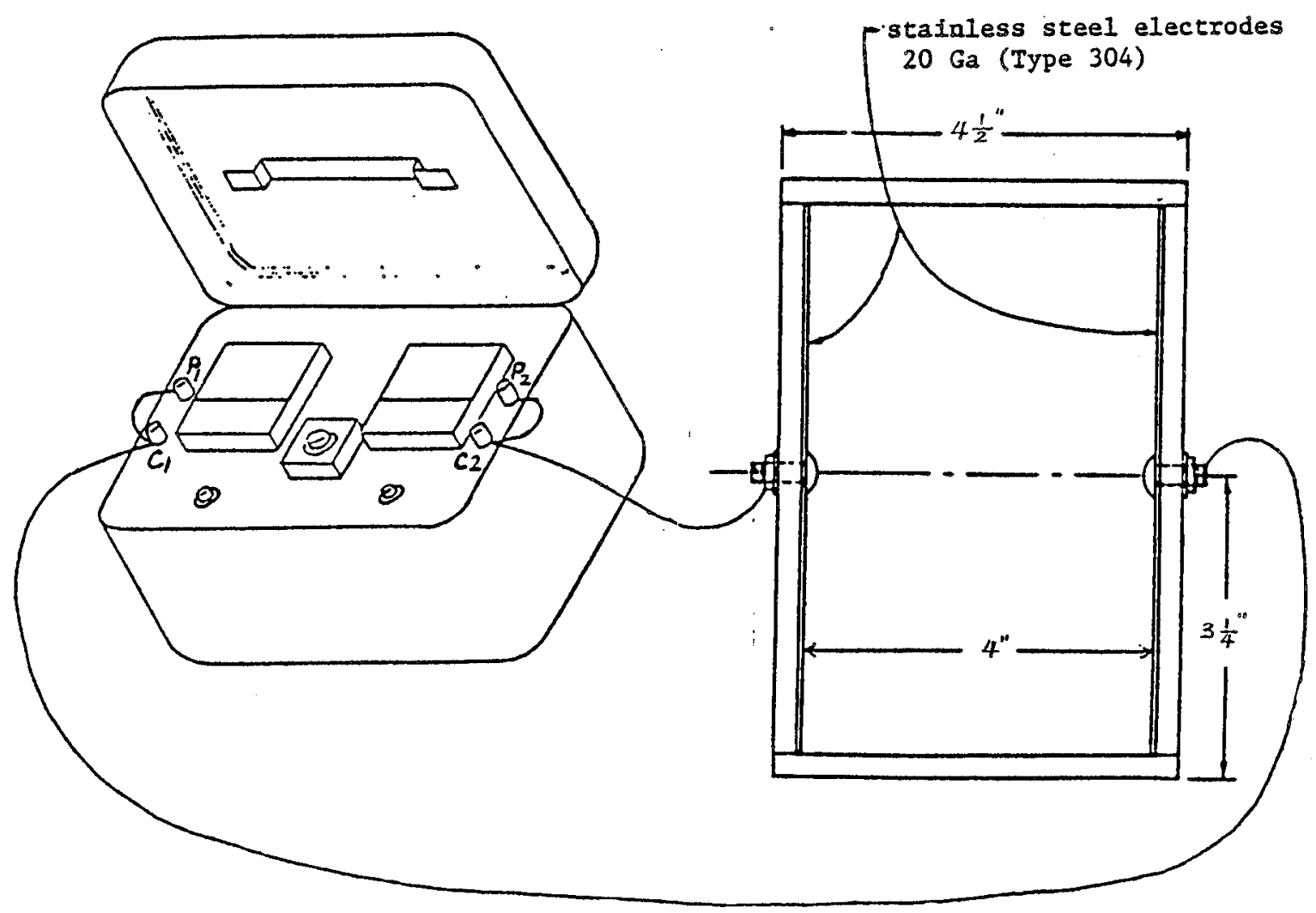

Figure 34 Connection of $R-40 \mathrm{C}$ Meter with Sample Box. (from [821) 
with the sample. The uniformly moist sample was then compacted in layers in the sample box, followed by measurement of the ash resistivity in accordance with the instructions furnished with the meter [82]. In the next step, the sample was removed from the box, mixed with an additional $100 \mathrm{ml}$ of deionized water, re-placed in the box and resistivity was again measured. The above, step was repeated until the minimum resistivity was reached. If the sample was not dried, the test began with the addition of 50 $\mathrm{ml}$ of deionized water, and $50 \mathrm{ml}$ increments of deionized water were used in the later steps.

Since the california tests do not take into account the contribution of the ash particles coarser than the No. 8 sieve to the ash resistivity, the resistivity obtained may not be representative of the total ash aggregate. An attempt was made to assess the effect of such maximum size Iimitation on the measured resistivity. One set of proof tests was performed on the ash aggregates finer than $3 / 8$ in. for four candidate ashes, and different values of ash resistivity from those obtained earlier were observed. Two revised procedures for this method are proposed:

(1) Enlarge the sample box to accommodate all coarse aggregates. If the ratio of the minimum box dimension to the maximum size of ash aggregates is set to be 5 , then a 10 in. $\times 15$ in. $\times 30$ in. sample box is needed in this study. However, this proposed revision could not be implemented 
in this research, because of the expense of fabricating such a large box, and the larger amounts of ash required per test.

(2) Crush the ash aggregates coarser than the No. 8 sieve and follow the same testing procedure. The shortcoming of this alternate includes the larger contact area of the crushed sample with water, which could yield a different amount of soluble salts or a different species of soluble salts, not occurring in the natural state. As mentioned in Chapter II, resistivity is a function of soluble salts, and here a different amount of soluble salts definitely change the resulting resistivity. However, if the long-term and worse case condition is to be considered, this crushing method is justified, because it generally results in a higher level of soluble salts and therefore a lower resistivity.

Accordingly, the crushing method was adopted. The sample was placed in a standard Proctor mold and compacted by a 10 lb compaction hammer with a free fall of 12 in. About $2000 \mathrm{~g}$ of representative ash per candidate ash was crushed until all crushed aggregates passed the No. 8 sieve. Thereafter, $1300 \mathrm{~g}$ of sample were tested following the same procedure as California Test 532 or 643 . The remaining sample was used for determination of the $\mathrm{pH}$. 
$\mathrm{pH}$

The ASTM Designation G 51 [83] describes in detail the testing procedure for conducting a field measurement of soil $\mathrm{pH}$, but with few instructions for the laboratory operation. Therefore, the laboratory determinations of $\mathrm{pH}$ of candidate ashes were essentially made in accordance with California Test 532 or 643 . Because the sampled ashes were stored in well-sealed plastic cans at a room temperature, it was assumed that they had not changed chemically.

The $\mathrm{pH}$ of an ash specimen was determined using a Corning pH Meter 125, a pH glass electrode and a calomel (reference) electrode. Three standard buffer solutions with pHs of 4,7 , and 10, were used to standardize the pH meter. For example, if one ash $\mathrm{pH}$ was near 4, the $\mathrm{pH}$ meter should be calibrated with respect to the buffer solution with a $\mathrm{pH}$ of 4 and measurement taken of the ash slurry.

Two rounded teaspoons of the ash were placed in a cup and mixed with 2 teaspoons of deionized water. The ash suspension was stirred with a glass rod until a uniform consistency was achieved. Next the $\mathrm{pH}$ electrodes were inserted into the ash slurry and the stabilized digital pH value shown on the meter was recorded. In some cases the waiting time for the stabilization of the $\mathrm{pH}$ reading took 5 minutes or more. Once one measurement was completed and the $\mathrm{pH}$ electrodes were retracted from the ash slurry, the 
surfaces of the electrodes were cleaned of attached particles, thereby reducing the error of measurement performed on the next ash slurry.

Another $\mathrm{pH}$ measurement method adopted by Indiana Department of Transportation (INDOT) was also used in this study for comparison (later this method is abbreviated as the INDOT method). A quantity of $20 \mathrm{ml}$ of deionized water was added to $20 \mathrm{~g}$ of ash in a $50 \mathrm{ml}$ beaker and this ash suspension was stirred several times during the next 30 minutes. After a one hour delay, the ash pH was determined using the same $\mathrm{pH}$ meter.

As discussed in Chapter II; the pH $^{-}$of soils is a function of soil water content. It was expected that bottom ashes would show the same trend. After the performance of the INDOT test, an additional quantity of deionized water was added to the ash water to investigate the effect of the ash-water ratio on the ash $\mathrm{pH}$.

- Another special test was performed on Gibson ash. In this test, $10 \mathrm{~g}$ of Gibson ash was mixed with increments of deionized water to a total volume of $500 \mathrm{ml}$. This provided the variation of ash $\mathrm{pH}$ with ash:water ratio. Assuming the density of deionized water be $1 \mathrm{~g} / \mathrm{cm}^{3}$, the ash:water ratio specified in the INDOT method is exactly 1:1; while that in California Test 532 or 643 is approximately 1:1, depending on the bulk unit weight of the sampled ash. From a 
scientific view, the INDOT method is a more quantitative test. However, if the ash to be examined is not sensitive to change of water content, California Test 532 or 643 is more practical and more easily conducted.

An attempt was made to examine the influence of shaking time on the ash $\mathrm{pH}$. A quantity of $100 \mathrm{~g}$ of ash was mixed with $100 \mathrm{ml}$ of deionized water and the ash suspension was continuously stirred by a mechanical stirrer. The determinations of ash $\mathrm{pH}$ were performed at one hour, one day, two days, and three days after the initiation of stirring.

In California Test 532 or 643 , there is still the limitation of the maximum size of the No. 8 sieve, i.e., only the aggregates passing the No. 8 sieve are used in the tests. To inspect the size effect, two more sets of tests were performed on the aggregates finer than $3 / 8$ in. and on the crushed ashes as mentioned in the previous section.

As in the case of soluble salts, there is still a question regarding the water content and what amount of acidic agents will dissolve in the water at the ash construction site. Both of these can influence the ash $\mathrm{pH}$. Therefore, it is still some doubt as to whether the $\mathrm{pH}$ values obtained in by the above two $\mathrm{pH}$ test methods can truly predict the site pH. Accordingly, performance of field $\mathrm{pH}$ measurements upon completion of the ash structure is still preferred. 


\section{CHAPTER $V$ PRESENTATION AND DISCUSSION OF RESULTS}

This chapter primarily presents and discusses the results of durability tests and corrosiveness tests performed on the candidate bottom ashes. More detailed discussions and recommendations are included in the sections dealing with nonstandard test methods. To increase the data base, additional tests were performed on samples studied by Huang [5] and their results are also summarized.

\section{Durability Tests}

Both soundness tests and freeze-thaw tests were used to determine the weighted loss (WL) after a specified number of alternation cycles. The WL, a measure related to the size reduction caused by the physical deterioration of freezing, is considered an indicator of durability. The higher the WL, the less the durability or the less the resistance to freeze-thaw action.

\section{Sodium Sulfate soundness Test}

.. Five-cycle soundness tests using sodium sulfate were performed on the old samples of candidate ashes; while 50-cycle freeze-thaw tests were conducted on the new 
samples. Before combining the results for evaluation of durability, care was taken to establish that no difference existed between the old sample and the new sample for each candidate ash. Particular attention was paid to Perry $K$ ash because a different coal source was burned at the two sampling periods.

Table 21 shows the sieve analysis results of old and new samples of Perry $K$ ash. The newly sampled ash is significantly coarser than the old sample. The $D_{60}$ of the new sample is about four times as large as that of the old sample. The coefficient of uniformity $c_{u}$ and the coefficient of curvature $c_{c}$. for each are also listed in Table 21. Based on the United Soil Classification system (USCS) (Holtz, [2I]), the new sample of Perry $K$ ash was classified as a well-graded gravel; while the old is a well-graded sand. Due to the coarser texture of the new sample, the permeability of the new sample should be higher than that of the old sample. The large difference in grain size distributions required the performance of an additional soundness test on the newly sampled Perry $K$ ash. Table 22 shows the grain size distributions of old samples and new samples of the other three candidate ashes. The results in this table demonstrate no sizable differences between the old samples and the new samples, and therefore no supplemental tests were necessary. 
Table 21 Comparison of Sieve Analysis Results of old Sample and New Sample of Perry $K$ Ash

\begin{tabular}{ccc} 
Sieve size & $\begin{array}{c}\text { Old sample } \\
\text { ofiner }\end{array}$ & $\begin{array}{c}\text { New sample } \\
\text { \% finer }\end{array}$ \\
\hline $3 / 2^{\prime \prime}$ & 100.0 & 98.2 \\
$3 / 4^{\prime \prime}$ & 100.0 & 83.4 \\
$3 / 8^{\prime \prime}$ & 94.3 & 56.8 \\
No.4 & 78.5 & 31.2 \\
No.8 & 53.5 & 12.4 \\
No.16 & 29.8 & 6.0 \\
No.30 & 17.0 & 3.9 \\
No.50 & 9.2 & 2.7 \\
\hline D6 in mm & 2.6 & 10.0 \\
$D_{30}$ in mm & 1.1 & 5.0 \\
$D_{10}$ in mm & 0.32 & 1.0 \\
$C_{u}$ & 8.1 & 5.0 \\
$C_{c}$ & 1.45 & 1.25 \\
Particle size & well-graded sand & well-graded gravel \\
Classification & & \\
\hline
\end{tabular}

a sampled by Huang [5] on 7-19-88. 
Table 22 Comparison of Sieve Analysis Results of Old and New Samples of Candidate Ashes except Perry $\mathrm{K}$ Ash

\begin{tabular}{|c|c|c|c|c|c|c|}
\hline \multirow[b]{2}{*}{ Sieve size } & \multicolumn{2}{|c|}{ Gibson } & \multicolumn{2}{|c|}{ Schahfer 14} & \multicolumn{2}{|c|}{ Schahfer 17} \\
\hline & $\begin{array}{l}\text { old } \\
\text { ofiner }\end{array}$ & $\begin{array}{c}\text { new } \\
\text { \%finer }\end{array}$ & $\begin{array}{l}\text { old } \\
\text { ofiner }\end{array}$ & $\begin{array}{c}\text { new } \\
\text { \%finer }\end{array}$ & $\begin{array}{c}\text { old } \\
\text { ofiner }\end{array}$ & $\begin{array}{c}\text { new } \\
\text { \%finer }\end{array}$ \\
\hline $3 / 2^{\prime \prime}$ & 100.0 & 100.0 & 100.0 & 100.0 & 100.0 & 100.0 \\
\hline $3 / 4 "$ & 100.0 & 100.0 & 100.0 & 100.0 & 97.2 & 96.2 \\
\hline $3 / 8^{\prime \prime}$ & 92.3 & 92.0 & 99.4 & 99.2 & 84.0 & 81.3 \\
\hline No. 4 & 81.0 & 80.8 & 98.5 & 98.9 & 50.1 & 60.4 \\
\hline No. 8 & 64.8 & 62.1 & 91.3 & 97.5 & 26.5 & 43.3 \\
\hline No. 16 & 46.8 & 39.3 & 61.9 & 69.8 & 14.9 & 29.9 \\
\hline No. 30 & 30.5 & 21.5 & 18.1 & 23.7 & 7.0 & 18.1 \\
\hline No. 50 & 19.7 & 7.2 & 4.8 & 3.1 & 3.7 & 5.0 \\
\hline
\end{tabular}

a sampled by Huang [5] on 5-17-88:

b sampled by Huang [5] on 5-12-88. 
According to ASTM Designation C 88 [32], if the sample has more than $10 \%$ of its particles coarser than $3 / 8$ in., the soundness test is also conducted on the coarse portion, following the procedure for coarse aggregate. Referring to Table 21 and 22, Perry $K$ ash and Schahfer 17 ash fall within this category, and therefore both procedures (for fine aggregate and for coarse aggregate) were performed on these ashes. The results of soundness tests are listed in Table 23, including the results of old samples and new samples of Perry $K$ ash. Among the four candidate ashes, Schahfer 14 ash, which is the only wet bottom ash produced by a cyclone furnace, has the lowest WL $(1.25 \%)$, implying that it has the highest resistance to the freeze-thaw environment simulated by soundness tests. In contrast, for Perry $\mathrm{K}$ ash, both the old and new samples, which were produced by a stoker furnace, have the highest WL, implying that it possesses a relatively low resistance to the freeze-thaw action. The newly sampled perry $K$ ash appears to be a iittle more durable than the old. The WLs of newly sampled Perry $K$ ash and the old samples of other candidate ashes will be used for comparison with those of the freeze-thaw tests later on.

Recall that the larger particles may be more vulnerable to freezing damage, as mentioned in chapter II. An attempt was made to verify this hypothesis by comparing the wL of each range of particle sizes for each candidate ash. 
Table 23 Results of sodium sulfate soundness Tests ${ }^{a}$

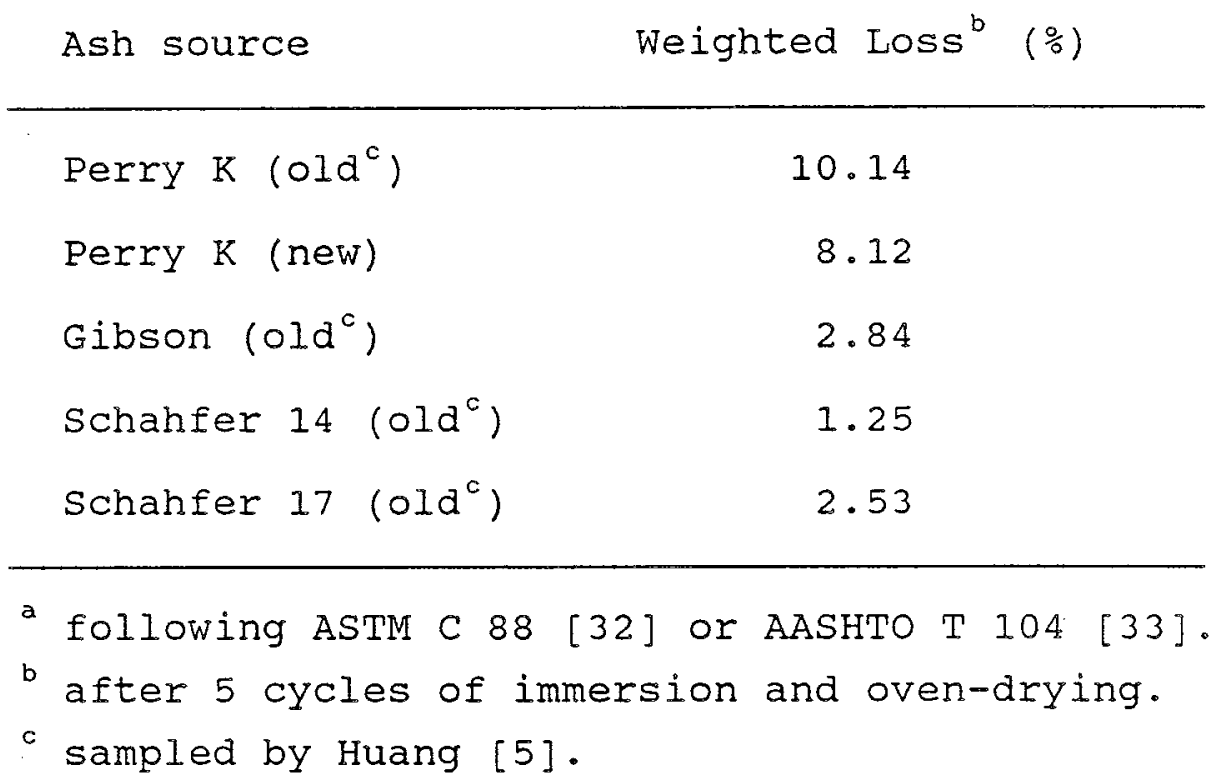


However, no consistent conclusion could be reached for the candidate ashes. Figure 35 shows the weighted losses versus particle sizes. In this figure, only the schahfer 14 ash seemed to follow the above rule, with Gibson ash, Perry $K$, and schahfer 17 ash showing an inverse relationship, i.e., the finer the particle the higher the WL.

\section{Freeze and Thaw Test}

A number of 50-cycle freeze-thaw tests were performed on the new samples of candidate ashes, in a totally immersed condition, as specified in AASHTO Designation $T 103$ [31]. The same requirement as given in ASTM Designation C 88 [32], applied to Schahfer 17 ash and Perry $K$ ash, i.e., the fine portions and the coarse portions of two ashes were tested separately following the individual procedures for fine aggregates and coarse aggregates. After the 50 cycles of freezing and thawing, the average maximum and the average minimum temperatures per cycle were calculated to be 46.8 and $-4.0^{\circ} \mathrm{F}$, respectively, and each cycle required, on the average, 3.3 hours.

The same relationships between particle size and weighted loss was observed as in soundness tests, i.e., the Schahfer 14 ashes followed the expected trend but the other three did not. The wLs obtained from the freeze-thaw tests are listed in Table 24. Again, as expected, Schahfer 14 ash 


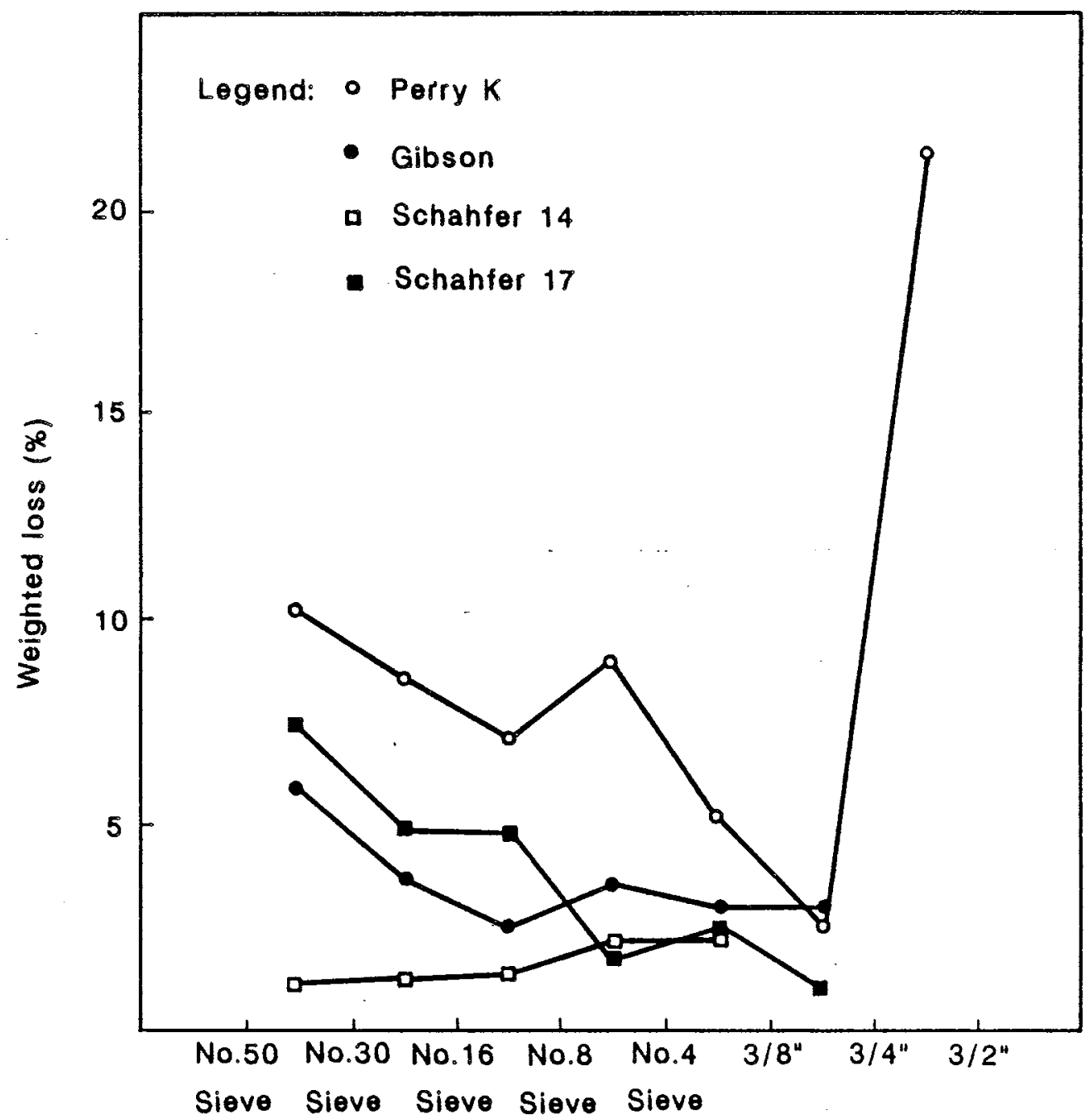

Figure 35 Weighted Loss versus Particle Size 
Yields the lowest WL among four candidate ashes, and Perry $\mathrm{K}$ has the highest WL. For comparison purposes, the WLs of soundness tests are also listed in Table 24 . It was found that the WLs obtained by freeze-thaw tests and soundness tests were more or less comparable. This implies that the five-cycle soundness test using sodium sulfate causes the same deterioration as the 50-cycle freeze-thaw test in a totally immersed condition, both giving the same amount of deterioration energy to the specimens. (Note: as mentioned in chapter II, the soundness test can not completely simulate the freezing action given by the freeze-thaw test.) From Table 24, the Schahfer 14 ash has a little higher WL in the freeze-thaw test than in the soundness test. Probably, the glass texture of schahfer 14 ash is more vulnerable to freezing (the freeze-thaw test) than to oven-drying (the soundness test).

Recall that in Chapter III it was predicted that the order of durability of candidate ashes would be Schahfer 14, Gibson, Schahfer 17, and Perry $K$ ash (see Table 20), based on the results of Los Angeles abrasion tests and degradation tests performed by Huang [5]. This order was verified by the results of the freeze-thaw tests (see Table 24), even though the Los Angeles abrasion tests and degradation tests provide totally different deterioration mechanisms. (Los Angeles abrasion tests provide the damage mode by friction and degradation tests provide the damage mode by 
Table 24 Comparison of Results of Soundness Tests and Freeze-Thaw Tests

\begin{tabular}{lcc} 
Ash source & $\begin{array}{c}\text { Soundness } \text { tests }^{\mathrm{a}} \\
\text { Weighted } \text { Loss }^{\mathrm{c}}(\%)\end{array}$ & $\begin{array}{c}\text { Freeze-thaw tests } \\
\text { Weighted Loss }\end{array}$ \\
\hline Perry $\mathrm{K}$ & 8.12 & 7.66 \\
Gibson & 2.84 & 3.38 \\
Schahfer 14 & 1.25 & 2.26 \\
Schahfer 17 & 2.53 & 3.55 \\
\hline
\end{tabular}

a following ASTM C 88 [32] or AASHTO T 104 [33].

b following AASHTO T 103 [31].

c after 5 cycles of immersion and oven-drying.

d after 50 cycles of freezing and thawing in a totally immersed condition. 
impact-crushing.) on the other hand, the results of the soundness tests indicate that schahfer 17 ash is somewhat more durable than Gibson ash. But this may be attributed to small testing error which could reverse the relationships. (Note: the difference of WLs between Schahfer 17 ash and Gibson ash is very small.)

Based on the results of two durability tests, it can be concluded (before the establishment of evaluation criteria) that the wet bottom ash produced by a cyclone furnace has a better resistance to frost action; while the dry bottom ash produced in a stoker furnace is less resistant. To acquire more data to evaluate the durability of Indiana bottom ashes, the five-cycle soundness tests were performed on the old samples of the other 7 ashes. Among them, only Richmond and culley bottom ashes were free of free fly ash. The testing results are listed in Table 25, showing the WL ranges obtained to be from 2.2 to $6.7 \%$. The freeze-thaw tests were judged not necessary since the results give similar WLs to the soundness tests.

\section{Corrosiveness Tests}

Four electrochemical characteristics of candidate ashes were determined. In general, the higher the soluble chloride and the soluble sulfate and the lower the minimum resistivity and $\mathrm{pH}$, the more corrosive the tested medium. 
Table 25 Results of Soundness Tests of Other 7 Ashes

\begin{tabular}{lc} 
Ash source & Weighted Loss $^{\mathrm{b}}\left(\frac{\%}{0}\right)$ \\
\hline Gallegher $^{c}$ & 2.19 \\
Mitchell $^{c}$ & 5.49 \\
Wabash $^{c}$ & 2.64 \\
Richmond $^{c}$ & 2.19 \\
Stout $^{c}$ & 6.34 \\
Culley $_{\text {Brown }}^{c}$ & 3.93 \\
\hline
\end{tabular}

a part finished by Huang [5].

$b$ after 5 cycles of immersion and oven-drying.

c sampled bottom ash mixed with fly ash. 
Because the majority of the tests were nonstandard, comment and discussions of results are appropriate.

\section{Soluble salts}

\section{Chloride content}

The blank value, the chloride content present in deionized water, was determined to be $0.136 \mathrm{ppm}$, i.e., 0.136 $\mu \mathrm{g}$ of $\mathrm{Cl}^{-}$per gram of water. Using Equations (16) and (17), the contents of total chlorides and soluble chlorides were calculated and are shown in Table 26. The units of $\mathrm{Cl}^{-}$ are $\mu \mathrm{g}$ of $\mathrm{Cl}^{-}$per gram of dried ash. From this table, Perry $\mathrm{K}$ ash has the highest soluble $\mathrm{Cl}^{-}$and Schahfer 14 has the lowest.

From Table 26, it is found that soluble $\mathrm{Cl}^{-}$is not proportional to the total $\mathrm{Cl}^{-}$among four ashes. The reason for this phenomenon needs to be explained. Define the dissolved percentage as $100 \% \times$ soluble $\mathrm{Cl}^{-} /$total $\mathrm{Cl}^{-}$. The dissolved percentages for four ashes are also included in Table 26. Among the four ashes, Schahfer 14 ash has the lowest dissolved percentage, and the other three ashes have a similar dissolved percentage of about $30 \%$. Recall in Chapter II that the amount of soluble salt depends on water content, pore flow condition (e.g., water velocity), the surface condition of ash particles, ash porous system, the 
Table 26 Chloride Contents of Candidate Ashes

\begin{tabular}{|c|c|c|c|}
\hline \multirow[b]{2}{*}{ Ash source } & \multicolumn{2}{|c|}{ Chloride content $\left(\mathrm{ppm}^{\mathrm{a}}\right)$} & \multirow{2}{*}{$\begin{array}{l}\text { Dissolved } \\
\text { percentage }\end{array}$} \\
\hline & Total & Soluble & \\
\hline \multirow[t]{2}{*}{ Perry K } & 51.6 & 15.5 & 30.0 \\
\hline & $(0.0052)^{c}$ & $(0.0016)^{c}$ & \\
\hline \multirow[t]{2}{*}{ Gibson } & 28.2 & 7.3 & 25.9 \\
\hline & $(0.0028)^{c}$ & $(0.0007)^{c}$ & \\
\hline \multirow[t]{2}{*}{ Schahfer 14} & 15.2 & 0.4 & 2.6 \\
\hline & $(0.0015)^{c}$ & $(0.00004)^{c}$ & \\
\hline \multirow[t]{2}{*}{ Schahfer 17} & 20.4 & 6.1 & 29.9 \\
\hline & $(0.0020)^{c}$ & $(0.0006)^{c}$ & \\
\hline
\end{tabular}

a ppm in $\mu \mathrm{g}$ of $\mathrm{Cl}^{-}$per gram of dried ash.

b $100 \% \times$ soluble $\mathrm{Cl}^{-} /$total $\mathrm{Cl}^{-}$.

c expressed as \% (by weight), $\mathrm{g}$ of $\mathrm{Cl}^{-} / \mathrm{g}$ of ash $\times 100 \%$. 
migrating rate of the salt itself, and the total content of the salt in the ash. (Note: the maximum dissolved amount of salt can not exceed its total content in the ash.) Here, based on California Test 422 [77], water content and flow conditions are identical for each ash. For the same salt $\left(\mathrm{Cl}^{-}\right)$and the definition of dissolved percentage, the migration rate and total $\mathrm{Cl}^{-}$are discarded. Therefore, only the surface condition of ash particles and ash porous system affect the dissolved ratio of $\mathrm{Cl}^{-}$. This is consistent with the fact that schahfer 14 ash particles are non-porous and have a glass texture, retarding $\mathrm{Cl}^{-}$migration from the interior to the outer water system.

\section{Sulfate content}

The total sulfates, the soluble sulfates, and the sulfate dissolved ratios are shown in Table 27 . Schahfer 14 ash has the smallest soluble sulfate, and Gibson ash has the largest, which is greater than $1000 \mathrm{ppm}$.

The Schahfer 14 ash also has the lowest dissolved ratio of $\mathrm{SO}_{4}^{2-}$, explained by the same rationale as with $\mathrm{CI}^{-}$. However, comparing Table 26 with Table 27, the sulfate dissolved percentage is generally smaller than the chloride dissolved percentage. Perhaps, the greater solubility of chloride compounds compared to sulfate compounds explains this observation. 
Table 27 Sulfate contents of Candidate Ashes

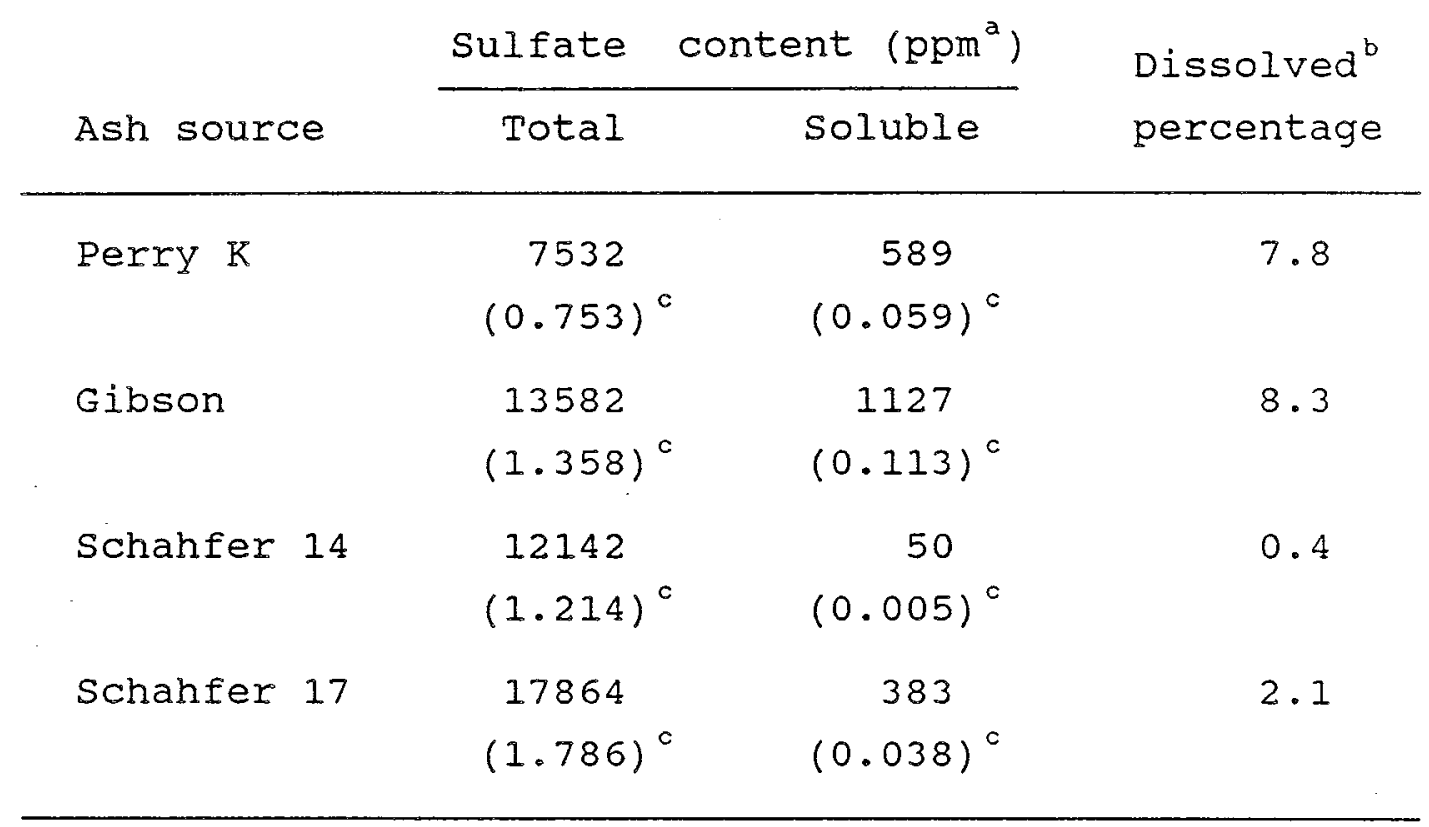

${ }^{2}$ ppm in $\mu \mathrm{g}$ of $\mathrm{SO}_{4}^{2-}$ per gram of dried ash.

b $100 \% \times$ soluble $\mathrm{SO}_{4}^{2-} /$ total $\mathrm{SO}_{4}^{2-}$.

c expressed as (by weight), $\mathrm{g}$ of $\mathrm{SO}_{4}^{2-} / \mathrm{g}$ of $\mathrm{ash} \times 100 \%$. 
Recall that Perry $K$ ash was the only ash which was never washed by water. It was expected that Perry $k$ ash might release more soluble salts than the other ashes. This is true for soluble $\mathrm{Cl}^{-}$(see Table 26); however, it does not hold for soluble $\mathrm{SO}_{4}^{2-}$ (see Table 27). (Note: Among the four ashes, Perry $\mathrm{K}$ ash contains the lowest content of total sulfate.)

\section{Time-Dependent Soluble Salts}

In situ, it may take more than a decade for soluble salts to completely dissolve (migrate) in the surrounding water, if pore water does not flow rapidly or no large disturbances occur within the ash mass. The laboratory testing procedure of shaking the ash-water solution for certain times can simulate the real situation only to a limited degree. It is expected that the measured soluble salt(s) will be different if the shaking procedure as specified in California Test 422 [77] is changed. It is of interest to determine how sensitive the measure of soluble salts are to the details of the shaking procedure. Two sets of tests were performed.

In California Test $422[77]$, the specified procedure is to shake the ash-water solution for 20 seconds twice in a one-hour interval. The first set of tests were performed by shaking each candidate ash-water solution every day in the 
way as specified above, up to 4 days, and the measurements of soluble salts were made every day at the time immediately before the shaking. This set was designated as the "dynamic" part of the time-dependent study. The testing results are listed in Table 28. The accumulated shaking energy of the $3 r d$ day is three times as much as that of the 1st day; however, the increase of soluble $\mathrm{Cl}^{-}$or $\mathrm{SO}_{4}^{2-}$ is only between $10 \%$ and $30 \%$. Therefore, it is concluded that after the lst day shaking, the measured soluble salt(s) are less sensitive to the further shakings.

The second set of tests were carried out by settling the ash suspension for three months after the 1st day of shaking, to simulate a long-term immersion condition of the ash mass after construction placement. This was designated as the "static" part of the time-dependent study. The testing results are listed in Table 29 . The increase of soluble $\mathrm{Cl}^{-}$or $\mathrm{SO}_{4}^{2-}$ after a three-month immersion approaches $30 \%$. It should be noted that the migrating path for a small scale sample (in the laboratory) is much shorter than the prototype ash mass.

Based on the results of the two sets of tests, the shaking procedures of California Test 422 [77] (for $\mathrm{Cl}^{-}$) or 417 [79] (for $\mathrm{SO}_{4}^{2-}$ ) are judged to be appropriate. 
- Table 28 Time-Dependent soluble Salts (dynamic ${ }^{a}$ )

\begin{tabular}{|c|c|c|c|c|c|}
\hline \multirow{2}{*}{ Ash source } & \multirow{2}{*}{$\begin{array}{l}\text { soluble } \\
\text { salt }\end{array}$} & \multicolumn{4}{|c|}{ soluble content (ppm $\left.{ }^{b}\right)$} \\
\hline & & Ist day & 2nd day & $3 r d$ day & 4th day \\
\hline \multirow[t]{2}{*}{ Perry K } & $\mathrm{Cl}^{-}$ & 15.5 & 16.0 & 17.4 & $-c$ \\
\hline & $\mathrm{SO}_{4}^{2-}$ & 589 & 675 & 705 & $-{ }^{c}$ \\
\hline \multirow{2}{*}{ Gibson } & $\mathrm{Cl}^{-}$ & 7.3 & 7.6 & 8.2 & 9.0 \\
\hline & $\mathrm{SO}_{4}^{2-}$ & 1127 & 1160 & 1252 & 1260 \\
\hline \multirow[t]{2}{*}{ Schahfer 14} & $\mathrm{Cl}^{\circ}$ & 0.4 & 0.4 & 0.5 & 0.5 \\
\hline & $\mathrm{SO}_{4}^{2-}$ & 50 & 56 & 58 & 60 \\
\hline \multirow[t]{2}{*}{ Schahfer 1} & $\mathrm{Cl}^{-}$ & 6.1 & 7.8 & 8.5 & $-^{c}$ \\
\hline & $\mathrm{SO}_{4}^{2-}$ & 383 & 419 & 434 & $-c$ \\
\hline
\end{tabular}

a stirring the ash-water solution once per day.

b $\mu g$ of salt per gram of dried ash.

c not determined. 
Table 29 Time-Dependent soluble salts (static ${ }^{a}$ )

\begin{tabular}{|c|c|c|c|}
\hline \multirow[b]{2}{*}{ Ash source } & \multirow[b]{2}{*}{ soluble salt } & \multicolumn{2}{|c|}{ soluble content $\left(\mathrm{ppm}^{\mathrm{b}}\right)$} \\
\hline & & lst day & 3 months \\
\hline \multirow[t]{2}{*}{ Perry $\mathrm{K}$} & $\mathrm{Cl}^{-}$ & 15.5 & 20 \\
\hline & $\mathrm{SO}_{4}^{2-}$ & 589 & 673 \\
\hline \multirow[t]{2}{*}{ Gibson } & $\mathrm{Cl}^{-}$ & 7.3 & 9 \\
\hline & $\mathrm{SO}_{4}^{2-}$ & 1127 & 1342 \\
\hline \multirow[t]{2}{*}{ Schahfer 14} & $\mathrm{Cl}^{-}$ & 0.4 & 0.8 \\
\hline & $\mathrm{SO}_{4}^{2-}$ & 50 & 62 \\
\hline \multirow[t]{2}{*}{ Schahfer 17} & $\mathrm{Cl}^{-}$ & 6.1 & 8 \\
\hline & $\mathrm{SO}_{4}^{2-}$ & 383 & 535 \\
\hline
\end{tabular}

a ash immersed in water for 3 months after 1st day shaking.

b $\mu g$ of salt per gram of dried ash. 
Resistivity

\section{Minimum Resistivity}

Table 30 lists the minimum resistivity of the four candidate ashes. The Perry $K$ ash has the lowest minimum resistivity and schahfer 14 ash has the highest, which is at least $6663 \mathrm{ohm}-\mathrm{cm}$. Because the $\mathrm{R}-40 \mathrm{C}$ meter can measure only a maximum resistance of $999 \mathrm{ohm}$ and the Box Factor of the sample box is 6.67 , the maximum capacity is $6663 \mathrm{ohm-cm}$. As expected, the minimum resistivity for each candidate ash occurred when the specimen was totally saturated. If more deionized water is added, the indicated resistivity starts to rise. The pHs of the specimens determined by $\mathrm{pH}$ paper are also included in Table 30 .

Comparing Table 30 with the field testing results in Table 19, it is found that the field resistivity is generally higher than the minimum resistivity (except in the case of schahfer 14 ash). This confirms the earlier discussion in chapter II, pointing out that field moisture never reaches saturation. The exceptional behavior of Schahfer 14 ash can be attributed to its quite high permeability. The high permeability prevented recovery of all the field ash leachate during sampling, and therefore resistivity performed on the leached specimen should reveal a higher resistivity. The $\mathrm{pH}$ in situ and that in the 
Table 30 Minimum Resistivity of Candidate Ashes

\begin{tabular}{lcc} 
Ash source & Minimum resistivity & $\mathrm{pH}^{\mathrm{b}}$ \\
\hline Perry K & 1287 & 6.5 \\
Gibson & 3286 & 5.7 \\
Schahfer 14 & $>6663^{\mathrm{c}}$ & 5.5 \\
Schahfer 17 & 4366 & 5.7 \\
\hline
\end{tabular}

a determined on ash particles finer than the No.8 sieve in accordance with California Test 532 [80] or 643 [81].

b determined by $\mathrm{pH}$ paper.

- 6663 is the maximum value the $\mathrm{R}-40 \mathrm{C}$ meter can indicate for the standard sample box. 
laboratory (both determined by $\mathrm{pH}$ paper) are almost the same.

Size Effect on Minimum Resistivity

The resistivity determinations as specified in California Test 532 [80] or 643 [81] were performed on the ash particles finer than the No. 8 sieve. They did not take into account the contribution of the coarser particles to the minimum resistivity. For natural soils or aggregates, this limitation of maximum size is reasonable because larger natural particles have a higher resistivity. For example, a moist clayey soil has a resistivity of 1000 to 2000 ohm-cm but sand and gravel may have a resistivity as high as $100000 \mathrm{ohm}-\mathrm{cm}$ [76]. Therefore, this restraint causes the test to give a conservative (lower) value of minimum resistivity. With waste materials such as bottom ash, the coarser particles may not contribute to a higher resistivity.

A verifying set of tests was conducted on the ash particles finer than $3 / 8$ in. More desirably and representatively, another set of tests was also performed on the crushed samples as described in the previous chapter. The results of these two sets of tests are summarized in Table 31, which also includes those of Table 30 for comparison purposes. Table 31 shows the size effect on 
Tabie 31 Size Effect on Minimum Resistivity

\begin{tabular}{lccc} 
& \multicolumn{3}{c}{ Minimum resistivity $($ ohm-cm) } \\
\cline { 2 - 4 } Ash source & No.8 sieve $^{\mathrm{a}}$ & $3 / 8^{\text {" }^{\mathrm{b}}}$ & crushed sample $^{\mathrm{c}}$ \\
\hline Perry K & 1387 & 994 & 980 \\
Gibson & 3286 & 2695 & 2201 \\
Schahfer 14 & $>6663$ & $>6663$ & $>6663$ \\
Schahfer 17 & 4366 & 5183 & 3082 \\
\hline
\end{tabular}

a determined on ash particles finer than the No. 8 sieve. b determined on ash particles finer than $3 / 8$ in.

c determined on crushed samples which pass through the No. 8 sieve. 
minimum resistivity, particularly for the ash containing coarser particles $(e . g .$, perry $K$ ash). It appears that coarser ash particles have a lower minimum resistivity, a phenomenon contrary to the observed trend for natural particles. Generally, crushed samples have the lowest minimum resistivity, which implies that crushed samples are more desirable. It is strongly recommended that for bottom ashes, crushed samples should be used to replace the Iimitation of maximum size of the No.8 sieve in determining the minimum resistivity in accordance with California Test 532 [80] or 643 [81]. The crushing method should be specified and controlled to avoid any occurrence of contamination. In Table 31, Schahfer 14 ash is shown to be insensitive to size limitation since about $98 \%$ of its particles pass the No.8 sieve.

\section{$\mathrm{pH}$}

Comparison of California Test and INDOT Method

Table 32 summarizes the results obtained by California Test 532 [80] or 643 [81] and those by the INDOT method. No significant differences are found between the two methods. However, the California Test 532 [80] or 643 [81] may be more desirable because of its ease of operation. AII candidate ashes show a basic nature, especially perry $\mathrm{K}$ ash. For comparison purposes, the $\mathrm{pH}$ values determined by $\mathrm{pH}$ 
Table $32 \mathrm{pH}$ Values of Candidate Ashes

\begin{tabular}{|c|c|c|c|}
\hline \multirow[b]{2}{*}{ Ash source } & \multicolumn{2}{|c|}{$\mathrm{pH}$ by use of $\mathrm{pH}$ meter } & \multirow{2}{*}{$\begin{array}{l}\text { pH by use } \\
\text { of pH paper }\end{array}$} \\
\hline & California Test & INDOT method ${ }^{b}$ & \\
\hline Perry $\mathrm{K}$ & 11.18 & 11.15 & 6.5 \\
\hline Gibson & 7.62 & 7.93 & 5.7 \\
\hline Schahfer 14 & 9.99 & 9.73 & 5.5 \\
\hline Schahfer 17 & 8.81 & 8.77 & 5.7 \\
\hline
\end{tabular}

a California Test 532 [80] or 643 [81].

b method used by Indiana Department of Transpotation. 
paper are also listed in Table 32. The large difference between the results obtained by a $\mathrm{pH}$ meter and by $\mathrm{pH}$ paper is easily seen. The results obtained by the $\mathrm{pH}$ meter are preferred because the $\mathrm{pH}$ meter measures the activity of $\mathrm{H}^{+}$ in the soil suspension (Jackson, [56]), which is of more concern in a corrosion action. The $\mathrm{pH}$ paper may merely measure the concentration of $\mathrm{H}^{*}$.

Size Effect on $\underline{\text { Ash }}$ pH

The above pH results were obtained from ash particles finer than the No.8 sieve as specified in California Test 532 [80] or 643 [81]. As with the minimum resistivity, and to examine the size effect on ash $\mathrm{pH}$, two other sets of tests were performed on ash particles finer than $3 / 8$ in. and on the crushed samples. Table 33 shows the results obtained by California Test 532 [80] or 643 [81] and those by the INDOT method. It can been seen that the size effect on ash $\mathrm{pH}$ is very significant. For perry $\mathrm{K}$ ash in particular, the crushed sample and ash particles finer than $3 / 8$ in. display an acidic $\mathrm{pH}$; while the particles finer than the No.8 sieve are very basic. A lower $\mathrm{pH}$ value is more aggressive to metals. Basically, crushed samples have lower pH values. Referring to Table 33, California Test 532 [80] or 643 [81] generally gives lower $\mathrm{pH}$ values than the INDOT method. Therefore, as in the case of resistivity, it is strongly recommended that for bottom ashes, crushed samples 
Table 33 Size Effect on Ash pH

(1) California Test 532 [80] or 643 [81]

Ash $\mathrm{pH}$

\begin{tabular}{lccc} 
Ash source & No.8 sieve $^{\mathrm{a}}$ & $3 / 8^{1 \mathrm{~b}^{\mathrm{b}}}$ & crushed sample $^{\mathrm{c}}$ \\
\hline Perry K & 11.18 & 3.77 & 4.80 \\
Gibson & 7.62 & 7.99 & 7.64 \\
Schahfer 14 & 9.99 & 9.88 & 9.59 \\
Schahfer 17 & 8.81 & 8.79 & 8.61 \\
\hline
\end{tabular}

(2) INDOT method

\begin{tabular}{lccc} 
& \multicolumn{3}{c}{ Ash pH } \\
\cline { 2 - 4 } Ash source & No.8 sieve & $3 / 8^{\mathrm{b}}$ & crushed sample $^{c}$ \\
\hline Perry K & 11.15 & 4.44 & 5.28 \\
Gibson & 7.93 & 8.14 & 7.15 \\
Schahfer 14 & 9.73 & 9.65 & 10.09 \\
Schahfer 17 & 8.77 & 8.96 & 8.56 \\
\hline
\end{tabular}

a determined on ash particles finer than the No. 8 sieve.

b determined on ash particles finer than $3 / 8$ in.

c determined on crushed samples which pass through the No. 8 sieve. 
should be used to replace the limitation of maximum size of No.8 sieve in determining the ash $\mathrm{pH}$ in accordance with California Test 532 [80] or 643 [81].

\section{Effect of Ash:Water Ratio on Ash $\mathrm{pH}$}

Table 34 shows the effect of ash:water ratio on ash $\mathrm{pH}$. All these tests were performed on ash particles finer than the No.8 sieve. Schahfer 14 ash seemed to be well-buffered at an ash:water ratio close to $1: 1$, but tended to be diluted (neutralized) with additional water. Perry $\mathrm{K}$ ash increased in $\mathrm{pH}$ with the addition of water to an ash:water ratio of $1: 1.5$, and then the $\mathrm{pH}$ stabilized... In contrast, Gibson ash and Schahfer 17 ash exhibit a behavior similar to several soils as shown in Fig 26. Their $\mathrm{pH}$ values continued to increase with a decreasing ash:water ratio. A complete profile of ash $\mathrm{pH}$ versus ash:water ratio for Gibson ash is shown in Fig 36. This figure shows that ash $p H$ can not increase with a decreasing ash:water ratio without limit. When the ash:water ratio reaches about $1: 20$, the $\mathrm{pH}$ of Gibson ash reached a maximum $\mathrm{pH}$ of 9.2 , and then started to decrease.

Effect of stirring Time on Ash pH

The stirring procedure for the ash suspension prior to $\mathrm{pH}$ determination has been described in the previous chapter. 
Table 34 Influence of Ash:Water Ratio on Ash pH

\begin{tabular}{lcccccccc} 
& \multicolumn{8}{c}{ Ash $\mathrm{pH}^{\mathrm{a}}$} \\
\cline { 2 - 8 } Ash source & $1: 0.6^{\mathrm{b}}$ & $1: 1^{\mathrm{b}}$ & $1: 1.5^{\mathrm{b}}$ & $1: 1.9^{\mathrm{b}}$ & $1: 2.4^{\mathrm{b}}$ & $1: 2.9^{\mathrm{b}}$ & $1: 3.4^{\mathrm{b}}$ \\
\hline Perry K & 9.48 & 11.15 & 11.27 & 11.23 & $-^{c}$ & $-^{\mathrm{c}}$ & $-^{\mathrm{c}}$ \\
Gibson & 7.69 & 7.93 & 8.18 & 8.31 & 8.32 & 8.41 & 8.56 \\
Schahfer 14 & 9.74 & 9.73 & 9.67 & $-^{\mathrm{c}}$ & $-^{c}$ & $-^{\mathrm{c}}$ & $-^{\mathrm{c}}$ \\
Schahfer 17 & 8.60 & 8.77 & 8.88 & 8.98 & $-^{\mathrm{c}}$ & $-^{\mathrm{c}}$ & $-^{\mathrm{c}}$ \\
\hline
\end{tabular}

a determined on ash particles finer than the No.8 sieve.

b ash:water ratio.

c not determined. 


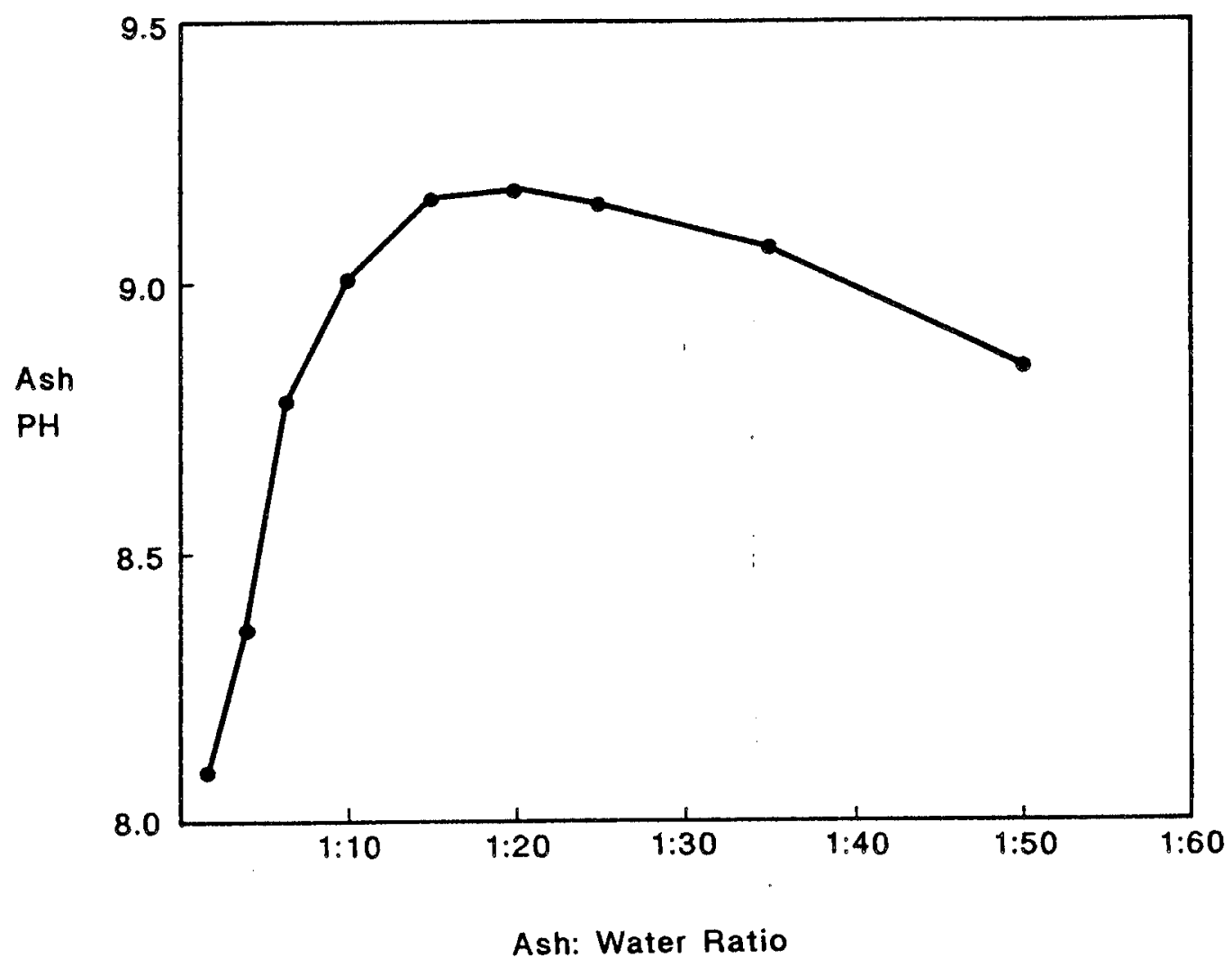

Figure $36 \mathrm{pH}$ value of Gibson Ash versus Ash:Water Ratio 
There is a question as to how well this stirring mechanism simulates the field condition. One set of tests was performed on ash suspensions which were continuously stirred for three days, simulating the extreme condition in which all ion species in the ash dissolved. Table 35 shows the results, which indicate that the $\mathrm{pH}$ of the ash-water systems decreases with increased stirring time. However, the large change of $\mathrm{pH}$ might be attributed to $\mathrm{CO}_{2}$ gradually entering the ash suspension from the air or oxidation of certain species in the ash. Therefore, no positive conclusion can be drawn from varying the stirring times, except that the ash $\mathrm{pH}$ should be determined immediately after the preparation of the ash suspension...

\section{Comparison with soils}

For evaluation purposes, a summary of four electrochemical characteristics of candidate ashes is shown in Table 36. The measurements made on crushed samples for ash $\mathrm{pH}$ and minimum resistivity are used. To provide additional evaluation data, the determinations of minimum resistivity and $\mathrm{pH}$ were also performed on the samples collected by Huang [5]. The testing results are summarized in Table 37. The values of minimum resistivity of these sample ashes are relatively low, and the $\mathrm{pH}$ values vary among ashes. 
Table 35 Influence of Stirring Time on Ash $\mathrm{pH}$

\begin{tabular}{ccc}
\multirow{2}{*}{$\begin{array}{c}\text { Strring time } \\
\text { (days) }\end{array}$} & \multicolumn{2}{c}{ Ash $\mathrm{pH}^{\mathrm{a}}$} \\
\cline { 2 - 3 } 0 & 10.03 & Schahfer 17 \\
1 & 9.89 & 9.09 \\
2 & $-^{b}$ & 8.10 \\
3 & $-^{b}$ & 8.08 \\
\hline
\end{tabular}

a determined on ash particles finer than the No. 8 sieve.

b not determined. 
- Table 36 Summary of Four Electrochemical Characteristics of Candidate Bottom Ashes

\begin{tabular}{|c|c|c|c|c|}
\hline Ash source & $\begin{array}{l}\text { Minimum }^{a} \\
\text { Resistivity } \\
\text { (ohm-cm) }\end{array}$ & $\mathrm{pH}^{\mathrm{a}}$ & $\begin{array}{l}\text { Soluble } \\
\mathrm{Cl}^{-}\left(\mathrm{ppm}^{\mathrm{c}}\right)\end{array}$ & $\begin{array}{l}\text { Soluble } e^{d} \\
\text { So }_{4}^{2-}\left(\mathrm{ppm}^{\mathrm{c}}\right)\end{array}$ \\
\hline Perry K & 980 & 4.8 & $\begin{array}{c}15.5 \\
(0.0016)^{e}\end{array}$ & $\begin{array}{c}589 \\
(0.059)^{e}\end{array}$ \\
\hline Gibson & 2201 & 7.6 & $\begin{array}{c}7.3 \\
(0.0007)^{e}\end{array}$ & $\begin{array}{c}1127 \\
(0.113)^{\mathrm{e}}\end{array}$ \\
\hline Schahfer 14 & $>6663$ & 9.6 & $\begin{array}{c}0.4 \\
(0.00004)^{e}\end{array}$ & $\begin{array}{c}50 \\
(0.005)^{e}\end{array}$ \\
\hline Schahfer 17 & 3082 & 8.6 & $\begin{array}{c}6.1 \\
(0.0006)^{e}\end{array}$ & $\begin{array}{c}383 \\
(0.038)^{e}\end{array}$ \\
\hline
\end{tabular}

a determined on crushed samples finer than the No.8 sieve following California Test 532 [80] or 643 [81].

b following California Test 422 [77].

c ppm in $\mu \mathrm{g}$ of salt per gram of dried ash.

d following California Test 417 [79].

- expressed as \% (by weight). 
Table 37 Minimum Resistivity and $\mathrm{pH}$ of Other 7 Ashes

\begin{tabular}{|c|c|c|c|}
\hline \multirow[b]{2}{*}{ Ash source } & \multirow{2}{*}{$\begin{array}{c}\text { Minimum resistivity } \\
\text { (ohm-cm) }\end{array}$} & \multicolumn{2}{|c|}{ Ash $\mathrm{pH}^{\mathrm{a}}$} \\
\hline & & Californiab & INDOT $^{c}$ \\
\hline Gallegher ${ }^{d}$ & 335 & 9.14 & 9.15 \\
\hline Mitchel1 ${ }^{d}$ & 1771 & 8.04 & 8.11 \\
\hline Wabash $^{d}$ & 1051 & 5.71 & 5.45 \\
\hline Richmond & 247 & 8.20 & 8.12 \\
\hline stout ${ }^{d}$ & 4249 & 6.56 & 6.86 \\
\hline Culley & 486 & 8.48 & 8.55 \\
\hline Brown $^{d}$ & 213 & 3.18 & 3.29 \\
\hline
\end{tabular}

a determined on ash particles finer than the No.8 sieve.

b California Test 532 [80] or 643 [81].

c method used by Indiana Department of Transportation. d sampled bottom ash mixed with fly ash. 
Recall in Chapter II Table 14 and Table 15, comparisons between soil and bottom ash characteristics were made. Some additional considerations need to be taken into account in order to facilitate the comparison.

(1) Comparison of Indiana bottom ashes and soils: Because, in Table 14, the soil resistivity is in terms of the average field resistivity, it can not be directly compared with the minimum resistivity of bottom ash obtained in this study. In addition, in Table 14, soluble chlorides and soluble sulfates are expressed as ppm on a basis of water volume, i.e., $\mathrm{mg}$ of salt per liter of water. For bottom ash it is necessary to convert ppm for solid weight to ppm for water volume. Two assumptions were made-to accomplish this: full saturation and static water in situ. Therefore, in a unit of ash-water volume, all soluble salts in the ash dissolve only in the immediately surrounding water. The calculation equations are listed below:

$$
\begin{aligned}
& w_{\text {eq }}=\frac{e_{\text {Dr } 50 \%}}{G s} \\
& \text { ppm }(\mathrm{mg} / \text { liter })=\frac{\text { ppm }(\mu g / g)}{w_{\text {eq }}}
\end{aligned}
$$

where $w_{\text {eq }}$ is the equivalent water content (in decimal); $e_{\text {Dr } 50 \%}$ is the void ratio at $50 \%$ of relative density (data available in Huang [5]); Gs is the specific gravity (data given in Table 19); ppm (mg/liter) is $\mathrm{mg}$ of salt per liter of water; and ppm $(\mu \mathrm{g} / \mathrm{g})$ is $\mu \mathrm{g}$ of salt per gram of ash. 
The converted soluble salts of candidate bottom ashes are shown in Table 38. It should be noted that sulfate concentration in Table 38 has been changed into $\mathrm{SO}_{3}$ concentration using a conversion factor of 1.2 , which is the ratio of molecular weight of $\mathrm{SO}_{4}^{2-}$ to that of $\mathrm{SO}_{3}$. Following the same format as Table 14, the statistical results of three characteristics of bottom ashes are shown in Table 39. Upon comparison of Table 39 and 14, it can be concluded that Indiana bottom ashes have a higher soluble sulfate content and a little lower soluble chloride content than soils, but a comparable $\mathrm{pH}$ value.

(2) Comparison of Indiana bottom ashes and metal-reinforced soils: Following the same format as Table 15, the statistical results of four characteristics of Indiana bottom ashes are listed in Table 40 (sulfate expressed as $\mathrm{SO}_{3}$ ). Comparing Table 40 with Table 15 , it is found that Indiana bottom ashes have a lower minimum resistivity and a higher soluble sulfate content than the soils used by Reinforced Earth Company, but a similar $\mathrm{pH}$ and soluble chloride content. 
Table 38 conversion of salt content to salt concentration

\begin{tabular}{|c|c|c|c|c|c|}
\hline Ash source & $e_{\text {Dr } 50 \%}{ }^{a}$ & $G s^{b}$ & $W_{\text {eq }}{ }^{c}$ & $\mathrm{Cl}^{-}(\mathrm{mg} / \mathrm{I})^{\mathrm{d}}$ & $\mathrm{SO}_{3}(\mathrm{mg} / \mathrm{I})^{\mathrm{e}}$ \\
\hline Perry $\mathrm{K}$ & 2.2 & 2.03 & 1.083 & 14.3. & 653 \\
\hline Gibson & 0.7 & 2.62 & 0.267 & 27.3 & 5065 \\
\hline Schahfer 14 & 0.65 & 2.82 & 0.230 & 1.7 & 261 \\
\hline Schahfer 17 & 1.0 & 2.59 & 0.386 & 15.8 & 1191 \\
\hline
\end{tabular}

a void ratio at $50 \%$ Dr (from Huang [5]).

b specific gravity (from Table 20 ).

c equivalent water content, $\frac{e_{D r 50 \%}}{G s}$ (in decimal).

d $\mathrm{Cl}^{-}$(from Table 36 )/W eq.

e $\mathrm{SO}_{4}^{2-}$ (from Table 36 ) / $\mathrm{w}_{\mathrm{eq}} \times 1.2$. 


\section{Table 39 Statistic Results of three Electrochemical Characteristics of Indiana bottom ashes (compared with Table 14)}

Ash pH (1:1 ash:water ratio)

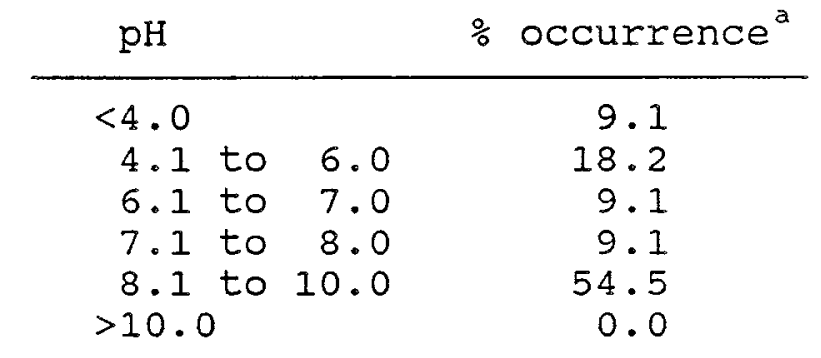

$\mathrm{Cl}^{-}$concentration (mg/liter) mg per liter \%occurrence ${ }^{b}$

\begin{tabular}{rr}
0 to 9 & 25.0 \\
10 to 19 & 50.0 \\
20 to 49 & 25.0 \\
50 to 99 & 0.0 \\
$>100$ & 0.0 \\
\hline
\end{tabular}

$\mathrm{SO}_{3}$ concentration (mg/liter) mg per liter \%occurrence ${ }^{b}$

\begin{tabular}{rrr}
\hline$=0.000$ & & 0.0 \\
0.001 to 0.999 & 0.0 \\
1.000 to 4.999 & 0.0 \\
$>5.000$ & & 100.0 \\
\hline
\end{tabular}

a based on the results of 11 bottom ashes (Tables 36 and 37).

$b$ based on the results of 4 candidate ashes (Table 36). 
Table 40 Statistic Results of four Electrochemical Characteristics of Indiana bottom ashes (compared with Table 15)

\begin{tabular}{rr} 
Minimum ash resistivity & percentage $^{a}$ \\
\hline >10000 ohm-cm & 0.0 \\
3000 to 10000 ohm-cm & 9.1 \\
1000 to 5000 ohm-cm 3000 ohm-cm & 18.2 \\
$<1000$ ohm-cm & 27.3 \\
\end{tabular}

Ash pH (1:1 ash:water ratio) percentage $^{a}$

\begin{tabular}{|c|c|}
\hline $\begin{array}{l}5 \text { to } 6 \\
6 \text { to } 8.5 \\
>8.5\end{array}$ & $\begin{array}{r}18.2 \\
9.1 \\
45.4 \\
27.3\end{array}$ \\
\hline $\mathrm{Cl}^{-}$content $(\mu \mathrm{g} / \mathrm{g})$ & percentage ${ }^{b}$ \\
\hline $\begin{array}{rr} & <10 \\
10 \text { to } & 50 \\
50 \text { to } & 100 \\
100 \text { to } 200 \\
>200\end{array}$ & $\begin{array}{r}75.0 \\
25.0 \\
0.0 \\
0.0 \\
0.0\end{array}$ \\
\hline $\mathrm{SO}_{3}$ content $(\mu \mathrm{g} / \mathrm{g})$ & percentage $^{b}$ \\
\hline $\begin{array}{rr} & <50 \\
50 \text { to } & 200 \\
200 \text { to } & 500 \\
500 \text { to } 1000 \\
>1000\end{array}$ & $\begin{array}{l}0.0 \\
25.0 \\
25.0 \\
25.0 \\
25.0\end{array}$ \\
\hline
\end{tabular}

a based on the results of 11 bottom ashes (Table 36 and Table 37).

$b$ based on the results of 4 candidate ashes (Table 36). 


\section{CHAPTER VI EVALUATION CRITERIA}

After completion of the laboratory testing, a variety of parameters either related to durability or corrosiveness of bottom ash were available. Based on these parameters, evaluation criteria were established to rate the suitability of Indiana bottom ashes. The evaluation criteria can be expressed, either in terms of being generally acceptable, or more quantitatively in terms of service life (in years). This chapter describes the process of establishing evaluation criteria based on acceptable values. However, an additional effort was made to connect evaluation with the concept of service life. Currently available criteria for bottom ash are derived from the available specifications or experiences for natural aggregates or soils. The evaluation criteria suggested in this chapter may be verified or modified in the future with the accumulation of experiences utilizing bottom ash.

\section{Durability Criteria}

Two durability tests involved in this study are designed to investigate the ability of a material to resist freezing and thawing action. Therefore, the established 
evaluation criteria are particularly appropriate for materials exposed to an environment, where frost action is significant. They may not be as suitable for locations where another environmental agent is dominant.

For both the soundness test and the freeze-thaw test, weighted loss (WL) is chosen as the aging indicator, although one may question how well WL is related to the actual serviceability of a material. This aspect was fully discussed in chapter II. As a rule of thumb, the higher the WL of a material the less durable the material. Therefore, the allowable WL sets the maximum threshold (upper limit) of weighted loss.

The ASTM or AASHTO specifications on aggregates provide several threshold values that depend on usage and particle size. Consulting these standard specifications, it is observed that none of them clearly indicates what service Iife corresponds to the stated allowable value of WL. secondly, due to climatic variation throughout the world, the intensity of frost action inevitably varies from place to place.

Figure 37 maps six climatic regions in the United states for the purpose of pavement design [84]. These regions are classified by the severity of the freeze-thaw action. The average length of each season (months) for the six U.S. climatic regions are listed in Table 41 . If the 

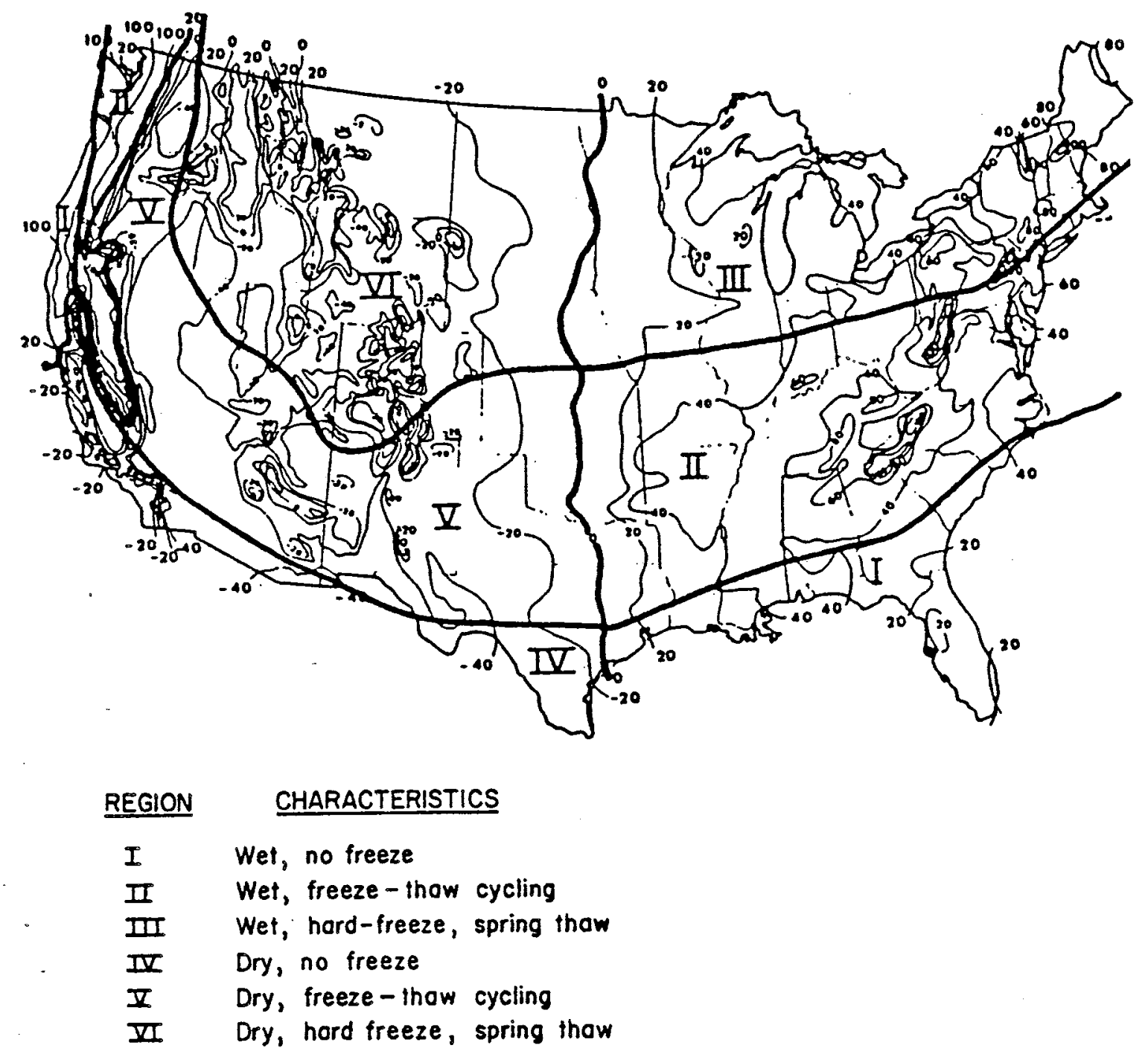

Figure 37 Six climatic Regions in the United states.
(from [84]) 
Table 41 Suggested Seasons Length for the Six U.S. Climatic Regions. (from [84])

\begin{tabular}{ccccc}
\hline $\begin{array}{c}\text { U.S. } \\
\text { Climatic } \\
\text { Region }\end{array}$ & $\begin{array}{c}\text { Winter } \\
\text { (Roadbed } \\
\text { Frozen) }\end{array}$ & $\begin{array}{c}\text { Spring-Thaw } \\
\text { (Roadbed } \\
\text { Saturated) }\end{array}$ & $\begin{array}{c}\text { Spring/Fall } \\
\text { (Roadbed } \\
\text { Wet) }\end{array}$ & $\begin{array}{c}\text { Summer } \\
\text { (Roadbed } \\
\text { Dry) }\end{array}$ \\
\cline { 2 - 5 } & 0.0 & 0.0 & 7.5 & 4.5 \\
I & 1.0 & 0.5 & 7.0 & 3.5 \\
III & 2.5 & 1.5 & 4.0 & 4.0 \\
IV & 0.0 & 0.0 & 4.0 & 8.0 \\
V & 1.0 & 0.5 & 3.0 & 7.5 \\
VI & 3.0 & 1.5 & 3.0 & 4.5 \\
\hline
\end{tabular}

- Number of months for the season. 
design life for an aggregate application is set to be constant, then the allowable WL should vary. with the usage location, i.e., a more rigorous (smaller) value for a severe frost zone and a larger value for a milder temperature area. However, existing specifications suggest only a single value, not taking into account the difference in the severity of the frost action with geographic region.

To use these two established criteria, two assumptions must be made. (1) The allowable WL corresponds to the general design life for each application; and (2) the allowable WL applies to the areas subjected to a severe freeze-thaw action (Region III in Figure 37). Regarding (1), the allowable WLs present in the current specifications reflect past experience, so that a material with a WL less than the allowable $W L$ is expected to perform as required over the design life. Regarding (2), practical judgments are required to apply these criteria to other climatic areas. For a less severe frost-action zone, either a higher allowable WL is used to produce the same design life or the same criterion is used with an increase in the design life. The increase of allowable WI or that of design life is dependent on the practical experience of local material engineers. The design lives of common aggregate applications are shown in Table 42 . 
- Table 42 Design Lives of Several Aggregate Applications

\begin{tabular}{lc}
$\begin{array}{l}\text { Application } \\
\text { of aggregate }\end{array}$ & $\begin{array}{c}\text { Design life } \\
\text { (Yrs) }\end{array}$ \\
\hline $\begin{array}{l}\text { Concrete mixture } \\
\text { Bituminous mixture }\end{array}$ & $40-80^{\mathrm{a}}$ \\
Base or Subbase & $300^{\mathrm{b}}$ \\
Embankment or & $30-50^{\mathrm{b}}$ \\
$\quad$ Subgrade & $>50^{\mathrm{c}}$ \\
Masonry Mortar & $>40^{\mathrm{c}}$ \\
\hline a dependent on use (structure or foundation) [9]. \\
b dependent on traffic conditions [84]. \\
c an estimated value by this writer.
\end{tabular}


Sodium Sulfate Soundness Test

Listed below are the allowable WLs for aggregates, tested by the five-cycle soundness test using sodium sulfate. If magnesium sulfate is used for the soundness test, the allowable WL can be modified by multiplying a factor of 1.5. Figure 38 shows the relationship between 408 sodium sulfate and magnesium sulfate soundness test results [12]. In spite of large scatter, this figure shows that the WL of the $\mathrm{MgSO}_{4}$ soundness test is approximately 1.5 times as much as that of the $\mathrm{Na}_{2} \mathrm{SO}_{4}$. For example, a WL of $18 \%$ for $\mathrm{MgSO}_{4}$ is equivalent to a WL of $12 \%$ for $\mathrm{Na}_{2} \mathrm{SO}_{4}$. Available specifications afford guidelines for allowable WL values.

The ASTM standard specifications:

(1) ASTM C 33 [85] - 10\% for fine concrete aggregate, and $12 \%$ for coarse concrete aggregate.

(Note: this specification suggests the use of the same allowable WL for aggregates exposed to any weathering condition.)

(2) ASTM D 1073 [86] - 15\% for fine aggregates for bituminous paving mixture.

(3) ASTM D 692 [87] - 12\% for coarse aggregates for bituminous paving mixture.

(4) ASTM D 2940 [88] - "blank" for graded aggregate materials for bases or subbases for highways or airports. 


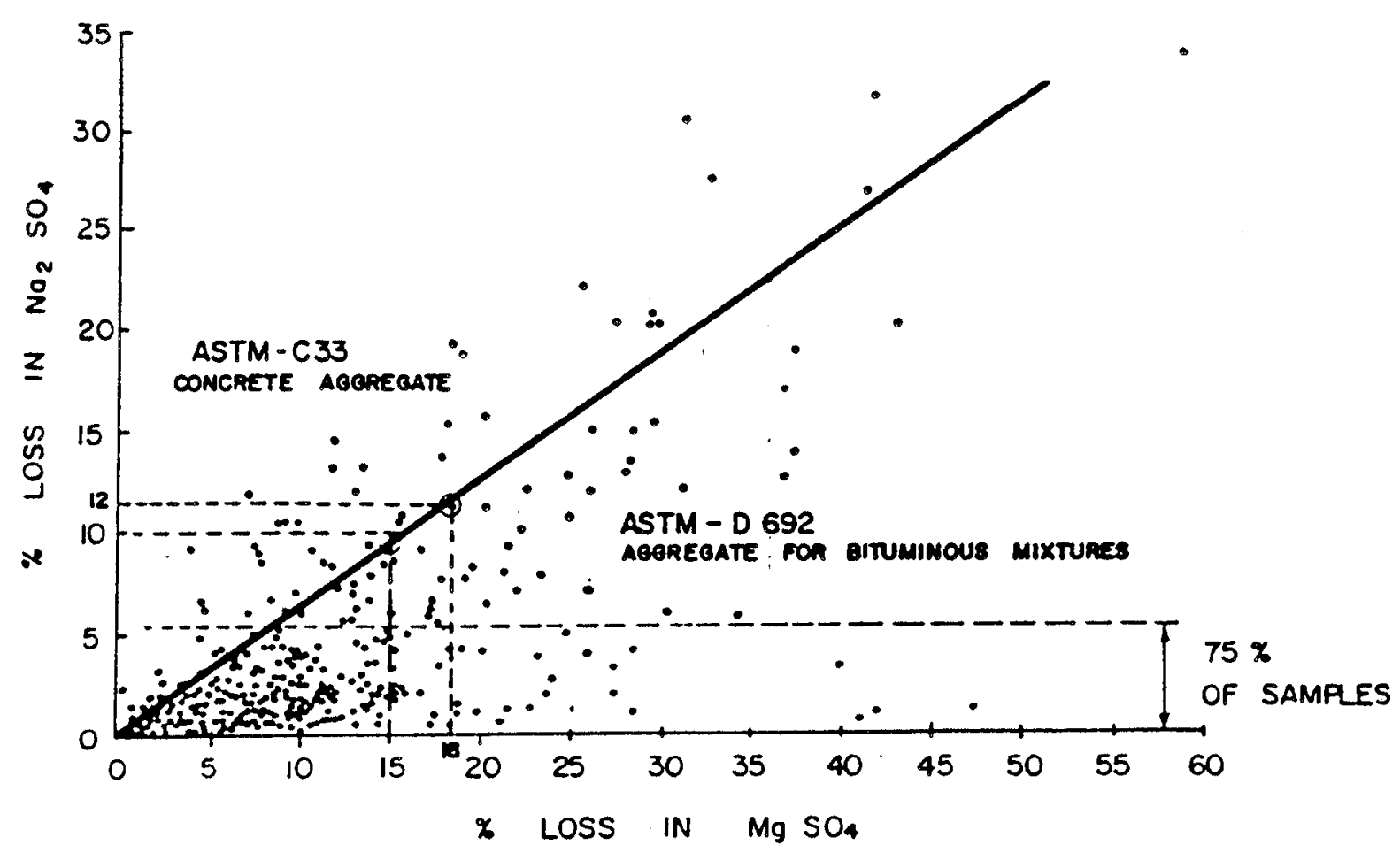

Figure 38 Relationship between sodium sulfate and Magnesium Sulfate Tests. (from Keyser, [12]) 
(Note: "blank" means no allowable WL is specified for this aggregate application.)

(5) ASTM D 1241 [89] - "blank" for materials for soil-aggregates subbases, bases, and surface courses.

The AASHTO standard specifications:

(1) AASHTO M 6 [90] - 10\% for fine aggregate for Portland cement concrete.

(2) AASHTO M 80 [91]. - 12\% for coarse aggregate for Portland cement concrete.

(3) AASHTO M 29 [92] - 15\% for fine aggregate for bituminous paving mixture.

(4) AASHTO M 283 [93] - 12\% for coarse aggregate for highway and airport construction.

(5) AASHTO M 45 [94] - 10\% fine aggregate for masonry mortar.

The INDOT standard specifications [95]:

(1) the allowable WL for fine aggregates - the same as the AASHTO specifications.

(2) For coarse aggregates, the allowable WL depends on the classification of the aggregate. Class $A$ is defined as the highest classification, with an allowable WL of $12 \%$; while class $F$ is the lowest classification, with an

- allowable WL of $25 \%$ Each class of aggregate corresponds to a different application. 
The Technical Specifications for Reinforced Earth Walls [96] by the Reinforced Earth Company:

(1) $30 \%$ after a 4-cycle $\mathrm{MgSO}_{4}$ soundness test for selected granular backfills of reinforced earth walls. Using the conversion factor of $0.67 * 1.25$ (where 0.67 is the ratio of the $\mathrm{Na}_{2} \mathrm{SO}_{4}$ WL to the $\mathrm{MgSO}_{4} \mathrm{WL}$ and 1.25 is the ratio of 5 cycles to 4 cycles), the WL equivalent to that after a 5-cycle $\mathrm{Na}_{2} \mathrm{SO}_{4}$ soundness test is $25 \%$. since this is a nonstandard criterion, a conservative value of $20 \%$ is used.

Table 43 synthesizes the above specifications. As mentioned earlier the allowable WL depends on application and particle size. Different aggregate applications correspond to distinct service conditions and stress levels. For example, the stress level in an embankment material may be much lower than those of pavement sections, so an aggregate for embankment use may have a higher tolerable WL, which can still insure the performance of the entire. pavement-embankment system.

A fine aggregate is defined as a material having less than $10 \%$ of its particles coarser than $3 / 8$ in.; while a coarse aggregate as a material having less than $10 \%$ of particles finer than the No.8 sieve. The allowable WL for a material other than these two groups can be interpolated between the allowable WL of a fine aggregate and that of a 
Table 43 Evaluation Criteria on Durability (based on weighted loss \%)

\begin{tabular}{|c|c|c|c|c|}
\hline \multirow{2}{*}{$\begin{array}{l}\text { Application } \\
\text { of aggregate }\end{array}$} & \multicolumn{4}{|c|}{ Particle size } \\
\hline & Fine & aggregate $^{b}$ & Coarse & aggregate $^{c}$ \\
\hline Concrete mixture & & $<10^{d}$ & & $<12$ \\
\hline Bituminous mixture & & $<15$ & & $<12$ \\
\hline Base or Subbase & & $<15$ & & $<12$ \\
\hline $\begin{array}{l}\text { Embankment or } \\
\text { Subgrade }\end{array}$ & & $<20$ & & $<20$ \\
\hline Masonry Mortar & & $<10$ & & $-{ }^{e}$ \\
\hline
\end{tabular}

a ability to resist freeze-thaw action only.

"with less than $10 \%$ of particles coarser than $3 / 8$ ".

c with less than $10 \%$ of particles finer than the No. 8 sieve.

d weighted loss $(\%)$ after 5 -cycle sodium sulfate soundness test or 50-cycle freeze-thaw test.

e not applicable. 
coarse aggregate.

If applied to the concept of design life, an aggregate meeting the durability requirement for an application can be expected to have, at least, a service life suggested in Table 42. It should be once again noted that the criteria are only suitable for a material in regions where frost action is the predominant environmental agent, e.g., Region III in Figure 37 .

Freeze and Thaw Test

Since there is no ASTM freeze-thaw test standard for aggregates, there are no specified acceptable values. AASHTO Designation M 6 [90] merely states that "The engineer should insert appropriate values (allowable WLs) based on his experience with the test." Only INDOT [95] provides an acceptance specification for aggregates tested by freeze-thaw.

Section 903 of INDOT standard Specifications [95] states that the WL from a 50-cycle freeze-thaw test can not exceed the allowable WL by a five-cycle sodium sulfate soundness test. In the previous chapter, it was found that both durability tests appeared to obtain comparable wLs. Accordingly, Table 43 (for the WL after a five-cycle sodium sulfate soundness test) can also be applied without change to the results of the 50-cycle freeze-thaw tests. For 
bottom ash evaluation, either of these two durability tests can be chosen, based on equipment available and time restrictions. The criteria shown in Table 43 can then be used to assess the durability of bottom ashes exposed to a freeze-thaw environment.

Table 42 shows the approximate design lives for several applications of aggregates meeting the given allowable WL specifications. The most rational method to calculate the design life would be determine the number of years in a service environment which corresponds to the observed WL as found by the five-cycle sodium sulfate soundness test or the 50-cycle freeze-thaw test. However, it is not possible with an innovative material such as bottom ash to obtain the long-term exposure test results. Therefore, the acceleration factor $\left(F_{a_{c c}}\right.$ ) for time can not be obtained.

An attempt was made to find another $F_{a_{c c}}$ based on an energy concept. The freezing damage might be assumed to be a pure energy consumption process during cooling. The consumption value per cycle of freeze-thaw in the laboratory $\left(C_{1 a b}\right)$ and that per year $\left(C_{s i t u}\right)$ in a service environment (e.g., Region III in Figure 37), might be individually computed. The $\mathrm{F}_{\mathrm{acc}}$ for energy could thereby be obtained by dividing $c_{1 a b}$ by $c_{\text {situ }}$. A modification factor should be added to take into account the effect of a faster cooling rate in the laboratory. The design life prediction would be 
the product of the modified $F_{a c c}$ and 50 (the number of freeze-thaw cycle in the laboratory). However, this hypothesis could not be implemented due to the complexity of the actual service environment and the difficulty in scaling the factor of cooling rate.

\section{Corrosiveness Criteria}

Most of the available specifications on underground corrosion were developed for soils. All criteria on soil corrosiveness are nonstandard. The data sources are from state highway departments, corrosion manuals, ASTM special publications, conferences, and construction companies. only the criteria based on the four electrochemical characteristics (chosen in the previous chapter) were compiled. The goal of this study was to combine these four parameters to assess the corrosiveness of bottom ash. As discussed in Chapter II, the corrosion rate in a medium depends on the metal type and the protective conditions. In this study, attention was restricted to the iron-like and steel structures. A review of the influence of the four electrochemical characteristics on corrosiveness shows:

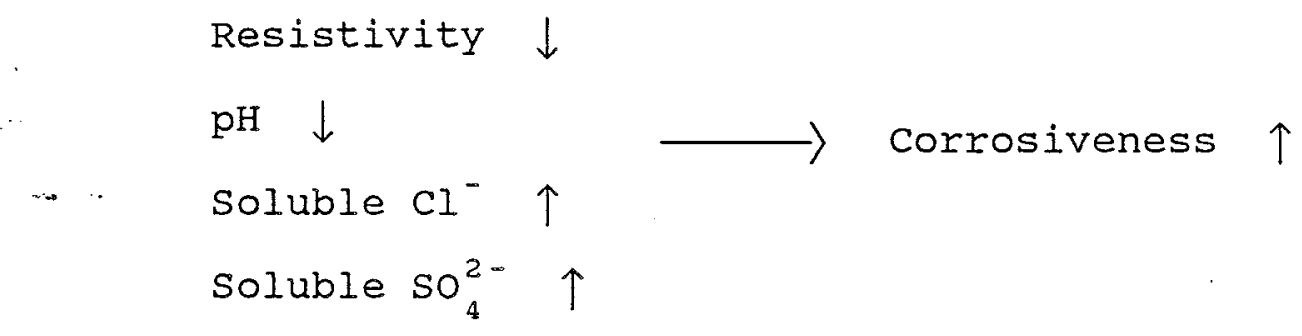


i.e., the lower the resistivity and $\mathrm{pH}$ and the higher the soluble chloride content and soluble sulfate content, the more corrosive the medium. The establishment of corrosiveness criteria includes three phases: (1) a set of threshold values for the four electrochemical characteristics; (2) a service life equivalent to the threshold values; and (3) a service life or corrosion rate equivalent to the determined values of electrochemical characteristics.

\section{A Set of Threshold Values}

The evaluation criteria on soil corrosiveness have been established based on a set of threshold values. Among the four electrochemical characteristics, resistivity seems to be the most predominant. As mentioned in chapter II, the soil resistivity governs the magnitude of corrosion current flowing through the soil-water electrolyte between two electrodes. It was found that the sequence of precedence of four characteristics are: resistivity, $\mathrm{pH}$, soluble $\mathrm{Cl}^{-}$, and soluble $\mathrm{SO}_{4}^{2-}$. Described below are available threshold values proposed by a number of investigators and institutions, roughly in a chronological order.

Historically, many investigators attempted to use resistivity, either field resistivity or saturated (minimum) resistivity, as a single indicator of soil corrosiveness. 
Waters [97] (as cited in Escalante, [43]) presented the relationship between soil resistivity and soil corrosivity, as shown in Table 44. Based on this table, a medium with a resistivity of less than $900 \mathrm{ohm-cm}$ is considered "very severely corrosive". Tomashov [36] and Palmer [98] suggested similar classifications, as shown in Tables 45 and 46 , respectively. Consulting these tables, a soil with a value less than 1000 ohm-cm is classified as being severely corrosive. Peabody [99] presented another acceptable relationship between soil resistivity and soil corrosivity, as shown in Table 47 , where a soil with a resistivity less than 2000 ohm-cm is regarded to be corrosive. Booth et al. [51] reported the threshold value of soil resistivity to be 2000 ohm-cm (Table 9). Escalante [43], as indicated earlier, concluded that a soil with a resistivity below 500 ohm-cm is corrosive.

Table 48 shows the AWWA (American Water Works Association) rating scale (as cited in McMullen, [35]; and Palmer [38]). Five parameters are included in this scale and soil resistivity has a higher weighting. If a soil has a summed evaluation point greater than 10, then it is corrosive. From Table 48, a soil will be classified as corrosive merely when its resistivity is less than 700 ohm-cm. By using this 10-point method to study the Des Moines Water Works soils, McMullen [35] indicated that the saturated resistivity is the best "single" parameter for 
Table 44 Relationship between Soil Resistivity and soil corrosivity. (from Waters, [97])

\begin{tabular}{cc}
\hline Soil Resistivity, ohm-cm & $\begin{array}{c}\text { Classification of } \\
\text { Soil Corrosiveness }\end{array}$ \\
\hline 0 to 900 & Very severe corrosion \\
900 to 2300 & Severely corrosive \\
2300 to 5000 & Moderately corrosive \\
5000 to 10000 & Mildly corrosive \\
10000 to $>10000$ & Very mildly corrosive \\
\hline
\end{tabular}


Table 45 Characteristics of Soil Resistivity. (From Tomashov, [36])

\begin{tabular}{|c|c|c|}
\hline \multicolumn{2}{|c|}{$\begin{array}{c}\text { Soil resistivity } \\
(\mathrm{ohm}-\mathrm{cm})\end{array}$} & $\begin{array}{c}\text { Evaluation of soil } \\
\text { aggressiveness }\end{array}$ \\
\hline & 500 & very high \\
\hline 500 & -1000 & high \\
\hline 1000 & -2000 & not so high \\
\hline 2000 & -10000 & medium \\
\hline & $>10000$ & low \\
\hline
\end{tabular}


Table 46 Steel Pipe corrosion Classification. (from Palmer, [98])

$\begin{aligned} 0 \text { to } 1000 & \text { ohm-cm very severely corrosive } \\ 1001 \text { to } 2000 & \text { ohm-cm severely corrosive } \\ 2001 \text { to } 5000 & \text { ohm-cm moderately corrosive } \\ 5001 \text { to } 10000 & \begin{array}{l}\text { ohm-cm mildly corrosive } \\ \text { ohm-cm very mildly corrosive }\end{array} \\ >10001 & \end{aligned}$


Table 47 Soil Corrosivity versus Resistivity. (from Reabody, [99])

\begin{tabular}{lr}
\multicolumn{1}{c}{ Soil Corrosivity } & Soil Resistivity, $\Omega \mathrm{cm}$ \\
\hline Very corrosive & 0 to 2000 \\
Corrosive & 2000 to 5000 \\
Moderately corrosive & 5000 to 10000 \\
Mildly corrosive & 10000 to 25000 \\
Relatively less corrosive & 25000 to 50000 \\
Progressively noncorrosive & 50000 to 100000 \\
\hline
\end{tabular}


Table 48 Soil-Test Evaluation AWWA Rating. (from Palmer, [38])

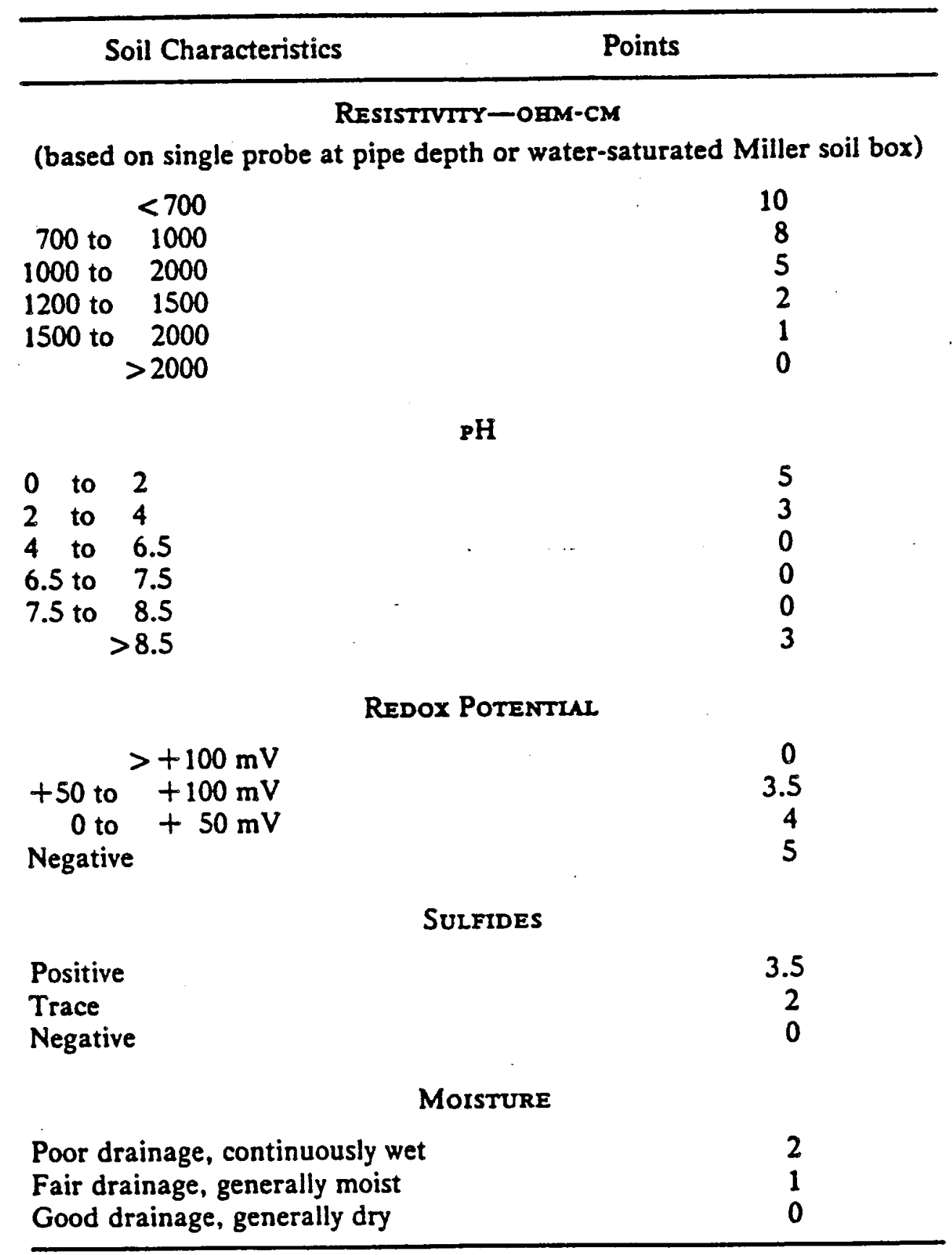


determining potentially corrosive soils. Based on his study, a soil having a saturated resistivity less than 1500 ohm-cm is corrosive. In the National Physical Laboratory criteria (as cited in Jablonski and Aliff, [73]), it is suggested that an aggressive site may be characterized by soil materials possessing a resistivity less than 2000 ohm-cm. In summary, the threshold values of soil resistivity to classify soil corrosivity is between 500 2000 ohm-cm.

Recently, a number of combinations of electrochemical characteristics were used to assess soil corrosiveness. California Department of Transportation (CATRANS) prepared a soil corrosive description [100] for reinforcing elements, as shown in Table 49. If soil minimum resistivity, soluble chloride, and soluble sulfate, are less than $1000 \mathrm{ohm}-\mathrm{cm}$, more than 500 ppm and 2000 ppm; respectively, the soil is said to be "very corrosive". The Reinforced Earth company (REC), in its design manual [101], suggested that a soil is acceptable for reinforcing strip backfills, if its minimum resistivity, $\mathrm{pH}$, soluble $\mathrm{Cl}^{-}$, and soluble $\mathrm{SO}_{4}^{2-}$, are greater than $1000 \mathrm{ohm}-\mathrm{cm}$, in a range of 5 - 10, less than $200 \mathrm{ppm}$, and less than $1000 \mathrm{ppm}$, respectively.

In 1981, the REC used coal ash for backfills in the Labadie coal Blending Project [102]. The acceptable criteria were a minimum resistivity of $3000 \mathrm{ohm}-\mathrm{cm}$, a $\mathrm{pH}$ of 
Table 49 Soil Corrosive Description. $\because$ (from [100])

Soil characteristics

$$
\begin{aligned}
& \rho^{\mathrm{a}}>1000 \text { and } \mathrm{pH}>7 \\
& \rho>1000 \text { and } \mathrm{pH}<7 \\
& \rho<1000 \\
& \rho<1000, \mathrm{Cl}^{-\mathrm{b}}>500 \\
& \quad \text { and } \mathrm{SO}_{4}^{2-\mathrm{b}}>2000
\end{aligned}
$$

Neutral and alkline

Acidic

Corrosive

Very corrosive

a in units of ohm-cm.

b in units of ppm. 
4.5 - 9.5, a maximum soluble $\mathrm{Cl}^{-}$of $100 \mathrm{ppm}$, and a maximum soluble $\mathrm{SO}_{4}^{2-}$ of $500 \mathrm{ppm}$. In 1987, the REC provided a similar set of criteria in the Technical specifications for Reinforced Earth Walls [96]. The criteria specify an acceptable backfill to have a minimum resistivity of 3000 ohm-cm, a pH of 5 - 10, a maximum soluble $\mathrm{cl}^{-}$of $200 \mathrm{ppm}$, and a maximum soluble $\mathrm{SO}_{4}^{2-}$ of $1000 \mathrm{ppm}$.

Jablonski and Aliff [73] used two methods to assess ash corrosiveness, i.e., the oil company policy for underground gas storage tanks and the Consulting Engineering company criteria for buried metallic structures. The oil company Policy is based on resistivity and $\mathrm{pH}$ as shown in Figure 39, where a soil with a maximum resistivity of $900 \mathrm{ohm}-\mathrm{cm}$ and a $\mathrm{pH}$ less than 5 is classified as "highly corrosive". The Consulting Engineering Policy, as shown in Figure 40, is similar to the oil Company Policy in that it is based on the same parameters. Figure 40 shows that a soil with either a resistivity less than $900 \mathrm{ohm}-\mathrm{cm}$ or a pH less than 5 is highly corrosive.

The Highway Design Manual Chapter 850 [103] provides a chart, as shown in Figure 41 , to select a minimum thickness of metal pipe for 50-year maintenance free service life, based on soil resistivity and $\mathrm{pH}$. This figure indicates that a protective coating is required for a metal pipe buried in a soil with either a resistivity less than 1500 


\begin{tabular}{|c|c|c|c|c|c|c|c|c|c|c|c|c|c|c|c|c|}
\hline \multirow{5}{*}{ 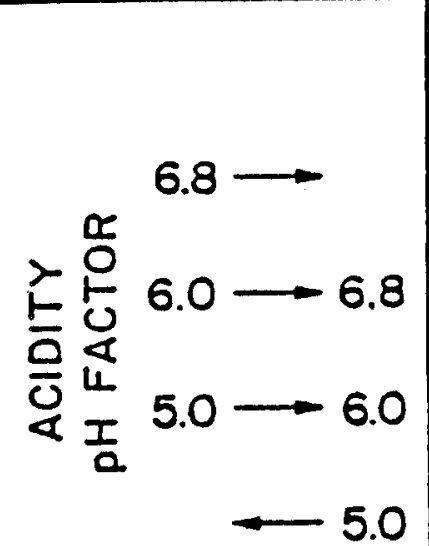 } & \multicolumn{4}{|c|}{$3000 \longrightarrow$} & \multicolumn{4}{|c|}{$1500-3000$} & \multicolumn{4}{|c|}{$900 \longrightarrow 1500$} & \multicolumn{4}{|c|}{-900} \\
\hline & 4 & 4 & 4 & 4 & 3 & 3 & 3 & 3 & 2 & 2 & 2 & 2 & 1 & 1 & 1 & 1 \\
\hline & 3 & 3 & 3 & 3 & 3 & 3 & 3 & 3 & 2 & 2 & 2 & 2 & 1 & 1 & 1 & 1 \\
\hline & 2 & 2 & 2 & 2 & 2 & 2 & 2 & 2 & 2 & 2 & 2 & 2 & 1 & 1 & 1 & 1 \\
\hline & 1 & 1 & 1 & 1 & 1 & 1 & 1 & 1 & 1 & 1 & 1 & 1 & 1 & 1 & 1 & 1 \\
\hline
\end{tabular}

\section{$1=$ HIGHLY CORROSIVE}

2 = MODERATELY CORROSIVE

3 = SLIGHTLY CORROSIVE

$4=$ NONCORROSIVE 


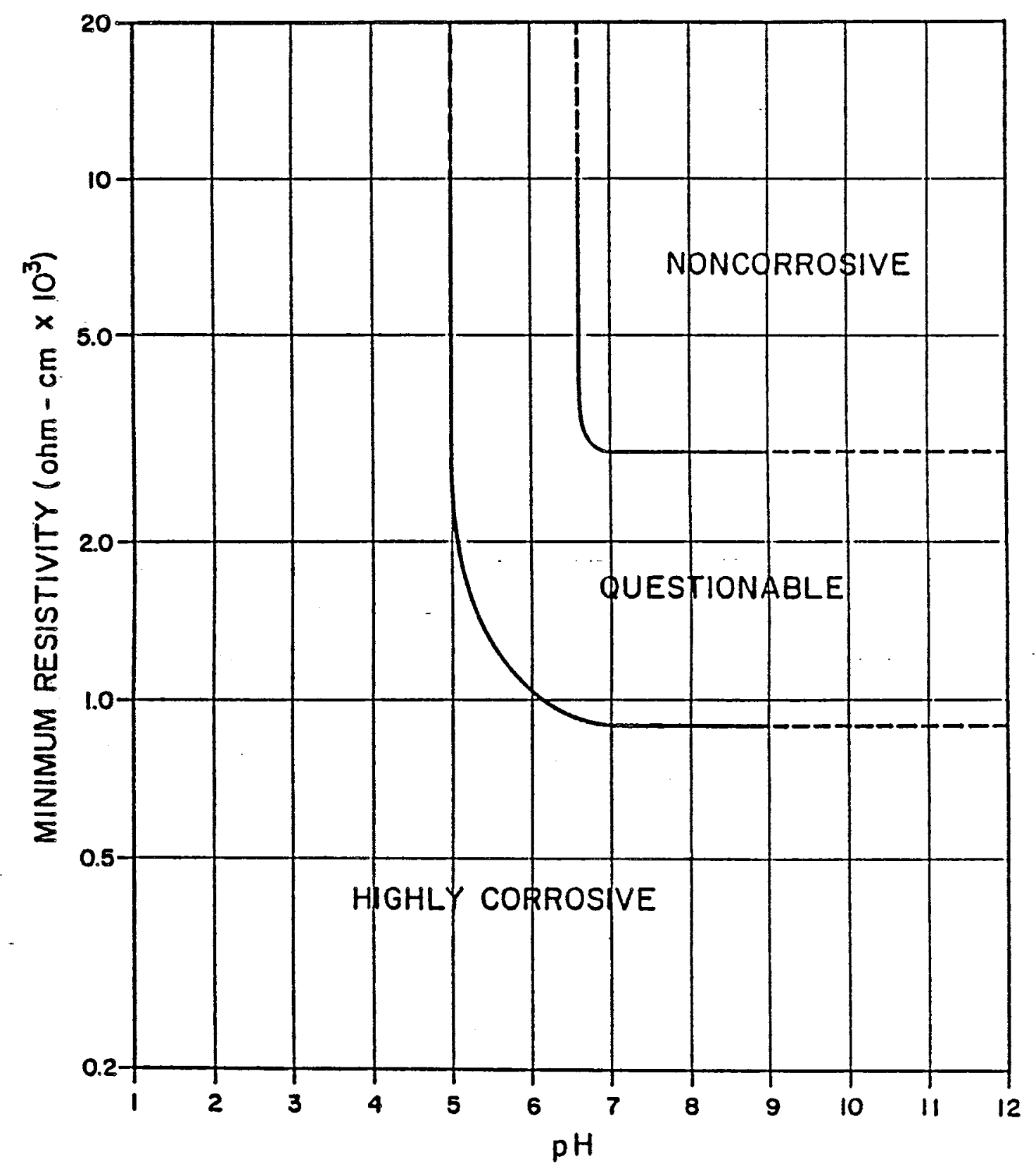

Figure 40

Consulting Engineering Company Criteria for Buried Metallic structures. (from Jablonski and Aliff, [73]) 


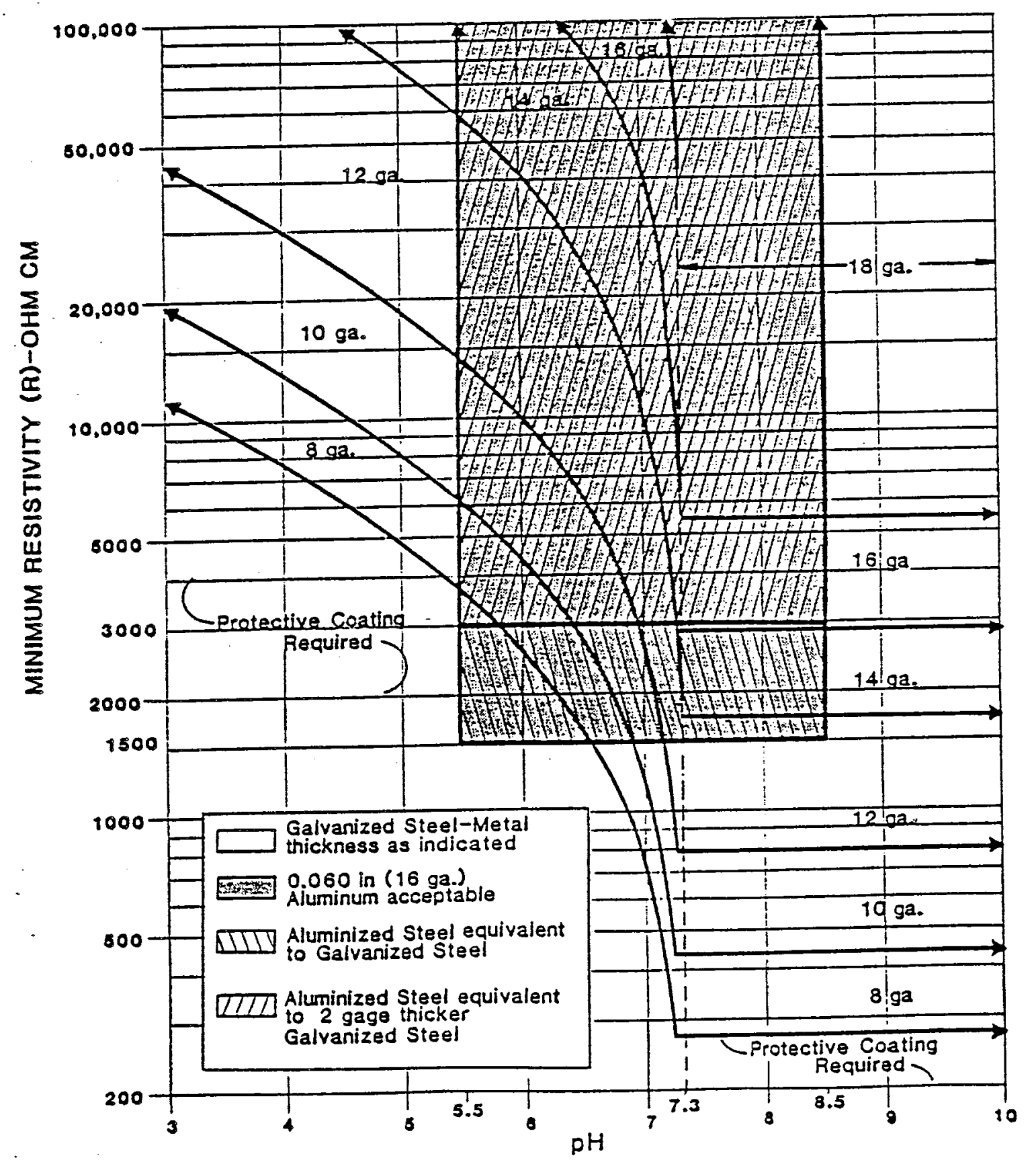

Figure 41 Minimum Thickness of Metal Pipe for 50-year Maintenance Free Service Life. (from [103]) 
ohm-cm or a pH less than 5.5. Most of the above specifications describe determinations of the four electrochemical characteristics that are conducted in accordance with California Test 643, 422, and 417 .

By carefully compiling the above-mentioned specifications, the evaluation criteria for ash corrosiveness to steel-type structures are shown in Table 50. The minimum limit of resistivity, i.e. $1500 \mathrm{ohm}-\mathrm{cm}$, is a more or less conservative threshold value. A pH of 5.5 is selected, based on the worse case. The maximum allowable values of soluble salts, i.e., $200 \mathrm{ppm}$ for $\mathrm{Cl}^{-}$and $1000 \mathrm{ppm}$ for $\mathrm{SO}_{4}^{2-}$, reflect the average limits. California Test 532 [80] provides corrosion criteria for reinforced concrete substructures. The acceptable levels, listed in Table 50, are a minimum resistivity of $1000 \mathrm{ohm}-\mathrm{cm}$, a minimum pH of 5.5, a maximum soluble $\mathrm{Cl}^{-}$of $500 \mathrm{ppm}$, and a maximum soluble $\mathrm{SO}_{4}^{2-}$ of $2000 \mathrm{ppm}$. For reinforced concrete, reinforcing bars are protected by a layer of concrete, and they will not corrode until the covering concrete layer cracks and the aggressive medium comes in contact with the bars. Accordingly, the corrosion criteria for reinforced concretes buried in bottom ash are less rigorous than that for steel structures (see Table 50). If bottom ash is used for concrete aggregate, it is recommended that the corrosion criteria for steel structures be used, from a conservative standpoint (because the extent to which Portland cement 
- Table 50 Evaluation Criteria on Ash Corrosivity

\begin{tabular}{lcccc}
$\begin{array}{l}\text { Buried } \\
\text { structure }\end{array}$ & $\begin{array}{c}\text { Minimum } \\
\text { resistivity } \\
\text { (ohm-cm) }\end{array}$ & $\mathrm{pH}^{\mathrm{b}}$ & $\begin{array}{c}\mathrm{Soluble}^{\mathrm{c}} \\
\mathrm{Cl}^{-}(\mathrm{ppm})\end{array}$ & $\begin{array}{c}\text { Soluble } \\
\mathrm{SO}_{4}^{2-}(\mathrm{ppm})\end{array}$ \\
\hline $\begin{array}{l}\text { Steel } \\
\text { structures }\end{array}$ & $>1500$ & $>5.5$ & $\begin{array}{c}<200 \\
(<0.02 \%)^{\mathrm{d}}\end{array}$ & $\begin{array}{c}<1000 \\
(<0.1 \%)^{\mathrm{d}}\end{array}$ \\
$\begin{array}{l}\text { Reinforced } \\
\text { Concretes }\end{array}$ & $>1000$ & $>5.5$ & $\begin{array}{c}<500 \\
(<0.05 \%)^{\mathrm{d}}\end{array}$ & $\begin{array}{c}<2000 \\
(<0.2 \%)\end{array}$ \\
\hline
\end{tabular}

a performed on crushed samples finer than the No.8 sieve following California Test 532 [80] or 643 [81].

b following California Test 422 [77].

c following California Test 417 [79].

d expressed as \% (by weight). 
alkalinizes bottom ash is not known).

$\ddot{*}$

Table 50 serves as the evaluation criteria, based on which a bottom ash can be classified as "corrosive" or "noncorrosive". Unlike other classification systems, these criteria have the following shortcomings as far as corrosion is concerned:

1) they do not give any quantitative information, e.g., corrosion rate and service life of a burial structure;

2) they may not be appropriate for metals other than steel;

3) they do not provide information about pitting potential (regional corrosion damage);

4) they do not give a proper estimation for metals having protective layers and large thickness;

5) they predict the initial or critical corrosivity of bottom ash alone but not the long-term case (Note: four electrochemical characteristics are time-dependent as well as corrosivity); and

6) they do not include site specific effects. However, if it is assumed that site factors, metal structural factors, and pitting potential are fixed, these criteria can serve as a convenient guide for selecting a noncorrosive bottom ash or in characterizing the severity of corrosiveness among a number of bottom ashes available for use. 
Service Life Equivalent to the Criteria

Darbin et al. [42], in their comprehensive review of the NBS data, selected burial site data more or less consistent with the normal range of environments for buried reinforcing strips and extended these data in accordance with Romanoff's proposal [39], i.e., a power-law equation of corrosion loss. Figure 42 shows the corrosion curves versus time for plain steel structures buried in 22 soils and two for sheetpiles in marine environments. The circled number designates the soil environment.

A zinc coating on galvanized steels forms a sacrificial anode which corrodes while protecting the base metal. Figure 43 plots the same-elements for galvanized steel with an assumed zinc coating of $80 \mu \mathrm{m}$ per side. The sacrificial benefit of zinc coating is revealed by zero steel loss for the first 10 years or longer. The most aggressive soil environment among the 22 soils has a resistivity of 1300 ohm-cm and a pH of 4.7. These approximately satisfy the above-established evaluation criteria for corrosivity, without considering the soluble salts.

Based on Figures 42 and 43 , and a failure criteria, it is possible to obtain the minimum service life of steel structures buried in a bottom ash which meets the above corrosion criteria. Darbin et al. [42] used reinforced steel strips as examples. They indicated that in Reinforced 


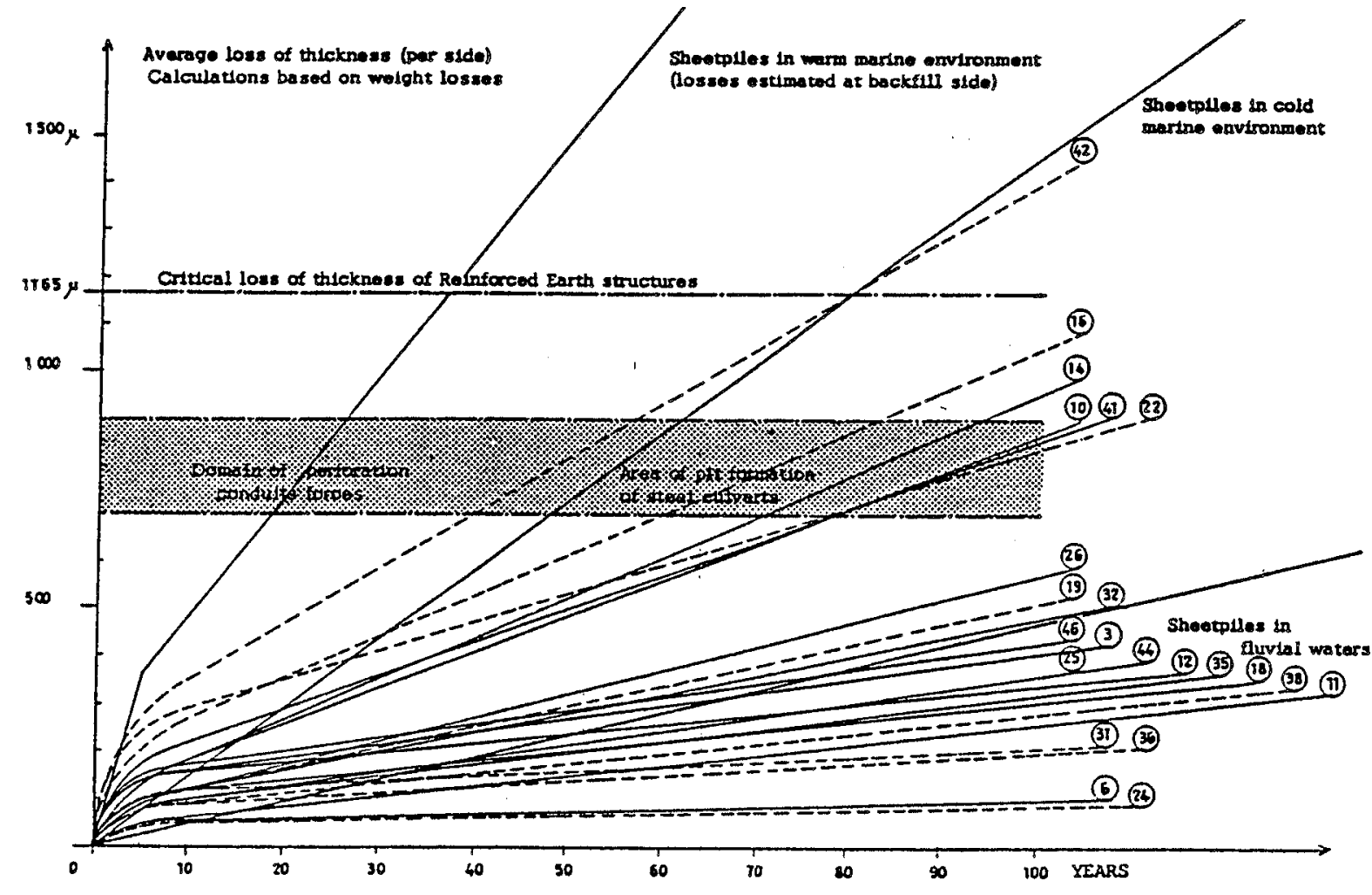

Figure 42 Extrapolated Corrosion Curves for Plain Steels. (from Darbin et al., [42]) 


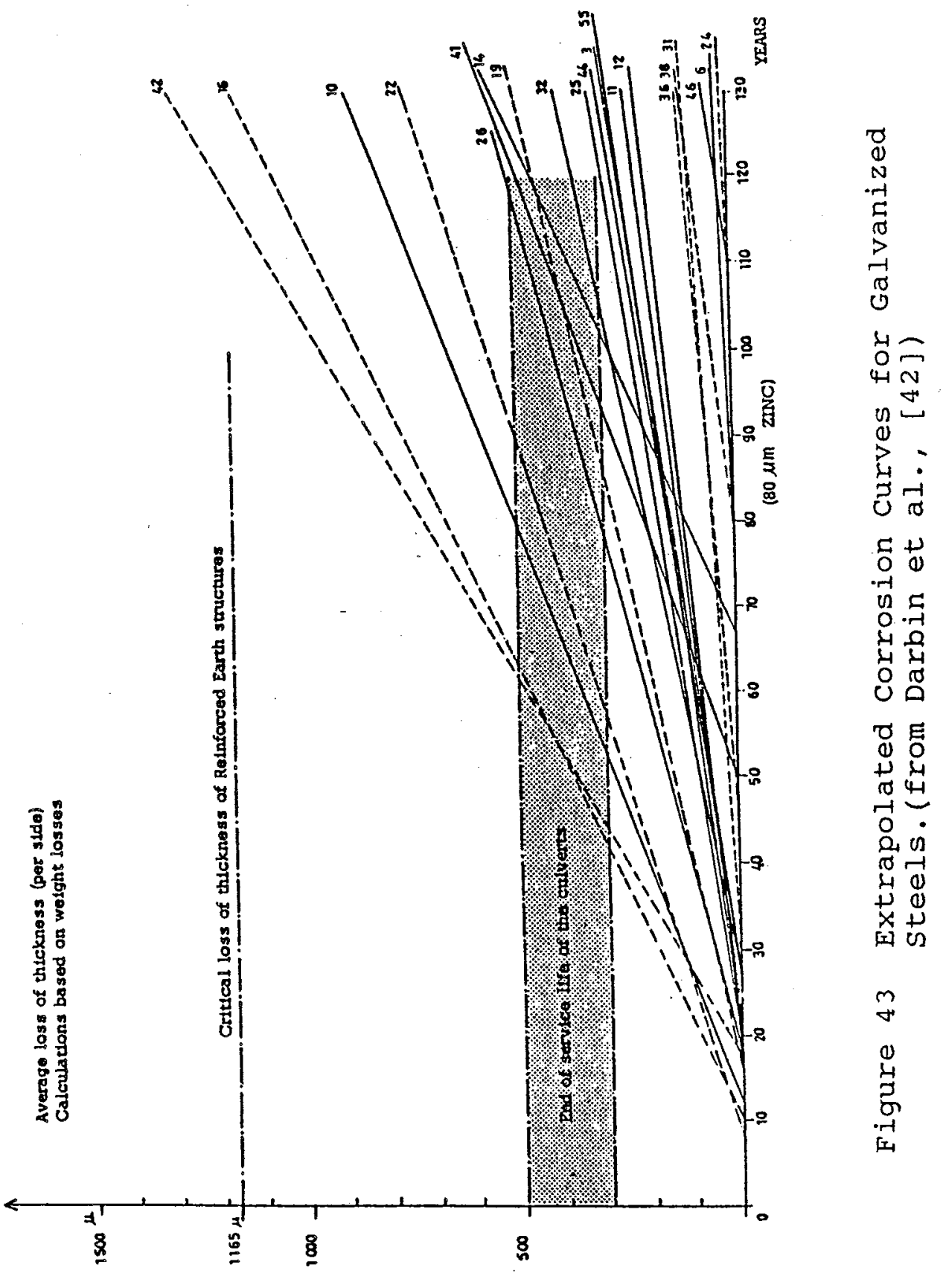


Earth structures, a reinforcing strip, with a nominal thickness "e" (in mm), is calculated for an effective thickness of $(e-1) \mathrm{mm}$; the additional millimeter being regarded as further safety factor against corrosion. If the yield stress of the strip is $24 \mathrm{~kg} / \mathrm{cm}^{2}$, the working stress is taken as $16 \mathrm{~kg} / \mathrm{cm}^{2}$, i.e., $2 / 3$ of the yield stress. The allowable loss in thickness is denoted $e_{1}$. Then the required equation is:

$$
\begin{aligned}
& (e-1) \times 16=\left(5-e_{1}\right) \times 24 \\
& \Rightarrow e_{1}=\frac{e+2}{3}(\text { in } \mathrm{mm})
\end{aligned}
$$

and the critical loss of thickness per side is $e_{1} / 2$. Mckittrick [104] reported that reinforcing strips are typically thin, varying in thickness from 3 to $9 \mathrm{~mm}$, and Reinforced Earth structures are normally designed for a service life of 75 to 100 years.

Darbin et al. [42] plotted the critical loss of thickness of $1.165 \mathrm{~mm}$ (for a strip with a nominal thickness of $5 \mathrm{~mm}$ ) in Figures 42 and 43. Accordingly, such a galvanized steel strip buried in a medium (meeting the above criteria) has a service life of 120 years. Using the same method, the service lives of steel strips with a thickness varying from 3 to $9 \mathrm{~mm}$ are calculated in Table 51. consequently, it is predicted that the above evaluation criteria guarantee a service life of 50-140 years for plain 
Table 51 Service Lives of Typical Reinforcing Strips. (after Darbin et al. [42])

\begin{tabular}{|c|c|c|c|c|}
\hline \multirow[b]{2}{*}{$e^{b}$} & \multirow[b]{2}{*}{$e_{1}^{c}$} & \multirow[b]{2}{*}{$\frac{1}{2} e_{1}^{d}$} & \multicolumn{2}{|c|}{$\begin{array}{l}\text { Service life of } \\
\text { reinforcing strips (yrs) }\end{array}$} \\
\hline & & & plain steel & galvanized steel $^{f}$ \\
\hline 3 & 1.667 & 0.833 & 50 & 90 \\
\hline 4 & 2.000 & 1.000 & 65 & 105 \\
\hline 5 & 2.333 & 1.166 & 80 & 120 \\
\hline 6 & 2.667 & 1.333 & 95 & 135 \\
\hline 7 & 3.000 & 1.500 & 110 & 150 \\
\hline 8 & 3.333 & 1.667 & 125 & 165 \\
\hline 9 & 3.667 & 1.833 & 140 & 180 \\
\hline
\end{tabular}

a buried in a medium meeting the criteria in Table 50 .

b nominal thickness of strip (in $\mathrm{mm}$ ).

c allowable loss (in mm), $=\frac{e+2}{3}$.

d critical loss of thickness per side (in $\mathrm{mm}$ ).

e obtained by comparing $\frac{1}{2} e_{1}$ with Figures 42 or 43 .

$f$ with a zinc coating of $80 \mu \mathrm{m}$. 
steel strips and that of 90-180 years for galvanized steel strips. For other types of steel structures, if failure criteria are given, the service life equivalent to the above corrosion criteria can be obtained by calculating the critical loss and comparing it with Figures 42 or 43 . Darbin et al. [42] also plotted the critical losses of thickness for culverts with thicknesses varying from 1.5 to $2.5 \mathrm{~mm}$ in Figures 42 and 43 , based on a failure criterion of $20 \%$ thickness loss per side. In this condition, the service life of culvert ranges from 40 to 60 years. It should be noted that the assumption of uniform corrosion is made, so that the time to pitting damage can not be predicted based on Figures 42 or 43 .

\section{Service Life Equivalent to Determined Parameters}

McMulien [35], in his study of the Des Moines Water Works soils, presented a multivariate regression model for predicting pipeline life. Using several distributions of the data, he found that the most accurate prediction was the linear model. The results of this analysis are listed below:

\section{Pipe Break Age}

$$
\begin{aligned}
(\text { in yrs })= & 65.78+0.028 \mathrm{SR} \\
& -6.338 \mathrm{pH}-0.049 \text { Redox }
\end{aligned}
$$

Coefficient of Correlation $(r)=0.61214$ 
Coefficient of Determination $\left(r^{2}\right)=0.37471$

$\because$ where $\mathrm{SR}$ is the saturated resistivity (in ohm-cm); and Redox is reduction-oxidation potential (in $\mathrm{mV}$ ).

The $r^{2}$ for this regression equation is not strong and the regression coefficients for $\mathrm{pH}$ and Redox are the opposite of normal expectations. The equation does not take into account pipe thickness and pitting damage.

Edgar [49], based on his study of twelve 35 to 40-year-old culvert pipes, suggested a relationship between weight loss and field resistivity as follows:

$$
W L=880(F R)^{-0.565}
$$

Coefficient of correlation $(r)=-0.831$

where WL is the weight loss (in $\mathrm{gm} / \mathrm{dm}^{2}$ ) after about 38 years and $F R$ is the field resistivity (in ohm-cm).

Dividing WL by 38 (yrs), the average rate of weight loss (WL') (in $\left.\mathrm{gm} / \mathrm{dm}^{2} / \mathrm{Yr}\right)$ is obtained,

$$
W L^{\prime}=23(F R)^{-0.565}
$$

If pipe thickness and acceptable loss are given and it is assumed that uniform corrosion (no pitting) exists, the service life of a culvert pipe can be then calculated, i.e., acceptable loss divided by W'

California Test 643 [81] provides a method for 
estimating the service life of steel culverts, based on resistivity and $\mathrm{pH}$. The estimation chart is shown in Figure 44. The value on the $y$ axis is the estimated years to perforation for an 18 gage steel culvert. A scale factor for each steel thickness is listed in the small table in Figure 44. The years to perforation for a greater steel thickness can be determined by multiplying the factor for that gage by the years to perforation obtained for an 18 gage steel culvert.

Based on Figure 41, the Highway Design Manual [103] gives an alternative way to determine the minimum thickness (gage) of corrugated metal pipe for 50 years of maintenance-free service life, based on various levels of $\mathrm{pH}$ and resistivity.

As mentioned above, California Test 532 [80] provides the criteria for evaluating the corrosion potential for reinforced concrete. Consulting Table 50, if a bottom ash is classified as "corrosive" to reinforced concrete, its soluble $\mathrm{Cl}^{-}$is then used to estimate the time to corrosion (or the time to concrete cracking) by means of the nomograph in Figure 45. This nomograph was initially developed by Beaton and stratfull [105] in 1963.

In the Corrosion of Earth Retaining systems - Interim Design Criteria [100], an algorithm is presented for computing the cross-section area (\%) remaining on steel 


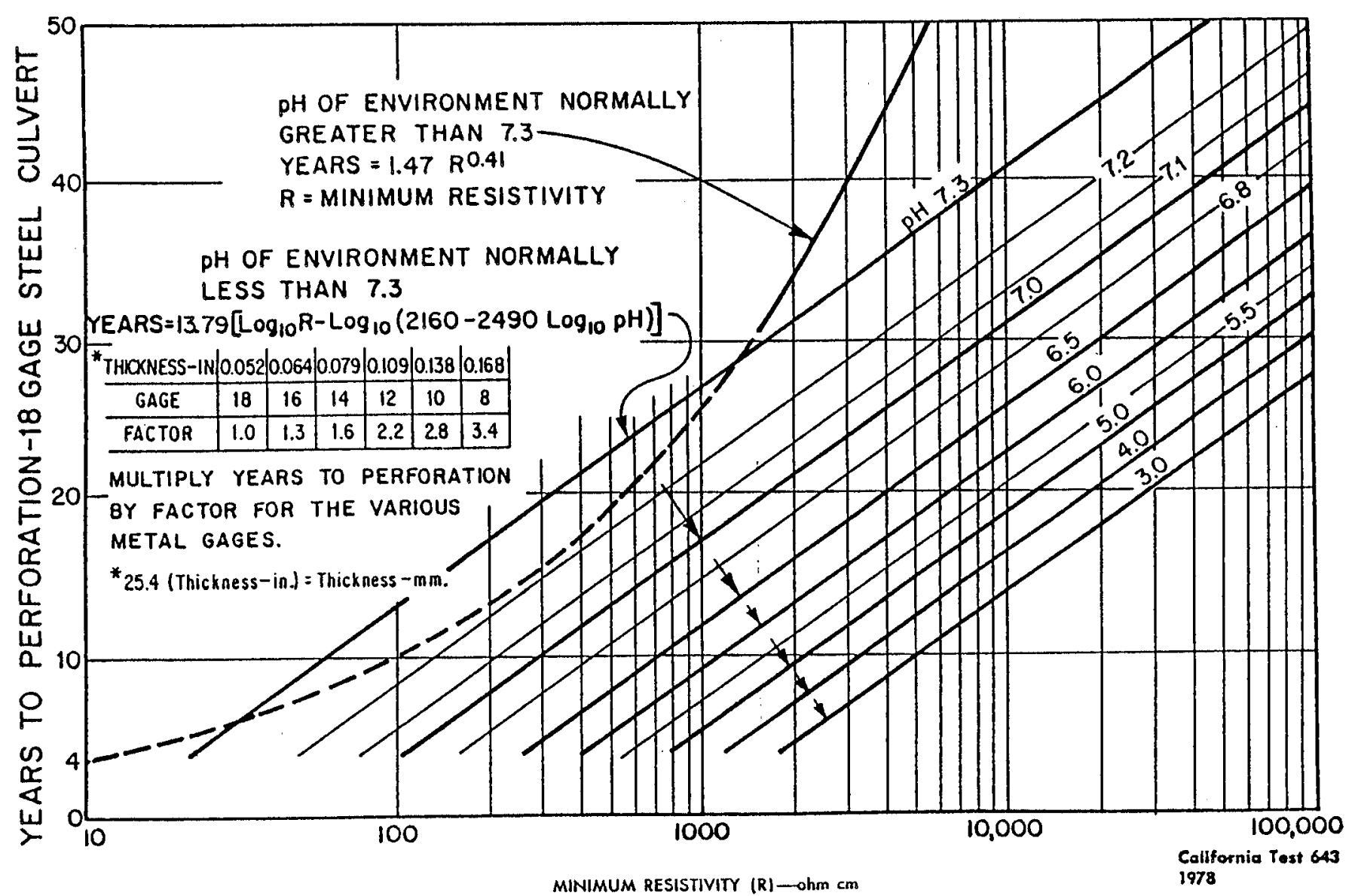

Figure 44 Chart for Estimating Years to Perforation of steel culverts. (from [81]) 


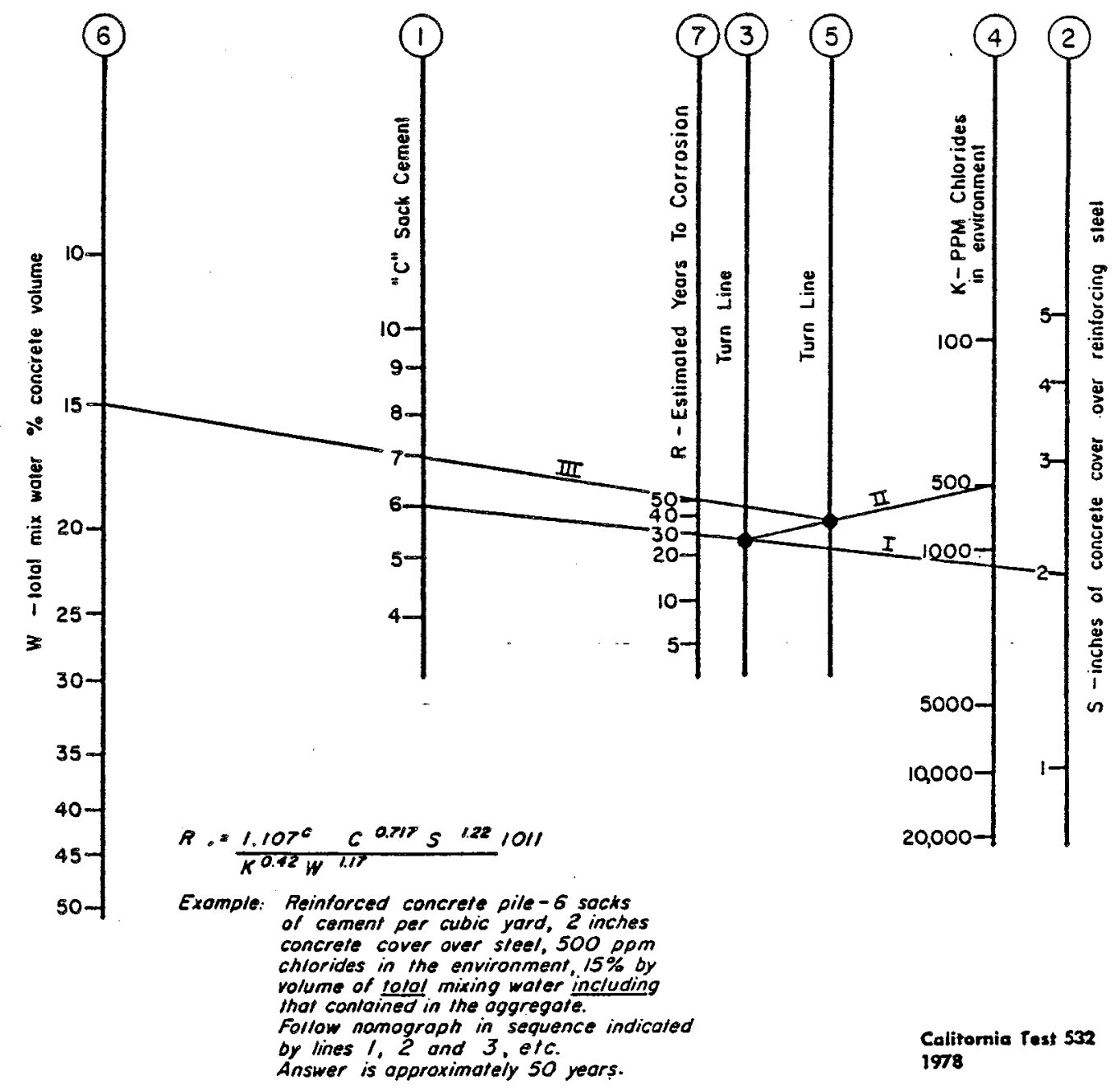

Figure 45 Chart for Estimating Time to Corrosion of Reinforced Substructures. (from [80]) 
reinforcing elements after corrosion loss, given soil type and years of service:

A) For round rod members

$$
A=\frac{[D-2 K(Y-C)]^{2}}{D^{2}} \times 100 \%
$$

B) For flat strap members

$$
A=\frac{[W-2 K(Y-C)][T-2 K(Y-C)]}{(W)(T)} \times 100 \% E Q
$$

where $\mathrm{A}=\%$ of original cross-sectional area remaining;

$$
\begin{aligned}
& D=\text { original diameter (in inches) } \\
& W=\text { original strap width (in inches); } \\
& T=\text { original strap thickness (in inches); } \\
& Y=\text { time of exposure in soils (in yrs); } \\
& K=\text { general corrosion rate factor; and } \\
& C=\text { useful life of coating (in yrs), (for bare steel, } \\
& \quad \text { C }=0 \text { ). }
\end{aligned}
$$

These two equations are relatively rational since soil corrosivity (K), geometry of a metal structure (D, W, T), and the protection condition (C) are all considered. The classification of soil type is illustrated in Table 49 . The values of $K$ and $C$ for different soil types and coatings are shown in Table 52. For normal soils, the values of cross-sectional area remaining $(\%)$, in a variety of conditions are shown in Table 53; and those for selected granular backfills are shown in Table 54. Comparing Table 
Table 52 Corrosion Factor (K) and Coating Life (C). (from [100])

\begin{tabular}{|l|c|c|c|c|}
\hline \multirow{2}{*}{ Soil Type } & \multirow{2}{*}{$k$} & \multicolumn{3}{|c|}{$c$} \\
\cline { 3 - 4 } & & Paint & $\begin{array}{c}\text { Galvanized } \\
2 \text { oz. }\end{array}$ & $\begin{array}{c}\text { Galvanized } \\
\text { oz. }\end{array}$ \\
\hline Normal & & & & \\
Neutral \& Alkaline & .0011 & 5 & 10 & 15 \\
Acidic & .0013 & 5 & 10 & 15 \\
Corrosive & .0028 & 5 & 6 & 9 \\
\hline Select Granular ** & & $;$ & & \\
Neutral \& Alkaline & .0005 & 5 & 20 & 30 \\
Acidic & .0005 & 5 & 20 & 30 \\
Corrosive & .0010 & 5 & 12 & 20 \\
\hline
\end{tabular}

**Specifically selected, well-draining backfill 
Table 53 Cross-sectional Area Remaining after 50 yrs for Normal Soils. (from [100])

\begin{tabular}{|c|c|c|c|c|c|c|c|}
\hline \multirow{3}{*}{ SOIL TYPE } & \multirow{3}{*}{ COATING } & \multicolumn{6}{|c|}{$\begin{array}{c}\text { CROSS-SECTIONAL AREA REMAINING, (PERCENT) } \\
\text { AFTER } 50 \text { YEARS }\end{array}$} \\
\hline & & \multicolumn{2}{|c|}{$\begin{array}{l}\text { HILFIKER } \\
\text { (WIRE MESH) }\end{array}$} & \multicolumn{3}{|c|}{$\begin{array}{l}\text { M.S.E. } \\
\text { (WELDED RODS) }\end{array}$} & \multirow{2}{*}{\begin{tabular}{|c}
$\begin{array}{c}\text { REINFORCED } \\
\text { EARTH } \\
\text { (STRAPS) }\end{array}$ \\
$60 \times 5 \mathrm{~mm}$ \\
$\left(2.362^{\circ} \times .197^{*}\right)$
\end{tabular}} \\
\hline & & $\left|\begin{array}{c}9 \text { go. } \\
\left(.148^{\circ} \phi\right)\end{array}\right|$ & $\left|\begin{array}{c}7 \text { ga. } \\
\left(.177^{\circ} \Phi\right)\end{array}\right|$ & $\begin{array}{c}165 \\
\left(.252^{\prime \prime} \phi\right)\end{array}$ & $\begin{array}{c}W 7 \\
\left(.299^{\circ} \emptyset\right)\end{array}$ & $\mid \begin{array}{c}W 11 \\
\left(.375^{\circ} \Phi\right)\end{array}$ & \\
\hline \multirow{4}{*}{$\begin{array}{l}\text { NEUTRAL \& } \\
\text { ALKALINE } \\
R \geq 1000 \\
P H \geq 7\end{array}$} & BARE & 5 & 15 & 30 & 40 & 50 & 40 \\
\hline & PAINT & 10 & 20 & 35 & 45 & 55 & 50 \\
\hline & $\begin{array}{l}\text { GALVANIZING } \\
\text { (20Z/FT²) }\end{array}$ & 15 & 25 & 40 & 50 & 60 & 55 \\
\hline & $\begin{array}{l}\text { GALVANIZING } \\
\left.\text { (30z/FT }{ }^{2}\right)\end{array}$ & 25 & 30 & 50 & 55 & 65 & 60 \\
\hline \multirow{4}{*}{$\begin{array}{c}\text { ACIDIC } \\
\mathrm{R} \geq 1000 \\
\mathrm{PH}<7\end{array}$} & BARE & 5 & 5 & 20 & 30 & 40 & 30 \\
\hline & PAINT & 5 & 10 & 30 & 40 & 50 & 40 \\
\hline & $\begin{array}{l}\text { GALVANIZING } \\
\text { (20Z/FT' } \\
\end{array}$ & 10 & 20 & 35 & 40 & 50 & 45 \\
\hline & $\begin{array}{l}\text { GALVANIZING } \\
\text { (3oz/FT' }\end{array}$ & 15 & 25 & 40 & 50 & 55 & 50 \\
\hline \multirow{4}{*}{$\begin{array}{c}\text { CORROSIVE } \\
R<1000\end{array}$} & BARE & 0 & 0 & 0 & 0 & 5 & 0 \\
\hline & PAINT & 0 & 0 & 0 & 0 & 10 & 0 \\
\hline & $\begin{array}{c}\text { GALVANIZING } \\
\left(20 z / F T^{2}\right)\end{array}$ & 0 & 0 & 0 & 5 & 10 & 0 \\
\hline & $\begin{array}{l}\text { GALVANIZING } \\
\text { (3oz }\left(F T^{2}\right)\end{array}$ & 0 & 0 & 0 & 5 & 15 & 0 \\
\hline $\begin{array}{c}\text { VERY } \\
\text { CORROSIVE } \\
R<1000 \\
\mathrm{Cl}^{-}>500 \\
\mathrm{SO}_{4}^{-}>2000\end{array}$ & \multicolumn{7}{|c|}{ NOT RECOMMENDED } \\
\hline
\end{tabular}


$\stackrel{\rightarrow}{\longrightarrow}$ Table 54 Cross-Sectional Area Remaining after 50 yrs for Selected Backfills. (from [100])

\begin{tabular}{|c|c|c|c|c|c|c|c|}
\hline \multirow{3}{*}{ SOIL TYPE } & \multirow{3}{*}{ COATING } & \multicolumn{6}{|c|}{$\begin{array}{c}\text { CROSS-SECTIONAL AREA REMAINING, (PERCENT) } \\
\text { AFTER } 50 \text { YEARS }\end{array}$} \\
\hline & & \multicolumn{2}{|c|}{$\begin{array}{l}\text { HILFIKER } \\
\text { (WIRE MESH) }\end{array}$} & \multicolumn{3}{|c|}{$\begin{array}{l}\text { M.S.E. } \\
\text { (WELDED RODS) }\end{array}$} & \multirow{2}{*}{$\begin{array}{c}\text { REINFORCED } \\
\text { EARTH } \\
\text { (STRAPS) } \\
\begin{array}{c}60 \times 5 \mathrm{~mm} \\
\left(2.362^{\circ} \times .197^{\circ}\right)\end{array}\end{array}$} \\
\hline & & $\begin{array}{c}990 . \\
1.148^{\circ}(1)\end{array}$ & $\begin{array}{c}7 \text { go. } \\
\left(.177^{\circ} \phi\right)\end{array}$ & $\begin{array}{c}W 5 \\
\left(.252^{*} \phi\right)\end{array}$ & $\left|\begin{array}{c}W 7 \\
\left(.299^{\circ} \phi\right)\end{array}\right|$ & $\begin{array}{l}W 11 \\
\left(.375^{\circ} \varnothing\right)\end{array}$ & \\
\hline \multirow{4}{*}{$\begin{array}{c}\text { NEUTRAL \& } \\
\text { ALKALINE } \\
R \geq 1000 \\
\text { PH } \geq 7\end{array}$} & BARE & 45 & 50 & 65 & 70 & 75 & 70 \\
\hline & PAINT & 50 & 55 & 65 & 70 & 75 & 75 \\
\hline & $\begin{array}{l}\text { GALVANIZING } \\
\left.\text { (20Z/FT }{ }^{2}\right)\end{array}$ & 65 & 70 & 80 & 80 & 85 & 85 \\
\hline & $\begin{array}{l}\text { GALVANIZING } \\
\left(30 z / F T^{2}\right)\end{array}$ & 75 & 80 & 85 & 90 & 90 & 90 \\
\hline \multirow{4}{*}{$\begin{array}{c}\triangle C I D I C \\
R \geq 1000 \\
p H<7\end{array}$} & BARE & 45 & 50. & 6.5 & 70 & 75 & 70 \\
\hline & PAINT & 50 & 55 & 65 & 70 & 75 & 75 \\
\hline & $\begin{array}{l}\text { GALVANIZING } \\
\left.\text { (20Z|FT }{ }^{2}\right)\end{array}$ & 65 & 70 & 80 & 80 & 85 & 85 \\
\hline & $\begin{array}{c}\text { GALVANIZING } \\
\left(302 / F T^{2}\right)\end{array}$ & 75 & 80 & 85 & 90 & 90 & 90 \\
\hline \multirow{4}{*}{$\begin{array}{l}\text { CORROSIVE } \\
-R<1000\end{array}$} & BARE & 10 & 20 & 35 & 45 & 55 & 45 \\
\hline & PAINT & 15 & 25 & 40 & 50 & 60 & 50 \\
\hline & $\begin{array}{l}\text { GALVANIZING } \\
\left(20 z / F T^{2}\right)\end{array}$ & 25 & 35 & 50 & 55 & 65 & 60 \\
\hline & $\begin{array}{l}\text { GALVANIZING } \\
\left(30 Z / F T^{2}\right)\end{array}$ & 35 & 45 & 60 & 65 & 70 & 70 \\
\hline $\begin{array}{c}\text { VERY } \\
\text { CORROSIVE } \\
\mathrm{R}<1000 \\
\mathrm{Cl}^{-}>500 \\
\mathrm{SO}_{4}^{-}>2000\end{array}$ & \multicolumn{7}{|c|}{ NOT RECOMMENDED } \\
\hline
\end{tabular}


53 with Table 54, under the same conditions (D, W, T, Y, K, and C) the cross-sectional area remaining (A) for selected backfills is higher than that of normal soils, indicating less corrosion potential of selected backfills. The criteria for a selected granular backfill are listed in Table 55. Consulting Table 21 and 22, most Indiana bottom ashes do not meet this requirement (Table 55), and thereby Table 53 is applicable to Indiana bottom ashes. On the other hand, given $A(\%)$ and a failure criteria, the service life (T) of a metal structure buried in a bottom ash can be calculated using the same equation. It should be noted that according to the linear relationship between $A$ and $K$, the equation also assumes the occurrence of uniform corrosion.

The above situations do not consider pitting damage and site conditions. Fisher and Bue [69] presented the average pitting rates for pipes in various sediment types as shown in Table 56. The pitting rate depends on soil resistivity, the pipe position relative to the groundwater table, and homogeneity of sediments. Given pipe thickness and failure criteria, the time to pipe damage by pitting can be calculated.

Thus far, this writer has presented all available criteria on soil corrosiveness and established criteria for bottom ashes. Only Table 50 will be used to assess the corrosivity of Indiana bottom ashes in the next chapter. 
Table 55 Criteria for selected Granular Backfills. (from [100])

$\begin{array}{lr}\text { Sieve Size } & \begin{array}{c}\text { Grading Limits, } \\ \text { Percent Passing }\end{array} \\ 6 \text { inches } & 100 \\ 3 \text { inches } & 100-75 \\ \text { No. } 4 & 25-0 \\ \text { No. } 200 & 5-0 \\ \text { Plasticity Index }<6 & \end{array}$


Table 56 Average Pitting Rates for Pipes in Various sediment Types. (from Fisher and Bue, [69])

\begin{tabular}{|c|c|c|c|c|}
\hline \multicolumn{5}{|c|}{ Homogeneous Sediments } \\
\hline $\begin{array}{c}\text { Soil } \\
\text { Resistivity }\end{array}$ & $\begin{array}{c}\text { Position of } \\
\text { Groundwater } \\
\text { Table }\end{array}$ & $\begin{array}{l}\text { Pipe Above } \\
\text { Groundwater } \\
\text { Table }\end{array}$ & $\begin{array}{l}\text { Pipe in } \\
\text { Groundwater } \\
\text { Table }\end{array}$ & $\begin{array}{l}\text { Pipe Below } \\
\text { Groundwater } \\
\text { Table }\end{array}$ \\
\hline \multirow{3}{*}{\multicolumn{2}{|c|}{$\begin{array}{cc}<30 & \Omega \mathrm{m} \\
30 \text { to } 40 & \Omega \mathrm{m} \\
>40 & \Omega \mathrm{m}\end{array}$}} & aggressive & very aggressive & aggressive \\
\hline & & nonaggressive & aggressive & slightly aggressive \\
\hline & & nonaggressive & slightly aggressive & nonaggressive \\
\hline \multicolumn{5}{|c|}{ Heterogeneous Sediments } \\
\hline \multicolumn{2}{|c|}{$\begin{array}{cc}\text { Soil } & \begin{array}{c}\text { Position of } \\
\text { Ground water } \\
\text { Table }\end{array}\end{array}$} & $\begin{array}{l}\text { Pipe Above } \\
\text { Groundwater } \\
\text { Table. }\end{array}$ & $\begin{array}{l}\text { Pipe in } \\
\text { Groundwater } \\
\text { Table }\end{array}$ & $\begin{array}{c}\text { Pipe Below } \\
\text { Groundwater } \\
\text { Table }\end{array}$ \\
\hline $\begin{array}{l}<30 \\
30 \text { to } 40 \\
>40\end{array}$ & $\begin{array}{l}\Omega \mathrm{m} \\
\Omega \mathrm{m} \\
\Omega \mathrm{m}\end{array}$ & $\begin{array}{l}\text { aggressive } \\
\text { aggressive } \\
\text { nonaggressive }\end{array}$ & $\begin{array}{l}\text { very aggressive } \\
\text { aggressive } \\
\text { slightly aggressive }\end{array}$ & $\begin{array}{l}\text { very aggressive } \\
\text { aggressive } \\
\text { slightly aggressive }\end{array}$ \\
\hline \multicolumn{3}{|c|}{ Environmental Conditions } & \multicolumn{2}{|c|}{ Average Pitting Rate, $\mu \mathrm{m} /$ year } \\
\hline \multicolumn{3}{|c|}{$\begin{array}{l}\text { Nonaggressive } \\
\text { Slightly aggressive } \\
\text { Aggressive } \\
\text { Very aggressive }\end{array}$} & \multicolumn{2}{|c|}{$\begin{array}{l}<100 \\
100 \text { to } 200 \\
200 \text { to } 500 \\
>500\end{array}$} \\
\hline
\end{tabular}


For the readers who would like to use the corrosion criteria in terms of service life, practical experience must be employed to evaluate these criteria. Additionally, for readers who are interested in ash corrosivity to metal(s) other than steel, it is suggested that the established criteria will be applicable if the service life or corrosion rate of the metal is modified by some factor (refer to Table 12), and judgment is employed. 


\section{CHAPTER VII EVALUATION RESULTS}

This chapter presents evaluation results of durability and corrosiveness of Indiana bottom ashes, based on the evaluation criteria established in the previous chapter. The results should provide a value guide for the utilization of bottom ash in the immediate future.

\section{Durability of Indiana Bottom Ashes}

Comparing Tables 24 and 25 with Table 43 , durability of Indiana bottom ashes was assessed. (Note: here, durability refers merely to the ability to resist frost action.) The evaluation results are summarized in Table 57. Since the WLs of the sampled Indiana ashes are all less than $10 \%$, they meet the most rigorous allowable WL, i.e., $10 \%$. Consequently, not only the four candidate bottom ashes but the other 7 Indiana ashes sampled by Huang [5] are quite acceptable and durable to freeze-thaw action. If these ashes also meet the requirements of gradation and strength for specific applications, they can be used extensively for a variety of constructions applications. Their minimum service lives can be approximated by Table 42 . 


\begin{tabular}{|c|c|c|c|c|}
\hline \multirow{2}{*}{ Ash source } & \multicolumn{4}{|c|}{ Acceptance } \\
\hline & Soundness & test $^{b}$ & Freeze-thaw & $\operatorname{test}^{c}$ \\
\hline Perry K & $A^{d}$ & & $\mathrm{~A}$ & \\
\hline Gibson & $\AA$ & & $A$ & \\
\hline Schahfer 14 & A & & $A$ & \\
\hline Schahfer 17 & A & & $\mathrm{A}$ & \\
\hline Gallegher & $A$ & & $-{ }^{e}$ & \\
\hline Mitchell & $A$ & & $-e^{e}$ & \\
\hline Wabash & $A$ & & $-e$ & \\
\hline Richmond & $A$ & & $-{ }^{e}$ & \\
\hline stout & $A$ & & $-{ }^{e}$ & \\
\hline Culley & $A$ & & $-{ }^{e}$ & \\
\hline Brown & A & & $-{ }^{e}$ & \\
\hline
\end{tabular}

a ability to resist freeze-thaw action only.

$b$ based on WL obtained in a 5-cycle sodium sulfate soundness test.

${ }^{c}$ based on WL obtained in a 50-cycle freeze-thaw test.

d denoted "acceptable", if the WL is less than the most rigorous allowable WL in Table 43 , i.e., 10\%.

e blank due to no test results. 


\section{Corrosiveness of Indiana Bottom Ashes}

Comparing Tables 36 and 37 with Table 50, corrosiveness of Indiana bottom ashes was assessed. Table 58 summarizes the evaluation results as far as steel structures are concerned. In Table 58, a bottom ash is classified to be corrosive to steel structures, if at least one of its electrochemical characteristics does not meet the criteria listed in Table 50; non-corrosive if all electrochemical characteristics meet the criteria. For the sample ashes studied by Huang [5], the evaluations were made based solely on $\mathrm{pH}$ and minimum resistivity. of 11 Indiana bottom ashes, 7 are classified as being corrosive to steel structures, about $63.6 \%$. Among the four candidate ashes, only two (Schahfer 14 ash and Schahfer 17 ash) are non-corrosive. Here, particular interest is focused on the Schahfer 14 ash, the only wet bottom ash in this study. Consulting Tables 36 and 50 again, Schahfer 14 ash has the largest minimum resistivity, a basic $\mathrm{pH}$, the lowest content of soluble chloride and soluble sulfate, and therefore it is the least corrosive of 11 ashes. It can be concluded that wet bottom ash is less corrosive, based on the one sample in this study. Gibson ash is classified to be corrosive due to its high content of soluble sulfate, even though the other three characteristics are acceptable.

Among the 7 corrosive ashes, Perry $K$ and Brown ashes 
$\because$ Table 58 Evaluation results of ash corrosiveness ${ }^{a}$

\begin{tabular}{|c|c|c|c|c|c|}
\hline \multirow[b]{2}{*}{ Ash source } & \multicolumn{4}{|c|}{ Acceptance } & \multirow[b]{2}{*}{$\begin{array}{l}\text { Overall } \\
\text { evaluat } \\
\text {-ion. }\end{array}$} \\
\hline & $\begin{array}{l}\text { Minimum } \\
\text { resistivity } \\
\text { (ohm-cm) }\end{array}$ & $\mathrm{pH}$ & $\begin{array}{l}\text { Soluble } \\
\mathrm{Cl}^{-} \text {(ppm) }\end{array}$ & $\mathrm{SO}_{4}^{\text {Soluble }} \underset{\text { (ppr) }}{\text { (ppra }}$ & \\
\hline Perry $\mathrm{K}$ & $N A^{b}$ & NA & $A^{c}$ & $\mathrm{~A}$ & $c^{d}$ \\
\hline Gibson & $A$ & $A$ & A & $\mathrm{NA}$ & C \\
\hline Schahfer 14 & $\mathrm{~A}$ & $A$ & A & A & $\mathrm{NC}^{\mathrm{e}}$ \\
\hline Schahfer 17 & A & $\dot{A}$ & $A$ & $\mathrm{~A}$ & $\mathrm{NC}$ \\
\hline Gallegher & NA & A & $-{ }^{f}$ & - & C \\
\hline Mitchell & A & $\AA$ & - & - & NC \\
\hline Wabash & $\mathrm{NA}$ & $A$ & - & - & $c$ \\
\hline Richmond & NA & $A$ & - & - & $\mathrm{C}$ \\
\hline stout & A & $\mathrm{A}$ & - & - & $\mathrm{NC}$ \\
\hline culley & NA & $\dot{A}$ & - & - & C \\
\hline Brown & $\mathrm{NA}$ & NA & - & - & $\mathrm{C}$ \\
\hline
\end{tabular}

a to steel structures.

b denotes "non-acceptable", if not meeting the threshold value in Table 50 (for steel structures).

c denotes "acceptable", if meeting the threshold value in Table 50 (for steel structures).

-d denotes "corrosive", if at least one characteristic

- doesn't meet the requirements of Table 50 (for steel structures).

e denotes "non-corrosive, if all characteristics meet the requirements of Table 50 (for steel structures).

${ }^{f}$ blank due to no test results. 
seems to be more corrosive, due to their unacceptable values of $\mathrm{pH}$ and minimum resistivity. However, if minimum resistivity is taken as the dominant estimator, then (referring to Table 37) four ashes having a minimum $\rho$ less than 500 ohm-cm (Gallegher, Richmond, Culley, and Brown ashes) will be designated as "more corrosive". Different criteria not only provide different evaluation results but also a different sequence of corrosivity among samples.

The application of the 7 corrosive bottom ashes should be restricted to construction where no steel structures are involved. In contrast, the 4 non-corrosive ashes may be used in construction where steel structures are nearby. If they are to be utilized as reinforced earth backfills, the minimum service lives of the reinforcing strip are approximated by Table 51. For other types of steel structures or to find the actual service life corresponding to the electrochemical characteristics, please refer to the last section of the previous chapter.

Table 59 shows the evaluation results of ash corrosivity to reinforced concrete structures. Of the Indiana bottom ashes tested, 54.5\% are corrosive. This value is lower than that for steel structures because the criteria for reinforced concrete is less rigorous than those for steel structures.

Since the criteria in Table 50 do not consider the site 
$\because \quad$ Table 59 Evaluation results of ash corrosiveness ${ }^{a}$

Acceptance

\begin{tabular}{|c|c|c|c|c|c|}
\hline Ash source & $\begin{array}{l}\text { Minimum } \\
\text { resistivity } \\
\text { (ohm-cm) }\end{array}$ & $\mathrm{pH}$ & $\begin{array}{l}\text { Soluble } \\
\mathrm{Cl}^{2} \text { (ppm) }\end{array}$ & $\begin{array}{c}\mathrm{Soluble}_{\mathrm{SO}_{4}^{2}}=(\mathrm{ppm}) \\
\text { (ppm }\end{array}$ & $\begin{array}{l}\text { Overali } \\
\text { evaluat } \\
\text {-ion }\end{array}$ \\
\hline Perry K & $\mathrm{NA}^{\mathrm{b}}$ & $\mathrm{NA}$ & $A^{c}$ & A & $\mathrm{C}^{d}$ \\
\hline Gibson & $\mathrm{A}$ & A & $A$ & A & $\mathrm{NC}$ \\
\hline Schahfer 14 & A & A & A & A & $\mathrm{NC}^{\mathrm{e}}$ \\
\hline Schahfer 17 & A & A & A & A & $\mathrm{NC}$ \\
\hline Gallegher & NA & A & $-{ }^{f}$ & - & $c$ \\
\hline Mitchell & A & A & - & - & NC \\
\hline Wabash & A & A & - & - & NC \\
\hline Richmond & NA & A & - & - & $c$ \\
\hline stout & A & A & - & - & $\mathrm{NC}$ \\
\hline Culley & NA & A & - & - & $c$ \\
\hline Brown & NA & $\mathrm{NA}$ & - & - & c \\
\hline
\end{tabular}

a to reinforced concrete structures.

b denotes "non-acceptable", if not meeting the threshold value in Table 50 (for reinforced concrete).

"denotes "acceptable", if meeting the threshold value in Table 50 (for reinforced concrete).

d denotes "corrosive", if at least one characteristic doesn't meet the requirements of Table 50' (for steel structures).

e denotes "non-corrosive, if all characteristics meet the requirements of Table 50 (for reinforced concrete).

$f$ blank due to no test results. 
factors, the currently-presented evaluation results may not reflect the future performance of ash-metal structures in situ. The field conditions, such as nonhomogeneity of ash mass and variation of water table, may more or less aggravate the corrosive tendency evaluated by laboratory test results, i.e., higher percentage of "being corrosive" in situ. Accordingly, this high percentage of corrosive bottom ashes (obtained in the laboratory study) sufficiently emphasizes the need for investigating the corrosiveness of bottom ash prior to mass utilization. 


\section{CHAPTER VIII SUMMARY AND CONCLUSIONS}

A decreasing supply of natural good-quality aggregates has increased interest in search for innovative materials. on the other hand, the huge production of industrial by-products has caused a serious disposal problem of waste materials. If utilization of these waste materials as a construction material becomes possible, it can solve the natural aggregates shortage at the same time.

One waste material of interest is bottom ash. However, prior to extensive utilization, chemical and physical properties and mechanical behavior of bottom ash should be investigated in order to determine that they can meet existing requirements for natural aggregates. In this study, durability and corrosiveness of bottom ash were of main concern.

Through literature review, the concepts of meaningful durability tests and underground corrosion were presented, and available durability tests and corrosion-related parameters were selected. All relevant parameters were determined in the laboratory, either in accordance with standard test methods or nonstandard methods. The sensitivity of nonstandard methods was examined and 
discussed.

$\because$

Based on past experiences with aggregates and soils, evaluation criteria of durability and corrosivenes of bottom ash were established, as shown in Tables 43 and 50 . The evaluation results were presented in Tables 57, 58, and 59 .

As a result of this study, three basic conclusions can be drawn:

\section{(1) Evaluation results}

a). All Indiana bottom ashes under investigation are durable. If they also meet the requirements of gradation and strength as .specified for different applications, they can considerably compensate for a reducing natural aggregate supply and can be utilized extensively in a variety of construction applications such as highway pavement, embankment or backfill, and concrete structure. Huang [5] concluded that sampled Indiana bottom ashes have comparable properties to those of natural granular soils, and their effects on the quality of ground water are minimal. If these combined conclusions hold true for other power plant ashes, it is predicted that utilization of such a mass-produced byproduct of the power industry will become more desirable in the future. The minimum service lives of Indiana bottom ash in aggregate 
applications are given in Table 42.

b). Disappointingly, bottom ash may be corrosive. About 64\% of Indiana bottom ashes are classified as being corrosive to steel structures and should be rejected as a backfill material for reinforced earth structures. This fact definitely prohibits extensive application of Indiana bottom ash to a site where steel structures are involved.In any instance dealing with metal inclusions, particular attention should be paid to investigation of the corrosiveness of the proposed bottom ash prior to use. Of 11 Indiana bottom ashes examined, only 4 are non-corrosive (see Table 58). These 4 ashes can be safely utilized in reinforced earth construction and will provide a minimum service life of the buried steel strips as shown in Table 51 .

(2) Testing results

a). Wet bottom ash produced in a cyclone furnace is more durable than dry bottom ash, which agrees with the work of seals et al. [6]. In contrast, dry bottom ash produced in a stoker furnace is less durable than that produced by other furnaces.

b). Wet bottom ash has the lowest content of soluble salts and the lowest dissolved percentage, due to its

$\therefore$. non-porous and glassy texture.

c). Among the 11 ashes studied, the only wet bottom ash, 
Schahfer 14, is found to be the most durable and the

$\because \quad$ least corrosive. Such a superiority of wet bottom ash projects a more popular utilization over dry bottom ash in the future, although the production of wet bottom ash in the United states is decreasing with time (Huang, [5]).

d). Ash minimum resistivity occurs when the specimen is totally saturated just as occurs with natural soils. Some Indiana bottom ashes react to $\mathrm{pH}$ and water content in the same manner as natural soils.

e). Generally, Indiana bottom ashes have a higher soluble sulfate content and a little lower soluble chloride content than natural soils:- When compared with the soils used by the Reinforced Earth Company, Indiana bottom ashes have a lower minimum resistivity and a higher soluble sulfate content, but a similar $\mathrm{pH}$ and soluble chloride content.

\section{(3) Testing methods}

a). The five-cycle sodium sulfate soundness test is more or less equivalent to the 50-cycle freeze-thaw test in a totally immersed condition, both yielding similar results. Based on equipment available and time restraints, one can choose either to examine the

- durability of a bottom ash of interest.

b). Basically, California Test methods can be used to 
determine the four electrochemical characteristics of a $\because$ bottom ash. The shaking procedure described in California Test 417 [80] or 422 [78] is preferred. The California Test method is better than the INDOT method for determining $\mathrm{pH}$, because of ease of performance. For bottom ash, a major test modification requires that determinations of resistivity and $\mathrm{pH}$ be performed on crushed particles of ash sample which pass the No.8 sieve; this takes into account the overall contribution of ash mass. The suggested crushing procedure for ash samples is described in Chapter IV.

Additional considerations are stated below:

(1) The evaluation criteria for durability and corrosiveness of bottom ash are still in the development stage. Before their successful application, field testing and observations should be employed to verify their appropriateness and modifications made to represent a more realistic state.

(2) The corrosiveness evaluation criteria established in this study did not consider the site factors. Therefore, in order to get a more reliable prediction of corrosion, site specific conditions should be taken into account.

(3) Some bottom ashes are not well graded. Therefore, in real applications, other materials may be added to improve their gradation. In this case, an additional 
durability test is required for the added material. A

$\because$ prediction of the durability can be achieved by a weighted average of the components. However, new corrosiveness testing must be performed on the ash-aggregate mix, since the complex chemical interaction between bottom ash and aggregate is difficult to predict.

(4) For use as a backfill for metal-reinforced earth, bottom ash should be well-mixed and uniformly compacted, reducing the level of nonhomogeneity of the ash mass. Recall that a nonhomogeneous medium causes the formation of more differential corrosion cells, which increases the pitting potential and corrosion rate.

(5) For the freeze-thaw test, it is suggested that the freezing rate or temperature gradient should be specified in the standard test method so that the results from different laboratories can be compared.

(6) The pH determination should be conducted immediately upon preparation of ash suspension and should be made by a glass $\mathrm{pH}$ electrode. 


\section{CHAPTER IX RECOMMENDATIONS FOR FURTHER RESEARCH}

Further research needs to be focused on the verification or modification of the evaluation criteria established in this study. The following recommendations are not only useful for bottom ashes but also for any other innovative material, as far as durability and corrosiveness are concerned.

\section{Meaningful Durability Tests}

As mentioned in Chapter II, durability is still not well understood. Recall, how the five elements of durability influence the performance and service life of a material; and how a material interacts with the surrounding environment. To date, few meaningful durability tests have been developed. The difficulty comes from selection of aging indicator(s), time required to perform long-term field tests, correlation between laboratory results and field results, and establishment of performance criteria. The freeze-thaw test used in this study is an example of this difficulty. The selected aging indicator, WL, is somewhat qualitatively related to the performance of a material, but not quantitatively related, as are strength and modulus, for 
example. Therefore, basing the evaluation criteria on the WL may not guarantee the required performance. Since there is no available correlation between this laboratory test and the field exposure condition, the service life (in situ) corresponding to the evaluation criteria can not be accurately predicted. The evaluation results of a material subjected to the freeze-thaw test may not be applicable to a site where an environmental agent other than freezing is prevalent. It is recommended that more meaningful durability tests be developed following the procedure suggested by ASTM E 632 (see Fig 7). Interpretation of existing test methods should also be improved. If a set of meaningful durability tests, each simulating a combined action of several real environmental agents, is implemented with a set of determined $\mathrm{F}_{\text {ac }} \mathrm{s}$ (acceleration factors), then the durability of any innovative material will be truly and meaningfully assessed in terms of service life.

\section{Application of Polarization Techniques}

In Chapter II, it is mentioned that polarization techniques may replace the lengthy burial tests because of their particular advantages. These advantages include: being less time-consuming, of comparable reliability, consideration of metal structural factors, and ease of performance in both the field and laboratory. Examples of the laboratory and field setups (Serra and Mannheimer, [68]) 
are shown in Figures 46 and 47 , respectively.

$\because$

For a saturated sample in the laboratory, the corrosion current measured by polarization techniques is equivalent to, and more reliable than, the evaluation result based on the four electrochemical characteristics. In addition, the time required to determine these four characteristics is much longer than that required for polarization techniques. Moreover, polarization techniques can measure the corrosion potential of a medium at different degrees of saturation. By placing any metal specimen of interest into the medium under study (see Figure 46), polarization techniques can provide a series of corrosion potentials of the medium to different metals. Furthermore, polarization techniques can give a long-term profile of corrosiveness of a medium to a metal, if determination of corrosion current is continuously performed. This can not be predicted by the evaluation result based on the four electrochemical characteristics, which merely gives the corrosiveness of a sample of the medium in an as-received state. If polarization techniques are applied in situ, the measured corrosion current covers the effects of all site variations, as do burial tests. Recently, the only shortcoming of these techniques, i.e. the ability to examine the pitting potential as in burial methods, has been overcome (Lau and Bernhardsson, [106]).

Because of the versatility of polarization techniques, 


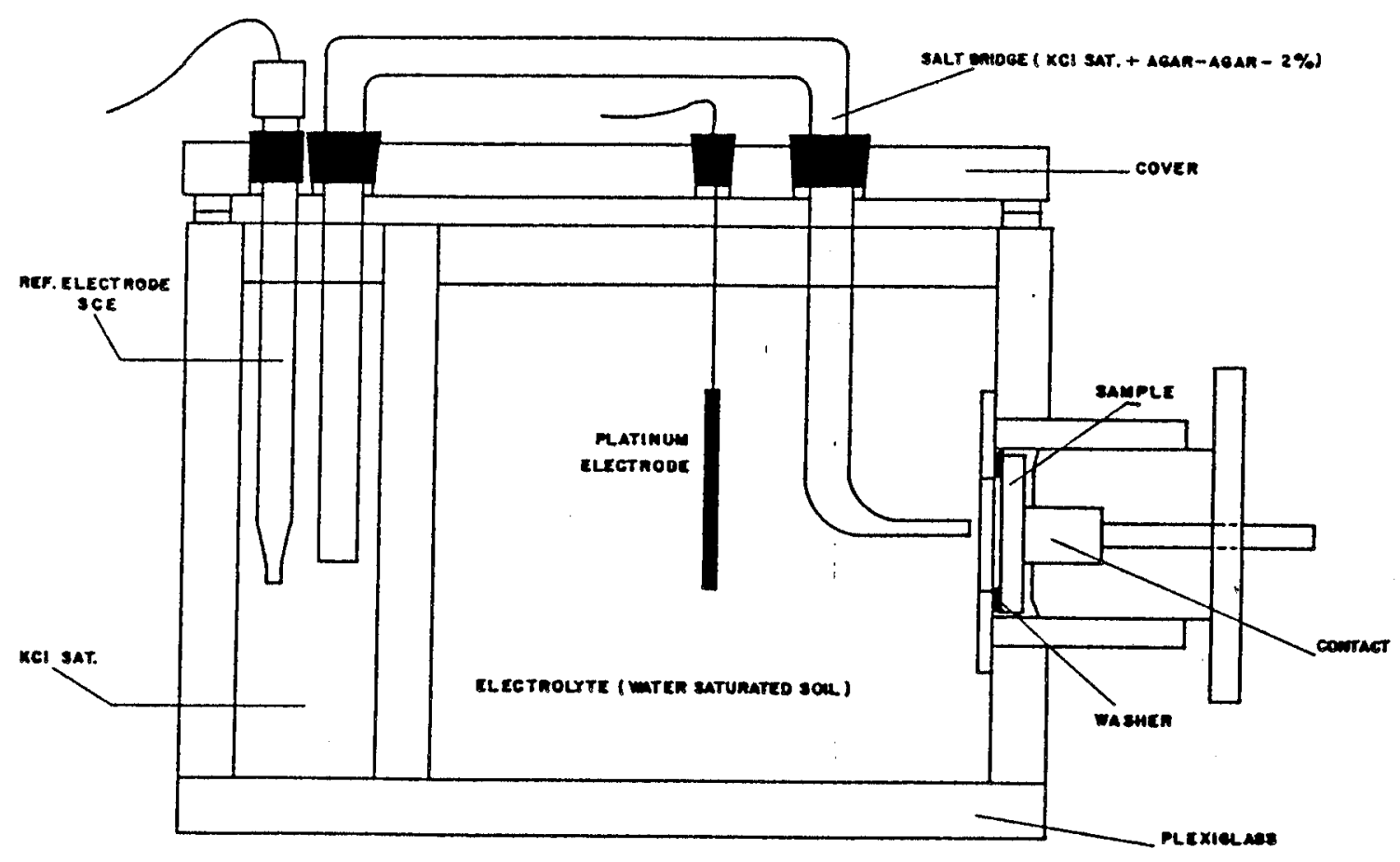

Figure 46 Laboratory Set-Up for Polarization Techniques. (from Serra and Mannheimer, [68]) 


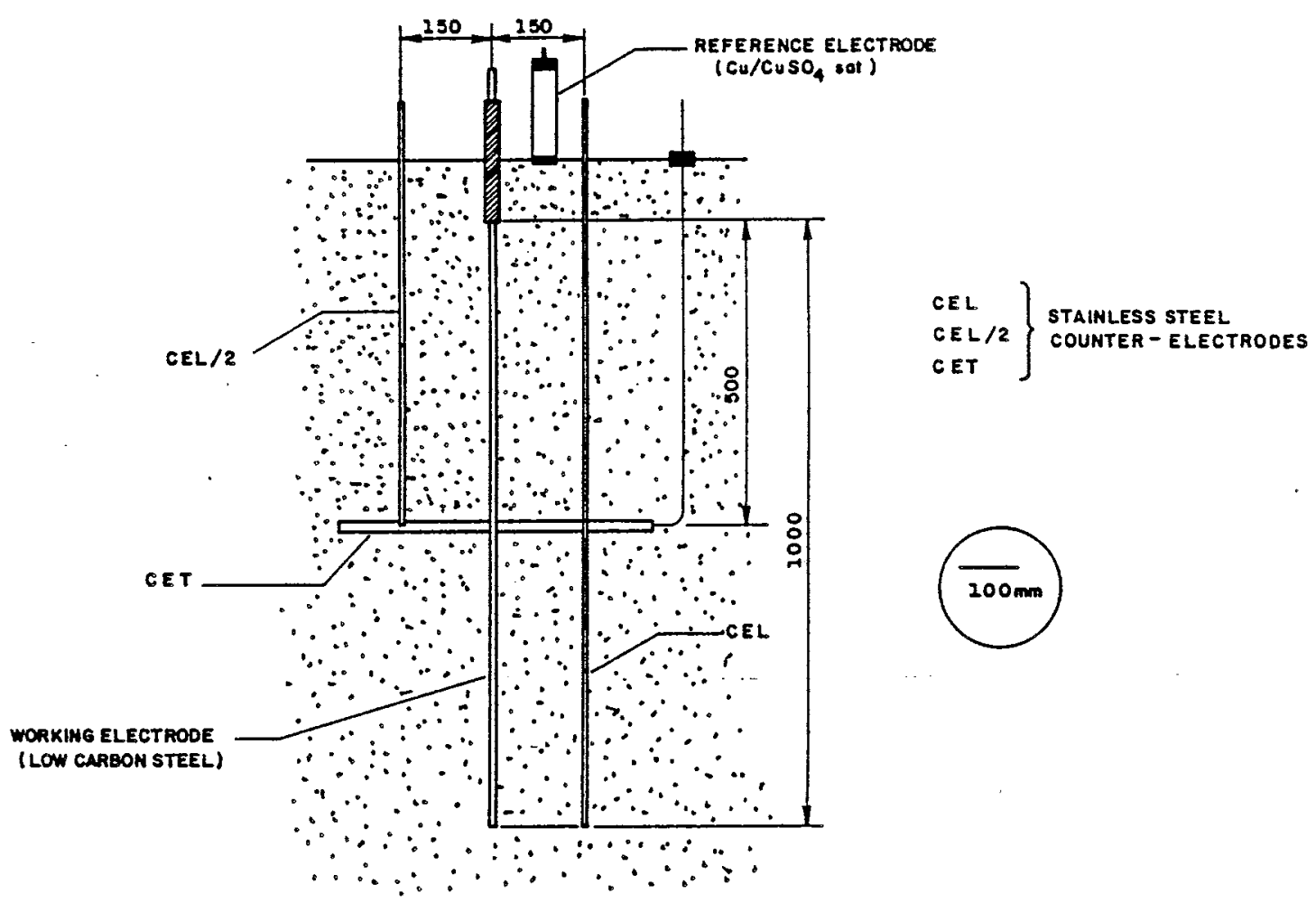

Figure 47 Example of Field set-Up for Polarization Techniques. (from Serra and Mannheimer, [68]) 
it is believed that they will be extensively used to examine the complex problems of underground corrosion. Polarization techniques can become a powerful tool to investigate the corrosion potential of any metal inclusion(s), either in the laboratory or in field, and for any adjacent materials. They can also be a rapid means to verify the corrosiveness criteria established in this study (Table 50).

Lastly, this writer cites the quotation of Thomas a'Kempis, a German monk of the 15th century, (as cited in Fitzgerald, [46]) as an epilogue of this study:

"Today I pray for the wisdom to build a better tomorrow on the mistakes and experiences of yesterday." 
BIBLIOGRAPHY 


\section{BIBLIOGRAPHY}

1. Witczak, M. W., Lovell, C. W., Jr. and Yoder, E. J., "A Generalized Investigation of Potential Availability of Aggregate by Regional Geomorphic Units within the Conterminous 48 states," Highway Research Record 353, 1971, pp. 31-39.

2. Golden, D. M., "Use of Coal Ash in Highway Construction: Kansas Demonstration Project," EPRI GS-6460, Interim Report, 1989, report summary.

3. Valley Forge Laboratories, "Development of Federal Procurement Guidelines for Use of Power Plant Ash in Transportation Products," Devon, Pennsylvania, 1983.

4. Huang, W. H., and Lovell, C. W., "Bottom Ash as Embankment Material," Geotechics of Waste Fills = Theory and Practice, ASTM STP 1070, 1990, 21 pages.

5. Huang, W. H., "Use of Bottom Ash in Highway Embankments, Subgrades, and Subbases", Ph.D Thesis, Purdue University, 1990, 260 pages, in press.

6. Seals, R. K., Moulton, I. K., and Ruth, B. E., "Bottom Ash: An Engineering Material," Journal of the Soil Mechanics and Foundation Division, ASCE, Vol. 98, No. SM4, 1972, pp311-325.

7. Shuler, T. S., "The Effects of Bottom Ash upon Bituminous Sand Mixtures," JHRP-76-11, Purdue University, 1976, 120pages.

8. Frohnsdorff, G. and Masters, L. W., "The Meaning of Durability and Durability Prediction," Durability of Building Materials and components, ASTM STP 691, P. J. Sereda and G. G. Litvan, Eds., American Society for Testing and Materials, Philadelphia, PA., 1980, pp. 17-30. 
9. Pihlajavaara, S. E., "Background and Principle of Long-Term Performance of Building Materials,"

$\because \quad$ Durability of Building Materials and components, ASTM STP 691, P. J. Sereda and G. G. Litvan, Eds., American Society for Testing and Materials, Philadelphia, PA., 1980, pp. 5-16.

10. Farhi, E., "Methodologies for Assessing Durability of New Materials and Components in Building," Durability of Building Materials and components, ASTM STP 691, P. J. Sereda and G. G. Litvan, Eds., American Society for Testing and Materials, Philadelphia, PA., 1980, pp. 91-97.

11. Blais, R. A., "General Specification for the Establishment in Quebec of a Materials Research Iaboratory of the National Research Council of Canada," National Research Council of Canada, 1977.

12. Keyser, J. H., "Durability of Materials and Construction," Durability of Building Materials and Components, ASTM STP 691, P. J. Sereda and G. G. Litvan, Eds., American Society for Testing and Materials, Philadelphia, PA., 1980, pp. 38-55.

13. Keyser, J. H., Bisaillon, A., and Jodoin, N., "Evaluation of Metropolitan Boulevard Elevated Expressway - A case Study," Annual Conference of the Road and Transport Association of Canada, Galgary, 1975.

14. Mitchell, J. K., Fundamentals of Soil Behavior, John Wiley \& Sons, Inc., 1976, pp. 7-18 (in Chinese).

15. Her, C. S., General Geology, Wu-Nan Pub. Company, Taipei, Taiwan, 1983, pp. 55-130.

16. Sereda, P. J., and Litvan, G. G., "Introduction," Durability of Building Materials and components, ASTM STP 691, P. J. Sereda and G. G. Litvan, Eds., American Society for Testing and Materials, Philadelphia, PA., 1980, pp. 1-2.

17. Haynie, F. H., "Theoretical Air Pollution and climate Effects on Materials Confirmed by Zinc Corrosion Data" Durability of Building Materials and components, ASTM STP 691, P. J. Sereda and G. G. Litvan, Eds., American Society for Testing and Materials, Philadelphia, PA.,

- 1980, pp. 157-175. 
18. Rösli, A., and Harnik, A. B., "Improving the Durability of Concrete to Freezing and Deicing Salts," Durability of Building Materials and Components, ASTM STP 691, P. J. Sereda and G. G. Iitvan, Eds., American Society for Testing and Materials, Philadelphia, PA., 1980, pp. 464-473.

19. Johnson, A. W., "Frost Action in Roads and Airfields A Review of the Literature," Special Report No.1, Highway Research Board, Washington D. C., 1952.

20. Litvan, G. G., "Freeze-Thaw Durability of Porous Building Materials", Durability of Building Materials and Components, ASTM STP 691, P. J. Sereda and G. G. Litvan, Eds., American Society for Testing and Materials, Philadelphia, PA., 1980, pp. 455-463.

21. Holtz, R. D. and Kovacs, W. D., An Introduction to Geotechnical Engineering, Prentice-Hall, Inc., 1981, pp. 190-193.

22. Khalil, S. M., Ward, M. A., and Morgan, D. R., "Freeze-Thaw Durability of Nonair-Entrained High Strength Concretes Containing superplasticizers," Durability of Building Materials and components, ASTM STP 691, P. J.' Sereda and G. G. Litvan, Eds., American Society for Testing and Materials, Philadelphia, PA., 1980 , pp. 509-519.

23. Rigan, J., "Application of one-Cycle Freeze Tests for Evaluation of Frost Resistance of Concrete", Durability of Building Materials and components, ASTM STP 691, P. J. Sereda and G. G. Litvan, Eds., American society for Testing and Materials, Philadelphia, PA., 1980, pp. 520-535.

24. Harnik, A. B., Meier, U., and Rösli, A., "Combined Influence of Freezing and Deicing salt on Concrete Physical Aspects," Durability of Building Materials and components, ASTM STP 691, P. J. Sereda and G. G. Litvan, Eds., American Society for Testing and Materials, Philadelphia, PA., 1980, pp. 474-484.

25. MacInnis, C. and Nathawad, Y. R., "The Effects of a Deicing Agent on the Absorption and Permeability of Various Concretes," Durability of Building Materials and Components, ASTM STP 691, P. J. Sereda and G. G. Litvan, Eds., American society for Testing and

- Materials, Philadelphia, PA., 1980, pp. 485-496. 
26. Hudec, P. P., "Durability of Carbonate Rocks as Function of Their Thermal Expansion, Water Sorption, $\therefore$ and Mineralogy", Durability of Building Materials and Components, ASTM STP 691, P. J. Sereda and G. G. Litvan, Eds., American Society for Testing and Materials, Philadelphia, PA.,1980, pp. 497-508.

27. Garden, G. K., "Design Determines Durability," Durability of Building Materials and components, ASTM STP 691, P. J. Sereda and G. G. Litvan, Eds., American Society for Testing and Materials, Philadelphia, PA., 1980, pp. 31-37.

28. Lounela, T. and Patrikka, P., "Maintenance Peiiods of Building Components," Rakentajain Kalenteri 1978, Helsinki, 1977, pp. 509-523 (in Finnish).

29. Masters, L. W., Wolfe, W. C., Rossiter, W. J., and Shaver, J. R., "State of the Art on Durability Testing of Building Components and Materials," NBSIR 73-132, National Bureau of Standards, Washington, D. C., March 1973.

30. Frohnsdorff, G., Masters, L. W., and Martin, J. W., "An Approach to Improve Durability Tests for Building Materials Components", NBS Technical Note 1120, 1980, 35 pages.

31. American Association of state Highway and Transportation Officials, "Standard Test Method for Soundness of Aggregates by Freezing and Thawing", AASHTO Designation T 103-78, Washington, D. C., 1986.

32. American Society for Testing and Materials, "standard Test Method for Soundness of Aggregates by Use of Sodium Sulfate or Magnesium Sulfate", ASTM Designation C 88, Philadelphia, PA., 1987.

33. American Association of State Highway and Transportation officials, "Standard Method of Test for Soundness Test of Aggregates by Use of Sodium Sulfate or Magnesium Sulfate", AAsHTO Designation T 104-86, Washington, D. C., 1986.

34. Hanna, T. H., Foundations in Tension $=$ Ground Anchors, 2nd edition, Trans Tech Pub./McGraw-Hill Book Co., 1982, pp. 81-122.

35. McMullen, L. D., "Advanced Concepts in Soil Evaluation for Exterior Pipeline Corrosion", Corrosion Control, AWWA Seminar Proceedings, 1982, pp. 41-59. 
36. Tomashov, N. D., Theory of Corrosion and Protection of Metals, MacMillan Co., New York, 1966, pp. 4.28-453.

37. Uhlig, H. H. and Revie, R. W., "Corrosion and corrosion Control" - An Introduction to Corrosion science and Engineering, 3rd edition, John wiley \& Sons, 1985, pp. $1-216$.

38. Palmer, J. D., "Environmental Characteristics Controlling the soil corrosion of Ferrous Piping," Effects of Soil characteristics on corrosion, ASTM STP 1013, V. Chaker and J. D. Palmer, Eds., American Society for Testing and Materials, Philadelphia, PA., 1989 , pp. 5-17.

39. Romanoff, M., "Underground Corrosion", NBS Circular 579, National Bureau of Standard, Washington D. C., 1957. 41. Slater, J., "Material Performance", Vol. 18, No.6, 1979, 34 pages.

40. Slater, J., "Material Performance," Vol.18, No.6, 1979, 34 pages.

41. Bennett, I. H. et al., "Economic Effects of Metallic corrosion in the United States", NBS Special Publ. 511-1, Washington D. C., 1978 .

42. Darbin, M., Jailloux, J.-M., and Montuelle, J., "Performance and Research on the Durability of Reinforced Earth Reinforcing Strips", Symposium on Earth Reinforcement, ASCE, 1978, pp.305-333.

43. Escalante, E., "Concepts of Underground Corrosion," Effects of Soil Characteristics on corrosion, ASTM STP 1013, V. Chaker and J. D. Palmer, Eds., American Society of Testing and Materials, Philadelphia, PA., 1989, pp. 81-94.

44. Laque, F. L., Marine Corrosion Causes and prevention, John Wiley \& Sons, New York, 1975.

45. Escalante, E., "Introduction," Underground Corrosion, ASTM STP 741, Edward Escalante, Ed., American Society for Testing and Materials, Philadelphia, PA., 1981, pp. $1-2$.

-46. Fitzgerald, J. H., III, "The Future as a Reflection of the Past," Effects of Soil Characteristics on Corrosion, ASTM STP 1013, V. Chaker and J. D. Palmer, Eds., American Society for Testing and Materials, Philadelphia, PA., 1989, pp. 1-4. 
47. Iverson, W. P., "Tests in Soils," Handbook of corrosion Testing and Evaluation, W. H. Ailor, Ed., 1971, pp.

$\because \quad .575-595$.

48. Romanoff, M., "Corrosion of steel Piles in Soils," NBS Monograph 58, National Bureau of Standards, Gaithersburg, MD, 1962 .

49. Edgar, T. V., "In-Service Corrosion of Galvanized Culvert Pipe," Effects of Soil Characteristics on Corrosion, V. Chaker and J. D. Palmer, Eds., American Society for Testing and Materials, Philadelphia, PA., 1989, pp. 133-143.

50. Bushman, J. B., and Mehalick, T. E., "Statistical Analysis of soil Characteristics to Predict Mean Time to Corrosion Failure of Underground Metallic Structures," Effects of Soil Characteristics on Corrosion, ASTM STP 1013, V. Chaker and J. D. Palmer, Eds., American Society for Testing and Materials, Philadelphia, PA., 1989, pp. 107-118.

51. Booth, G. H., Cooper, A. W., and Cooper, P. M., "Criteria of Soil Aggressiveness Towards Buried Metals, II. Assessment of Various Soils," British Journal Corrosion, Vol.2, 1967, pp. 109-115.

52. Gupta, S. K. and Gupta, B. K., "The Critical Soil Moisture Content in the Underground Corrosion of Mild Steel," Corrosion Science, Vol.19, No.3, 1979, pp. $173-178$.

53. Headon, A. C. and Chan, H. T., "Laboratory Corrosion Studies of Metals in Coal Ash," Sixth International Ash Utilization Symposium Proceedings, Reno, Nevada, 1982, pp. 168-186. DOE/METC/82-52 (Vol.2).

54. Starkey, R. L. and Wight, K. M., Anaerobic Corrosion of Iron in Soil, American Gas Association, New York, 1945, pp. 99 .

55. Costanzo, F. E. and Mcvey, R. E., "Development of the Redox Probe Field Technique," Corrosion, No.14, 1958, pp. 268-272.

56. Jackson, M. L., Soil Chemical Analysis, Prentice-Hall, Inc., 1958, pp. 38-56. 
57. Camitz, G. and Vinka, T.-G., "Corrosion of steel and Metal-Coated steel in Swedish Soils - Effects of soil

- Parameters," Effects of soil Characteristics on Corrosion, ASTM STP 1013, V. Chaker and J. D. Palmer, Eds., American Society for Testing and Materials, Philadelphia, PA., 1989, pp. 37-53.

58. Haviland, J. E., Bellair, P. J., and Morell, V., "Durability of Corrugated Metal Culverts," Highway Research Record No. 242, National Research Council, Highway Research Board, Washington D. C., 1968, pp. 41-66.

59. Denison, I. A. and Hobbs, R. B., "Corrosion of Ferrous Metals in Acid Soils," Journal of Research, NBS 13, No.125, RP696, 1934 .

60. Smith,W. T., Analysis of the Merits of Soil Corrosion Survey Work for the Amarillo-Denver Line, Western Gas, 1931, pp. 30 .

61. Escalante, E., "The Effect of Soil Resistivity and Soil Temperature on the corrosion of Galvanically coupled Metals," ASTM Symposium on Galvanic Corrosion, Phoenix, $\mathrm{AZ}$, 1986, in Galvanic Corrosion, ASTM STP 978.

62. Rabeler, R. C., "Soil Corrosion Evaluation of Screw Anchors," Effects of Soil Characteristics on corrosion, ASTM STP 1013, V. Chaker and J. D. Palmer, Eds., American Society for Testing and Materials, Philadelphia, PA., 1989, pp. 54-80.

63. Moran, G. C. and Labine, P., Eds., Corrosion Monitoring in Industrial plants Using Nondestructive Testing and Electrochemical Methods, ASTM STP 908, Philadelphia, PA., 1984, pp. 197-493.

64. Stern, $M$ and Geary, A. L., "Electrochemical Polarization - I. A Theoretical Analysis of the Shape of Polarization Curves," Electrochemical society, Vol.99, 1952, pp. 407-413.

65. Annand, R., "An Investigation of the Utility of Instantaneous Corrosion Rate Measurements for Inhibitor Studies," Corrosion, Vol.22, No.8, 1966, pp. 215-228.

.66. Schwerdtfeger, W. J. and Mcdorman, O. N., "Measurements of the Corrosion Rate of a Metal from its Polarizing

- Characteristics," Electrochemical Society, Vol.99, 1952, pp. 407-413. 
67. Pearson, J. M., "Null Methods Applied to Corrosion Measurements, " Trans. Electrochemical Society, Vol.81,

$\because \quad 1942$, pp. 485-510.

68. Serra, E. T. and Mannheimer, W. A., "On the Estimation of the corrosion Rates of Metals in soils by Electrochemical Measurements," Underground Corrosion, ASTM STP 741, E. Escalante, Ed., American society for Testing and Materials, Philadelphia, PA., 1981, pp. $111-122$.

69. Fisher, K. P. and Bue, B., "Corrosion and Corrosivity of Steel in Norwegian Marine Sediments," Underground Corrosion, 'ASTM STP 741, E. Escalante, Ed., American Society for Testing and Materials, Philadelphia, PA., 1981, pp. 24-32.

70. Department of Industry Committee on corrosion, Industrial Corrosion Monitoring, Her Majesty's office, London, 1978, pp. 28.

71. Neter, J., Wasserman, W., and Kutner, M. H., Applied Linear statistical Models, 2nd edition, Richard D. Irwin, Inc., 1985, pp. 226-263.

72. Kroon, D. H., "Integrity Assurance Program for Underground Storage Tank Systems," presented at the National Association of Corrosion Engineers National Conference, San Francisco, CA, March 1987, and reprinted as Paper No. CP-13, Corrpro Companies, Inc., Medina, OH, April 1987.

73. Jablonski, G. J. and Aliff, O. E., "Corrosiveness of Power Plant Ashes", Eighth International Ash Utilization Symposium Proceedings, Washington, D. C., October, 1987, pp. 48-1-48-23. EPRI CS-5362 (Vol.2).

74. Diamond, S., "Selection and Use of Fly Ash for Highway Concrete", Joint Highway Research Project, Report 85-8, Purdue University, West Lafayette, Indiana, 1985.

75. American Society for Testing and Materials, "standard Test for Field Determination of Soil Resistivity Using the Wenner Four-Electrode Method", ASTM Designation D 57-78, Philadelphia, PA., 1986.

-76. SoilTest, Inc.,"Earth Resistivity Manual", 1979, 48 pages.

77. California Department of Transportation, "Method of Testing soils and waters for chloride content", California Test $422,1978,1$ page. 
78. American Society for Testing and Materials, ASTM Designation C 311-85, "Standard Methods of Sampling And

- Testing Fly Ash or Natural Pozzolans for Use as a Mineral Admixture in Portland cement concrete", ASTM Designation C 331-85, Philadelphia, PA., 1986.

79. California Department of Transportation, "Method of Testing Soils and Waters for sulfate content", California Test $417,1986,2$ pages.

80. California Department of Transportation, "Method for Estimating the Time to corrosion of Reinforced Concrete Substructures," California Test 532, 1978, 7 pages.

81. California Department of Transportation, "Method for Estimating the Service Life of Steel Culverts", California Test $643,1978,6$ pages.

82. SoilTest, In., "Technical Data - strata scout Resistivity Meter R-40C", 11 pages.

83. American Society for Testing and Materials, "Standard Test Method for $\mathrm{pH}$ of soil for Use in corrosion Testing", ASTM Designation G 51-77, Philadelphia, PA., 1986.

84. American Association of State Highway and Transportation officials, AASHTO Guide for Design of Pavement structures, Part II, Washington, D. C., 1986, pp. 7-73.

85. American Society for Testing and Materials, "Standard Specification for Concrete Aggregate", ASTM Designation C 33, Philadelphia, PA., 1986.

86. American Society for Testing and Materials, "Standard Specification for Fine Aggregates for Bituminous Paving Mixture", ASTM Designation D 1073, Philadelphia, PA., 1986.

87. American Society for Testing and Materials, "Standard Specification for Coarse Aggregates for Bituminous Paving Mixture", ASTM Designation D 692, Philadelphia, PA., 1986.

88. American Society for Testing and Materials, "Standard Specification for Graded Aggregate Materials for Bases or Subbases for Highways or Airports", ASTM Designation D 2940, Philadelphia, PA., 1986. 
89. American Society for Testing and Materials, "Standard Specification for Materials for Soil-Aggregate

$\because \quad$ Subbases, Bases, and Surface Courses", ASTM Designation D 1241, Philadelphia, PA., 1986.

90. American Association of State Highway and Transportation officials, "Standard Specification for Fine Aggregate for Portland cement concrete", AASHTO Designation M 6, Washington, D. C., 1986.

91. American Association of state Highway and Transportation officials, "standard specification for coarse Aggregate for Portland cement Concrete", AASHTO Designation M 80, Washington, D. C., 1986.

92. American Association of State Highway and Transportation officials, "standard specification for Fine Aggregate for Bituminous Paving Mixture", AASHTO Designation M 29, Washington, D. C., 1986.

93. American Association of state Highway and Transportation officials, "Standard specification for Coarse Aggregate for Highway and Airport Construction", AASHTO Designation M 283, Washington, D. C., 1986.

94. American Association of State Highway and Transportation officials, "Standard specification for Fine Aggregate for Masonry Mortar", AASHTO Designation M 45, Washington, D. C., 1986.

95. Indiana Department of Transportation, "Section 903 Aggregates," INDOT Standard Specification, 1988.

96. Reinforced Earth Company, Technical Specifications for Reinforced Earth Walls, 1987, New Jersey, 9 pages.

97. Waters, F. O., "Soil Resistivity Measurements for Corrosion Controls," Corrosion, Vol. 8, No. 12, 1952, pp. 407 .

98. Palmer, J. D., "Soil Resistivity - Measurement and Analysis," Material Performance, Vol. 13, No. 1, January 1974 .

99. Peabody, A. W., Control of Pipeline Corrosion, National Association of Corrosion Engineers, 1967.

100. California Department of Transportation, Corrosion of Earth Reinforcing systems = Interim Design criteria, 1984,5 pages. 
101. Reinforced Earth Company, Design Manual of Reinforced Earth, New Jersey, 1986, pp. 6-8.

$\div$

102. Reinforced Earth Company, "Recommended Testing Procedure for Backfill Acceptable Behind Reinforced Earth concrete Panels - Labadie Coal Blending", 1981, 2 pages.

103. California Department of Transportation, Highway Design Manual, Chapter $850,1988,34$ pages.

104. Mckittrick, D. P., "Reinforced Earth: Application of Theory and Research to Practice," Ground Engineering, Vol. 12, No. 1, 1978, pp. 19-31.

105. Beaton, J. L., and Stratfull, R. F., "Environmental Influence on Corrosion of Reinforcing in Concrete Bridge Substructures," Highway Research Record, No. 14, January, 1963, pp. 60-78.

106. Lau, P. and Bernhardsson, S., "Electrochemical Techniques for the study of Pitting and Crevice Corrosion Resistance of Stainless steels," Electrochemical Techniques for Corrosion Engineers, R. Baboian, Ed., National Association of Corrosion, 1986, pp. 281-286. 